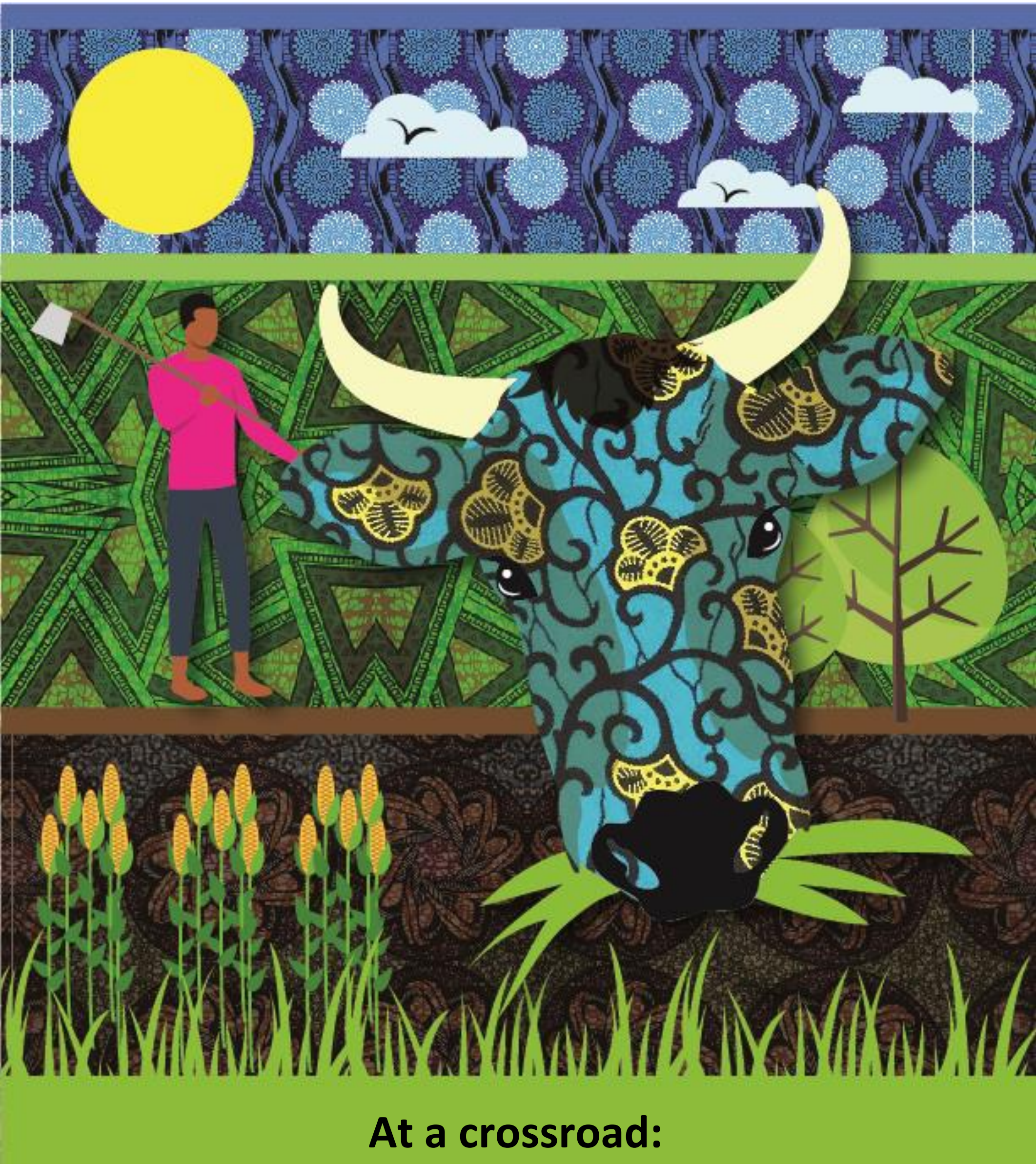

Potential impacts and trade-offs of improved livestock feeding and forages in smallholder farming systems of East Africa 



\section{Propositions}

1. Improved feeding has a key role to play in greening livestock in East Africa.

(this thesis)

2. Integrating forages into cropping systems is required to deliver multiple benefits. (this thesis)

3. The transaction costs of collaboration can outweigh its innovation benefits.

4. Influencing public discourse is a much overlooked scientific impact pathway.

5. Systems thinking is a scientific challenge, but daily life to smallholder farmers.

6. A single story is a danger once it becomes the only story.

7. Feminism is not about an individual woman, but the system.

Propositions belonging to the thesis, entitled

At a crossroad: Potential impacts and trade-offs of improved livestock feeding and forages in smallholder farming systems of East Africa

Birthe K. Paul

Wageningen, $17^{\text {th }}$ of September 2019 



\section{At a crossroad: Potential impacts and trade-offs of improved livestock feeding and forages in smallholder farming systems of East Africa}




\author{
Thesis committee \\ Promotor \\ Prof. Dr P.A. Tittonell \\ Professor of Farming Systems Ecology \\ Wageningen University \& Research

\section{Co-promotors} \\ Dr J.C.J. Groot \\ Associate professor, Farming Systems Ecology \\ Wageningen University \& Research \\ Prof. Dr M. Herrero \\ Chief Research Scientist \\ Commonwealth Scientific and Industrial Research Organization, Australia \\ University of Queensland, Australia

\section{Other members} \\ Prof. Dr P.C. Struik, Wageningen University \& Research \\ Dr R. Ripoll Bosch, Wageningen University \& Research \\ Dr S. Fonte, Colorado State University, United States of America \\ Dr L.W. Willemen, University of Twente
}

This research was conducted under the auspices of the C.T. de Wit Graduate School for Production Ecology and Resource Conservation of Wageningen University. 


\title{
At a crossroad: Potential impacts and trade-offs of improved livestock feeding and forages in smallholder farming systems of East Africa
}

Birthe K. Paul

\author{
Thesis \\ submitted in fulfilment of the requirements for the degree of doctor \\ at Wageningen University \\ by the authority of the Rector Magnificus, \\ Prof. Dr A.P.J. Mol, \\ in the presence of the \\ Thesis Committee appointed by the Academic Board \\ to be defended in public \\ on Tuesday 17 September 2019 \\ at 1.30 p.m. in the Aula.
}


Birthe K. Paul

At a crossroads: Potential impacts and trade-offs of improved livestock feeding and forages in smallholder farming systems of East Africa, 257 pages

PhD thesis, Wageningen University, Wageningen, the Netherlands (2019)

With references, with summary in English

ISBN 978-94-6395-064-0

DOI https://doi.org/10.18174/497381 




\section{Table of contents}

Chapter $1 \quad$ General introduction p. 9

Chapter 2 Tropical forage technologies can deliver multiple benefits in sub-Sahara

$\begin{array}{ll}\text { Africa: a quantitative review } & \text { p. } 23\end{array}$

Chapter 3 Livestock feeding systems and feed gaps in smallholder farms in East

$\begin{array}{ll}\text { Africa } & \text { p. } 45\end{array}$

Chapter 4 Prioritizing climate-smart livestock technologies in rural Tanzania: a

$\begin{array}{ll}\text { minimum data approach } & \text { p. } 67\end{array}$

Chapter 5 Agricultural intensification scenarios, household food availability and

greenhouse gas emissions in Rwanda: Ex-ante impacts and trade-offs p. 99

Chapter 6 Agro-environmental trade-offs across smallholder livestock systems in

$\begin{array}{ll}\text { Babati, Northern Tanzania } & \text { p. } 123\end{array}$

$\begin{array}{lll}\text { Chapter } 7 & \text { General discussion } & \text { p. } 149\end{array}$

$\begin{array}{ll}\text { References } & \text { p. } 171\end{array}$

$\begin{array}{ll}\text { Appendices } & \text { p. } 197\end{array}$

$\begin{array}{ll}\text { Summary } & \text { p. } 237\end{array}$

$\begin{array}{ll}\text { PE\&RC Training and Education Statement } & \text { p. } 243\end{array}$

$\begin{array}{ll}\text { Acknowledgments } & \text { p. } 245\end{array}$

$\begin{array}{ll}\text { About the Author } & \text { p. } 249\end{array}$

$\begin{array}{ll}\text { List of Publications } & \text { p. } 251\end{array}$

$\begin{array}{ll}\text { Funding } & \text { p. } 257\end{array}$ 

Chapter 1

\section{General introduction}

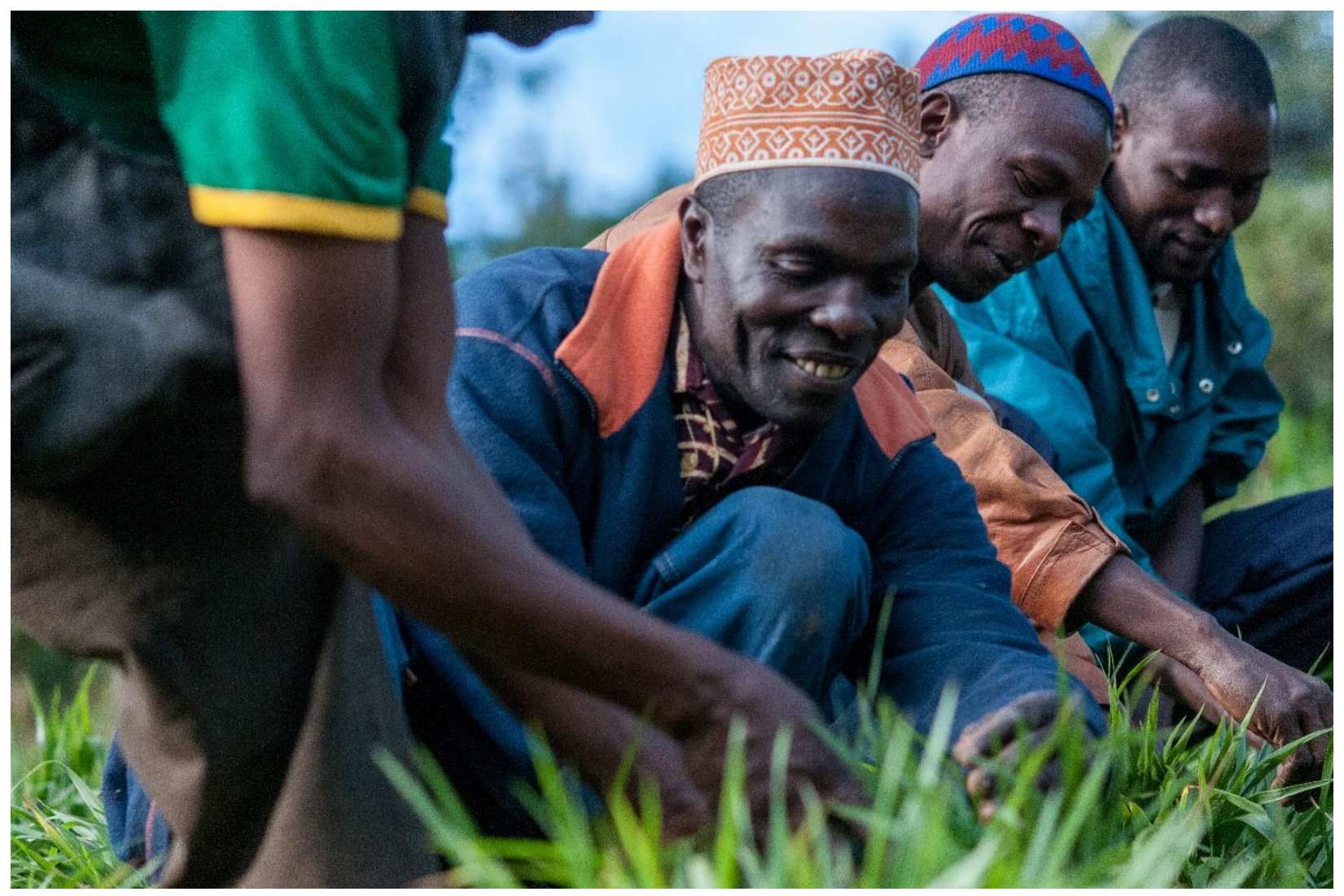




\subsection{Background}

Livestock are a resource of significant benefit to society in the form of food, income, nutrients, employment, insurance, traction, and clothing (Herrero et al., 2013). By 2050, the total demand for meat, milk and eggs is projected to almost double mostly in the developing world due to population growth, urbanization, income increase and change in dietary preferences - the 'livestock revolution' (Alexandratos and Bruinsma, 2012; Delgado et al., 1999; FAO, 2009). Dairy development provides economic opportunities for millions of poor smallholder farmers (Udo et al., 2011). Livestock is also associated with negative environmental impacts, including greenhouse gas (GHG) emissions, air pollution, high water consumption, loss of biodiversity and land degradation (de Vries and de Boer, 2010; Herrero et al., 2015; Steinfeld et al., 2006). Improved livestock feeding and forages have previously been highlighted as a triple-win strategy towards achieving climate-smart agriculture, increasing food security and resilience, and decreasing GHG intensities (Bryan et al., 2013; Peters et al., 2013; Thornton and Herrero, 2010). Tropical forages include a wide variety of sown or planted grasses, herbaceous or dual-purpose legumes and shrubs that are integrated into different agricultural systems to increase livestock productivity which is often constrained by quantity and quality feed (Rao et al., 2015). Livestock feeding and forages are thus at multiple crossroads: at a point where crucial decisions regarding future pathways are made, where productivity and environmental impacts meet, and where scientific disciplines including agronomy, soil and animal science intersect. However, knowledge on quantity and quality of feed gaps, and the potential impacts and trade-offs of improved livestock feeding practices on productivity, environment and livelihood dimensions across various crop-livestock systems in East Africa is limited and fragmented.

\subsubsection{Mixed crop-livestock systems and dairy development in East Africa}

Global livestock systems can be distinguished as follows: a) pastoral and agro-pastoral with larger livestock herds, mainly composed of local breeds, which are grazed on public, private or communal land; b) intensive crop-livestock systems based on stall-feeding of 1-5 cross-bred or exotic cattle, forage cultivation and concentrate supplementation; c) semi-intensive mixed crop-livestock systems where animals split their time between enclosures and grazing and/or being tethered; $d$ ) others including forest-based, urban and landless systems. In pastoral and agro-pastoral systems, the main objective is meat production with milk as a by-product, whereas in intensive and semi-intensive mixed croplivestock systems dairy is often the focus (McDermott et al., 2010; Robinson et al., 2011; Seré and Steinfeld, 1996). Mixed crop-livestock systems, where crops and livestock are produced on the same farm, are widespread in developing countries. Two-thirds of the global population are engaged in these 
systems, and they produce around $50 \%$ of the world's cereals, $60 \%$ of its meat and $75 \%$ of the milk. In Sub-Saharan Africa (SSA), they even provide $80 \%$ of the meat and $90 \%$ of the milk (Herrero et al., 2010 , 2013). Mixed systems enable farmers to reap synergetic effects from integrating arable cropping and livestock rearing. Exchange between the crop and livestock production components can happen in various forms, including feeding of crop residues and cultivated forage for livestock, use of animal manure for field fertilization, provision of animal draft power for tillage and land preparation. Animals also act as insurance and asset that can be liquidated in times of need and supply regular income from the sale of milk and eggs that supplement the seasonal income from crop yields (Herrero et al., 2010). This provides several advantages to smallholders, including diversified livelihoods, adaptive capacity to changing socio-ecological contexts and closer nutrient cycling (Rufino, 2007). The 'sustainability imperative', or the notion that crop-livestock integration is key to sustainable intensification in SSA, has put crop-livestock systems back into the policy and research focus (Ayantunde et al., 2018; Herrero et al., 2010; Sumberg, 2003). Smallholder mixed crop-livestock systems have been shown to use more environmentally sustainable practices than specialized systems. Such practices include mulching with crop residues, cover crops and green manure, intercropping and crop rotations, and use of manures (Rudel et al., 2016). Crop-livestock integration is most likely to benefit rural farmers in areas with favorable agro-ecological conditions, high population density and good market linkages. Remote semiarid and arid areas are more suitable to agro-pastoralist and pastoralist livelihoods with a low degree of crop-livestock integration. In peri-urban areas with high demand for animal source food and vegetables, specialization into livestock or crop production is financially attractive (McIntire et al., 1992; Sumberg, 2003).

In East Africa, the majority of the mixed crop-livestock systems are rain-fed and located in the tropical highlands and sub-humid and humid zones (Figure 1). Upgrading and intensification of smallholder dairy development is seen as a viable poverty alleviation strategy. It can provide opportunities for daily income throughout the year, in contrary to crop income that is bound to harvest seasons. Milk has even been coined 'white gold' for its potential of income generation (Makoni et al., 2013; van der Lee et al., 2018). Dairy intensification, away from agro-pastoral systems towards (semi)-intensive crop-livestock systems, is one of the trends observed across highland areas in East Africa, especially in areas with good infrastructure and developed milk markets (Duncan et al., 2013; Thorpe et al., 2000). Intensification in this context refers to increasing the output per animal and labor unit through increased use of inputs or change of management techniques. Countries in East Africa are at various stages of dairy development (Bebe et al., 2002). Kenya has a well-developed dairy value chain with many actors and support services, 
increased investment and a progression towards system formalization. It also has the highest per capita annual milk consumption levels, and established artificial insemination (AI) services that started 40 years ago. Ethiopia, Tanzania, Rwanda and Uganda dairy development trajectories are much less developed, with simpler value chains and nascent Al programs. Factors for Kenya's success in dairy development are supportive agricultural policies, colonial history, and the traditional importance of milk in urban and rural diets (Bebe et al., 2002; Makoni et al., 2013).

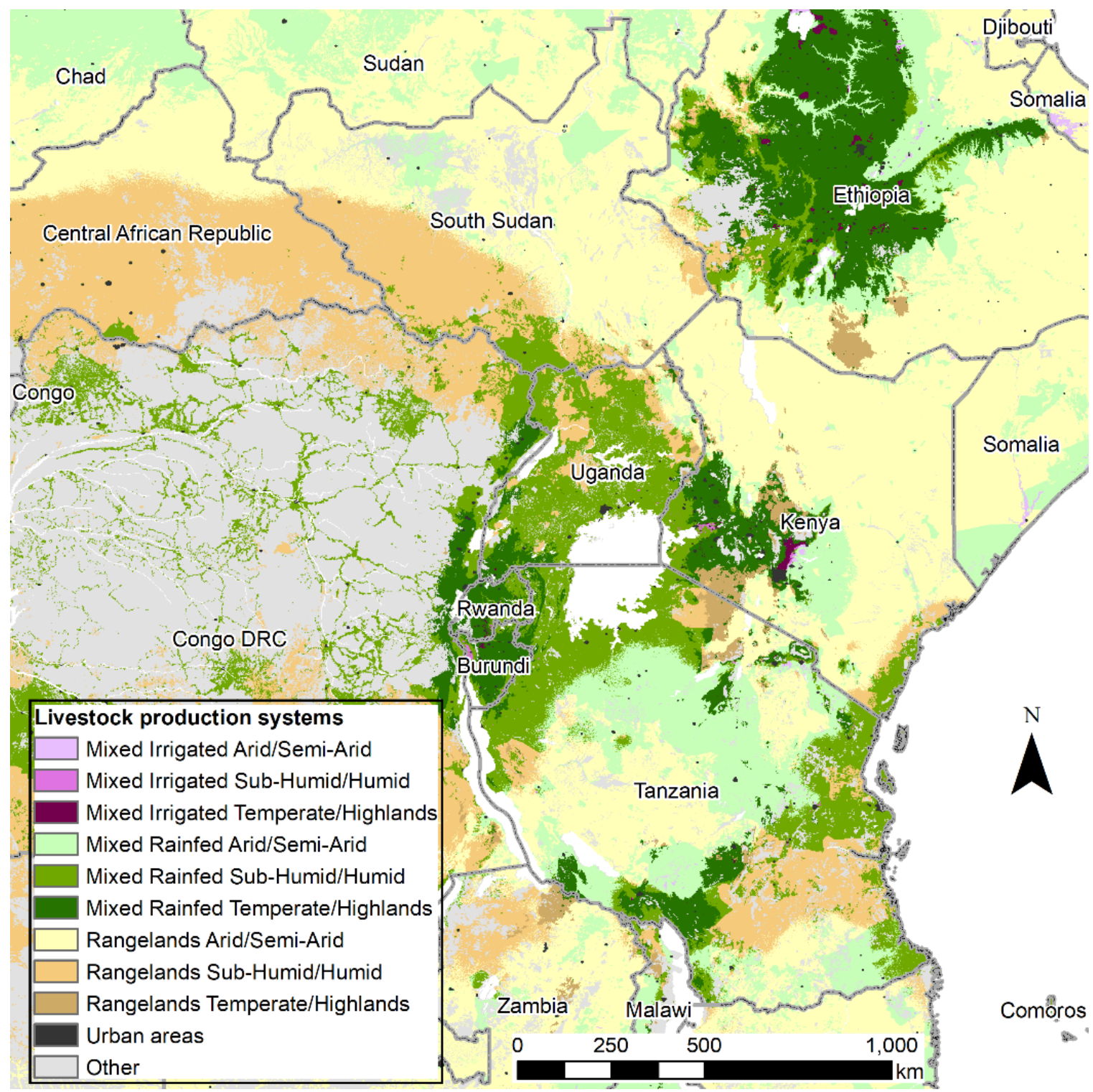

Figure 1: Livestock production systems across East Africa (Robinson et al., 2014). 


\subsubsection{Feed limitations constrain livestock productivity}

The shortage of sufficient quantity and quality feed on a consistent basis has often been cited as one key constraint facing smallholder livestock farmers in East Africa (Bebe et al., 2008; Hall et al., 2007; Kabirizi et al., 2006; Mtengeti et al., 2008; Sumberg, 2002b). In market-oriented dairy farming systems in Kenya and Ethiopia, feed has been shown to determine the majority of the production costs of milk (Muriuki and Thorpe, 2001). Intensifying dairy production, therefore, requires improvements in the feed base to increase milk production (Bebe et al., 2002). Livestock systems in SSA have some of the lowest feed conversion efficiencies for milk and meat globally, thus the highest amounts of feed needed to produce a unit of livestock product. This is mainly due to low productivity and quality of livestock diets as most smallholders in mixed systems rely mainly on crop residues, grazing, cut-and-carry forage from common and private lands, and comparatively little on cultivated forages (Herrero et al., 2013). Across Kenya, natural pastures and to a lesser extent Napier grass (Pennisetum purpureum) form the bulk of feed resources during both rainy and dry season. During the dry season, a wider range of resources are fed, including crop residues, purchased off-farm feeds, and grazing of public land. Farmers only have small acreages of planted forages on farm, including dual-purpose and herbaceous legumes such as Lablab purpureus or Desmodium intortum. Diminishing grazing lands and intensification is leading to the replacement of natural pasture grazing with planted forage, and increasing purchase of concentrates and other feeds (Romney et al., 2004; Lukuyu et al., 2009). In the dairy intensification hotspot of the Kenyan highlands, over three-quarters of the smallholder dairy farms already fall under semi-intensive or intensive systems. Smallholder dairy systems in Kenya are characterized by small herds of Frisian and Ayshire cross-breeds, stall-feeding, forage cultivation, and dependence on external inputs and services (Bebe et al., 2002). In many rain-fed smallholder farming systems, it is not only scarcity in quantity and quality of forage produced, but also seasonality. Dry season feed availability can become more important than overall herbage production (Ates et al., 2018).

Sufficient animal nutrition is required to sustain animal productive functions, including growth, reproduction, and production of milk and wool, and provision of draught power and transport. Animal nutritive requirements include essential energy, proteins, minerals, vitamins and water (ILCA, 1990). Feed intake is the amount of feed voluntarily consumed, and is determined by the saturation value of feeds, which depends on palatability and digestibility. Fermentation kinetics and passage of feed constituents (carbohydrate and protein), through the gastrointestinal tract, influence feed intake and nutrient supply to the animal (Herrero, 1997). The amount of energy in feed that can be potentially utilized by animals is commonly expressed in metabolizable energy (ME). ME is the gross energy of a 
feed minus losses through feces, urine and gases. Protein is the basic structural material from which all body tissue is constructed, and crude protein (CP) therefore, is an essential ingredient of feed (ILCA, 1990). Requirement calculations can take into account maintenance (stable body weight and condition), growth, gestation, milk production, and mobility (ILCA, 1990). There are many standards and methods for feed evaluation and requirement calculations, including the US National Research Council (NRC) standards of nutrient requirements of dairy cattle (NRC, 2001), the Australian feeding standards developed by CSIRO (CSIRO, 2007), and the Dutch feed evaluation system (Tamminga et al., 1994; Van Es, 1975). Most of these methods have been developed from feeding and energy balance trials and rumen studies with high-yielding ruminants in Europe, USA and Australia. However, African animals have been shown to be able to adapt to sub-maintenance energy levels by lowering requirements. Maintenance requirements do not always need to be met for other production to continue, e.g. cattle can lose weight and still produce milk and provide draught power. Compensatory growth refers to the ability of animals to recuperate after periods of underfeeding (ILCA, 1990).

Characterization of feeding systems is the basis to diagnose bottlenecks and design intervention strategies optimizing feed utilization and animal production. This can be achieved for example through surveys and on-farm forage sampling (e.g. Mtengeti et al., 2008; Mutimura and Everson, 2011) as well as participatory assessments, or a combination of both (Bacigale et al., 2014). For example, the Feed Assessment Tool (FEAST) has been designed to systematically and rapidly assess local feed resource availability and use in smallholder systems. It consists of a Participatory Rural Appraisal (PRA) and a short quantitative survey that aims to give quick guidance towards site-specific strategies to improve feed utilization and livestock productivity (Duncan et al., 2016). Databases such as Feedipedia can assist in quantifying nutritional values of feeds identified in surveys. Feedipedia provides information on nature, occurrence, chemical composition, nutritional value and recommended use of almost 1400 livestock feeds. Feed composition and nutritional values are important to formulate diets and rations that meet animal requirements (Feedipedia, 2012-2017). However, feed gaps towards higher dairy productivity across mixed crop-livestock systems in East Africa have not been quantified to date, and existing feed basket data is often qualitative and scattered. A better understanding of feed gaps is crucial to target improved feeding interventions.

\subsubsection{Environmental impacts of livestock in East Africa}

Despite its various benefits, the livestock sector is one of the most significant contributors to a range of environmental problems from local to global scales, including land degradation, air pollution, climate 
change, and loss of biodiversity (Herrero et al., 2015). First, livestock production is the largest anthropogenic land user, occupying one-third of the global ice-free surface for feed production and grazing (Steinfeld et al., 2006). Further intensification of livestock production will increase land use for feed production, competition for natural resources and trade-offs between food, feed and energy production (Thornton, 2010). Second, nutrient depletion is a major form of land degradation in mixed crop-livestock systems, and nutrient balances are often negative, indicating nutrient mining (Stoorvogel et al., 1993). Areas of high population density and therefore diminishing farm sizes represent the most severe cases of ongoing deterioration of soil fertility, which is causing progressive impoverishment (Shepherd and Soule, 1998). In addition, around $20 \%$ of the global rangelands and pastures are degraded through overgrazing, compaction and erosion (Steinfeld et al., 2006). Third, livestock production is a significant source of GHG emissions. Estimations range from $8-18 \%$ of global anthropogenic emissions, depending on the methodological approach. Main contributors are land use change due to conversion of forests and other natural vegetation to pasture and arable feed production $\left(\mathrm{CO}_{2}\right)$, enteric fermentation from ruminants $\left(\mathrm{CH}_{4}\right)$, and manure management $\left(\mathrm{N}_{2} \mathrm{O}, \mathrm{CH}_{4}\right)$ (Steinfeld et al., 2006; Herrero et al., 2011, 2015). The majority of future increases in agricultural emissions are expected to take place in low- to middle-income countries (Smith et al., 2007).

While industrialized countries have to dramatically reduce current levels of GHG emissions, developing countries face the challenge of finding low carbon development pathways as an alternative to the carbon-intensive industrialized agriculture. Current emission intensities, the amount of GHG produced per kg of milk or meat, are high throughout SSA, mainly due to low livestock productivity and low feed quality (Herrero et al., 2013). Climate-smart agriculture (CSA) is a framework aiming at transforming agricultural systems towards the 'triple win' of increased food security, climate change adaptation or reduced climate-related risks and mitigation. In developing countries, mitigation should be considered as ha co-benefit while priority lies with food security and adaptation. Increased resource use efficiency is key to CSA (Lipper et al., 2014; Campbell et al., 2014). While triple-wins are possible, implementing CSA will often involve trade-offs that need to be weighed following stakeholders' objectives (Thornton et al., 2018). Whole-farm modeling of greenhouse gas emissions from smallholder farming in East Africa exist (e.g. Hillier et al., 2011; Ortiz-Gonzalo et al., 2018; Seebauer, 2014), using International Panel on Climate Change (IPCC) Tier 1 and 2 methods. However, GHG estimations need to be combined with trade-off analysis on livelihood dimensions to be meaningful in the East African smallholder context. Knowledge on mitigation contributions of improved livestock feeding practices and their trade-offs or co-benefits with food security and income is needed to inform low emission livestock development. 


\subsubsection{Improved livestock feeding and forages}

One of the main approaches for addressing the feed scarcity has been to develop improved feed and forage options and innovations and evaluate them for their yield and quality, and impact on livestock production parameters (Ayele et al., 2012; Hall et al., 2007). Feed improvements can include various interventions, such as crop residue feeding (e.g. Duncan et al., 2016), increasing the quality of crop residues, dual-purpose cereals such as maize, millet and sorghum, dual-purpose legumes including cowpea and groundnut (Lenné et al., 2003), supplementation with concentrates, ratio formulation and planted forages. Tropical forages are a wide variety of sown or planted grasses, herbaceous or dualpurpose legumes and shrubs (also mostly legumes) that are integrated into agro-pastoral, silvo-pastoral and intensive or extensive mixed agricultural systems for grazing or cut-and-carry (Rao et al., 2015). They can serve various objectives and roles in farming systems, and they can occupy different spatial and temporal niches (Lenné and Wood, 2004; Peters et al., 2001). Intensification with forage technologies can be a simple improvement such as new varieties, improved management or change in feeding regime, or more complex sets of new practices that integrate forages in production systems. Forages need to be integrated into cropping systems, especially with food crops, to not compromise smallholders' food security. Forages adapted to harsh environmental conditions could also be planted on area unsuitable for cropping (Ates et al., 2018; Maass et al., 2015; Rudel et al., 2015). There are a few well-documented forage technologies: fodder shrubs including Calliandra calothyrus, Sesbania sesban, Leucaena trichanda in East Africa (Franzel et al., 2003; Place et al., 2009), and herbaceous legumes (Stylosanthes guianensis, S. hamata, Mucuna pruriens) and dual-purpose legumes such as cowpea (Vigna unguiculata) in West Africa (Elbesha et al., 1999; Tarawali et al., 1999; Kristjanson et al., 2005).

Improved livestock feeding has been highlighted as a triple-win strategy towards achieving climate-smart agriculture (Bryan et al., 2013; Thornton and Herrero, 2010). The climate change mitigation potential of common feeding improvements in tropical systems alone has been estimated to be around $7 \%$ of the global mitigation potential of agriculture (Thornton and Herrero, 2010). Climate change mitigation can be achieved through: i) increased carbon accumulation particularly in deeper soil layers through conversion from cropland to perennial, sown forages; ii) reduced methane emissions from enteric fermentation through higher nutritional value and digestibility of feed that reduces emissions per unit milk or meat produced; iii) lower nitrous oxide emissions through high biological nitrification inhibition (BNI) capacities of e.g. some Brachiaria spp. (following Cook and Schultze-Kraft, 2015 now Urochloa spp.); and iv) increase of aboveground biomass through integration of fodder trees in silvopastoral systems (Peters et al., 2013). 
In addition to climate regulation, tropical forages can contribute to soil rehabilitation and improvement. Forage grasses can increase $\mathrm{C}$ accumulation through their deep-rootedness and perennial nature. Forage legumes have positive environmental impacts through nitrogen fixation, and increased water efficiency through deep reaching taproots. Pioneering species such as Stylosanthes spp. can assist in rehabilitation of severely degraded land. Grasses, legumes and shrubs, when planted as hedgerows, cover crops or live barriers, can reduce soil erosion and runoff (Rao et al., 2015; Schultze-Kraft et al., 2018). However, information on tropical forage technologies and their impacts in SSA is scattered. A comprehensive stocktaking is required to gain an overview of which magnitude of productivity, environmental and livelihood impacts can be achieved with which forage technology.

\subsubsection{Farming systems approaches and trade-off analysis}

Safeguarding global food security and reversing environmental change are posing previously unknown complex and interlinked challenges. The interactions between components, instead of single components alone, are determining the response of any given system. Systems approaches are needed which strive to overcome previous boundaries between disciplines (interdisciplinary) and between research and practice (transdisciplinary) (Hieronymi, 2013). Models are useful to study and predict the behavior and performance of agro-ecosystems. They can also reduce resource requirements from field and farm experimental research, and they can help to formulate management recommendations (Jones et al., 2017). Agricultural systems modeling has been applied to questions of system intensification and diversification beyond single crops, and minimizing trade-offs and exploiting synergies between system components (Groot et al., 2017). Trade-offs influence the adoptability, impact and sustainability of possible innovations and future pathways. To address those multiple dimensions in one approach, trade-off analysis often employs interdisciplinary, bio-economic models. Multi-objective optimization, in particular, is considered a useful approach as farmers are not ultimate profit maximizers but have to balance various functions of their production system (Klapwijk et al., 2014a; Kanter et al., 2016; Salmon et al., 2018). Quantitative systems modeling can help to systematically explore trade-off frontiers, which can be expected to be different for farm types with contrasting biophysical conditions and resource endowment (Van Wijk et al., 2009; Giller et al., 2011; Thornton and Herrero, 2010; Groot et al., 2012). Changes in available technologies, market conditions and policies can lead to adjustment of the efficiency frontiers and can thus reduce the trade-offs between performance criteria such as profitability and GHG mitigation (Descheemaeker et al., 2016). Participatory approaches are key to understand relationships between sustainability pillars, including trade-offs and synergies (Ripoll-Bosch et al., 2012). 
Despite the need for trade-off analyses, few studies are available that explore the resource-constraint driven trade-offs (Ayantunde et al., 2018).

Improved livestock feeding and forages are at multiple crossroads: they are one of the linking factors between crop, soil and livestock, and they can have multiple impacts on various productivity, environmental and livelihood dimensions. Farming systems approaches and modelling is needed to explore forage integration and relationships with various components of farming systems, and estimate their multi-dimensional impacts and trade-offs (Figure 2). To date, there are only a few studies which employ farming systems modeling tools to explore potential whole-farm multi-dimensional impacts of planted forages, mostly from Asia and Latin America. None of these studies includes GHG emissions as environmental impact indicator (Komarek et al., 2012, 2015; Lisson et al., 2010; Parsons et al., 2011).

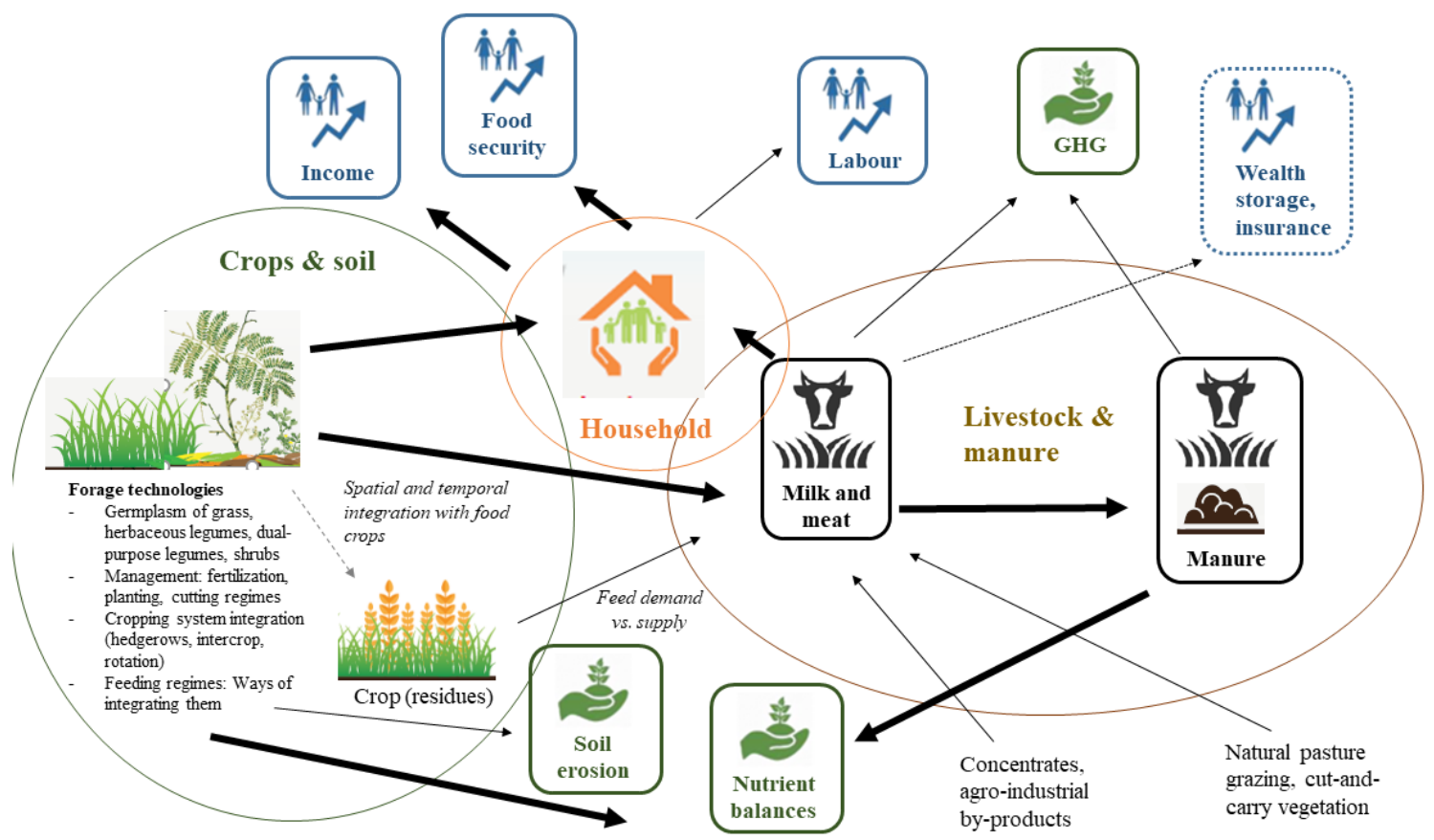

Figure 2: The role of improved forage technologies in mixed crop-livestock farming systems, and their potential impacts on productivity, environment and livelihood dimensions. The farming system is sub-divided in crops \& soil (green circle), livestock \& manure (brown circle), and household (orange circle) components. Bold arrows indicate an increase in the relationship brought by the introduction of tropical forages, a slim arrow a decrease. Livestock productivity dimensions are indicated in black boxes, environmental dimensions in green boxes, and livelihood dimensions in blue boxes. 


\subsection{Study objectives and hypotheses}

The main objective of this thesis research is to explore potential impacts and trade-offs associated with the implementation of improved livestock feeding and forage technologies at farm scale, across a diversity of smallholder crop-livestock systems in East Africa. I hypothesize that improving feeding practices can lead to increasing productivity and incomes, while reducing GHG emission intensities. Impacts and tradeoffs are explored from different perspectives and scientific disciplines, considering productivity, environmental and livelihood dimensions. Results aim to inform policy makers, project designers, investors, donors and other decision-makers on prioritizing options towards low emission livestock development.

Specific objectives are as follows:

1. To take stock of evidence on tropical forage technologies and their multi-dimensional agronomic, livestock, environmental and economic impacts in sub-Sahara Africa (Chapter 2);

2. To characterize current feeding systems and quantify feed gaps of East African smallholder farms (Chapter 3);

3. To quantify multi-dimensional baseline performance and efficiencies of various crop-livestock systems in Tanzania and Rwanda in terms of food security, greenhouse gas emissions, carbon and nitrogen balances, income and labor (Chapters 4, 5, 6);

4. To explore potential impacts, synergies and trade-offs of improved livestock feeding practices in Tanzania and Rwanda, thereby supporting prioritization of options towards low emission livestock development (Chapters 4, 5, 6).

The following hypotheses were explored:

- Livestock is an important source and pathway towards higher income and available food for smallholder farmers;

- Current feeding systems of smallholder farming systems are associated with feed gaps, resulting in low dairy productivity;

- Tropical forage technologies can potentially deliver multiple benefits to farmers in the areas of livestock production, income, food production and soil conservation;

- Whole-farm greenhouse gas emissions in East African smallholder crop-livestock systems are determined by enteric fermentation and manure which makes it a key for climate change mitigation; 
- Improved livestock feeding practices can result in synergetic effects of higher livestock productivity and incomes, and lower GHG emission intensities.

\subsection{Thesis outline}

In this thesis, I combine and apply insights and methods from different scientific disciplines to explore potential multi-dimensional impacts and trade-offs of improved livestock feeding and forages at farm scale across a diversity of smallholder crop-livestock systems in East Africa. Figure 3 summarizes the positioning of the thesis' chapters. The $x$-axis denotes the impact dimensions and respective indicators that are addressed across the chapters, including productivity, environment and livelihood domains. The left y-axis (green) indicates analysis and modeling approaches and tools employed in the respective chapters, such as multi-variate statistics, meta-analysis methods, livestock and economic modeling, and bio-economic multi-objective optimization modeling. The right y-axis (blue) illustrates which data collection methods and sources the chapters employed, stretching from expert knowledge to household surveys and on-farm measurements and monitoring (Figure 3).

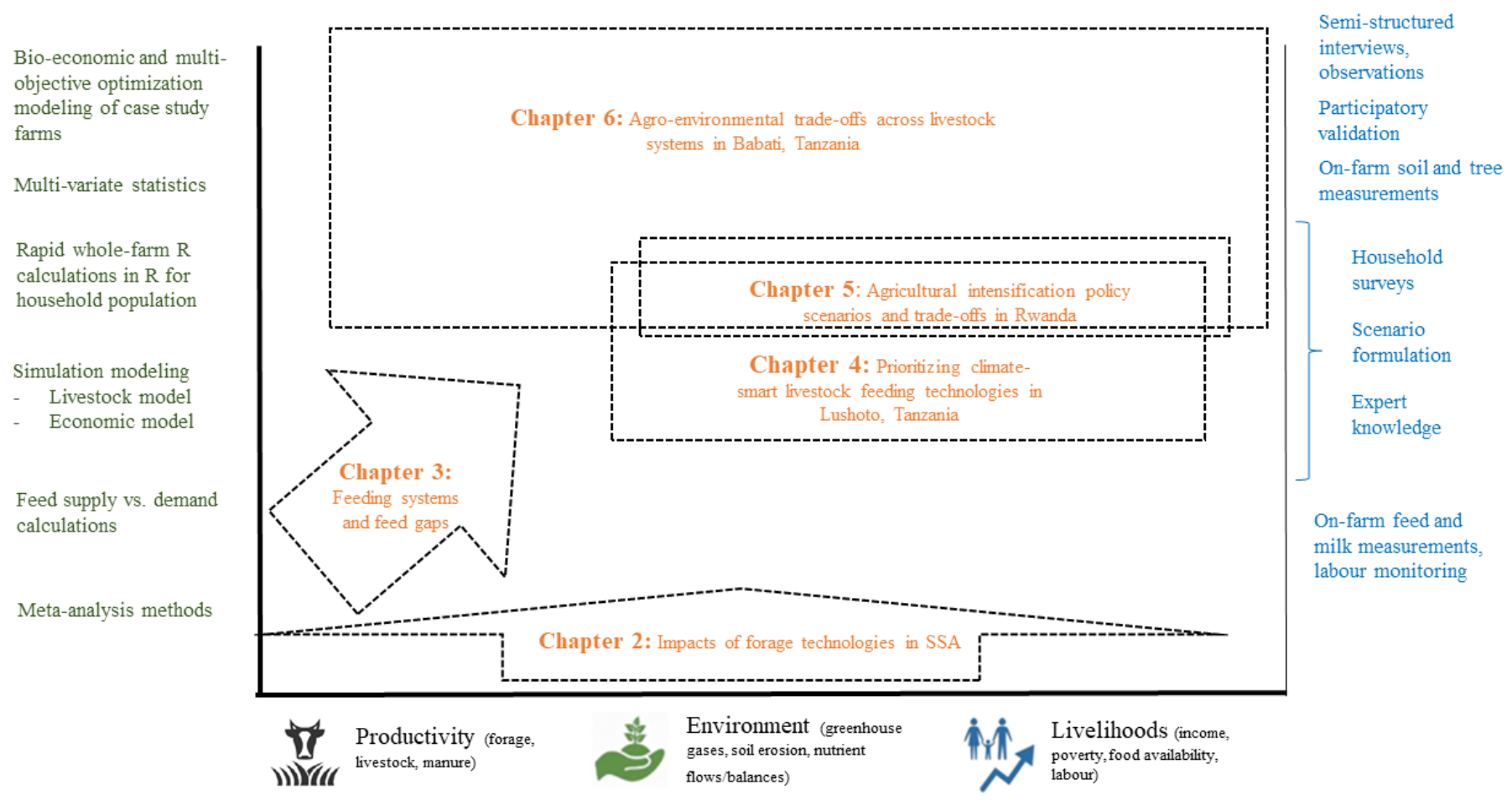

Figure 3: Overview and interlinkages of thesis chapters according to impact dimensions addressed ( $x$-axis), and analysis and modeling approaches (green left y-axis) and data collection methods used (blue right y-axis). 
Chapter 1 is the general introduction, which summarizes past research and outlines research gaps, which are followed by this thesis' objectives. Chapter 7 (general discussion) reflects on the contribution of the work to the body of scientific knowledge and wider implications for social and policy debates.

In Chapter 2, I systematically review the available literature on the effects of different tropical forage technologies on productive, environmental and livelihood dimensions in Sub-Sahara Africa (Objective 1). Forage technologies are classified into improved germplasm, improved management, cropping system integration and feeding regime. Weighted response ratios are calculated, showing the effect of tropical forage technologies on forage productivity, livestock productivity, soil erosion (soil loss), and effect on intercropped or subsequent food crops. Chapter 2 thus scopes the potential contribution of forages to sustainable intensification and opens up questions for exploring multi-dimensional impacts and tradeoffs which are pursued in Chapters $4-6$.

Chapter 3 assesses feed limitations in smallholder farms of East Africa (Objective 2). I introduce and provide proof-of-concept for a relatively simple approach to quantify feeding systems and feed gaps in data-scarce smallholder systems. Feed gap here is defined as the difference between livestock feed demand for an attainable milk production level and actual feed supply at the individual herd level. The approach is illustrated with pilot evidence from crop-livestock production systems across three agroecological zones in Tanzania, which broadly represent the diversity found in East Africa. Data collection included on-farm feed and milk measurements, labor monitoring, household surveys and farm observations. In doing so, this chapter outlines the magnitude of productivity and feed problems, which are further analyzed in the following chapters.

Chapters 4, 5 and 6 generate understanding of existing feed gaps and potential impacts of improved forage technologies. All three chapters aim at exploring multi-dimensional performance of croplivestock systems and ex-ante multi-dimensional impacts and trade-offs of improved livestock feeding interventions across various sites in Tanzania and Rwanda, using differing approaches (Objective $3 \& 4$ ).

Chapter 4 calculated potential economic and GHG impacts for an entire population of 164 households in Lushoto, Tanzania using a minimum data requirement modeling approach. The economic household model TOA-MD computed household income and poverty rate, and the livestock simulation model Ruminant added simulations of milk and methane production from enteric fermentation. Coupling the two models allowed me to evaluate the impacts and trade-offs of two improved feeding strategies on economic and environmental performance of the farms, including improving the quality of feed with 
Napier grass (Pennisetum purpureum), forage legume Desmodium (Desmodium uncinatum) and locally available concentrates.

Chapter 5 takes a different approach to ex-ante analysis by calculating two relatively simple whole-farm indicators for a population of 900 household dataset across various agro-ecologies in Rwanda - food availability and greenhouse gas emissions. The analysis allowed to quantify i) the contributions of offfarm activities, cash crops, food crops and livestock to food availability; and ii) the contributions of manure, enteric fermentation and soils to total GHG emissions across different regions. Modeled scenarios were chosen to represent three prominent policy programs in Rwanda - improved livestock feeding under the Livestock Intensification Program (LIP) is compared to Girinka (one cow given to poor farmers), and improved seeds and fertilization under the Crop Intensification Program (CIP).

Chapter 6 has an integrative character with respect to the ex-ante impact assessment and trade-off analysis in this thesis, as it combines a wide variety of productivity, environment and livelihood dimensions as well as analysis of approaches. The analysis used a survey dataset with 96 households from Babati in Northern Tanzania to construct a livestock system typology, using multivariate statistics. Whole-farm and multi-objective optimization modeling with FarmDESIGN was conducted for four representative farms of contrasting types, and agro-environmental impacts including income, labor requirements, GHG emissions, and N balances were compared. Semi-structured interviews and farm observations informed the optimization, aiming to explore ways to reduce such agro-environmental trade-offs.

By combining various perspectives, approaches, methods and data sources from different scientific disciplines, this thesis aims to inform policy makers, project designers, investors, donors and other decision-makers on prioritizing options towards low emission livestock development. 
Chapter 2

Tropical forage technologies can deliver multiple benefits in sub-Sahara Africa: a quantitative review

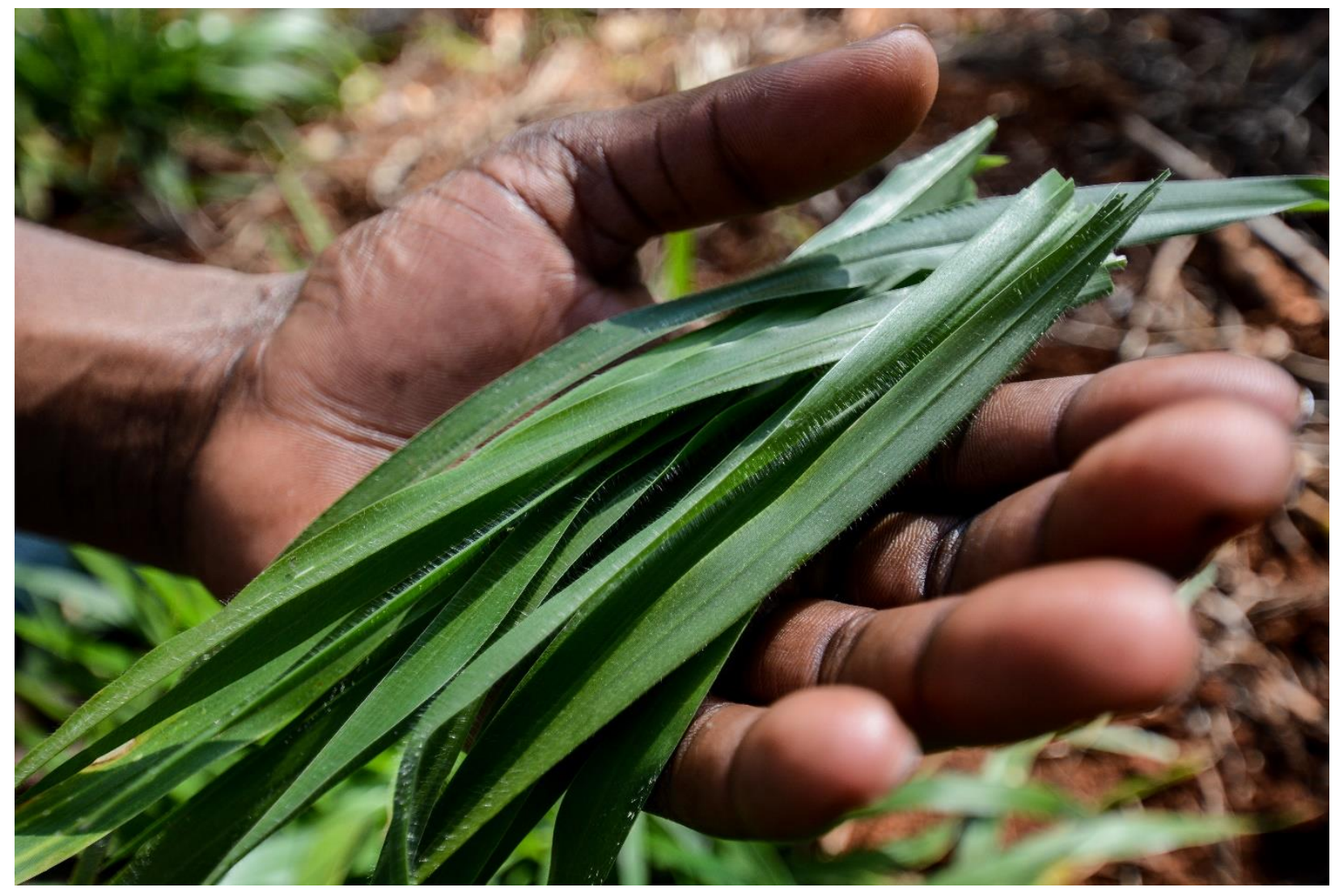

This article is submitted as:

Paul, B.K., Koge, J., Maass, B., Notenbaert, A., Peters, M., Groot, J.G.J., Tittonell, P. Tropical forage technologies can deliver multiple benefits in Sub-Sahara Africa: a quantitative review. Agronomy for Sustainable Development. 


\section{Introduction}

Two thirds of the global rural population are engaged in mixed crop-livestock systems, and these farmers produce around $50 \%$ of the world's cereals, $60 \%$ of its meat and $75 \%$ of milk. Mixed systems enable farmers to synergize cropping and livestock husbandry through draft power for land cultivation, manure application for crop fertilization, and feeding of crop residues and planted forages (Herrero et al., 2010). Scarcity of quantity and quality livestock feed on a consistent basis is often cited as a major constraint faced by mixed crop-livestock farmers in Sub-Sahara Africa (SSA), especially during the dry season. Feed is also a major production cost in dairy production (Bebe et al., 2008; Hall et al., 2007). SSA has some of the lowest feed conversions for milk and meat globally, thus the highest amounts of feed needed to produce a unit of livestock product. This is mainly due to low animal productivity and low quality of livestock diets as most smallholders in mixed systems rely on crop residues, grazing, cut-andcarry forage from common and private lands, and comparatively little on cultivated forages (Herrero et al., 2013). One of the main approaches for addressing this scarcity has been to develop feed and forage options and innovations, and evaluate them for their yield and quality, and impact on livestock production parameters (Ayele et al., 2012; Hall et al., 2007). Tropical forage crops are a wide variety of sown or planted grasses, herbaceous or dual-purpose legumes and shrubs (also mostly legumes) that are integrated into agro-pastoral, silvo-pastoral and intensive or extensive mixed agricultural systems for grazing or cut-and-carry (Rao et al., 2015). They are complex by nature due to their various objectives and roles in farming systems, and they can occupy different spatial and temporal niches. In a crop role, herbaceous and dual-purpose legumes can be sown on arable land to meet short-term or seasonal fodder needs; in a niche role, herbaceous and dual-purpose legumes and shrubs can be grown on farm boundaries, fallows, roadsides, crop under-story, to meet planned and opportunistic fodder needs; or in a companion role, they can be sown as grass-legume pasture to satisfy long-term feed requirements (Lenné and Wood, 2004; Peters et al., 2001). Intensification with forage technologies can take two forms: simple improvements such as new varieties or change in feeding regime, or more complex sets of new practices that integrate forages in production systems. Forages need to be spatially and temporally integrated into cropping systems, especially with food crops, to not compromise smallholders' food security. Forages adapted to harsh environmental conditions could also be planted on area unsuitable for cropping (Ates et al., 2018; Maass et al., 2015; Rudel et al., 2015).

Forage-based sustainable intensification processes of mixed crop-forage-livestock tree systems can be classified into three dimensions: i) genetic intensification (the development and use of superior grass 
and forage cultivars for increased livestock productivity); ii) ecological intensification (development and application of improved farm and natural resource management strategies); and iii) socio-economic intensification (improvement of local and national institutions and policies enabling technologies to achieve wider use) (Rao et al., 2015). Tropical forages are usually not a stand-alone technology, but an intermediate product used to increase livestock productivity. The breadth of effects includes economic, social and environmental landscapes (White et al., 2013). In addition to increasing milk and meat production, they can also contribute to other objectives such as reducing risks in the face of feed scarcity, increasing yields of associated food crops through weed suppression, pest and disease reduction (in rotations or as an intercrop), and increased manure quantity and quality for crop fertilization (Peters et al., 2001). Tropical forage technologies are also reported to have environmental co-benefits. Climate change mitigation can be achieved through: i) increased carbon accumulation particularly in deeper soil layers through conversion from cropland to perennial, sown forages; ii) reduced methane emissions from enteric fermentation through higher nutritional value and digestibility of feed that reduces emissions per unit milk or meat produced; iii) lower nitrous oxide emissions through high biological nitrification inhibition (BNI) capacities of e.g. some Brachiaria spp. (now Urochloa spp.); and iv) increase of aboveground biomass through integration of fodder trees in silvopastoral systems (Peters et al., 2013). In addition to climate regulation, tropical forages can contribute to soil rehabilitation and improvement. Forage grasses can increase $\mathrm{C}$ accumulation through their deeprootedness and perennial nature. Forage legumes have positive environmental impacts through nitrogen fixation, and increased water efficiency through deep reaching taproots. Pioneering species such as Stylosanthes spp. can assist in rehabilitation of severely degraded land. Grasses, legumes and shrubs, when planted as hedgerows, cover crops or live barriers, can reduce soil erosion and runoff (Rao et al., 2015; Schultze-Kraft et al., 2018). The potential, multi-dimensional benefits and impacts of improved forages in smallholder systems in SSA are summarized in Figure 1. 


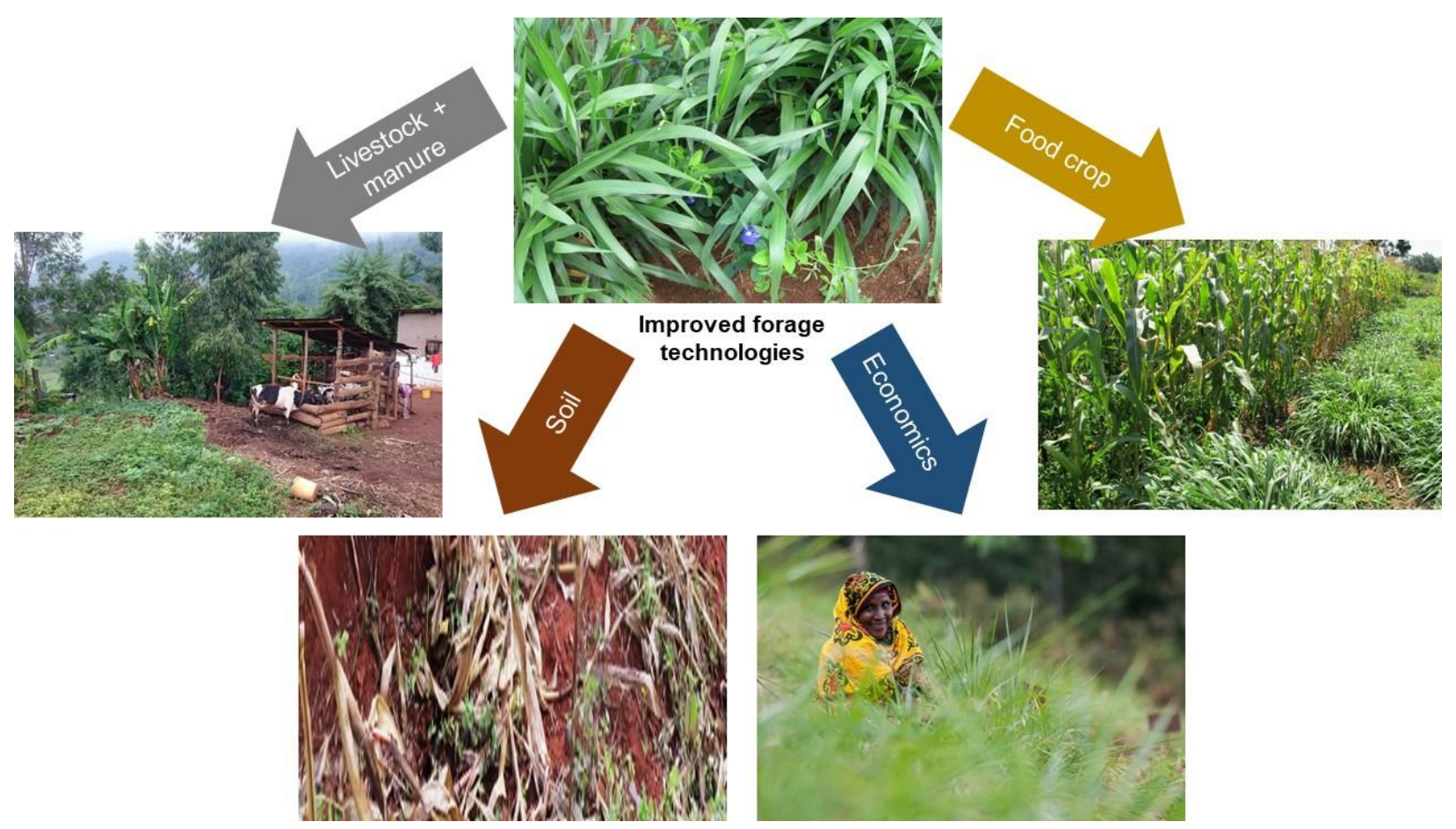

Figure 1: Improved tropical forage technologies have been promoted for use in smallholder systems in Sub-Sahara Africa (SSA) for their potential multiple benefits: increased herbage production and better nutritive quality, leading to increased livestock productivity (meat, milk, manure), soil quality (erosion, carbon, nutrients), economic performance of the household, and food crop productivity (grains and stover). Photo credits: B.K. Paul, CIAT (forages, livestock + manure, soil), G. Smith, CIAT (economics) and B.L. Maass (food crop).

Research on tropical forages in SSA has been spread over time and regions. Yet a comprehensive overview of forage technologies, as well as ranges and magnitudes of their multi-dimensional impacts, is currently lacking. This study aims to take stock of the state of forage research in SSA by conducting a systematic, quantitative literature review with the following objectives: i) provide an overview of past experimental research in terms of tested forage technologies, measured impacts and study locations; ii) quantify magnitudes of impacts of tropical forage technologies on forage productivity and quality, livestock productivity, soil quality, economic performance and food crop productivity at the plot, animal and household levels; and iii) present the variability of forage agronomy data.

\section{Materials and methods}

\subsection{Literature search and study selection}


We performed a systematic literature search to compile peer-reviewed articles in June 2016. We used the scientific search engine Scopus, employing the following search terms: "livestock", "feeds" OR "forage" OR "fodder", and "Africa". We complemented this search with references cited in the primary literature and unpublished studies obtained from the authors' personal networks. For inclusion into this review, we only selected studies that met the following criteria: 1) the study reported empirically measured, original data on one of the target impact indicators (see section 2.2), thus, excluding simulated data or data cited in reviews or secondary articles; 2 ) the article examined at least one tropical forage technology (grass, herbaceous or dual-purpose legume, leguminous shrub) but not crop residues, concentrates or tree products - if the technology was a dual-purpose legume, it was only included if the forage or livestock impact was assessed as well; 3) the article focused on ruminants and not on monogastric livestock; 4) the study reported data from experimental, 'improved' treatments and a control treatment; 5) the reported data was continuous and numerical thus not reported in scores, ranks, percentages or as graphs; 6) the study was written in English; 7) basic experimental information was available in the Materials and Methods section; and 8) the study was conducted in Sub-Sahara Africa. Using these criteria, 73 studies were found suitable to be included in the review (see references of review). These studies were published during 30 years between 1985 and 2015 (Figure 2a). For each of the 113 experimental sites across the 73 studies, we noted the geographical location. If precise geographical coordinates were not reported in the publication, we chose the center of the lowest-level known administrative unit and added GPS coordinates extracted from Google maps. We mapped the dominant livestock production system of the study locations (Robinson et al., 2011) (Figure 2b). 




b

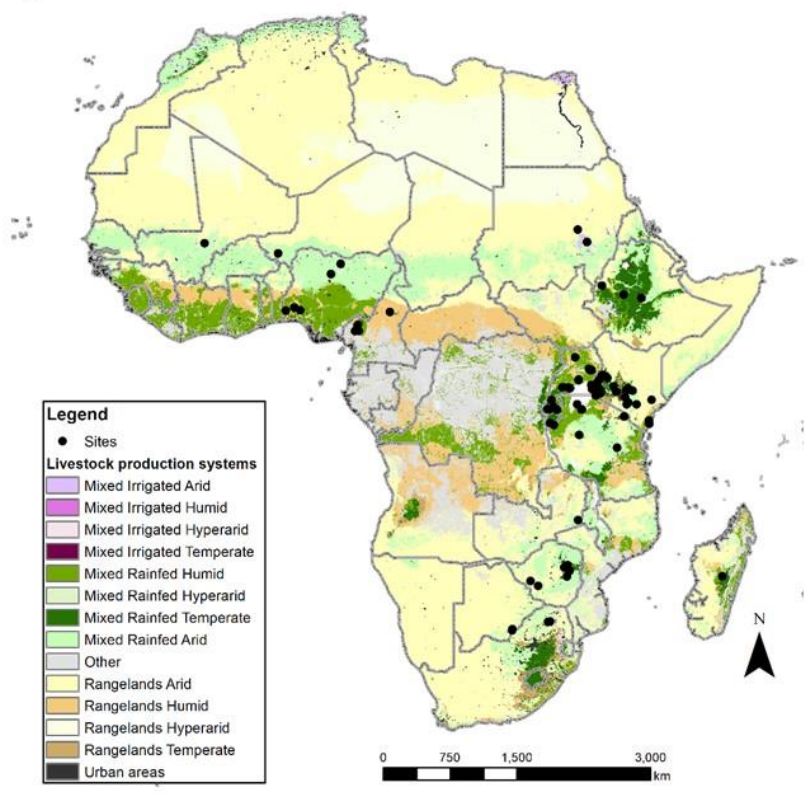

Figure 2: Cumulative number of studies included in this review per publication year (a), and experimental study sites from all studies mapped on dominant livestock production systems across SSA (Robinson et al., 2011) (b). The systematic search of peer-reviewed literature in 2016 was complemented with references cited in the primary literature and unpublished studies obtained for the authors' personal networks. Using seven selection criteria, 73 studies with 113 experimental sites were found suitable to be included in the review, published between 1985 and 2015. If precise geographical coordinates were not reported in the publication, we chose the center of the lowestlevel known administrative unit and added GPS coordinates extracted from Google maps. Studies were conducted in 14 countries in SSA, most of which in East Africa (49). Most sites were located in the mixed rainfed crop-livestock zones (24 sites humid, 24 sites tropical highlands/temperate), and only five sites in rangeland areas (four arid, one hyperarid).

\subsection{Forage technologies, impact dimensions and data retrieval}

Different forage technologies were tested in on-station and on-farm agronomic trials as well as feeding trials. Note that we are using the scientific names of forages under which the studies were published, even though the names of many important species have recently changed, e.g. all Brachiaria spp. to Uruchloa spp., Napier grass (Pennisetum purpureum) to Cenchrus purpureus, and Panicum maximum to Megathyrsus maximus, amongst others (Cook and Schultze-Kraft, 2015). Forage technologies were classified as follows: a) Germplasm referring to newly introduced forages (i. grass; ii. herbaceous legume; iii. dual-purpose legume) that were tested in on-station or on-farm trials against a local control forage; b) Management comprising i. fertilization regimes (mineral fertilizer and manure) and ii. planting method such as manure application in planting holes and compared treatment performance to the 
farmers' practices; c) Cropping system integration describing i. forage grass and/or shrub planted as hedgerow with food crops, ii. forage grass, legume and/or shrub intercropped with food crop, or iii. forage grass intercropped with forage legume; d) Feeding regime including the supplementation of basal feed like residues or grasses with leguminous forages, fed as either fresh biomass, or vines, haulms, hay or leaf 'meal - forages can be i. herbaceous legume, ii. dual-purpose legume or iii. shrub (Table 1). 
Table 1: Technology groups and types, and forage species included in the review. The scientific names of forages under which the studies were published are used despite recent name changes (i.e. Brachiaria spp. to Urochloa spp., Pennisetum purpureum to Cenchrus purpureus, and Panicum maximum to

Megathyrsus maximus in the grasses; Centrosema pubescens to C. molle and Pueraria phaseoloides to Neustanthus phaseoloides in the legumes) following Cook and Schultze-Kraft (2015).

\begin{tabular}{|c|c|c|}
\hline Technology & Technology sub-group & Forage species \\
\hline \multirow{3}{*}{$\begin{array}{l}\text { a) Germplasm: Newly introduced forage germplasm - } \\
\text { compared to local species as control }\end{array}$} & i. Grass & Brachiaria brizantha/B. hybrids/B. decumbens, Pennisetum purpureum \\
\hline & ii. Herbaceous legume & $\begin{array}{l}\text { Stylosanthes guianensis, Centrosema macrocarpum/C. pubescens, Pueria } \\
\text { phaseoloides, Mucuna pruriens, Desmodium heterocarpon-ovalifolium, Zornia } \\
\text { glabra, Dioclea guianensis, Arachis pintoi, Aeschynomene histrix, Flemingia } \\
\text { macrophylla }\end{array}$ \\
\hline & iii. Dual-purpose legume & Vigna unguiculata \\
\hline \multirow{2}{*}{$\begin{array}{l}\text { b) Management: Improved agronomic measures applied to } \\
\text { forage dual purpose and herbaceous legumes and grasses - } \\
\text { compared to same crop without improved agronomy as control }\end{array}$} & i. Fertilizer & $\begin{array}{l}\text { Pennisetum purpureum, Lablab purpureus, Desmodium uncinatum, Mucuna } \\
\text { pruriens, Stylosanthes scabra, Macroptilium atropurpureum }\end{array}$ \\
\hline & ii. Planting method & Pennisetum purpureum \\
\hline \multirow{3}{*}{$\begin{array}{l}\text { c) Cropping system integration: Forage dual purpose and } \\
\text { herbaceous legumes, grasses and shrubs are combined with } \\
\text { food crops as hedgerow or intercrop, and forage legume and } \\
\text { grass intercropped - compared to same situation without } \\
\text { combination as control }\end{array}$} & $\begin{array}{l}\text { i. Grass/shrub hedgerow with } \\
\text { food crop }\end{array}$ & $\begin{array}{l}\text { Pennisetum purpureum, Calliandra calothyrsus, Leucaena leucocephala/L. } \\
\text { diversifolia, Sesbania sesban }\end{array}$ \\
\hline & $\begin{array}{l}\text { ii. Grass/legume/shrub intercrop } \\
\text { with food crop }\end{array}$ & $\begin{array}{l}\text { Desmodium uncinatum/D. intortum, Pennisetum purpureum, Chloris gayana, } \\
\text { Vigna unguiculata, Lablab purpureus, Stylosanthes fruticosa/S. hamata, } \\
\text { Mucuna pruriens, Clitoria ternata, Cajanus cajan, Vigna trilobata, Gliricidia } \\
\text { sepium, Sesbania sesban }\end{array}$ \\
\hline & iii. Grass-legume intercrop & $\begin{array}{l}\text { Desmodium uncinatum/D. intortum, Pennisetum purpureum, Brachiaria spp, } \\
\text { Arachis pintoi, Stylosanthes scabra/S. guianensis, Macroptilium } \\
\text { atropurpureum, Panicum maximum, Clitoria ternatea, Tripsacum laxum, } \\
\text { Setaria splendida, Macrotyloma axillare, Centrosema molle }\end{array}$ \\
\hline \multirow[t]{3}{*}{$\begin{array}{l}\text { d) Feeding regime: Supplementation of basal diet with } \\
\text { improved, mostly leguminous forages as fresh biomass, vines, } \\
\text { haulms, hay or leaf meal - compared to basal diet as control }\end{array}$} & i. Herbaceous legume & $\begin{array}{l}\text { Desmodium intortum, Canavalia ensiformis, Centrosema macrocarpum, } \\
\text { Macroptilium atropurpureum, Neontonia wightii, Stylosanthes scabra/S. } \\
\text { guianensis, Mucuna pruriens, Medicago sativa, Aeschynomene histrix }\end{array}$ \\
\hline & ii. Dual-purpose legume & Arachis pintoi, Cajanus cajan, Lablab purpureus, Vigna unguiculata \\
\hline & iii. Shrub & $\begin{array}{l}\text { Calliandra calothyrsus, Leucaena leucocephala, Gliricidia sepium, Sesbania } \\
\text { sesban, Colospermum mopane }\end{array}$ \\
\hline
\end{tabular}


Effects of forage technologies on five dimensions were considered, which follow the economic, social and environmental domains outlined in White et al. (2013) and Rao et al. (2015): i) Forage productivity and quality: dry herbage matter (DM) yield, crude protein (CP) and metabolizable energy (ME) contents; ii) Livestock productivity: milk yield, dry matter intake (DMI), live weight gain (LWG), manure production, and nitrogen content in manure; iii) Soil quality: soil loss (SL), soil organic carbon (SOC); iv) Household economics: revenue and benefit; and v) Food crop productivity: grain and stover yields. Figure 3a summarizes the number of studies per impact dimension and indicator that were used in this review. An adequate number of studies were available to calculate germplasm impacts on forage production and quality; management on forage production and quality; cropping system integration on forage production and quality, soil quality, economic performance and food crop production; and feeding regime on livestock production (Figure $3 b$ ).

a

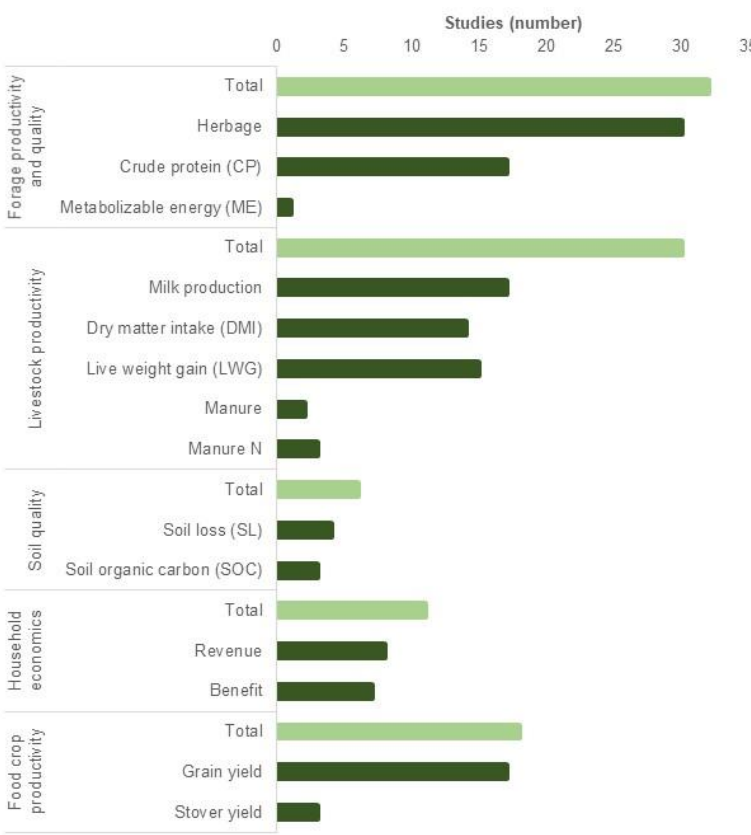

b

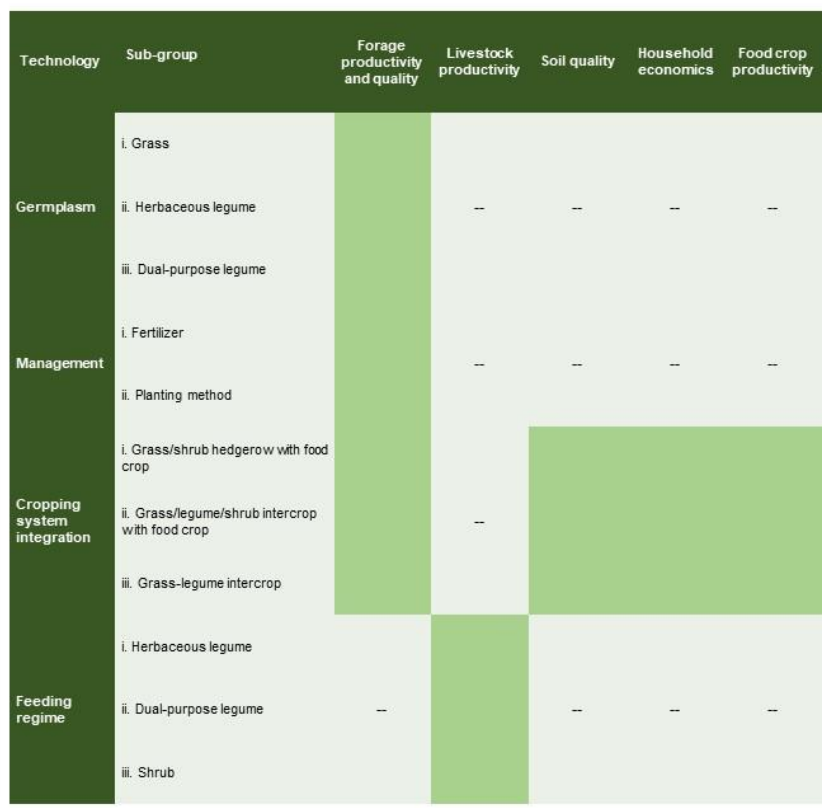

Figure 3: Number of studies reporting performance on five impact dimensions and respective indicators (a), and impact dimensions per technology group that are reported in this review (b). Most studies focused on forage productivity and quality $(n=32)$ and livestock productivity $(n=32)$, with the least amount of studies on soil quality $(n=6)$. Data on only one impact dimension was reported by 50 studies, two impact dimensions by 19 studies, and three dimensions by three studies. An adequate number of studies were available to calculate germplasm effects on forage productivity and quality; management on forage productivity and quality; cropping system integration on forage productivity and quality, soil quality, economic performance and food crop production; and feeding regime on livestock productivity. 
Data was extracted from the 73 selected papers into a Microsoft Access database. In addition to impacts, we extracted experimental and technology descriptions including type of technology and forage species, cropping system, management, and number of replications $(N)$. The selected 73 papers contained 971 pairs of comparisons of treatment vs. control.

\subsection{Data analysis}

We used methods such as weighted response ratios from the field of meta-analysis (Hedges et al., 1999) to quantify magnitudes of effects of tropical forage technologies on forage productivity and quality, livestock productivity, soil quality, economic performance and food crop productivity. Similar to Delaquis et al. (2018), the breadth of technologies and effects included in the study resulted in a lack of directly comparable measures, indicators and variables. Combined with the lack of quality of reported agronomic data in literature, this study could not take a full, statistically powerful meta-analysis approach fulfilling the criteria laid out by Philibert et al. (2012), including analyzing the heterogeneity of data with random-effect models, sensitivity analysis and investigation of publication bias.

We quantified the effect of forage technologies on the impact indicators (see section 2.2) calculating response ratios (RR) for individual observations:

$$
R R=\left(\frac{X_{E}}{X_{C}}\right)
$$

Where $\mathrm{X}_{\mathrm{E}}$ is the impact indicator value for the forage technology treatment, and $\mathrm{X}_{\mathrm{C}}$ is the impact indicator value for the control treatment.

For most observations in our dataset, the original studies did not report measures of variance. Consequently, we decided to rely on a non-parametric approach to weighing observations instead of using the inverse of the pooled variance. Effect sizes were weighed by replication to assign more weight to well-replicated studies:

$$
W_{R}=\frac{N_{C} * N_{E}}{\left(N_{C}+N_{E}\right)}
$$

Where $W_{R}$ is the weighing factor by replication, $N_{C}$ the number of treatments per control, and $N_{E}$ the number of replicates per experimental treatment. If no $N$ was reported for a study, $N=1$ was assumed. 
Multiple observations from the same field site or several treatments with only one control are not independent and this needs to be accounted for in the weights. To avoid bias, the weighing factor by replication was, thus, further divided by the number of measurements and treatments:

$$
W_{o}=\frac{W_{R} / T}{M}
$$

Where $W_{o}$ is the overall weighing factor per observation, $W_{R}$ is the weighing factor by replication, $T$ the number of treatments per respective control, and $M$ the number of measurements per treatment. This ensured that all experimental comparisons in multi-factor and multi-year studies could be included in the data set without dominating the overall effect size.

Mean effect sizes for the overall sample and per technology type were estimated as follows:

$$
\overline{R R}=\frac{\sum\left(R R_{i} * W_{O i}\right)}{\sum W_{O i}}
$$

With $R R_{i}$ being the effect size of the ith comparison, and $W_{O i}$ the overall weighing factor for the ith comparison.

Standard errors were calculated. Indicator units differed between studies, but standardization was not considered necessary for computation of response ratios. Live weight gain could not be presented as the response ratio as data were both positive and negative.

\section{Results \& discussion}

\subsection{Technologies, locations and impact dimensions: Overview of past research}

Seventy-three studies were found suitable to be included in the review, published during 30 years between 1985 and 2015. The number of experimental forage studies peaked in the period from 1999 to 2007 (Figure 2a). The International Livestock Research Institute (ILRI), the International Center for Tropical Agriculture (CIAT), and the International Center for Agricultural Research in the Dry Areas (ICARDA) and regional networks have been leading the international forage research in SSA over the last 30 years. They have been especially active in breeding and evaluating yields of germplasm. In the national agricultural research systems (NARS), programs were established in the 1960s and 1970s to test and adapt forage genotypes. In the 1990s, a strong movement started towards participatory research to match varietal characteristics with needs and interests of smallholder livestock keepers, to ultimately reach higher adoption (Hall et al., 2007; Stür et al., 2013). In addition to planted forages, crop residues are a major feed source in mixed crop-livestock systems throughout SSA. Residues, and their competing 
uses as animal feed or for soil amendment, have received quite some recent research attention (e.g. Duncan et al., 2016; Homann Kee-Tui et al., 2015; Tittonell et al., 2015; Valbuena et al., 2012). Also, dual-purpose cereal crops have been researched from biophysical, socio-economic, cultural, and policy angles. The International Crops Research Institute for the Semi-Arid Tropics (ICRISAT), ICARDA, the International Institute for Tropical Agriculture (IITA), ILRI and the International Maize and Wheat Improvement Center (CIMMYT) have focused on developing dual-purpose varieties for grain and forage, e.g. sorghum, cowpea, maize, millet and groundnut (Lenné et al., 2003). Planted forages, on the contrary, have not benefitted from a similar level of research investment in SSA.

Studies were conducted in 14 countries, most of which were in East Africa (49). Within East Africa, most studies reported results from Kenya (30). Eight studies were conducted in West Africa, five in Central Africa, and nine in Southern Africa. Most sites were located in the rainfed mixed crop-livestock zones (24 sites humid/sub-humid, 24 sites tropical highlands/temperate), and only five sites in rangeland areas (four arid/semi-arid, one hyper-arid) (Figure 2b). Studies included a wide variety of forage grasses, legumes and shrubs (Table 1). These different species reflect the focus on improving forage availability in different production systems, such as smallholder dairy in eastern Africa or sedentary crop-livestock farmers in West Africa. Pastoral communities are unlikely to invest in new forages for communally grazed grasslands until joint grazing management strategies are in place. Therefore, planted forage research has focused on mixed crop-livestock farmers and to a lesser extent on sedentary agropastoralists. The advancement of Kenya's dairy industry has been largely based on the wide spread of Pennisetum purpureum (Pengelly et al., 2003). However, certain other species dominate in specific regions: the World Agroforestry Center (ICRAF) and partners promoted agroforestry with multi-purpose shrubs and trees with a focus on cut-and-carry systems in eastern Africa. Calliandra calothyrsus is most commonly planted as it is fast-growing and tolerant of frequent cuttings. However, it is not as nutritious as other species including Leucaena leucocephala and L. trichandra, and Sesbania sesban. In 2006, it was estimated that over 200,000 smallholders had been planting these fodder tree species in the East African highlands. A key advantage is that they require little land, which is crucial in high-potential highland areas with high population pressure. They are also multi-purpose, contributing to firewood and erosion control. Challenges constraining uptake are lack of availability of seedlings as well as lack of skills to grow them, especially during the establishment phase (Franzel et al., 2014; Place et al., 2009). Only a few studies were found that report results from experimental research with forage technologies from southern Africa. Four of the nine total studies were conducted in Botswana, and focused either on 
leguminous shrubs or forage legumes, with only one study on forage grass-legume intercropping (Brachiaria hybrid cv. Mulato and Arachis pintoi).

In West Africa, the focus has been on herbaceous and dual-purpose legumes. Stylosanthes guianensis and S. hamata (Stylo), Mucuna pruriens (Mucuna), Centrosema pascuorum and Aeschynomene histrix have been promoted for use in fodder banks and improved fallows in West Africa by ILRI and its national partners. These technologies aimed to alleviate feed stress of agro-pastoralists in sub-humid zones, especially during the dry season. For a large part of the dry season, a fodder bank planted with herbaceous legumes close to the homestead can maintain a crude protein content of $9 \%$ compared to $<7 \%$ of the naturally available pastures during that time. Those legumes can also increase subsequent crop yields on the same plot due to nitrogen fixation and improvement of physical soil quality. Stylo has already been introduced in and promoted since the late 1970s, and Mucuna since the late 1980s. The uptake of Stylo has been relatively slower than, for example, that of Mucuna in southwestern Benin. In 1999, it was estimated that 27,000 households in West Africa had adopted these technologies (Elbasha et al., 1999; Tarawali et al., 1999). Dual-purpose cowpea (Vigna unguiculata) is another crop that has been developed and promoted for mixed crop-livestock systems in the dry savannah zones of West Africa by ILRI and IITA. The crop is popular in West Africa, with an estimated eight Mio. ha planted in 1997. Various dual-purpose cowpea varieties have been developed and tested that can deliver benefits to household food production, livestock feed, soil quality and nutrient cycling. Improved dual-purpose cowpea varieties could replace traditional varieties that could either produce grain or fodder. An impact assessment from northern Nigeria indicated that expected returns are high (Kristjanson et al., 2002, 2005; Tarawali et al., 2003). It needs to be noted that the focus on literature published in English has led to a bias against francophone literature from West and Central Africa.

Most studies focused on forage productivity and quality $(n=32)$ and livestock productivity $(n=30)$, with the least studies on soil quality $(n=6)$. Effects on food crop productivity was measured by 18 studies, though they contained a high number of observations $(n=302)$. Fifty studies reported data on only one impact dimension, while 19 studies reported on two impact dimensions and only three studies on three dimensions (Figure $3 \mathrm{~b}$ ). Most often, it was studies on improved cropping system integration that assessed several dimensions such as forage production, soil quality and food crop production (Figure 3b). Only a few forage technologies have been investigated in all their aspects in a chosen location. This points to the fact that forage research is a challenging field that moves between various disciplines with their own approaches and methods - e.g. it needs agronomic expertise to study forage production and 
soil impacts through on-farm or on-station trials, animal nutrition expertise to assess livestock production impacts through feeding trials, and economic analyses for income quantification. White et al. (2013) found similar results in a global review of forage impact studies. In particular, effects on gender and labor were reported less often, and rather in a qualitative way (White et al., 2013).

\subsection{Magnitudes of multi-dimensional effects of forage technologies}

Herbage yields and crude protein content of improved germplasm as compared to a local control were reported by 51 observations (Figure 4a). Average herbage production of improved forage technologies was 2.65 times higher than the local controls, and crude protein content $18 \%$ higher. When differentiating impacts by technology groups, introducing improved forage germplasm had the largest effect on forage productivity. Grass germplasm exhibited on average three times higher herbage yield than the local control, followed by herbaceous legumes with almost doubling herbage productivity, and dual-purpose legumes with $27 \%$ higher yield. Grass germplasm (Pennisetum purpureum, Brachiaria spp.) has been tested in East Africa (Uganda and Rwanda), whereas herbaceous legume and dual-purpose cowpea germplasm experimentation took place predominantly in West Africa. Overall, these results justify why fodder grasses have been a more important research area in Africa than fodder legumes, indicating where the large gains can be made (Lenné and Wood, 2004). Fertilizer application and planting method increased average herbage production by $21 \%$ and $7 \%$, respectively. Intercropping a forage grass with a legume increased average total herbage production by $49 \%$ when compared to a forage grass only (Figure 4b). Regarding forage quality, grass-legume intercropping almost doubled the $\mathrm{CP}$ content of the overall forage (Figure 4c), while metabolizable energy remained almost equal (Figure 4d). Grass-legume intercropping is a popular topic with 68 observations on herbage productivity effects, and 17 observations on CP effects. Experimentation was conducted all over Africa, involving various different grass and legume species and combinations (e.g. Panicum maximum and Lablab purpureus, Pennisetum purpureum and Desmodium intortum, Brachiaria hybrid cv. Mulato II and Centrosema molle or Clitoria ternatea). However, in many rainfed smallholder farming systems, it is not only the quantity and quality of forage produced that matters, but particularly their seasonality. Especially in dryer areas, dry-season feed availability can become more important than overall herbage production (Ates et al., 2018). 
a. Overall germplasm

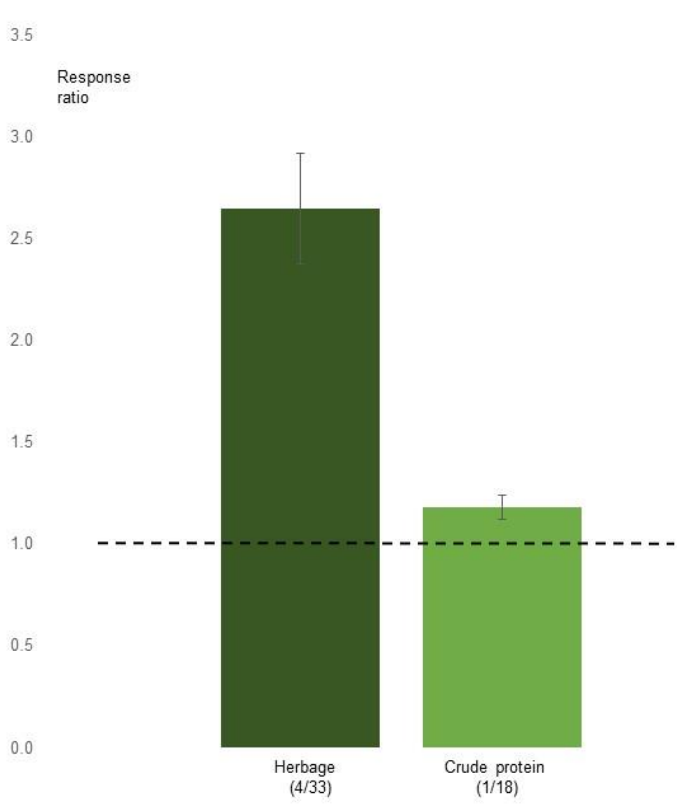

b. Herbage

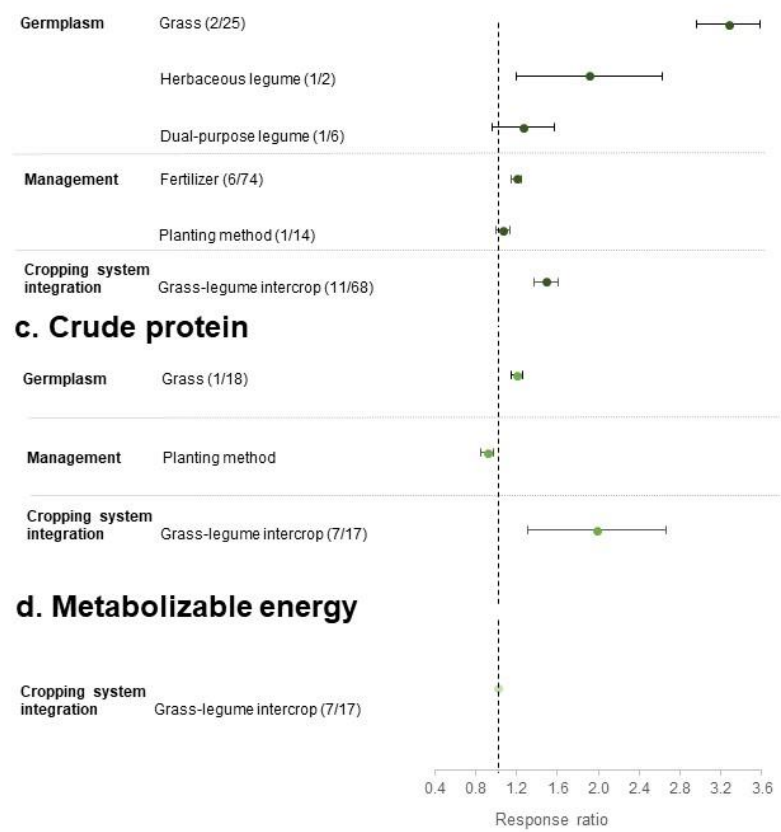

Figure 4: Weighed mean response ratios with standard error for improved germplasm effects on forage productivity and quality (a), and effects by technology group (germplasm, management, cropping system integration) and their sub-groups on herbage (b), crude protein content (c), and metabolizable energy (d). One observation from the effect of herbaceous legume on manure (d) and shrub on manure $N(e)$ was excluded due to lack of sufficient data points. The dashed line indicates a response ratio of 1 , which is the threshold for increase $(>1)$ or decrease $(<1)$ when compared to the control. The number of studies and observations are reported in brackets.

Impacts of improved feeding regimes with forages on livestock production were measured and reported by 74 observations. Overall, they improved milk yield by an average of $35 \%$, dry matter intake (DMI) by $25 \%$, nitrogen content of manure by $24 \%$ and manure quantity by $12 \%$ when compared to the basal diets (Figure 5a). Herbaceous legumes had the largest average effect on milk yield, increasing productivity by $47 \%$ (Figure $5 b$ ). Herbaceous legumes also had the largest effect on DMI, higher than dual-purpose legumes or shrubs (Figure 5c). Much fewer observations reported impacts on manure production and nutrients in manure (Figures $5 \mathrm{~d}$ and $5 \mathrm{e}$ ). Often-tested herbaceous legumes include Stylosanthes spp., Desmodium spp., Mucuna pruriens, while dual-purpose legumes include mostly Lablab purpureus and Vigna unguiculata (cowpea). Dairy animals are frequently used to assess improved forage quality as it translates rapidly into higher milk yield. The lower magnitude of impacts from livestock feeding regimes, when compared to forage productivity, points to the fact that higher quantity and quality of feed does not directly translate into livestock productivity response as several other factors such as current nutritional status of the animals, animal health, breed and management 
practices might be limiting productivity. A combination of interventions is often necessary (breed, management, health, etc.) to reach desired effects. Published livestock productivity effects observed in studies under controlled conditions, such as on-station feeding trials, are most likely much greater than those obtained in uncontrolled on-farm situations.

a. Overall feeding regime



b. Milk

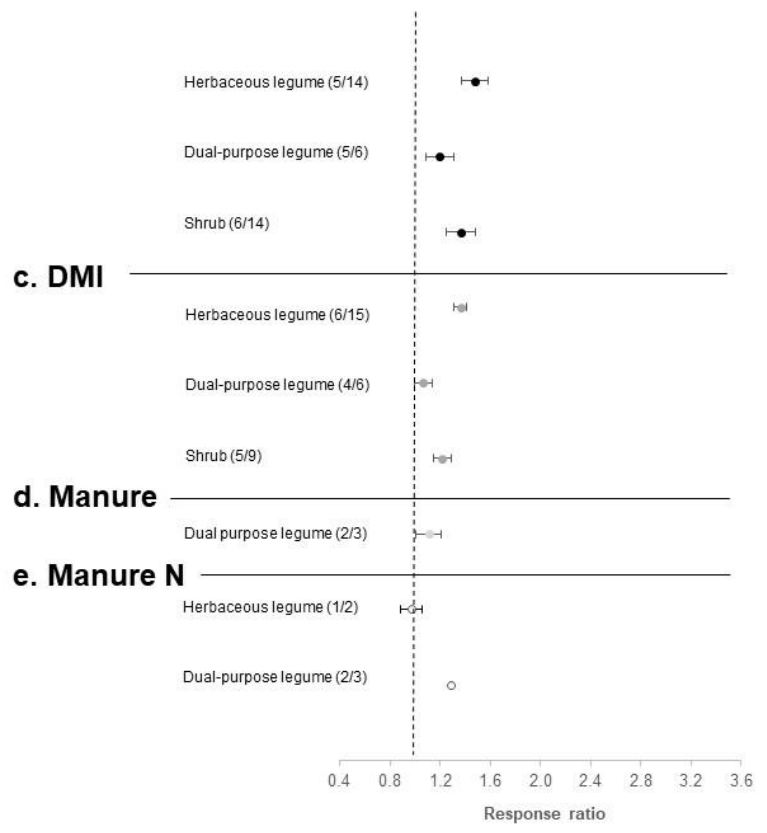

Figure 5: Weighed mean response ratios with standard error for improved feeding regime effects on livestock productivity indicators (a), and effects by technology sub-group on milk (b), dry matter intake (DMI) (c), manure production (d) and $\mathrm{N}$ content of manure (e). The dashed line indicates a response ratio of 1 , which is the threshold for increase $(>1)$ or decrease $(<1)$ when compared to the control. The number of studies and observations are reported in brackets.

Tropical forages have also been measured to have effects on soil quality, household economics and food crop productivity. A total of 88 observations reported effects of forage integration in cropping systems on soil quality, 85 observations on household economics, and 302 observations on food crop yields. Forage integration into cropping systems has often been highlighted as key to deliver multiple benefits to farmers, yet there are only few successful and published examples (Maass et al., 2015). Intercropping food crops (maize, sorghum and millet) with forage grasses and legumes was the subject of a few publications. Food crops studied were mainly maize, and to a lesser extent sorghum and millet. Forages that were intercropped with food crops were mostly annual forage legumes such as Lablab purpureus and Vigna unguiculata. Perennial intercropped herbaceous or dual-purpose legumes included Mucuna pruriens and Stylosanthes spp. that are under sown or relay-planted, and often allowed to grow 
throughout the subsequent season(s) as improved fallow. Only in one case were food crops intercropped with a forage grass (Chloris gayana). Various studies focused on Desmodium spp. and mostly refer to the push-pull system in which the pest control factor has an additional effect on food crop yields (Hassanali et al. 2008). Hedgerow cropping with fodder shrubs was mainly experimented with within East Africa, with Calliandra spp., Leucaena spp. and to a lesser extent Sesbania, planted in fields of maize (and soybean), and wheat (and beans). Integrating planted forages into cropping systems overall almost halved soil loss, and increased SOC by an average of $10 \%$. On average, they almost tripled economic revenue and benefit and increased crop grain yields by $60 \%$ and stover yields by $33 \%$ (Figure 6a). Intercropping a forage grass or legume with a food crop was more profitable than hedgerow cropping, more than tripling economic benefit (Figure $6 \mathrm{e}$ ) and resulted in $75 \%$ higher food crop yields (Figures f). Hedgerow cropping with fodder shrubs can lead to competition and lower food crop yields, depending on the exact agronomic arrangement and agro-ecological conditions. Variability was high in the economic data, which was also reported by Franzel et al. (2014) for fodder shrub hedgerow cropping. Net return in Kenya and Uganda varied widely, depending on the number of trees grown on the farm, the amount of supplementation with leaf meal, and the milk prices, which can vary between locations and seasons and influence profitability. Inconsistent valuation methods and assumptions also complicate the economic comparisons, e.g. full costs are often not reported. This corroborates results by White et al. (2013) who reviewed global literature on forage technology impacts.

a. Overall cropping system integration

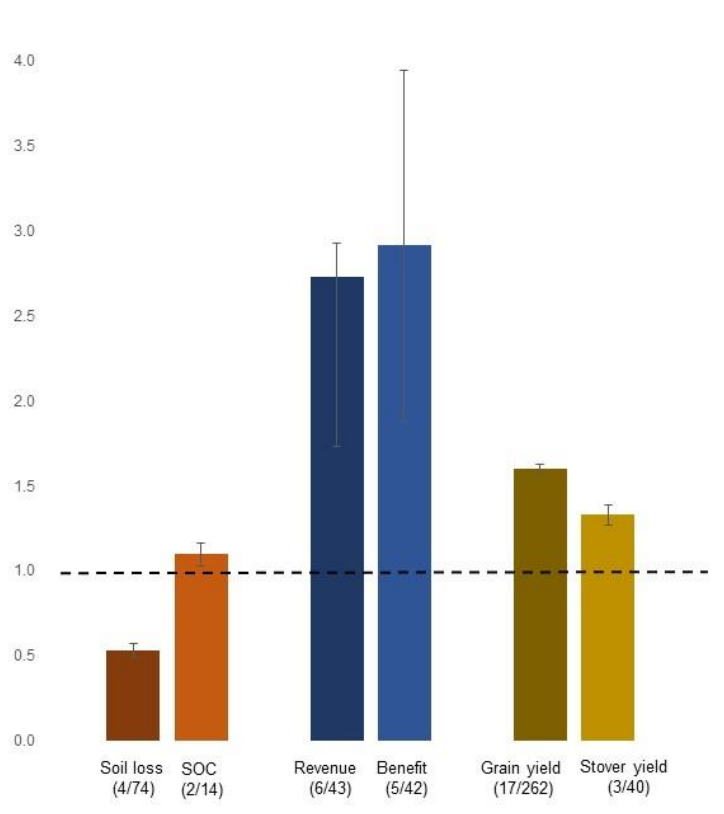

b. Soil loss
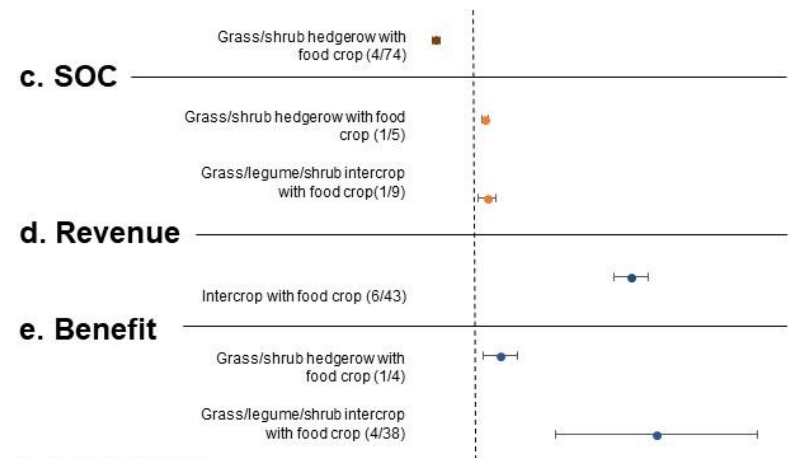

f. Grain yield

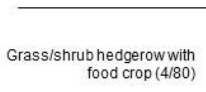

Intercrop with food cro

g. Stover yield

Grass/legume/shrub intercrop
with food crop (3/40)

$\begin{array}{llllllllllll}0.4 & 0.8 & 1.2 & 1.6 & 2.0 & 2.4 & 2.8 & 3.2 & 3.6 & 4.0 & 4.4\end{array}$

Response ratio 
Figure 6: Weighed mean response ratios with standard error for overall effects of cropping system integration technologies on soil quality, household economics and food crop productivity (a), and effects of technology subgroups on soil loss (b), soil organic carbon (SOC) (c), revenue (d) and benefit $€$, and grain (f) and stover yields (g). Impact dimensions are differentiated by colors with red for soil quality, blue for economic performance, and brown for food crop productivity. The dashed line indicates a response ratio of 1 , which is the threshold for increase $(>1)$ or decrease $(<1)$. Number of studies and observations are reported in brackets.

This review demonstrates the central role planted forages can play in agricultural productivity, environmental sustainability and livestock nutrition in smallholder mixed crop-livestock systems in SSA, which has been suggested before (e.g. Ates et al., 2018). These results underline the potential of tropical forage technologies to contribute to sustainable intensification. Multi-dimensional impacts of technologies become increasingly recognized as key, also for integration in farming systems and adoption. For example, in the discussions around Climate-Smart Agriculture (CSA) and Sustainable Intensification (SI), concepts of synergies and trade-offs between various objectives become more and more important (Campbell et al., 2014). Multi-disciplinary research is needed to gain a comprehensive view of multi-dimensional impacts and trade-offs of forage technologies. Understanding whole system implications of forage introduction into a farming system is required - e.g. for estimating trade-offs in labor requirements or food security when intensifying livestock production (Ates et al., 2018). Other authors have also been calling for a practical systems-based approach to forage research (Pengelly et al., 2003; Sumberg, 2002). Farming systems research, together with simulation modeling to estimate forage and livestock production impacts and their interactions, and whole-farm economic analysis to evaluate benefits and risks, can provide decision support to farmers as well as evidence for researchers and funding agencies to prioritize (research) investments (Pengelly et al., 2003). In fact, farmers seem to make decisions based on balancing or satisfying multiple objectives, instead of optimizing one single objective - which has been coined 'satisficing behavior' (Simon, 1957; Van Kooten et al., 1986). For example, smallholder crop-livestock farmers might not only be interested in increasing cash income, but also protecting their soils and providing nutritious food for the family. In that sense, technologies that can deliver multiple benefits might be especially attractive (Box 1). 
Box 1: Multi-dimensional benefits of forage grasses are valued by farmers in Tanzania - field testimoniesThe International Center for Tropical Agriculture (CIAT) has been leading various research for development (R4D) projects throughout Tanzania (TZA) since 2012, attempting to address forage impacts in a multi-dimensional way. Different Pennisetum, Tripsacum, Brachiaria and Panicum grass species and accessions have been tested on-farm for agronomic and livestock performance under various levels of replication and researcher control. In the Southern Highlands of Tanzania (Njombe, Mufindi, and Rungwe districts), farmers still have sufficient farmland available but the dairy value chain is poorly developed and input and output markets lacking. Farmers report that the Brachiaria hybrids cvs. Cayman and Cobra increase milk production by $1.5-2 \mathrm{~kg}$ per milking event, mainly achieved through higher animal intake due to high crude protein content and palatability. Intercropping with a legume such as Stylosanthes guianensis, protein content of the forage is even higher (Figure 7a). Increased and sustained income is another major impact of dairy production, as daily sales to cooperatives and neighbors are supporting the household's cash flow (Figure 7b). However, Cobra and Cayman are less drought-tolerant than Brachiaria hybrid cv. Mulato II, for example, which helps to maintain animal health and milk production through the long dry season in the area. In the Lushoto district, Usambara Highlands, farm sizes are small and erosion potential is high due to high population density and sloping landscapes. Napier grass (Pennisetum purpureum) and Guatemala grass (Tripsacum andersonii) are planted for simultaneously achieving high quantities of feed and controlling soil erosion (Figure 7c). Guatemala grass, however, is becoming less attractive due to its high water consumption and competition with close-by food crops. When asking farmers in this area for reasons to keep cows, availability of manure for cropland fertilization is often-mentioned (Figure 7d). If planted close to the homestead, it can also significantly reduce labor required to fetch forage from far. In the dry season, household members can spend 4-5 hours a day to fetch sufficient forage (Figure 7e). Throughout Tanzania, but especially in Kilimanjaro and Manyara districts around Arusha, forage production and sale is also becoming an attractive means for direct income generation. A $50 \mathrm{~kg}$ bag of Brachiaria splits can sell for around 15,000 TSh (USD 6.5), serving as planting material. In the dry season, when fresh forage is scarce, a bale of hay (12-15 kg) from Rhodes grass (Chloris gayana) sells for 3,500 TSh (USD 1.5), while hay from natural pasture species (Hyparrhenia rufa, $H$. filipendula, H. hirta) goes for 5000 Tsh (USD 2.2) per man load (30 kg). Haymaking is especially lucrative for feed supply throughout the dry season, ensuring year-round forage availability (Figure 7f). It is often those multiple 
benefits of a forage technology that motivate farmers to adopt a forage technology.

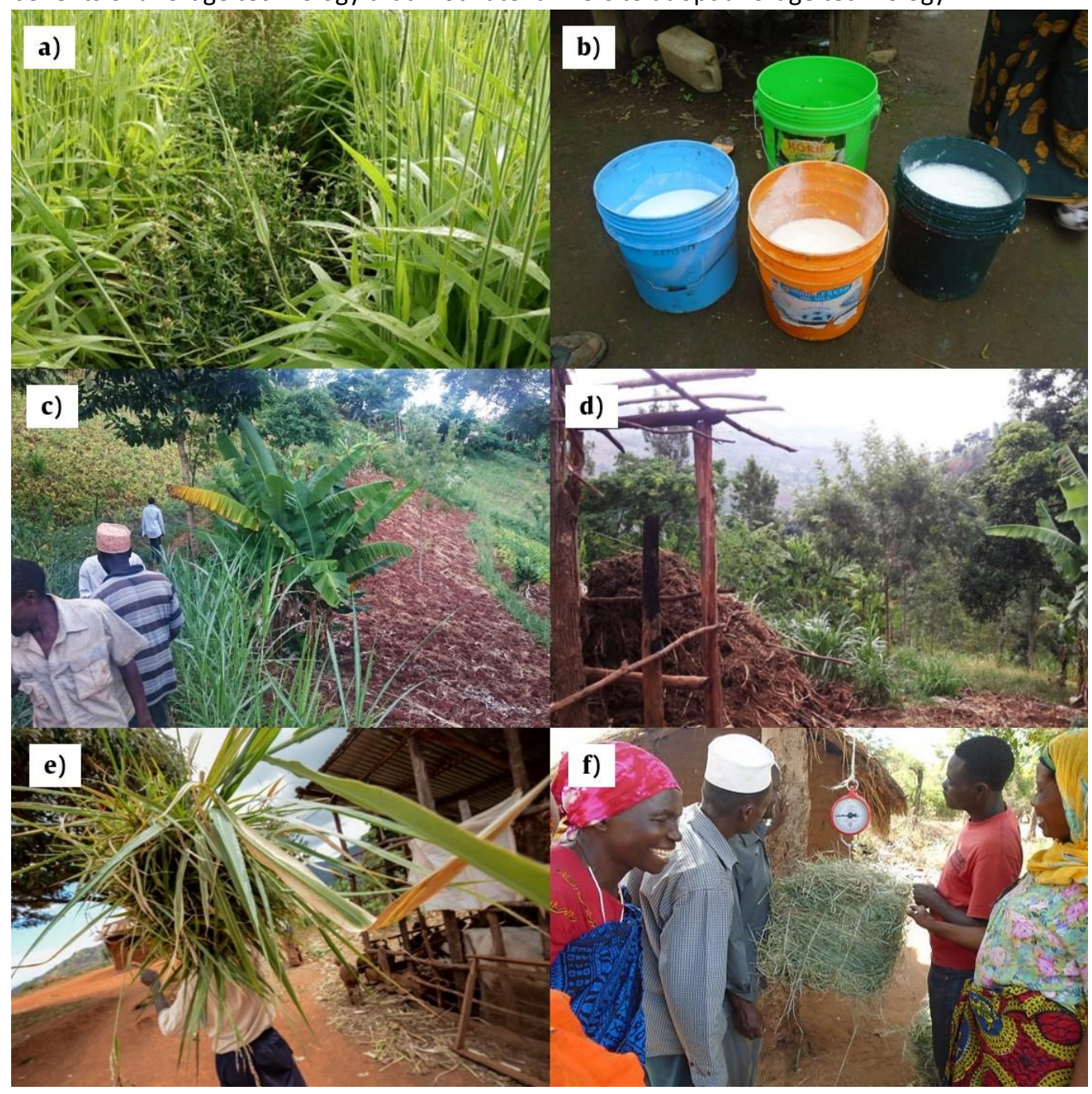

Figure 7: Field pictures from Southern Highlands, Usambara highlands, Manyara and Kilimanjaro, Tanzania. $B$. hybrid cv. Cayman intercropped with S. guinanensis in Rungwe district in Southern Highlands (a). Fresh raw milk is ready for sale to neighbours and cooperatives in Rungwe district, Southern Highlands (b). Napier grass planted on contours for reduction of soil erosion as well as supply of fodder in Lushoto (c). Farmyard manure is a highly valued input to crop production and can be increased in quantity and quality through feeding improved forages in Lushoto (d). Farmer carrying Napier grass back to his farm for feeding in Lushoto (e). Weighing a bale of hay from Rhodes grass in Babati, Manyara district (f). Photo credits: B. Nzogela, CIAT (a, b, f); B.K. Paul, CIAT (c, d); G. Smith, CIAT (e). 
Yet, despite many years of research and development and the proven potential for multi-dimensional benefits, adoption of forage technologies has remained below expectation across tropical farming systems in developing countries (De Haan et al., 2006; Hall et al., 2007; Owen et al., 2012; Pengelly et al., 2003; Shelton et al., 2005). Especially in East Africa, where farmers have small land holdings, the area of land required to grow forages is one of the key limiting factors. However, lack of land tenure (Njarui et al., 2017), different intra-household access to land and division of labor by women and men, women's burdens of domestic chores (Kebebe et al., 2017; Omollo et al., 2018), or other gender-related issues may be equally important. The number of socio-economic factors involved in forage adoption can help explain why the highly participatory research for development (R4D) activities in South-Asia have resulted in successful forage adoption (Lisson et al., 2010; Millar and Connell, 2010; Stür et al., 2013). A deeper lying explanatory factor is related to livestock farmers' objectives. Livestock intensification is not always the main focus of farmers who keep livestock primarily for providing draught power, as assets and risk management strategy, or for cultural reasons (Sumberg and Thomas, 1995; Lankoande and Sumberg, 2013). There is also some cultural reluctance to grow forages if producers are unfamiliar with

the concept of investing labor (planting, management and harvesting), as well as capital (seeds, land) in something that was previously "for free". Such investment is mostly common for food crops but not for feed (Sumberg and Thomas, 1995).

\subsection{Variability of forage productivity}

Absolute forage grass yield figures are highly variable (Table 2). Herbage DM yields for Pennisetum purpureum range from 0.25 to $37.3 \mathrm{t} /$ ha with most values around $3-10 \mathrm{t} / \mathrm{ha}$, with the lowest value recorded in a semi-arid environment per season. Crude protein contents for Pennisetum purpureum reached as much as $16.3 \%$ in an experiment in Kitale, Kenya, while most other figures range between 5 and $8 \%$ (Table 2). The high variability in forage agronomic performance in terms of biomass production is remarkable. These might have two reasons: Firstly, Napier grass is native to SSA and adapted to a wide range of soil and agro-ecological conditions from 0 to $2100 \mathrm{~m}$ above sea level, as well as annual rainfall between 750 and $2500 \mathrm{~mm}$ (Negawo et al., 2017). However, yields can vary widely, depending on the cultivar grown, and its interactions with agro-climatic conditions and management. Globally, some studies have even reported yields of up to $66 \mathrm{t} \mathrm{DM/ha/year} \mathrm{in} \mathrm{Malaysia,} 78 \mathrm{t} \mathrm{DM/ha/year} \mathrm{in} \mathrm{Brazil} \mathrm{or} 90$ t DM/ha/year in Zimbabwe (Negawo et al., 2017), which is significantly more than the ranges reported for SSA in this review. Similarly, the CP content of Napier grass is significantly influenced by cutting treatments and intervals, and fertilization (Negawo et al., 2017). The choice of experimental control and 
fertilization regime might also explain some of the observed variability, which calls for future statistical analysis of the literature data. Secondly, despite the efforts of eminent forage researchers (e.g. Tarawali et al., 1995; 't Mannetje, 2000), the research field and methods of forage agronomy are not standardized, also due to the comparably less research that has taken place as compared to food crops. Forage biomass production is assessed in various ways in terms of establishment time, cutting interval, cutting height and reporting times (per harvest, season, year or more). This made results less comparable across sites and studies. Besides, it reflects the low level of forage research capability available in SSA, e.g. shown by seven forage agronomists out of 545 agricultural scientists in Kenya, according to Murithi and Minayo (2011). Consequently, there is a need for both implementing proposed standards in forage agronomy and forage capacity building. Further statistical analysis of forage productivity data could elucidate influencing factors for the observed site-year variability.

\section{Conclusions}

Quantitative literature reviews are key to summarizing evidence on what is known, synthesizing it for use within or outside of the research domain, and formulating future research priorities. To the best of our knowledge, this review for the first time: i) provides a comprehensive overview of focus and location of past research on tropical forages in SSA; ii) quantifies the range and magnitude of multi-dimensional effects of forage technologies including livestock productivity, soil quality, household economics and food crop productivity; and iii) presents variability in forage agronomy data.

This review demonstrated the central role improved forages can play in sustainable intensification in SSA. It further highlights an urgent need for interdisciplinary and systems-level approaches to quantify potential synergies and trade-offs between different productivity, environmental and livelihood dimensions. Results of this review can be taken up by environmental and agricultural scientists and practitioners in SSA to design and target livestock feeding interventions that deliver multiple benefits to farmers. Magnitudes of responses can be used for more accurate ex-ante impact assessments and scenario analyses. Knowledge gaps and recommendations for future research include: i) Statistical analysis of influencing factors for site-year variability in forage effects; ii) Innovative spatial and temporal integration of various forages in cropping systems using rigorous agronomic methods; iii) Multi-disciplinary experimental studies that reveal multiple impacts of best-bet forage technologies in one location; iii) Farming systems modeling approaches that can use experimental results to simulate synergies and trade-offs on productivity, environment and livelihood dimensions. 
Chapter 3

\section{Livestock feeding systems and feed gaps in smallholder farms in East Africa}

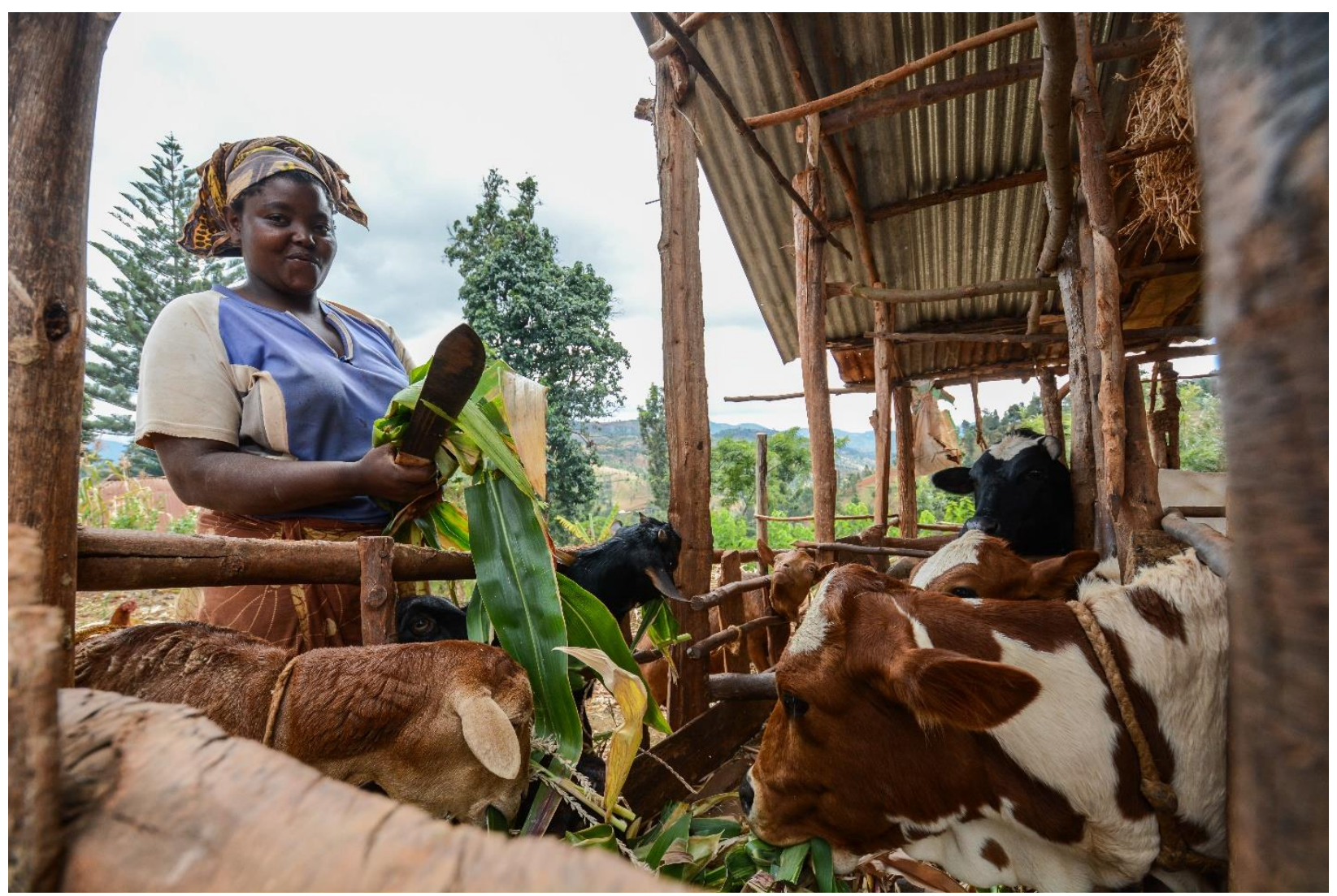

This chapter is under review as:

Paul, B.K., Birnholz, C., Nzogela, B., Notenbaert, A., Herrero, M., Bwire, J., Groot, J.G.J., Tittonell, P.A. Livestock feeding systems and feed gaps in smallholder farms in East Africa. Agricultural Systems. 


\section{Introduction}

Livestock are a global resource of significant benefit to society in the form of food, income, nutrition, employment, insurance, traction, and clothing (Herrero et al., 2012). By 2050, the total demand for meat, milk and eggs is projected to almost double worldwide, with the largest increases expected in the developing world. This 'livestock revolution' is driven by population growth, urbanization, income increase and change in dietary preferences by the growing middle class (Delgado et al., 1999; Herrero and Thornton, 2013). Combined with the importance of livestock for household income in smallholder systems, the livestock revolution may provide a unique pathway out of poverty for poor livestock keepers, provided that pro-poor policies and investments can support smallholder participation in the related value chains. Especially for ruminants, the prospects for smallholders to be competitive primary meat and milk producers are good due to low economies of scale, under-utilized family labor and the ability of ruminants to utilize low-quality roughage (McDermott et al., 2010).

Smallholder livestock production and associated feeding systems in East Africa vary widely, depending on socio-economic, cultural and agro-ecological factors. Livestock systems in East Africa can be distinguished as follows: a) pastoral and agro-pastoral with larger livestock herds, mainly composed of local breeds, grazed on natural public, private or communal grassland in areas with low agro-ecological potential; b) intensive crop-livestock systems based on stall-feeding (also called cut-and-carry or zerograzing) of 1-5 cross-bred or exotic cattle, forage cultivation and concentrate supplementation in high potential agro-ecological areas where manure is highly valued as crop fertilizer; c) semi-intensive mixed crop-livestock systems where the animals split their time between enclosures and grazing and/or being tethered; d) others including forest-based, urban and landless systems. In pastoral and agro-pastoral systems, the main objective is meat production with milk as a by-product, whereas in intensive and semi-intensive mixed crop-livestock systems the focus is often on dairy (McDermott et al., 2010; Robinson et al., 2011; Sere and Steinfeld, 1996). In Africa, 60\% of ruminants are found in mixed croplivestock systems, occupying $20 \%$ of the total area (Herrero et al., 2008). It commonly assumed that the shortage of sufficient quantity and quality feed on a consistent basis is a key constraint facing smallholder dairy farmers. In (semi-) intensive systems, it constitutes major production cost and absorbs much of the available on-farm labor (Bebe et al., 2002). Feed links livestock to land use and requirements, directly through grazing and forages, and indirectly through residues and grains. Diet quality also is the basis of feed use efficiency, which determines greenhouse gas emission intensity through non- $\mathrm{CO}_{2}$ emissions from enteric fermentation and manure (Herrero et al., 2013). Despite the 
importance of feed baskets for livestock productivity and environmental impacts, empirical measurements of feed quantities supplied in smallholder systems in East Africa are rare.

The concept of yield gap has become increasingly popular in the last decade, witnessing a large number of applications in the realm of food crops. Yield gap is the difference between potential and actual crop yield. Potential yields are obtained with a specific crop cultivar when water and nutrients are nonlimiting and biotic stresses are controlled; while actual crop yields are those effectively achieved in farmers' fields (Van Ittersum et al., 2013). The production ecology principles underlying crop yield gaps have also been applied to livestock production systems, as outlined by van de Ven et al. (2003) and van der Linden et al. (2015). Other approaches to livestock yield gaps were employed to estimate how livestock production can be made more efficient, including in India and Ethiopia (Mayberry et al., 2017); Kenya, Tanzania, Uganda, Ethiopia, Senegal and Burkina Faso (Henderson et al., 2016); and Mexico (Cortez-Arriola et al., 2014). Moore et al. (2009) introduced the specific concept of a 'feed gap', defined as times of the year when feed supply is insufficient to meet livestock demand. However, the existing approaches to feed gaps either rely on extensive available data to calibrate various time-intensive models, or use survey data and assumptions on feed baskets without measured feed quantities.

Methods to quantify feeding systems and feed gaps for smallholder systems in data-scarce environments are currently lacking. In this context, this study aims to introduce and test a relatively simple approach to quantify feeding systems and feed gaps in East African farms, comparing feed demand and supply at the individual herd level. The approach is illustrated with pilot evidence from various crop-livestock production systems across three agro-ecological zones in Tanzania, which broadly represent the diversity found in the region. The paper concludes with discussing feeding system diversity and intensification, magnitudes of feed gaps and their causes, and the usefulness of the approach, including shortcomings and recommendations for future research.

\section{Material and Methods}

\subsection{Conceptual approach}

In this study, feeding systems comprise feed quantity and quality, but also feed management (grazing vs. cut-and-carry) as well as required labor. Livestock feed gaps are defined as the difference between attainable feed demand and actual feed supply at the individual herd level. Attainable feed demand refers to calculated feed requirements to support a locally attainable milk production level, while actual 
feed supply is the feed offered to a specific herd on farm (Figure 1). The approach to match 'feed demand' and 'feed supply', and define the difference between both as 'feed gap', originates from Moore et al. (2003) and Bell et al. (2017). The use of 'attainable' and 'actual' feed supply and demand concepts is based on production ecology principles. Applied to livestock production systems, they differentiate between potential/attainable, limited and actual livestock yields. Potential production is solely defined by temperature, day length, and animal genetics, while actual yields are those achieved in farmers' fields. Limiting factors (water, feed quantity and quality) and reducing factors (e.g. diseases, pollutants) explain the difference between potential and actual yields (van der Linden et al., 2015; van der Ven et al., 2003). In places where potential yields are far from actual yields, it is more useful to work with a locally attainable yield that can be achieved by resource-endowed smallholder farmers in their most productive fields (Tittonell and Giller, 2013). Different from van de Ven et al. (2003) and van der Linden et al. (2015), this approach to feed gaps does not consider growth limiting and reducing factors other than feed. In contrary to Moore et al. (2003) and Bell et al. (2017), we test our approach with a one-time pilot measurement only, thus ignoring the time scale of magnitude and variability of feed gaps. For this approach to yield comprehensive insights into seasonal feed gaps, the data collection has to be repeated as needed. This approach is designed to operate in data-scarce environments such as smallholder farming systems in East Africa, focusing on relatively simple calculations and minimum measured data without time and resource-intensive calibration of multiple models. 


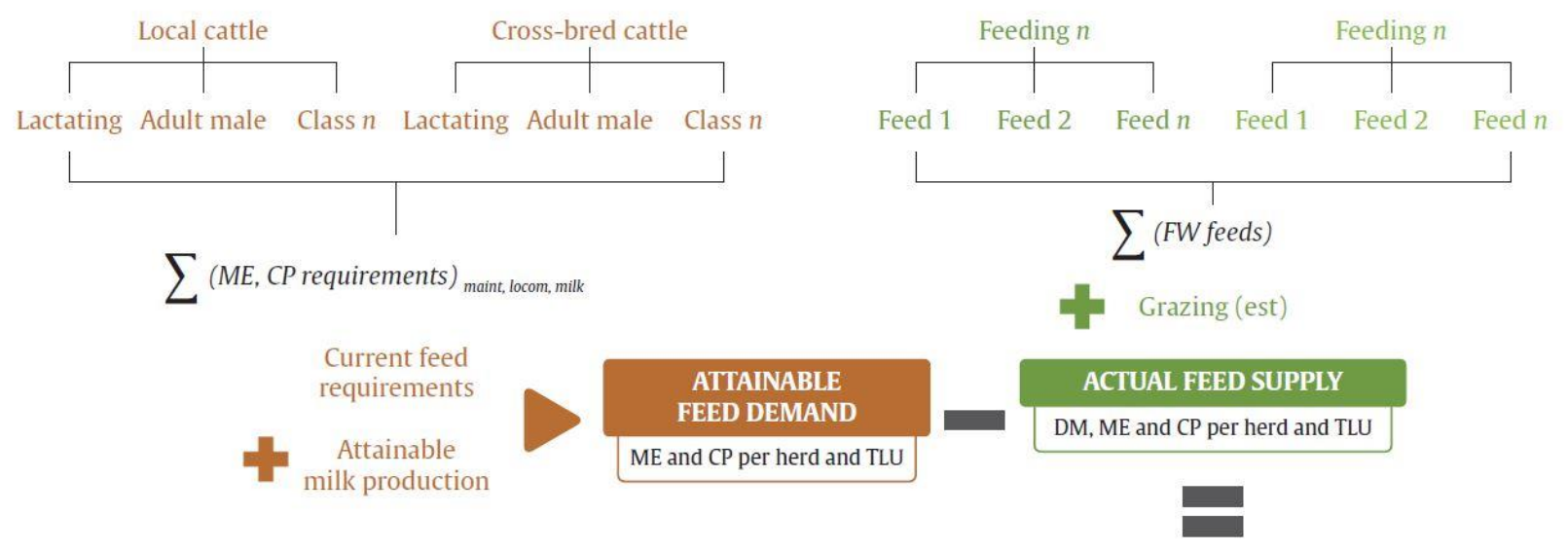

\section{FEED GAP}

Relative feed gap of ME and $\mathrm{CP}(\%)=$

feed gap / actual feed supply

Figure 1 Conceptual overview of the feed gap approach to smallholder dairy farms in East Africa. $n$ indicates additional feedings, feed items or livestock classes. $\mathrm{FW}=$ fresh weight, $\mathrm{DW}=$ dry weight, $\mathrm{ME}=$ metabolizable energy, $\mathrm{CP}=$ crude protein, TLU = Tropical Livestock Unit. Requirement calculations include maintenance, milk production and locomotion.

\subsection{Pilot study sites and farm selection}

Three study sites in Tanzania were selected for the pilot study, spread over three administrative regions: Lushoto in Tanga, Mvomero in Morogoro, and Babati in Manyara region (Figure 2). 


\begin{tabular}{|c|c|c|c|c|c|}
\hline Ward & Bashnet & Dabil & Dareda & Galapo & Magugu \\
\hline Village & Long & Sabilo & Seloto & Hallu & Matufa \\
\hline Elevation (masl) & 2055 & 1617 & 1657 & 1193 & 1148 \\
\hline Annual precipitation (mm) & 844 & 743 & 785 & 685 & 700 \\
\hline Mean temperature $\left({ }^{\circ} \mathrm{C}\right)$ & 16 & 19 & 19 & 21 & 21 \\
\hline $\begin{array}{l}\text { Population density } \\
\text { (persons } / \mathrm{km} 2 \text { ) }\end{array}$ & 165 & 98 & 286 & 34 & 39 \\
\hline \multicolumn{6}{|l|}{ Lushoto } \\
\hline$\overline{\text { Ward }}$ & Gare & \multicolumn{3}{|c|}{ Mbuzii } & Ubiri \\
\hline Village & Yamba & \multicolumn{3}{|c|}{ Mbuzii, Boheloi } & Ubiri \\
\hline Elevation (masl) & 1502 & \multicolumn{3}{|c|}{1154} & 1016 \\
\hline Annual precipitation (mm) & 1095 & \multicolumn{3}{|c|}{1109} & 813 \\
\hline Mean temperature $\left({ }^{\circ} \mathrm{C}\right)$ & 17 & \multicolumn{3}{|c|}{19} & 20 \\
\hline Population density & 323 & \multicolumn{3}{|c|}{339} & 274 \\
\hline
\end{tabular}

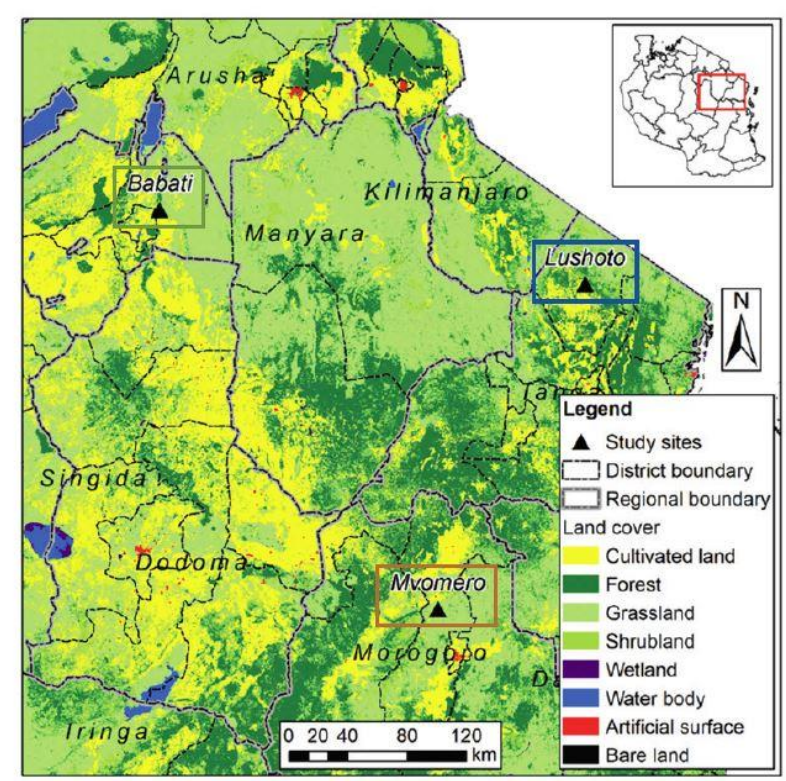

Figure 2 Locations of study sites Lushoto, Mvomero and Babati in Tanzania, and their general characterization. Onfarm data collection for the pilot study took place in ten villages across nine wards in the three pilot study sites. Data for the site characterization was retrieved from the following sources: Funk et al., 2015; Hijmans et al., 2005; Jarvis et al., 2008; Linard et al., 2012. Data for the map was retrieved from Chen et al., 2014; GADM 2018.

Data collection took place in different villages in five wards in Babati, one ward in Morogoro and three wards in Lushoto, which differed in average elevation, precipitation and temperature, and population density (Figure 2). The sites represent different (sub)-humid agro-ecological zones and dairy-oriented production systems, excluding (semi)-arid, pastoralist systems. Mvomero and Lushoto are sites of the Tanzania dairy value chain under the CGIAR Research Program on Livestock, and were selected through a systematic process of spatial map overlays, stakeholder consultations, scoping visits and partner preferences to represent areas with intensive/more commercial rural producers who are significantly engaged in selling milk to urban consumers (https://livestock.cgiar.org/). Babati is one of the sites of the AfricaRISING research program in Tanzania, representing a high socio-economic and agro-ecological diversity and potential for sustainable intensification. Dairy production takes place in agro-pastoral, semi-intensive and intensive mixed crop-livestock systems (https://africa-rising.net/).

We hypothesized to find a diversity of feeding systems and feed baskets in the different study sites, as the relative use of different feed types differs with level of farming intensity. In sites with lower agroecological potential and levels of intensification, grazing would prevail, complemented with crop 
residues in the dry season. With increasing potential for crop production, grazing land diminishes and crop residues, collected or tethered natural vegetation, and planted forages increase. In areas with the highest level of farming intensity and market connection, concentrated feeding also gains importance (Tittonell et al., 2015; Figure 3). Lushoto was expected to have the most intensified feed baskets, with the highest percentages of planted fodder and supplements, and no grazing. Mvomero was estimated to have the most extensive feeding systems, relying mostly on grazing, while Babati was thought to be in between both systems with grazing as well as large reliance on crop residues but little planted fodder (Figure 3).

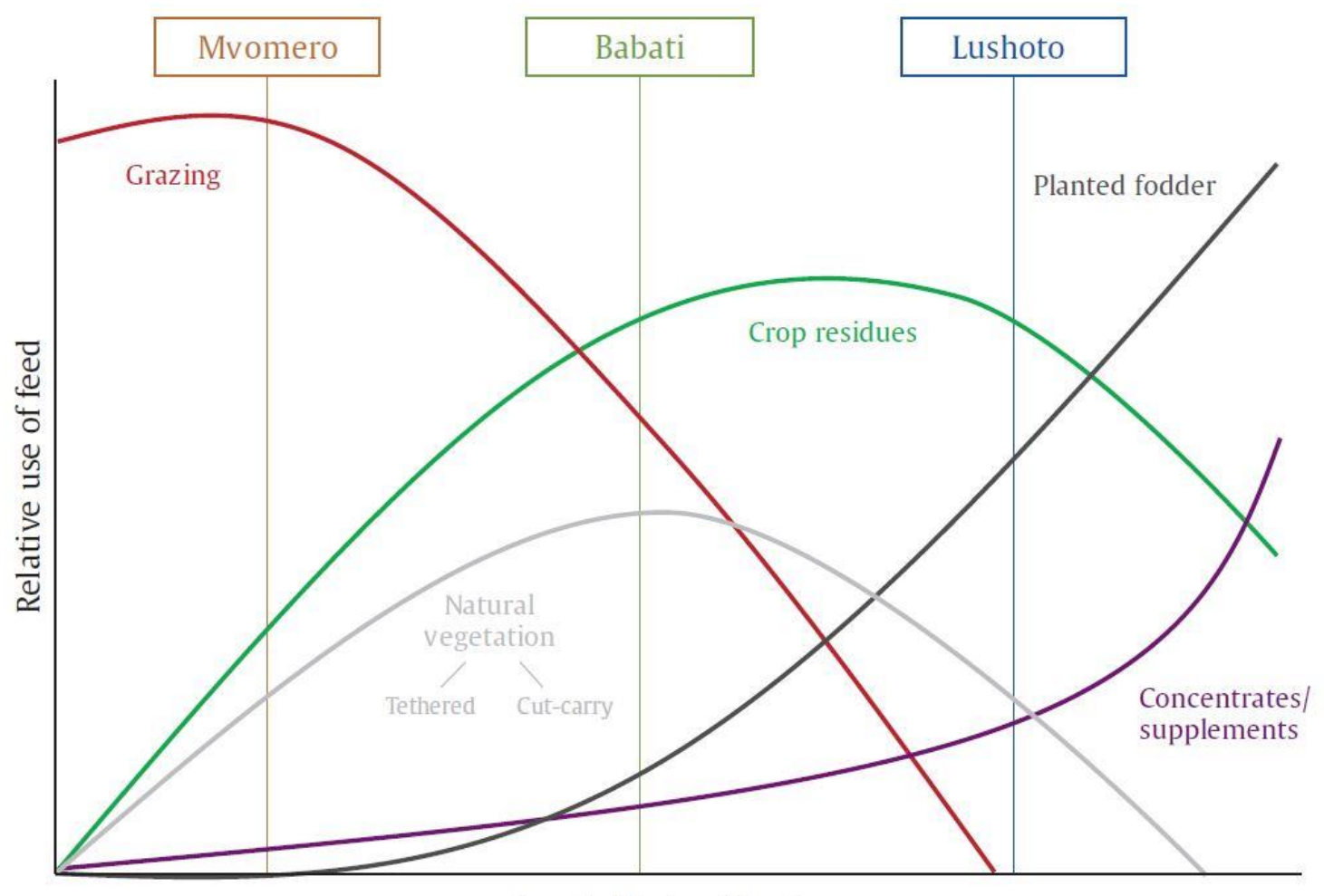

Level of intensification

Figure 3 Conceptual diagram of changing feed baskets following intensification. Colors denote various types of feed and the change of their relative use with level of intensification. Tanzania pilot study sites Mvomero, Babati and Lushoto were expected to be positioned along the gradient with different corresponding feed baskets.

In total, 28 farms were sampled, with eight farms in Lushoto, nine farms in Mvomero and eleven farms in Babati. In each site, farmers were stratified according to existing farming system typologies. In Babati, three farm types were picked from Paul et al. (in review - Chapter 6), namely smallest $(n=5)$, dairy $(n=3$ ) and large livestock ( $n=3$ ) farms. In Lushoto, the typology was based on an unpublished participatory typology (Tongruksawattana \& Ngunjiri, 2015) and included small $(n=2)$, medium $(n=3)$ and large $(n=3)$ farms. One of the targeted small farmers was not available at the time of data collection, and no 
replacement could be identified. In Mvomero, no pre-existing typology was available, so in discussion with extension officers and local scientists, farmers were stratified into small $(n=2)$, medium $(n=3)$ and large $(n=4)$ farms. One of the large farmers was intended to be a small farmer, but was reclassified during data analysis. GPS locations of all farms were recorded.

\subsection{Data collection}

On-farm data collection was carried out in Babati from 20 to 24 April 2016, Mvomero from 28 April to 2 May 2016, and in Lushoto from 16 May to 2 June 2016 with four trained extension officers. The timing corresponded to the peak of the rainy season in Mvomero and Babati. In Lushoto, sampling was performed after the rains had just stopped but feed availability was still similar to the rainy season. Empirically measured data included the number and breeds of all cattle, quantity of fresh feeds, milk production, and labor spent on animals. Farmers were asked to not alter their usual feeding and management practices during the day of data collection. Amount of feeds supplied to cattle were weighed and recorded in fresh weight (FW) with a hanging scale during all feedings in the course of an entire day (6am to $7 \mathrm{pm}$ ). Feeds were separated into identifiable groups, weighed separately, and returned to the feeding trough. Sub-samples of approximately 200 gr were taken and analyzed with near-infrared spectroscopy (NIRS) for dry matter (DM) and crude protein (CP) content at the Ministry of Livestock and Fisheries' Tanzania Veterinary Laboratory Agency (TVLA) in Temeke District, Dar es Salaam. Milk production was measured with a measurement cup after each milking. Time for different livestock-related activities (feed collection, chopping, milking, herding) was measured with a stopwatch, and the household member performing the task was recorded.

\subsection{Data analysis}

Households with several herds of cattle which were managed and fed differently were analyzed and presented separately. Herd IDs are composed of household number and small letters (a, b, c) which indicate several herds per household.

Feed supplied per individual feed items in FW were summed up to a total amount of feed per day. Total feed supplied per day was then converted into DM, CP, and metabolizable energy (ME). Feed parameters were taken from the sample analysis, literature, feed databases and expert knowledge 
(Table 1). If species from several genus were found (e.g. Amaranthus, Brachiaria, Cynodon and Desmodium), nutritional values were found comparable in all cases and values from one species was picked to represent the mix. Among the cut and carry grasses fed to the livestock were local grasses that could not be identified, and are presented as "mixed unknown species". Estimation of their feed properties was based on comparable feeds found in the area such as planted grasses and was validated with experts. In Babati and Mvomero sites where livestock were grazing and feed intake could not be measured, DM intake was estimated assuming $3 \%$ of livestock body weight (BW) under medium quality of natural pastures.

Table 1 Feed parameters for dry matter (DM), crude protein (CP) and metabolizable energy (ME) and their sources as used in the analysis.

\begin{tabular}{|c|c|c|c|c|}
\hline & $\begin{array}{l}\text { DM } \\
\%\end{array}$ & $\begin{array}{l}\mathrm{CP} \\
\% \text { of DM }\end{array}$ & $\begin{array}{l}\mathrm{ME} \\
\mathrm{MJ} / \mathrm{kg} \mathrm{DM}\end{array}$ & Source \\
\hline Banana leaves (Musa spp) & 20.7 & 9.5 & 9.9 & $\begin{array}{l}\text { Feedipedia: } \\
\text { https://www.feedipedia.org/node/12458 }\end{array}$ \\
\hline Bean residues (Phaseolus vulgaris) & 88.0 & 7.1 & 7.4 & $\begin{array}{l}\text { Feedipedia: } \\
\text { https://www.feedipedia.org/node/12006 }\end{array}$ \\
\hline Brewers' waste & 85.0 & 10.0 & 12.0 & Expert estimation \\
\hline Comellina (Comellina benghalensis) & 8.3 & 13.3 & 8.6 & Sample Lushoto, expert estimation \\
\hline $\begin{array}{l}\text { Cynodon (Cynodon dactylon, } \\
\text { plectostachyus) }\end{array}$ & 30.6 & 9.9 & 8.6 & $\begin{array}{l}\text { Feedipedia: } \\
\text { https://www.feedipedia.org/node/12125 }\end{array}$ \\
\hline Guatemala grass (Tripsacum andersonii) & 22.0 & 8.8 & 8.4 & $\begin{array}{l}\text { Feedipedia: } \\
\text { https://www.feedipedia.org/node/12169 }\end{array}$ \\
\hline Maize bran (Zea mays) & 83.3 & 11.4 & 11.0 & $\begin{array}{l}\text { Sample Mvomero; Feedipedia: } \\
\text { https://www.feedipedia.org/hode/12280 }\end{array}$ \\
\hline Maize residues (Zea mays) & 80.0 & 1.3 & 7.6 & $\begin{array}{l}\text { Sample Babati; Feedipedia: } \\
\text { https://www.feedipedia.org/node/12874 }\end{array}$ \\
\hline Mixed unknown species & 25.0 & 9.1 & 7.3 & Lukuyu et al. (2016) \\
\hline Napier grass (Pennisetum purpureum) & 15.0 & 11.0 & 9.9 & Duncan et al. (2012) \\
\hline Natural pasture & 25.0 & 9.1 & 7.3 & Lukuyu et al. (2016) \\
\hline Sugarcane leaves (Saccharum officinarum) & 28.6 & 4.0 & 6.9 & Sample Lushoto; Duncan et al. (2012) \\
\hline
\end{tabular}


Actual feed supply is presented as two indicators: Per herd, and per Tropical Livestock Unit (TLU). Livestock BW was estimated by extension officers and local researchers per site. BW for adult male and female cross-bred and local cattle varied between $315 \mathrm{~kg}$ in Lushoto (local breed not present), 355 and $225 \mathrm{~kg}$ in Babati and 330 and $245 \mathrm{~kg}$ in Mvomero. BW for the remaining animal classes (heifer, yearling bull, calf) was set proportionate to adult cattle weights (heifer and yearling bull $75 \%$ of adult weight, calf 35\%). One TLU was defined as $250 \mathrm{~kg} \mathrm{BW}$, resulting in different TLU units per livestock class and site.

Current feed requirements were calculated based on Paul et al. (2008). According to this study, $6.27 \mathrm{~g}$ $\mathrm{CP}$ and $0.589 \mathrm{MJ}$ per kg metabolic weight (MW) are required for maintenance, while $82 \mathrm{~g}$ CP and 5.023 MJ are required per kg milk produced. The above-mentioned livestock BW and the measured milk production level of the day was used in the calculations. In grazing cattle, ME and CP requirements increased by $30 \%$ and $5 \%$ due to higher energy demands of locomotion. The energy requirements of grazing correspond to a median value of various estimations given in Vallentine (1990). Attainable target milk yield levels were set at $5 \mathrm{~kg} /$ day/cow for all adult female local breeds and $15 \mathrm{~kg} /$ day $/$ cow for all adult female improved breeds, irrespective of their lactation state at the day of measurement (Wassena et al., 2015). Feed requirements for the attainable target milk yield were added to current feed requirements and presented as attainable feed demand, expressed in ME and CP.

Feed gaps were quantified as the difference between attainable feed demand and actual feed supply. We express the relative feed gap in percentage by dividing the feed gap by attainable feed requirement for ME and CP (Figure 1). Positive numbers denote a feed gap, the situation when actual feed supply is insufficient to meet attainable feed demand. Negative numbers indicate a feed surplus when actual feed supply exceeds attainable feed demand.

\section{Results}

\subsection{Livestock production and feeding systems}

Different livestock production systems were present in the three pilot sites (Table 2). Mvomero was the most extensive site, with largest farm areas (average $6.2 \mathrm{ha}$ ) and herd sizes (9.7 TLU). In Lushoto, exclusive zero-grazing systems with 1-2 cross-bred cows (1.7 TLU) and relatively small farm sizes (3.2 ha) were dominant, while Babati had a mixture of both systems (3.9 ha, 5.9 TLU). Grazing on both private and communal pastures and cropland was common in Babati, while in Mvomero only communal pastures were used. Grazing took on average between 6.5-11 hours a day. Despite the focus on dairy 
production, only two farmers in Lushoto had lactating cows at the time of data collection, producing on average $2.8 \mathrm{~kg} /$ day/cow. Average daily milk production per cow was lower in Babati $(2.7 \mathrm{~kg} / \mathrm{day})$ and Mvomero (1.5 kg/day). Livestock systems in Babati were most labor-intensive (3.2 h/TLU/day), while the cut-and-carry systems in Lushoto required the least amount of labor (1.4 h/TLU/day). Most livestockrelated labor was supplied by men, especially for collecting feed and grazing, while women provided almost exclusive care (>95\%) for $18 \%$ of herds (Table 2 ). 
Table 2 Key data describing the livestock production and feeding systems in the pilot sites in Tanzania. TLU = tropical livestock unit, $h=h o u r s, F W=$ fresh weight.

\begin{tabular}{|c|c|c|c|c|c|c|c|c|c|c|c|c|c|c|c|}
\hline & & & & & & & Men & & & Wome & & & & & \\
\hline & Type & $\begin{array}{l}\text { 음 } \\
\frac{0}{0} \\
\frac{1}{1}\end{array}$ & 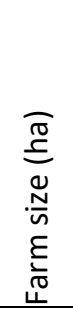 & $\stackrel{\ni}{\longmapsto}$ & 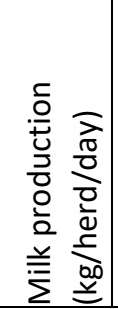 &  &  &  & 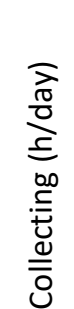 & 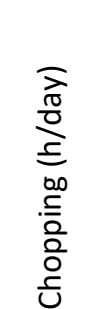 & $\begin{array}{l}\frac{7}{\sqrt{0}} \\
\frac{0}{0} \\
\frac{0}{0.0} \\
. \frac{1}{N} \\
\frac{0}{0} \\
0\end{array}$ & $\begin{array}{l}\text { Total } \\
\text { labor per } \\
\text { herd } \\
\text { (h/day) }\end{array}$ & $\begin{array}{l}\text { Total } \\
\text { labor per } \\
\text { TLU } \\
\text { (h/day) }\end{array}$ & $\begin{array}{l}\text { Total } \\
\text { labor per } \\
\text { feed } \\
\text { supplied } \\
\text { (h/100kg } \\
\text { FW/day) }\end{array}$ & $\begin{array}{l}\text { Female } \\
\text { labor (\% } \\
\text { of total } \\
\text { labor) }\end{array}$ \\
\hline \multirow[t]{8}{*}{ Lushoto } & Small & 1 & 1.8 & 2.2 & 0 & 0 & 0 & 0 & 0 & 1.0 & 0 & 1.0 & 0.5 & 1.4 & 96 \\
\hline & & 2 & 1.2 & 0.9 & 0 & 2.0 & 0.5 & 0 & 0 & 0 & 0 & 2.5 & 2.6 & 6.7 & 0 \\
\hline & Medium & 3 & 1.5 & 1.7 & 6.3 & 3.5 & 0 & 0 & 0 & 0 & 0 & 3.5 & 2.1 & 2.3 & 0 \\
\hline & & 4 & 4.5 & 2.2 & 2 & 1.7 & 0 & 0 & 0 & 0 & 0 & 1.7 & 0.8 & 2.0 & 0 \\
\hline & & 5 & 4 & 1.3 & 0 & 0.6 & 0.1 & 0 & 0.8 & 0 & 0 & 1.5 & 1.2 & 2.0 & 56 \\
\hline & Large & 6 & 2.6 & 2.5 & 0 & 1.1 & 0 & 0 & 0 & 0 & 0 & 1.1 & 0.4 & 0.5 & 0 \\
\hline & & 7 & 6.7 & 0.9 & 0 & 2.1 & 0.1 & 0 & 0 & 0 & 0 & 2.1 & 2.2 & 3.1 & 0 \\
\hline & & 8 & 3.2 & 2.2 & 0 & 0 & 0 & 0 & 3.1 & 0 & 0 & 3.1 & 1.4 & 4.2 & 100 \\
\hline \multirow[t]{5}{*}{ Babati } & Poor & $9 a$ & 2.1 & 4.5 & 1.3 & 0 & 0 & 8.2 & 0 & 0 & 0 & 8.2 & 3.7 & 8.7 & 0 \\
\hline & & $9 b$ & ibid & 4.7 & 13.1 & 3.9 & 0 & 0 & 2.7 & 0 & 0 & 6.5 & 5.2 & 16.9 & 41 \\
\hline & & 10 & 1.6 & 4.5 & 0 & 0 & 0 & 8.4 & 0 & 0 & 0 & 8.4 & 4.9 & 16.3 & 0 \\
\hline & & 11 & 1.2 & 9.1 & 1.2 & 0 & 0 & 9.8 & 0 & 0 & 0 & 9.8 & 3.9 & 16.5 & 0 \\
\hline & & 12 & 2.4 & 9.2 & 0 & 0 & 0 & 8.8 & 0 & 0 & 0 & 8.8 & 7.0 & 29.7 & 0 \\
\hline
\end{tabular}




\begin{tabular}{|c|c|c|c|c|c|c|c|c|c|c|c|c|c|c|c|}
\hline & & 13 & 0.8 & 5.9 & 0 & 0.1 & 0 & 6.5 & 0 & 0 & 0 & 6.6 & 2.6 & 8.3 & 0 \\
\hline & \multirow[t]{3}{*}{ Large } & 14 & 12 & 2.6 & 4.4 & 0 & 0 & 0 & 0 & 0 & 11.0 & 11.0 & 8.7 & 32.7 & 100 \\
\hline & & 15 & 3.9 & 2.9 & 4.0 & 0 & 0 & 9.0 & 0 & 0 & 0 & 9.0 & 4.1 & 12.7 & 0 \\
\hline & & 16 & 11 & 13 & 4.7 & 0 & 0 & 9.5 & 0 & 0 & 0 & 9.5 & 2.1 & 6.4 & 0 \\
\hline & \multirow[t]{6}{*}{ Dairy } & $17 a$ & 2 & 4 & 1.0 & 3.5 & 0.3 & 0 & 0.1 & 0 & 0 & 3.8 & 0.8 & 2.2 & 2 \\
\hline & & $17 b$ & ibid & 1.4 & 7.1 & 4.5 & 0.3 & 0 & 0 & 0 & 0 & 4.8 & 1.1 & 3.6 & 1 \\
\hline & & $17 c$ & ibid & 6.4 & 0.9 & 0 & 0 & 10.9 & 0 & 0 & 0 & 10.9 & 1.2 & 4.0 & 0 \\
\hline & & $18 a$ & 4 & 8.2 & 0 & 0 & 0 & 0 & 1.0 & 0 & 0 & 1.0 & 0.1 & 0.3 & 100 \\
\hline & & $18 \mathrm{~b}$ & ibid & 9.7 & 0 & 0 & 0 & 9.4 & 0 & 0 & 0 & 9.4 & 1.6 & 4.3 & 0 \\
\hline & & 19 & 2 & 2.8 & 0 & 1.2 & 0 & 0 & 0 & 0 & 0 & 1.2 & 0.4 & 1.0 & 0 \\
\hline \multirow[t]{10}{*}{ Mvomero } & \multirow[t]{3}{*}{ Small } & 20 & 0.1 & 1.8 & 6.0 & 0 & 0 & 0 & 1.0 & 0 & 0 & 1.0 & 0.3 & 1.2 & 100 \\
\hline & & $21 a$ & 3.2 & 2.6 & 6.8 & 0.8 & 0 & 0 & 0 & 0 & 0 & 0.8 & 0.1 & 0.2 & 0 \\
\hline & & $21 b$ & ibid & 1.9 & 0 & 1.3 & 0 & 0 & 0 & 0 & 0 & 1.3 & 0.3 & 1.3 & 0 \\
\hline & \multirow[t]{3}{*}{ Medium } & 22 & 1.2 & 8 & 1.5 & 0 & 0 & 8.0 & 0 & 0 & 0 & 8.0 & 5.6 & 13.5 & 0 \\
\hline & & 23 & 0.1 & 15 & 7.0 & 0 & 0 & 8.5 & 0 & 0 & 0 & 8.5 & 1.3 & 4.4 & 0 \\
\hline & & 24 & 21 & 6.8 & 7.0 & 0 & 0 & 7.0 & 0 & 0 & 0 & 7.0 & 0.9 & 5.3 & 0 \\
\hline & \multirow[t]{4}{*}{ Large } & 25 & 0.4 & 8.3 & 1.0 & 0 & 0 & 8.5 & 0 & 0 & 0 & 8.5 & 0.9 & 2.9 & 0 \\
\hline & & 26 & 18 & 25 & 4.5 & 0 & 0 & 8.3 & 0 & 0 & 0 & 8.3 & 2.9 & 10.1 & 0 \\
\hline & & 27 & 9.3 & 19 & 6.5 & 0 & 0 & 9.0 & 0 & 0 & 0 & 9.0 & 5.1 & 21.0 & 0 \\
\hline & & 28 & 2.4 & 7.9 & 0 & 0 & 0 & 0 & 0 & 0 & 9.0 & 9.0 & 3.4 & 15.1 & 100 \\
\hline
\end{tabular}


Feed in Lushoto was exclusively supplied as cut-and-carry, while in Mvomero grazing dominated except among small farmers. Only in Babati some farmers kept two separate herds of local grazing cattle and cross-bred zero-grazing cattle (Figure 4). Total daily DM supplied per TLU varied per site, from average 12.6 kg DM in Lushoto to $10.5 \mathrm{~kg}$ DM in Babati and 7.3 kg DM in Mvomero. The bulk of feed in all sites (Lushoto 51.3\%, Babati 58.2\%, Mvomero 94.7\%) originated from natural vegetation either grazed or cutand-carry. Planted forages only constituted 3.8 and $4.2 \%$ in Babati and Mvomero respectively, and 31.2\% in Lushoto, with Napier grass (Pennisetum purpureum) being the most common species. Maize, and to a lesser extent, bean residues and banana leaves were important feeds in Babati (35.5\%) and Lushoto (16.4\%), while no residues were fed in Mvomero. Less than 3\% of total feeds were local concentrates, with brewers' waste (millet and wheat remains of local beer brewing) in Babati, and maize bran in Lushoto (Figure 4).

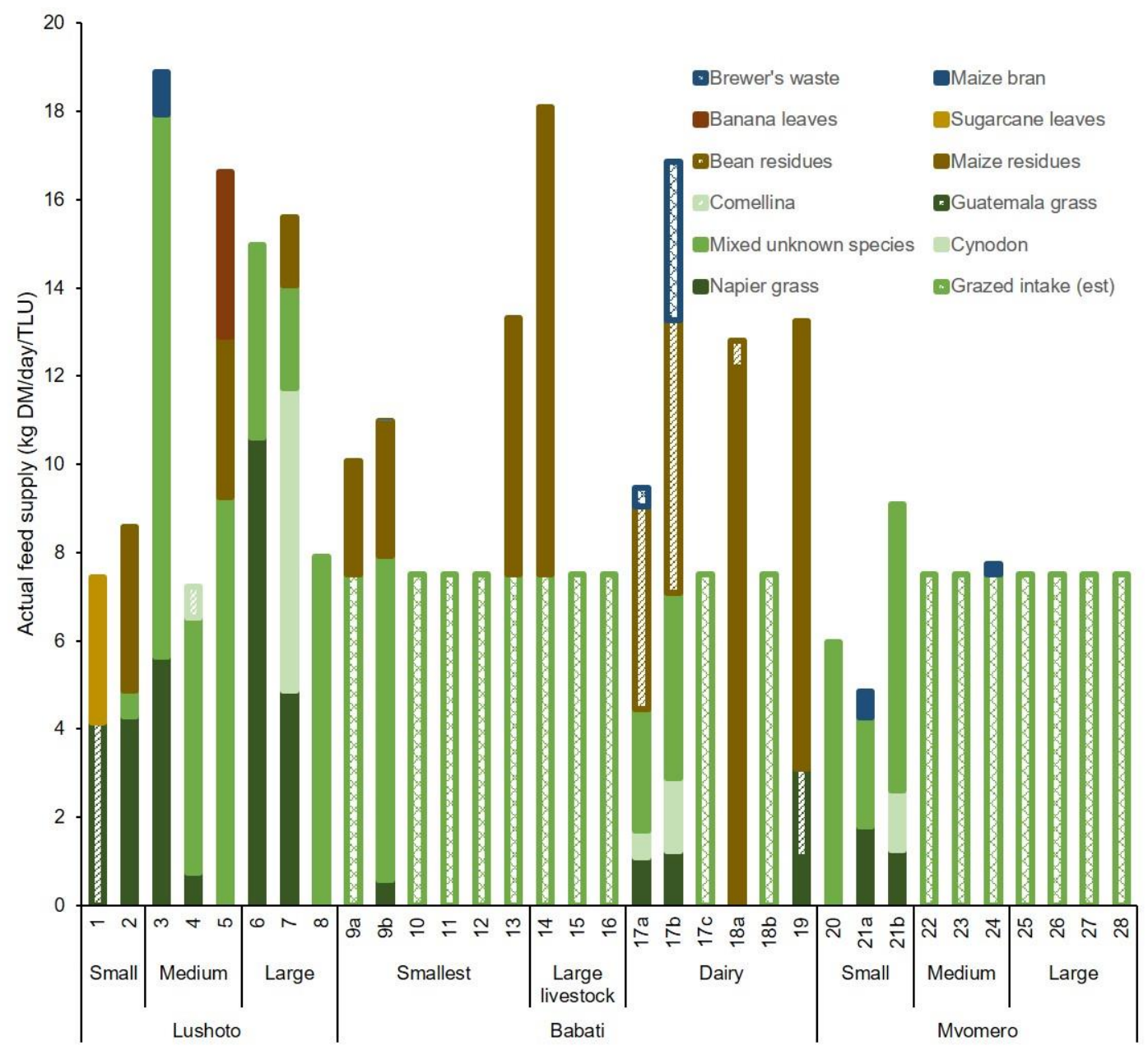


Figure 4 Dry matter (DM) of actual feed supply per day and Tropical Livestock Unit (TLU) to individual herds across individual farms. Numbers on $\mathrm{x}$-axis denote herd IDs. In green colors all green forages (darker green planted forages, medium green grazing natural pastures, and light green natural grasses cut-and-carry), brown colors crop residues, and blue colors commercial feeds.

ME and CP of actual feed supplied were compared to calculated livestock requirements under current production levels (Figure 5). 90.9\% of the herds were supplied with more ME and CP in their feed than they currently require (Figures 5a, 5b). Two herds in Mvomero provided less ME and CP than currently required, while two different herds in Babati were insufficiently fed with ME or CP. Farmers in Lushoto all supplied more ME and CP than required under current milk production levels (Figure 5). 


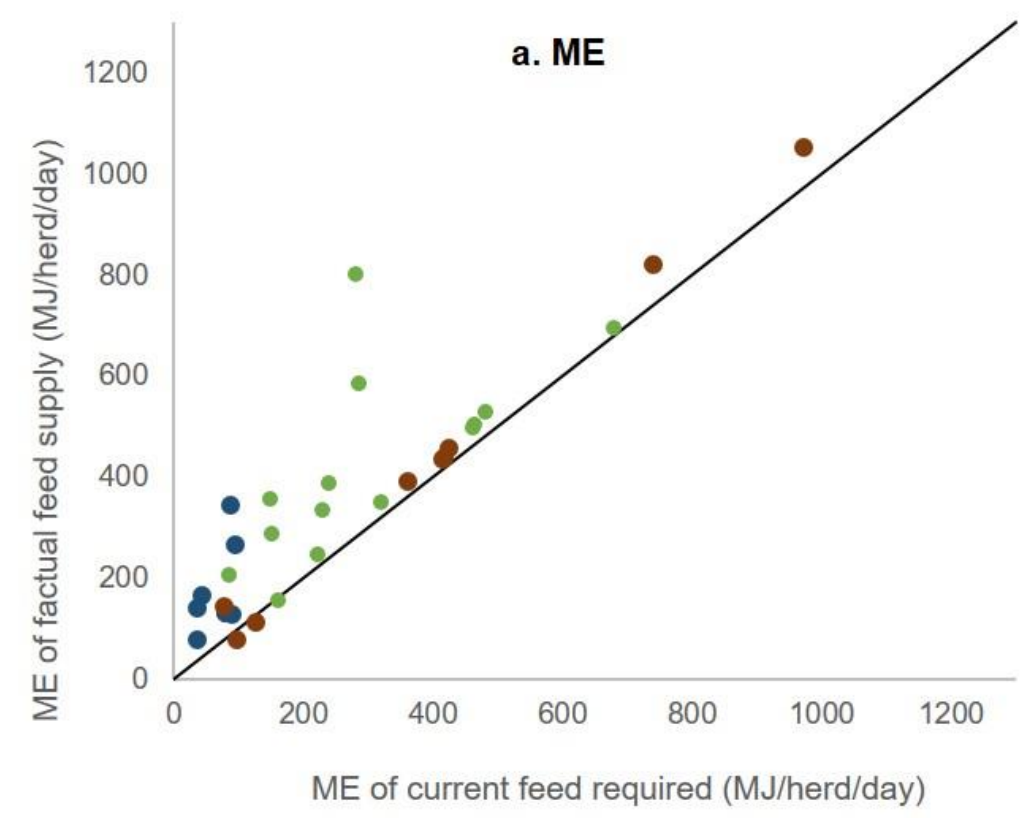

- Lushoto - Babati Mvomero - 1:1 line

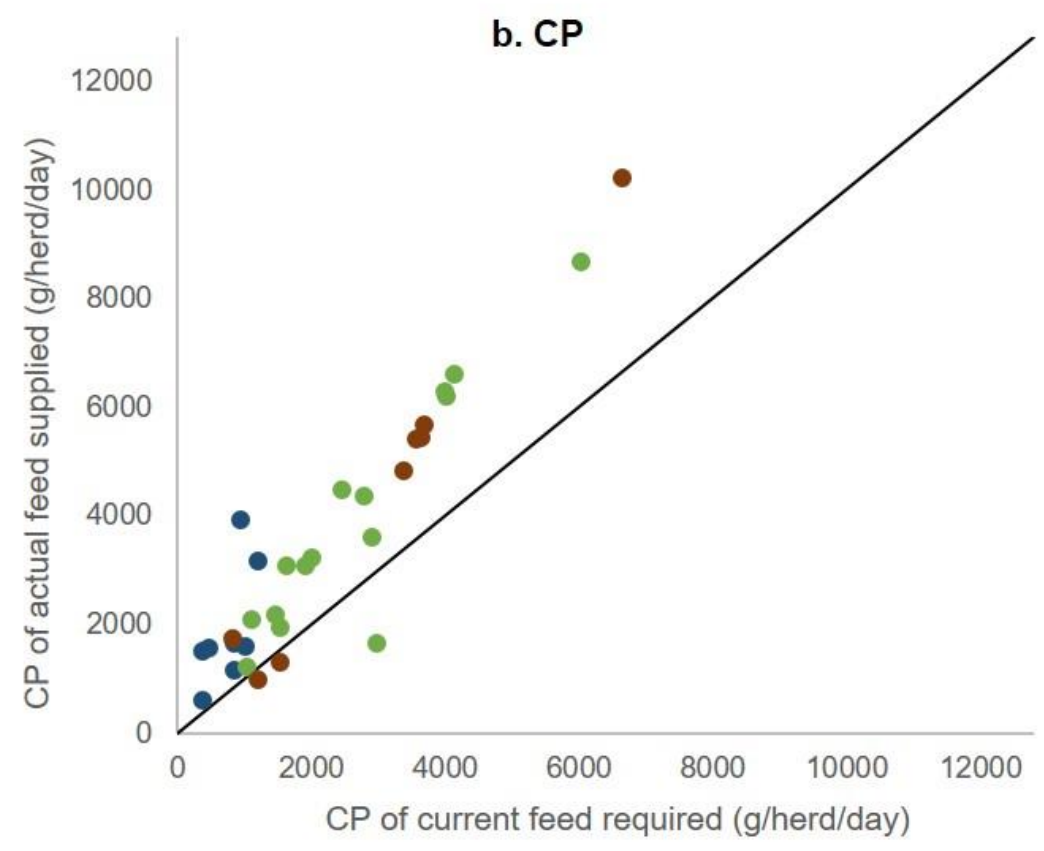

Figure 5 Actual feed supply versus calculated current feed requirements at the actual production level in ME (metabolizable energy) (a) and CP (crude protein) (b) per TLU (Tropical Livestock Unit) and day across the three sites. The line represents 1:1, where $\mathrm{ME}$ and $\mathrm{CP}$ in actual feed supply corresponds to calculated feed requirements. 


\subsection{Feed gaps}

ME and CP of actual feed supplied to cattle herds were compared to attainable feed demand, the calculated ME and CP requirements under attainable milk production levels (Figure 6). Overall, the ME feed gap was $-20.6 \%$ and CP -9.5 , thus total feed supplied across sites would suffice to satisfy cumulative attainable feed demand. However, $61 \%$ of herds in all sites faced a ME feed gap, and 55\% a CP feed gap. Feed gaps differed per site, with most herds facing a feed gap in Mvomero (90\% ME, 70\% CP) (Figure 6c) and the fewest in Lushoto (38\% ME, 50\% CP) (Figure 6a). In Babati, two herds (herd IDs 18a, 19) had no ME but large CP gaps due to low feed quality provided (predominantly maize and bean residues) while having several adult non-lactating cows (Figure 6b). Only $24 \%$ of herds did not have any ME nor CP feed gap (Figure 6).
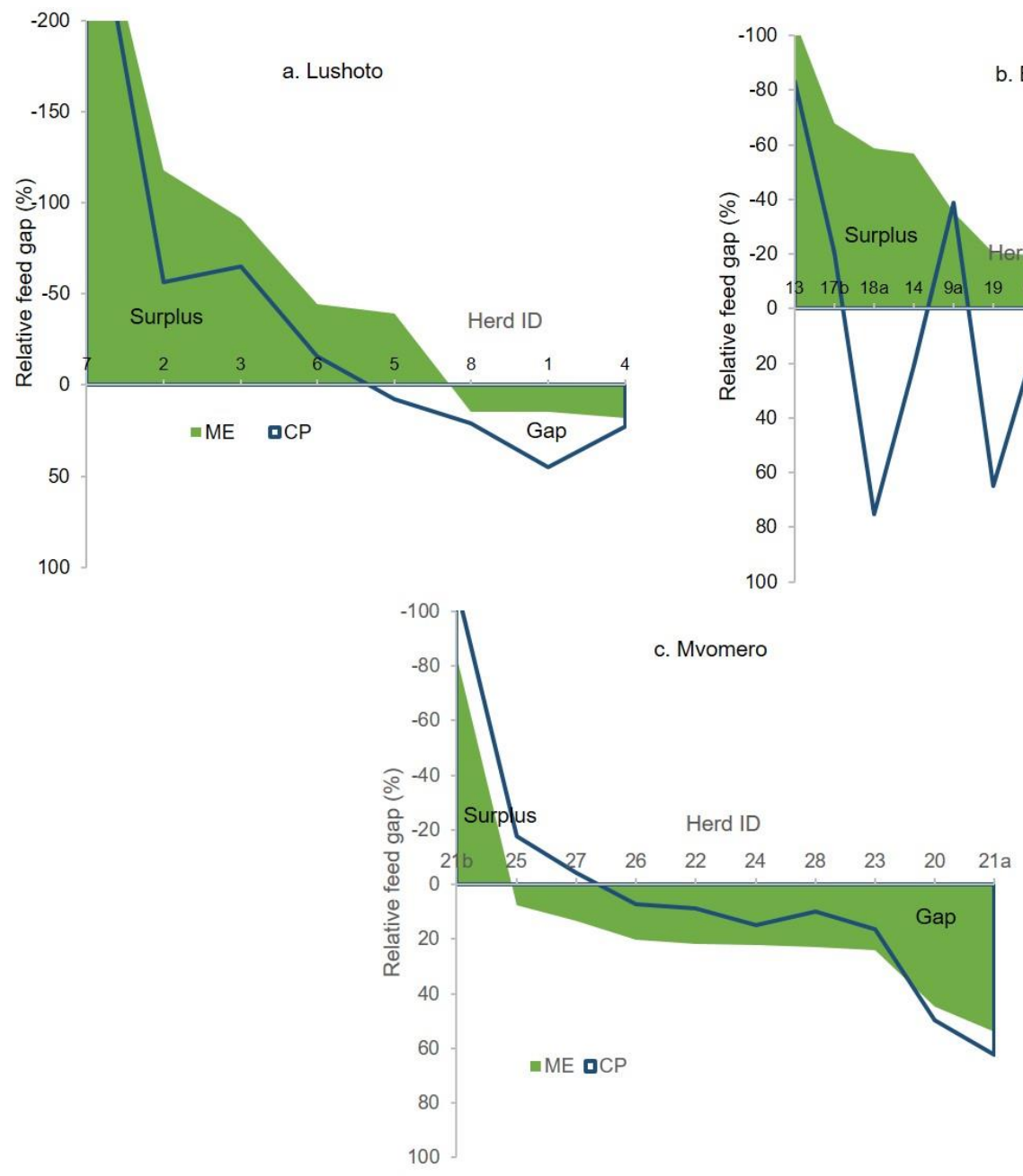

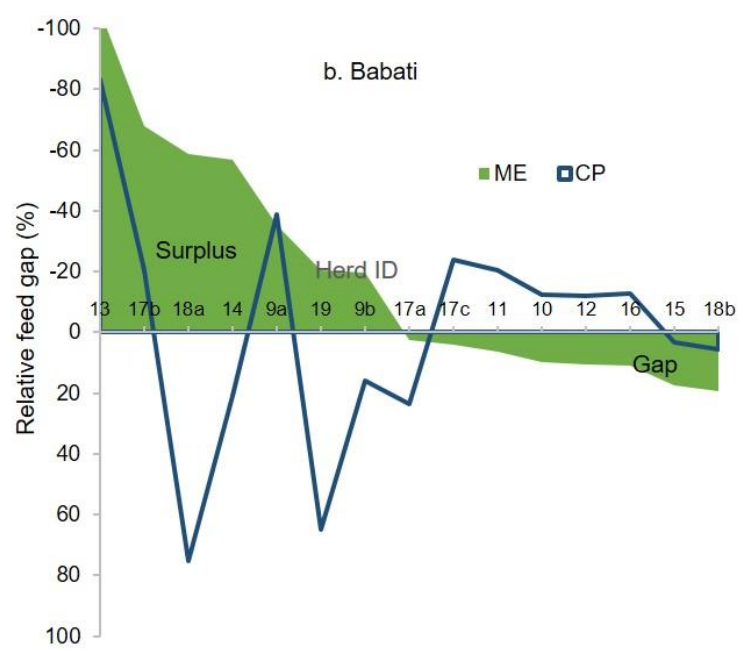


Figure 6 Relative feed gap in metabolisable energy (ME) and crude protein (CP) for herds in Lushoto (a), Babati (b) and Mvomero (c). Positive numbers denote a feed gap, the situation when actual feed supply is insufficient to meet attainable feed demand. Negative numbers indicate a feed surplus when actual feed supply exceeds attainable feed demand. Herds are sorted on $x$-axis from smallest to highest ME gap.

\section{Discussion}

\subsection{Feeding systems and feed gaps in East Africa}

Pilot evidence from three sites in Tanzania provided insights into feeding systems and feed gaps in East Africa. As hypothesized, the research sites were positioned on a gradient of feeding intensification (Figure 3). Natural vegetation continued to play an important role in livestock's diet in both grazing and cut-and-carry systems. However, their future supply is not guaranteed with continued privatization of land and increasing population densities. Planted forages constituted a considerable part of the feed basket only in Lushoto, while supplementary feeding with purchased feed was not common and only occasionally provided in Babati and Lushoto. Residue feeding was more common in Babati where farm sizes are comparably large and mechanized agriculture is present. In general, a diverse feed basket seems to be a consequence as well as a necessity in smallholders mixed crop-livestock systems. During the dry season, the variety of feed baskets is likely to be even higher as smallholders are struggling to find sufficient feed (Lukuyu et al., 2011).

The trend towards livestock intensification, away from agro-pastoral systems towards (semi)-intensive crop-livestock systems to maximize use of scarce resources, has been observed across East Africa. Intensification in this context refers to increasing the output per animal and labor unit through increased use of inputs or change of management techniques. In the Kenyan highlands, for example, over three-quarters of the smallholder dairy farms already fall under semi-intensive or intensive systems. Various factors influenced this intensification: if land was limiting, more farmers moved towards stall-feeding systems, while grazing was predominant if labor was scarce. In general, increasing population density, market access, conducive policies and favorable agro-ecology have been identified (Bebe et al., 2002; Lukuyu et al., 2011). However, the mix of systems in Babati suggests that the transition towards feeding intensification is not as gradient as presented in Figure 3 , but rather a switch or entire re-organization of production systems (Green, 2017).

Most on-farm cattle-related labor was provided by men in this pilot study, not only for grazing but also for fetching feed in cut-and-carry systems. Elsewhere, livestock-related decision-making and labor in 
Tanzania has been reported to be strongly gendered. Cattle tends to be a male asset, and men tend to care for cattle in terms of grazing, buying/selling, and veterinary treatment. Women mostly took care of the dairying aspect of cattle, including sometimes even control over income from milk (Galiè et al., 2015). Systematic and reliable labor data is however hard to come by as it is often collected through surveying, and difficulties to recall make farmer-reported labor data error-prone. Questions on gender distributions of labor suffer, in addition, from socially-desired responses. Comprehensive data from Africa suggests that women's share of labor is rather around 50\% in Tanzania instead of the often assumed 60-80\% (Palacios-Lopez et al., 2017). The cut-and-carry systems in Lushoto required less labor per farm and TLU than the mixed systems in Babati and grazing systems in Mvomero. However, this does not depict the difference in type of labor, with fetching feed being more physically demanding labor than grazing.

$61 \%$ of herds in all Tanzanian sites faced a ME feed gap, and 55\% a CP feed gap. However, overall, total actual feed supplied across all sites and herds would suffice to satisfy the cumulative attainable feed demand. The fewest herds faced a feed gap in Lushoto (38\% $\mathrm{ME}, 50 \% \mathrm{CP}$ ), although it is important to consider that actual feed supplied is considerably reduced through high feed losses due to poor cattle housing and feeding techniques under zero-grazing. In the dry season, when feed availability is more constrained, the ME gap is likely to be much wider calling for quantity-focused technologies such as drought-resistant planted forages or forage conservation techniques. In Babati, two herds had no ME but large CP gaps due to low feed quality provided (predominantly maize and bean residues), pointing to the need for higher quality feed such as forage legumes or purchased supplements. $24 \%$ of herds did not experience a feed gap, meaning that feed quantity and quality were not limiting the production. Other yield-limiting factors such as lack of sufficient drinking water provision, or reducing factors such as diseases, might be the reason (van der Ven et al., 2003).

Possible causes for such persisting feed gaps are manifold. Farmers are not always primarily aiming at closing yield gaps and therefore, could decide not to adopt improved technologies. Sumberg (2002) argued that low adoption of improved livestock nutrition technologies might not be due to poor communication or extension services but farmers that prioritize other economic, cultural and social aims over productivity increase. Policies, including subsidies, can also act as a disincentive to maximization of production. In Tanzania, cattle are not necessarily kept to maximize income, but also perceived as a safe way to store wealth, currency for dowries, a risk management strategy, a status symbol, and as a means 
of transport and draft power (Galiè et al., 2015). Therefore, Snyder et al. (2016) argue to include into yield gap analysis the wider social, economic and political context that shapes farmers' decisions.

\subsection{Assessing feed gaps - approaches and future improvements}

This study aimed to introduce a quantitative approach to assessing smallholder dairy feeding systems and feed gaps in data-scarce environments, which was illustrated using pilot evidence from Tanzania. The approach complements other approaches, which are more time, data and resource demanding. Van der Ven et al. (2003) and van der Linden et al. (2015) provided the theoretical foundation for livestock yield gap analysis by applying production ecology concepts. In contrary to this study that focusses on feed only, they include various growth defining (genotype, climate), growth limiting (feed, water), and growth reducing (diseases, stress) factors. Based on these principles, the dynamic LiGAPS-Beef model was developed using daily climate data, which can be seen as analogous to mechanistic crop models in data requirements, functionality and detail of results (van der Linden et al., 2018). Henderson et al. (2016) and Mayberry et al. (2017) worked with a combination of household and livestock models with a more limited data demand. However, as these studies mainly rely on survey data complemented with expert opinion, assumptions are made on feed quantities supplied. Common farming systems surveys (e.g. ImpactLite, https://ccafs.cgiar.org/impactlite-tool) often leave out planted and collected forages and focus on residue feeding and grazing. If dedicated feed surveys are available (such as the Feed Assessment Tool FEAST, https://www.ilri.org/feast), they mostly rely on farmer recall data for feed baskets which is sufficient for participatory technology testing and research, but of limited use for productivity and environmental estimations. The approach of Moore et al. (2009) and Bell et al. (2017) is similar to this study in taking a relatively simple demand versus supply approach. However, they rely on long-term simulations of a variety of forages to identify the time during the year where forage supply cannot meet livestock demand. The lack of quantitative survey data on feed baskets as well as the lack of large agronomic datasets for multiple model calibration makes it challenging to apply the existing approaches to data-scare smallholder environments. The feed gap approach piloted in this study can work where such data is not available as it is based on relatively simple calculations without time, data and resource-intensive calibration of multiple models. However, on-farm feed measurements would have to be repeated as needed, but at least a few times a year to capture seasonal variations.

Deviations, both positive and negative, between actually supplied ME and CP and calculated current feed requirements (Figure 5) point to uncertainties in underlying data and calculations. On the livestock requirement side, exact body weight was not measured, and temporary weight gain and loss was not 
taken into account. On the feed supply side, varying storage time of feeds might lead to different DM contents of the same feeds between different feedings and farms, leading to uncertainties in conversions to total ME and CP contents. Moreover, feed losses in smallholder zero-grazing systems might be high, up to $30-50 \%$ of total feed. Lastly, the intake through grazing and the quality of natural vegetation fed under grazing or cut-and-carry is unknown and challenging to estimate. Lukuyu et al. (2016) found a high variability when testing the quality of natural vegetation used as feed across Tanzania.

Methods to quantify feeding systems and feed gaps for smallholder systems and data-scarce environments such as in East Africa are currently lacking. Therefore, the approach presented in this paper complements other approaches, which are more time, data and resource demanding. Suggestions for future improvements of this approach include: a) Conduct a sensitivity analysis to identify the parameters and inputs that contribute most to output uncertainty and that would merit dedicated follow-up research; b) Include seasonal variability of feed gaps through monitoring feed supplied across different wet and dry seasons; c) Reduce uncertainty in actual feed supply estimations by increasing empirical verifications of DM content throughout the day, and measuring quality of natural pastures at various points across seasons; d) Reduce uncertainty in livestock requirement calculations by basing the grazing estimations on production values, improving how locomotion is being accounted for, empirically verifying livestock BW, and including requirements for BW changes.

\section{Conclusions}

Feed is a critically limiting factor in productivity of smallholder dairy systems in East Africa. This study aimed to introduce and provide proof-of-concept for a relatively simple approach to quantify feeding systems and feed gaps in data-scarce smallholder systems, comparing feed demand and supply at the individual herd level. The approach was illustrated with pilot evidence from crop-livestock production systems across three agro-ecological zones in Tanzania, which broadly represent the diversity found in East Africa.

A diversity of different livestock and feeding systems along an intensification gradient were present in the three study sites in Tanzania. Mvomero was the most extensive site, with the largest farm areas, herd sizes, and communal grazing systems. Lushoto was dominated by cut-and-carry feeding of small crossbred dairy herds and small land sizes. Babati represented a mixture of both systems that were 
present concurrently. Natural vegetation contributed the largest part to cattle feed baskets in both grazing and cut-and-carry systems, while planted forages only played a significant role in Lushoto. Grazing systems were more labor intensive per TLU than cut-and-carry systems. Most labor for feeding was provided by men, which contrasts findings from other studies in the region. Although the trend seems to go towards intensifying feeding systems, the co-existing mix of systems, however, suggests that the transition might be less gradient than commonly suggested.

$61 \%$ of all herds faced an ME feed gap, and 55\% a CP gap between actually supplied feed and calculated requirements at attainable milk production levels. Feed gaps were more prevalent in Mvomero than in Lushoto, although feed losses are likely to be high (up to $30-50 \%$ ) in cut-and-carry systems. $24 \%$ of herds did not experience a feed gap, and other yield limiting factors (e.g. lack of sufficient drinking water provision) or reducing factors (e.g. as diseases) might be the reason for the low milk production levels. Possible causes for persisting feed gaps are manifold, and include the importance of multi-functionality of livestock in Tanzania. Farmers might not primarily aim at closing feed gaps and maximizing production, but prioritize other functions such as risk management and wealth storage.

Methods to quantify feeding systems and feed gaps for smallholder systems and data-scarce environments such as in East Africa are currently lacking. Therefore, the approach presented in this paper complements other approaches, which are more time, data and resource demanding. Suggestions for future improvements of this approach include: a) Conduct a sensitivity analysis to identify the parameters and inputs that contribute most to output uncertainty and that would merit dedicated follow-up research; b) Include seasonal variability of feed gaps through monitoring feed supplied across different wet and dry seasons; c) Reduce uncertainty in actual feed supply estimations by increasing empirical verifications of DM content throughout the day, and measuring quality of natural pastures at various points across seasons; d) Reduce uncertainty in livestock requirement calculations by basing the grazing estimations on production values, improving how locomotion is being accounted for, empirically verifying livestock BW, and including requirements for BW changes.

A good handle on current feeding practices and feed gaps is necessary to dissect key issues and factors currently limiting livestock production in a smallholder farming context. Governments, private sector, development agencies and donors can use approach and insights presented to prioritize feeding technologies and target investments. Results can also inform and validate modeling approaches that require detailed feed baskets. 
Chapter 4

\section{Prioritizing climate-smart livestock technologies in rural Tanzania: A minimum data approach}

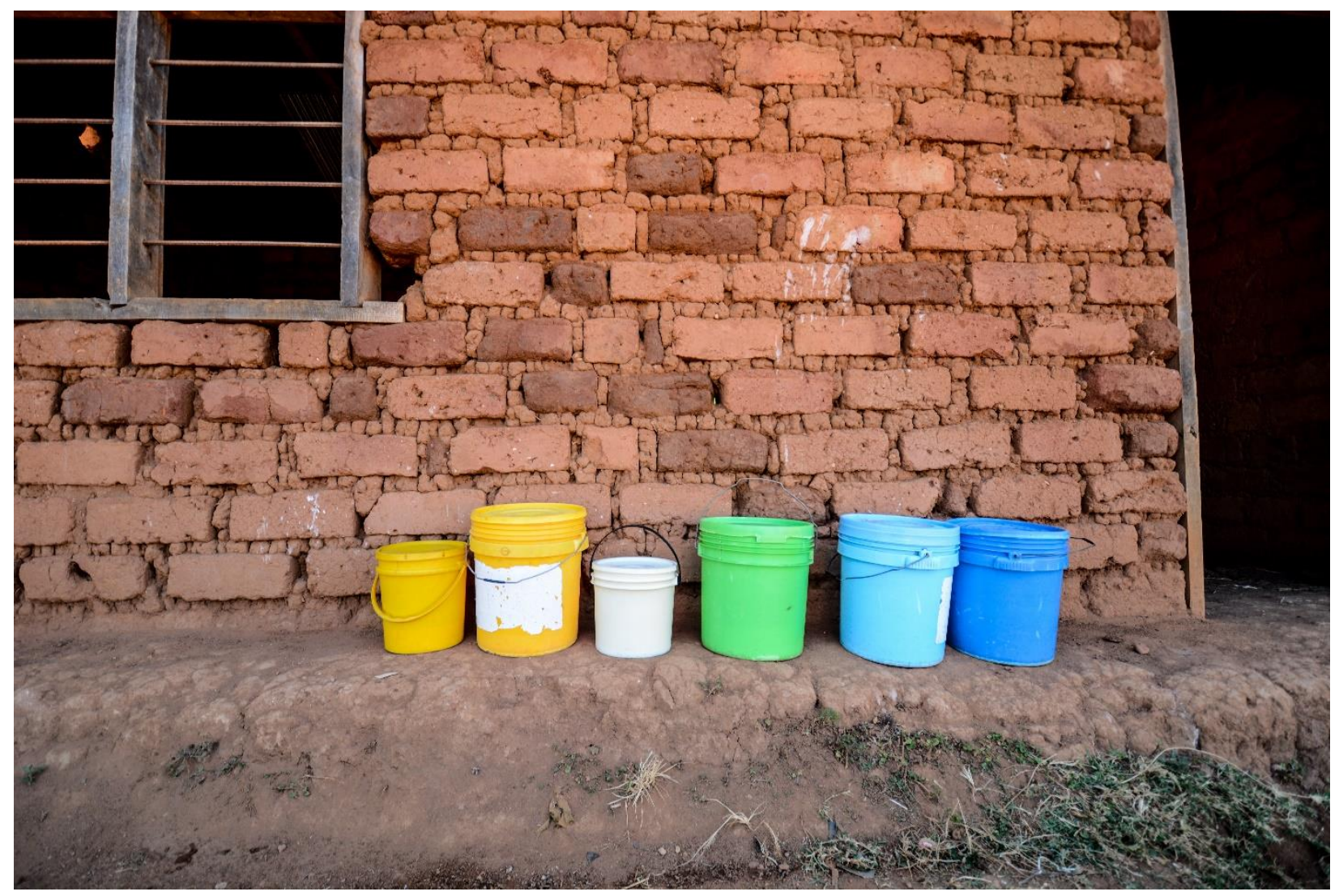

This chapter is published as:

Shikuku, K.M., Valdivia, R., Paul, B.K., Mwongera, C., Winowiecki, L., Laderach, P., Herrero, M., Silvestri, S. (2017). Prioritizing climate-smart livestock technologies in rural Tanzania: A minimum data approach. Agricultural Systems, 151, 204-216. 


\section{Introduction}

In sub-Saharan Africa (SSA), climate change is projected to have a negative impact on smallholder livestock production systems, which play an important role in the livelihoods of rural communities (Thornton et al., 2009; Tubiello et al., 2007). The risks posed by climate change are more severe for populations most dependent on crop and livestock production for overall household food security (Battisti and Naylor, 2009). Further concerns have been raised about the negative environmental impacts of increased greenhouse gas (GHG) emissions, for example on exacerbating the subtropical drought occurrences (IPCC, 2007; Easterling et al., 2007). Addressing climate change has, therefore, become tremendously urgent both from an adaptation as well as a mitigation perspective (Paris Agreement (http://unfccc.int/paris agreement/items/9485.php), IPCC).

Human population in SSA is expected to more than double to 2.4 billion by 2050 (UN, 2015).

Furthermore, demand for animal products is expected to increase given not only the growth in population, but also higher incomes, increased urbanization, and change in dietary preferences (Delgado et al., 1999; Thornton et al., 2007). The rising demand for livestock products will require an associated increase in farming systems productivity (Staal et al., 2001). Current livestock systems in SSA have low overall performance, which results in low herd productivity and high GHG emission intensity (Herrero et al., 2015). The reasons for this are mainly associated with poor feed quality, which in turn determines low digestibility, and poor animal health (Herrero et al., 2015).

Scarcity of resources, impacts of climate change, and the increase in demand for livestock products have made some traditional coping mechanisms less effective (Sidahmed, 2008). Increased resource-use efficiency is, therefore, a necessary component for environmental sustainability of the livestock sector (FAO, 2013). There is an urgent need to develop and implement 'climate-smart' livestock management options that can achieve the triple win scenario of increasing productivity, adapting and building resilience to climate change, and mitigating climate change through reduction of GHG emissions (FAO, 2013; Lipper et al., 2014; Steenwerth et al., 2014). Improved livestock breeds, together with improved forage quality and diet supplementation are among the livestock management strategies that have high potential to address poor livestock system performance and reduce emissions intensity (FAO, 2013). With well-functioning markets and improved livestock management practices, incentives and opportunities can be created for farmers and other stakeholders to invest in adequate livestock intensification. Adoption of improved livestock management practices might, however, present tradeoffs, if for example, income increases and poverty declines but net GHG emissions increase as households shift from no-livestock systems to livestock keeping. Considering the complexity of livestock 
systems in developing countries, Thornton et al. (2009) suggested that improved management strategies should be based on a combination of factors, including feed and nutrition, genetics and breeding, and health and environment, with different combinations for different systems.

The objectives of this study were: (i) to analyze the synergies and trade-offs of adopting improved feeding practices and livestock breeds in Lushoto district of Tanzania; and (ii) to assess how alternative livestock management options can increase productivity, improve food security, and reduce methane emissions intensity. The study used household surveys, stakeholder consultations, and secondary data as inputs into livestock and economic models to assess trade-offs of economic and environmental outcomes of improved livestock feeding strategies and improved breeds.

\section{Methodology}

\subsection{Study area}

The study was conducted in the Lushoto district of Tanzania, which lies within the western Usambara Mountains in northeastern Tanzania (Figure 1). This region has a unique and diverse history as it is one of the 25 global biodiversity hotspots due to the high number of endemic species (Critical Ecosystem Partnership Fund, 2005) while also having a rich agricultural history of cultivation on the steep mountainous slopes (Jambiya, 1998). The major economic activity in the study area is agriculture, and major crops include: maize, beans, potatoes, cassava, vegetables (such as tomatoes, cabbages, peppers), coffee and temperate fruits (such as avocados and peaches) (Lyamchai et al., 2011; Silvestri et al., 2015). Farming systems across Lushoto district are diverse and include mixed crop-livestock systems, intensive horticultural systems, extensive cereal systems, perennial cropping systems such as coffee, among others (Kristjanson et al., 2012; Lyamchai et al., 2011). However, off-farm employment continues to be an important income-generating activity (Jambiya, 1998; Lyamchai et al., 2011). Within Lushoto district, keeping livestock is a common household practice, with about 84 percent of households producing small livestock (goats and sheep) and 43 percent producing large livestock (cattle), and 45 percent producing fodder (Lyamchai et al., 2011). For decades, Lushoto district has received national and international attention to curb the high soil erosion rates and conserve indigenous forests (Watson, 1972; Tenge et al., 2005). However, low productivity, small farm sizes, high soil erosion rates, and migration out of farming continue to challenge farming systems in Lushoto (Foerch et al., 2011; Okoba et al., 2007; Tenge et al., 2005; Wickama et al., 2014; Winowiecki et al., 2015). 


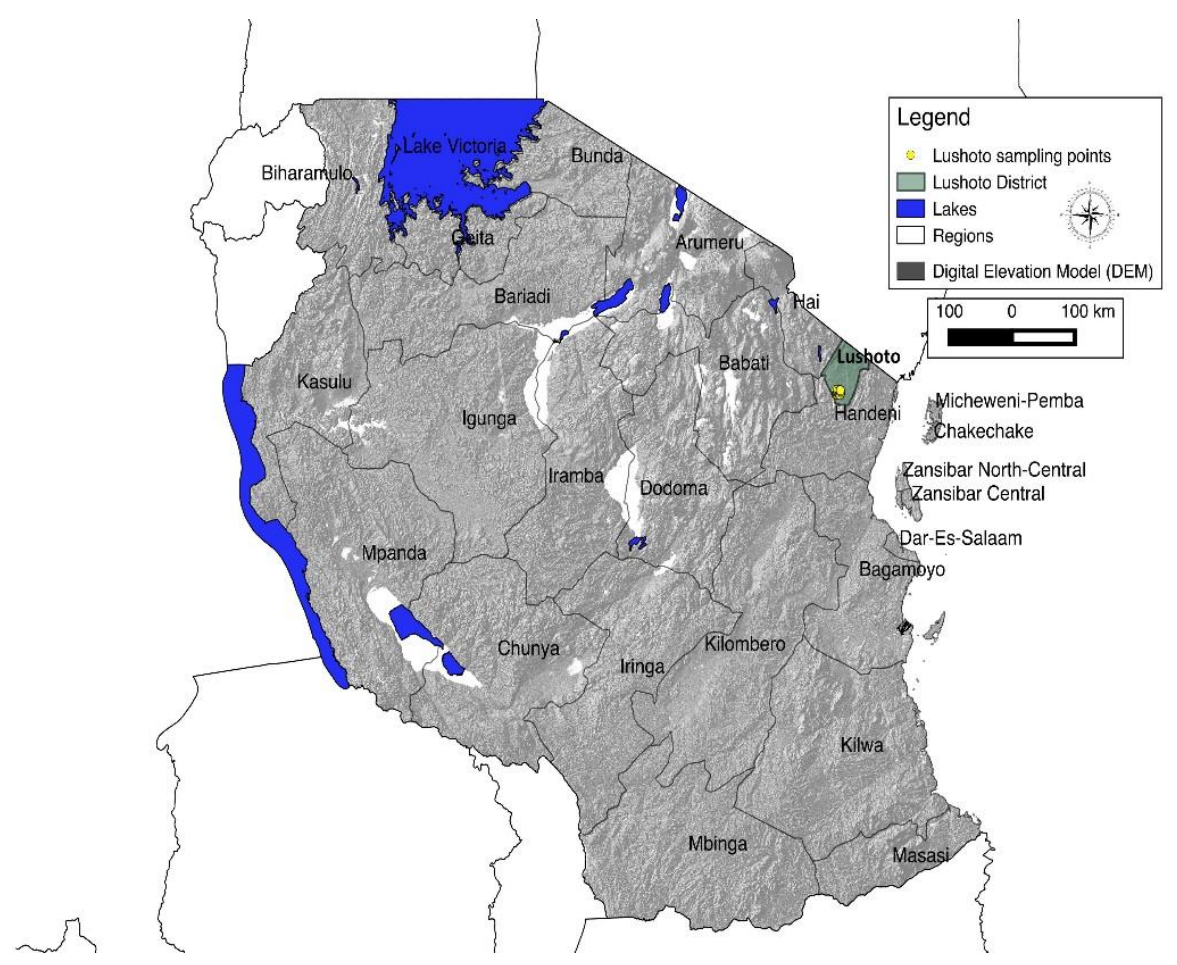

Figure 1. Study site: Lushoto district, Tanzania.

\subsection{Household survey data collection}

This study used household survey data collected in 2012 under the CGIAR research program on Climate Change, Agriculture, and Food Security (CCAFS) (Rufino et al., 2012). Data were collected using a stratified sampling strategy, described in detail by Rufino et al. (2012). Three main agricultural production systems were used to stratify the sampling design within Lushoto district: i) farm households growing staple crops only; ii) farm households growing staple crops plus horticultural crops such as tomatoes and cabbages, and iii) farm households growing staple crops plus cash crops such as coffee and tea. Within each of the identified production systems, seven representative villages were randomly selected. A total of 200 households were sampled from the selected villages. Household interviews were conducted to capture data on household composition; crop and livestock production activities; household assets; agricultural inputs and labor use for cropping and livestock activities; utilization of agricultural products including sales and consumption; and off-farm employment and other sources of livelihoods such as remittances and subsidies. The final sample size used for analysis was 164 farm households for which data was complete to estimate the simulation models.

Given the evidence that livestock ownership is correlated with income levels (Claessens et al., 2012; Homann Kee-Tui et al., 2016), we stratified our sample of farm households into three strata according to 
the type of livestock owned: i) stratum 1 comprised of households with local cow breeds only; ii) stratum 2 comprised of households with improved cow breeds only; and iii) stratum 3 comprised of households without cows. The number of farm households that had both local and improved breeds in our sample was very small; hence, this category was not included in the analysis. Out of the 164 farm households, 17 percent owned local cows only, 43 percent owned improved breeds only, and 40 percent did not own cows.

\subsection{Ruminant model and model inputs}

The Ruminant model (Herrero et al., 2002) was used to simulate milk production and methane $\left(\mathrm{CH}_{4}\right)$ emissions from enteric fermentation. A dynamic component of the model estimates feed intake and supply of nutrients to the animal from knowledge of the fermentation kinetics and passage of feed constituents (carbohydrate and protein) through the gastrointestinal tract. A static component of the model determines the animal's response to nutrients in terms of growth and milk production.

Validations have been carried out for more than 80 tropical and temperate diets, and the results suggest that the model has the required accuracy not only as a research tool but also for providing decision support at the farm level (Herrero, 1997). Among other uses, the model has previously been applied to estimate $\mathrm{CH}_{4}$ emission factors of tropical livestock (Herrero et al., 2013), and in various modeling studies across SSA (Bryan et al., 2013; Waithaka et al., 2006; Zingore et al., 2009).

Feeding data from the household survey could not be used to construct individual diets per household due to the lack of high-quality information on quantity and types of feeds throughout the year. Therefore, two uniform baseline diets ('dry' and 'wet' seasons) were constructed for local and crossbred dairy cattle for the entire study population. The diets were based on previous participatory, community level feeding system assessments (Mangesho et al., 2015; Morris et al., 2014).

The main livestock system in the area was intensive cut and carry (zero-grazing), where livestock is kept in pens year-round. All collected and purchased feed is provided in situ to the cows (Morris et al., 2014). The different feed baskets for the dry and wet seasons were recorded. There are two rainy seasons lasting for a total of eight months, while the dry seasons stretch over four months of the year. Naturally occurring green forages are collected from roadsides and constitute the primary component throughout the year. Maize bran was the only purchased feed in the area and was only used in small amounts $(500 \mathrm{~g}$ day $^{-1}$ ) by about 30 percent of farm households throughout the year, although cottonseed cake and sunflower cake were also locally available. Another source of feed was cultivated fodder, mainly Napier grass (Pennisetum purpureum), although the acreage was low due to land shortage and lack of 
knowledge on cultivated fodder. Seasonality of feed availability is high - especially cultivated fodder and natural forages, and maize residues which is most abundant only after harvest. Overall, cows were underfed due to land shortage for growing and collecting fodder, and total fresh weight of daily feed was estimated to lie between $40-60 \mathrm{~kg}$. Farmers did not report different feeding for local or crossbred cows (Mangesho et al., 2015).

Table 6.1 summarizes the diets used in the Ruminant model. In the dry season, the diet comprised approximately 20 percent Napier grass (Pennisetum purpureum), 35 percent collected natural grasses, 40 percent maize residues, and 5 percent maize bran concentrate. The total amount of feed corresponded to $12.9 \mathrm{~kg}$ dry weight (DW) per cow per day. For the wet season, the diet comprised 40 percent Napier grass, 40 percent collected grass, 15 percent maize residues, and 5 percent maize bran concentrate, totaling $14.4 \mathrm{~kg}$ DW per cow per day. For the Ruminant model, local cow body weight was set to $250 \mathrm{~kg}$, while a crossbreed was assumed to be $350 \mathrm{~kg}$.

Farmers of village innovation platforms in Lushoto identified growing improved forages and supplementing with concentrate feeds as two of the most promising interventions to improve their livestock feeding, in addition to adequate feed rations and feed conservation (Lukuyu et al., 2015). Based on these findings, we developed two livestock feeding options to be simulated using the Ruminant model (Table 1). The design of the livestock feeding options was based on the kinds of data available. We linked qualitative and quantitative information to generate a minimum dataset that allowed us to use the Trade-off Analysis for Multi-Dimensional Impact assessment (TOA-MD) model. The first feeding option (hereafter option 1) represented an improvement in feed quality while keeping the feed quantity almost constant. We assumed that the contribution of Napier grass to the diet increased from 21.7 percent to 31 percent in the dry season and to 54 percent in the wet season. In the dry season, the increase in Napier grass was expected to reduce the contribution of low-quality natural grasses from 40 percent to 28 percent and that of maize residues from 38.8 percent to 27 percent. In the wet season, the increase in Napier was expected to reduce the contribution of low quality natural grasses from 40 percent to 27 percent and the one of maize residue from 14 percent to 7 percent. We further increased the contribution of concentrate feeding from 6 percent to 14 percent in the dry season and from 5.5 percent to 12 percent in the wet season, adding higher quality sunflower seedcake to the mix. 
Table 1. Livestock diet data used in the Ruminant model

\begin{tabular}{|c|c|c|c|c|c|c|}
\hline & \multicolumn{3}{|c|}{ Dry season (4 months) } & \multicolumn{3}{|c|}{ Wet season (8 months) } \\
\hline & \multicolumn{6}{|c|}{ Base scenario } \\
\hline & Baseline & $\begin{array}{l}\text { Improved } \\
\text { quality of } \\
\text { diet }\end{array}$ & $\begin{array}{l}\text { Improved quality } \\
\text { of diet plus } \\
\text { increased } \\
\text { quantity of feed }\end{array}$ & Baseline & $\begin{array}{l}\text { Improved } \\
\text { quality of } \\
\text { diet }\end{array}$ & $\begin{array}{l}\text { Improved } \\
\text { quality of diet } \\
\text { plus } \\
\text { increased } \\
\text { quantity of } \\
\text { feed }\end{array}$ \\
\hline $\begin{array}{l}\text { Local grass (kg } \\
\mathrm{DM} / \mathrm{day})\end{array}$ & 4.50 & 3.60 & 4.50 & 5.80 & 4.00 & 5.80 \\
\hline $\begin{array}{l}\text { Napier grass (kg } \\
\mathrm{DM} / \text { day) }\end{array}$ & 2.60 & 4.00 & 5.00 & 5.80 & 8.10 & 11.00 \\
\hline $\begin{array}{l}\text { Maize residue (kg } \\
\mathrm{DM} / \text { day) }\end{array}$ & 5.00 & 3.50 & 3.50 & 2.00 & 1.00 & 1.00 \\
\hline $\begin{array}{l}\text { Maize bran (kg } \\
\text { DM/day) }\end{array}$ & 0.70 & 1.50 & 3.00 & 0.70 & 1.50 & 3.00 \\
\hline $\begin{array}{l}\text { Sunflower cake (kg } \\
\text { DM/day) }\end{array}$ & 0.10 & 0.30 & 0.00 & 0.10 & 0.30 & 0.00 \\
\hline \multirow[t]{2}{*}{$\begin{array}{l}\text { Cotton cake (kg } \\
\text { DM/day) }\end{array}$} & 0.00 & 0.00 & 1.00 & 0.00 & 0.00 & 1.00 \\
\hline & \multicolumn{6}{|c|}{ Sensitivity analysis with $+10 \%$ variation } \\
\hline $\begin{array}{l}\text { Local grass (kg } \\
\mathrm{DM} / \mathrm{day} \text { ) }\end{array}$ & 4.95 & 3.96 & 4.95 & 6.38 & 4.40 & 6.38 \\
\hline $\begin{array}{l}\text { Napier grass (kg } \\
\mathrm{DM} / \text { day) }\end{array}$ & 2.86 & 4.40 & 5.50 & 6.38 & 8.90 & 12.10 \\
\hline $\begin{array}{l}\text { Maize residue (kg } \\
\mathrm{DM} / \text { day) }\end{array}$ & 5.50 & 3.85 & 3.85 & 2.20 & 1.10 & 1.10 \\
\hline $\begin{array}{l}\text { Maize bran (kg } \\
\text { DM/day) }\end{array}$ & 0.77 & 3.30 & 3.30 & 0.77 & 1.65 & 3.30 \\
\hline $\begin{array}{l}\text { Sunflower cake (kg } \\
\mathrm{DM} / \text { day) }\end{array}$ & 0.11 & 0.00 & 0.00 & 0.11 & 0.33 & 0.00 \\
\hline \multirow[t]{2}{*}{$\begin{array}{l}\text { Cotton cake (kg } \\
\mathrm{DM} / \text { day) }\end{array}$} & 0.00 & 1.10 & 1.10 & 0.00 & 0.00 & 1.10 \\
\hline & \multicolumn{6}{|c|}{ Sensitivity analysis with $-10 \%$ variation } \\
\hline $\begin{array}{l}\text { Local grass (kg } \\
\mathrm{DM} / \text { day) }\end{array}$ & 4.05 & 3.24 & 4.05 & 5.22 & 3.60 & 5.22 \\
\hline $\begin{array}{l}\text { Napier grass (kg } \\
\mathrm{DM} / \text { day) }\end{array}$ & 2.34 & 3.60 & 4.50 & 5.22 & 7.30 & 9.90 \\
\hline $\begin{array}{l}\text { Maize residue (kg } \\
\mathrm{DM} / \text { day) }\end{array}$ & 4.50 & 3.15 & 3.15 & 1.80 & 0.90 & 0.90 \\
\hline $\begin{array}{l}\text { Maize bran (kg } \\
\text { DM/day) }\end{array}$ & 0.63 & 1.35 & 2.70 & 0.63 & 1.35 & 2.70 \\
\hline $\begin{array}{l}\text { Sunflower cake (kg } \\
\text { DM/day) }\end{array}$ & 0.09 & 0.27 & 0.00 & 0.09 & 0.27 & 0.00 \\
\hline $\begin{array}{l}\text { Cotton cake (kg } \\
\text { DM/day) }\end{array}$ & 0.00 & 0.00 & 0.90 & 0.00 & 0.00 & 0.90 \\
\hline
\end{tabular}

Note: Base runs of baseline and scenario diets were repeated with $a+10 \%$ and $-10 \%$ variation to test sensitivity of the approach 
The second feeding option (hereafter option 2) assumed an improvement of the feed quality in the diets similar to the first feeding scenario, and an increase in the quantity from $12.9 \mathrm{~kg}$ to $17.0 \mathrm{~kg}$ dry matter (DM) in the dry season and $14.4 \mathrm{~kg}$ to $21.8 \mathrm{~kg}$ DM in the wet season per cow and day. Under this scenario, we further increased the contribution of protein concentrates from 6.2 percent to 24 percent in the dry season and from 5.5 percent to 19 percent in the wet season. Maize bran was combined with cottonseed instead of sunflower seed in this scenario.

In order to deal with uncertainty and lack of heterogeneity in the feeding data, we conducted sensitivity tests where we assumed an increase and decrease in the total quantity of feed in the three diets (baseline and the two feeding options). We kept the percentage contributions of the different feed constituents constant (Tables 7, 8, 9, and 10). We assumed that any additional inputs to livestock production (including Napier grass) would be purchased and not produced on-farm due to small sizes of land and farm orientation for self-consumption of crops. Therefore, it was assumed that there would be no changes to land allocation.

\subsection{Trade-off Analysis for Multi-Dimensional Impact Assessment model (TOA-MD)}

The TOA-MD model is a parsimonious model that is used to simulate potential technology adoption rates, ex-ante impact assessment, and ecosystem services analysis, across heterogeneous farm populations and for different types of households (Antle, 2011; Antle et al., 2014). The TOA-MD model has key features that make it appropriate for assessment of technologies for climate smart agriculture (CSA). The model represents the whole farm production system which can be composed of a crop subsystem containing multiple crops, a livestock subsystem with multiple livestock species, an aquaculture sub-system with multiple species, and the farm household characteristics (e.g. household size, off-farm income, etc). Furthermore, the TOA-MD is a model of a population of farms, not a model of an individual or "representative" farm. Accordingly, the fundamental parameters of the model are population statistics - means, variances and correlations of the economic variables in the models and the associated outcome variables of interest. With suitable biophysical and economic data, these statistical parameters can be estimated for an observable production system. Another unique feature of the TOAMD model is its parsimonious, generic structure, which means that it can be used to simulate any farm system. One virtue of this model design is that, unlike many large, complex simulation models, it is easy to address the inherent uncertainty in impact assessments by using a set of minimum data and 
sensitivity analysis to explore how results change with the relatively small number of model parameters (Antle et al., 2010).

The TOA-MD model simulates the proportion of farms that utilize a baseline system (e.g. system 1) and the proportion of farms that would adopt an alternative system (e.g. system 2) within defined strata of the population. The model then predicts an adoption rate for each stratum of the population, using the assumption that farmers are economically rational and adopt practices that are expected to provide the highest economic return. Accordingly, this predicted adoption rate should be interpreted as the proportion of farms for which the new system's practices are economically feasible, after correcting for the opportunity costs associated with the technology (Antle and Valdivia, 2011). Positive opportunity costs of an improved technology would discourage adoption. If there are institutional or behavioral factors that constrain adoption - such as limited access to financial resources, or risk aversion - then this predicted adoption rate is likely to be an upper bound on the actual adoption rate that is observed. Based on the predicted rate of adoption, the TOA-MD model also simulates economic, environmental and social impact indicators for the sub-population of adopting farms, the sub-population of nonadopters, and the entire population. The TOA-MD can also simulate supply curves for ecosystem services associated with agricultural systems and assess impacts of environmental change, such as climate change, with or without adaptation. Further details on the impact assessment aspects of the model are provided in Antle (2011) and Antle et al. (2014).

We applied the TOA-MD following the approach described by the Agricultural Model Inter-comparison and Improvement Project (AGMIP, www.agmip.org) to integrate livestock simulation models with economic models for impact assessment (Antle et al., 2015a). Returns to crop production for the baseline system were calculated as a product of amount produced and the farm-gate price of the crop product and summed over all crops that the household produced. Prices for crop and livestock products were derived from the median of estimated village prices by farmers and verified by comparing with observed prices in the village. The variable cost of crop production included farmers' estimates of cash expenses for production during the observed year, including land preparation and farm inputs (herbicides, pesticides, seeds, and fertilizer). Returns to livestock production were separated into two categories: one for milk production and another one for other livestock products (manure and eggs). Revenue from milk was calculated from the average milk yield per cow, the number of cows, a lactation period of 150 days for local cows and 270 days for improved breeds, and the village price for milk. The value of manure was calculated from the amount of manure produced ( $\mathrm{kg} /$ per farm), adjusted by a utilization factor of 0.7 to account for the proportion of manure used for fertilizing the fields (Homann 
Kee-Tui et al., 2015), and village price for manure. The value of the number of animals sold, given away and consumed was calculated based on village prices. The variable cost of livestock production comprised the cost of feeding and pest control (both internal and external pests). Our analysis assumed a feeding season length of eight months in the wet season and four months in the dry season. The economic indicators used in this paper are farm income (USD/year) and the income-based poverty rate, defined as the proportion of the population living under 1.25USD/day/person. The environmental indicator is the methane emission intensity ( $\mathrm{CH} 4 /$ l of milk per year) and was obtained from the Ruminant model output.

\subsection{Income-Based Food Security Indicator}

Changes in technology that would improve crop and livestock productivity and farm incomes have a direct effect on food security. Several studies have used a range of food security indicators based on calories, dietary diversity, or wealth (e.g. asset ownership) but focused mostly to access and availability. Antle et al. (2015b) proposed a new method for measuring food security that can be used for technology impact assessment and can be constructed with data usually available. The Income-Based Food Security Indicator (IBFS) is similar to the Foster-Greer-Thorbecke (FGT) poverty indicators, but instead of comparing income to a poverty line, the IBFS estimates the income required to purchase a food basket that meets nutritional requirements and then compares this food security income requirement to the household's per capita income (Antle et al., 2015b). In this study, we use the IBFS indicator to assess the impact of improved livestock feeding scenarios on food security. Following Antle et al. (2015b), we estimated the IBFS following three steps. First, the share of income devoted to food purchases was obtained from existing literature and specified as a parameter, $S_{\mathrm{f}}$. Second, the cost $\left(C_{\mathrm{f}}\right)$ of a nutritionally adequate food basket was estimated using data on per capita nutritional requirements (macronutrients and micronutrients), typical food consumption patterns, and the nutritional content of foods. Third, the IBFS threshold was defined as $\tau_{\mathrm{f}}=C_{\mathrm{f}} / S_{\mathrm{f}}$, indicating the amount of income needed per person for the purchase of a nutritionally adequate diet. If a household's per capita income is less than $\tau_{\mathrm{f}}$, then the household cannot afford a nutritionally adequate food basket. We then used the TOA-MD to estimate the potential adoption of the proposed technologies and the changes in per-capita and farm income. The model then uses this information and the IBFS threshold to estimate the percentage of food insecure households. 


\subsection{Characterizing the farming systems in Lushoto}

In the Tanzanian farming systems considered in this study, the current or base system (from now called System 1) consisted of households that were not feeding livestock on improved diets. System 1 was parameterized using the distribution of farm characteristics observed in a subset of the population, including farm size, household size, off-farm income, and net returns from crop and livestock activities. Farmers in our sample produced several staple crops (maize, beans, cassava, yams, potatoes); horticultural crops (cabbages, tomatoes, peppers, cucumbers, onions), and cash crops (coffee and tea). In the base system, current livestock feeding (for farms that owned cattle) included local grass, Napier grass, and maize residue. Herd composition and herd size remained unchanged in the base system. The average milk yield was about $2 \mathrm{l} /$ day for farms with local cows and $5 \mathrm{l} /$ day for farms with improved breeds.

The other important parameters in the TOA-MD model were the correlations between the economic returns to the activities within each system and the correlation between the returns of the base system and the alternative system (Antle, 2011). We parameterized System 2 (i.e. the alternative or proposed technology) using simulated milk yields from the Ruminant model. First, we calculated relative yields - a ratio of simulated yield with improved feeding or improved feeding with an improved breed to simulated yield with current feeding. The relative yields were then multiplied by the actual milk output for System 1 to obtain milk output for System 2 (Antle et al., 2015). Multiplying the milk output by the average market price of milk, we obtained returns from milk for System 2. In order to calculate the cost of milk production for System 2, we first took the ratio of cost of milk production in System 1 to returns from milk production for System 1 and multiplied this adjustment factor with the returns to milk production from System 2. We acknowledge that using average price and livestock production cost data reduces heterogeneity in returns to milk production. There is, however, heterogeneity in herd sizes as well as in other livestock production activities. Our approach, therefore, follows the minimum data approach as described by Antle and Valdivia (2006) using the TOA-MD to simulate economic and environmental impacts. Methane emissions for TOA-MD simulations were calculated using Ruminant model's input data on emissions, the lactation period, and the total quantity of milk produced.

\subsection{Scenario design}

Using the livestock feeding options described in section 2.3, we developed a set of scenarios that combined the livestock feeding strategies with increasing herd size and different assumptions regarding the cost of acquiring additional cows. Construction of these scenarios was informed by existing 
evidence to indicate that with market access and improved infrastructure, improved breeds produce higher milk yields resulting in positive economic gains for farmers and improvement in food security (Henderson et al., 2016). Design of the scenarios was also consistent with efforts by development projects such as the East Africa Dairy Development project (EADD) that promote adoption of improved breeds and improved livestock feeding accompanied by better market access and infrastructure. Economic modeling, therefore, began by assessing economic and environmental impacts of the two options considered in the Ruminant model, that is, improved quality of livestock diets only and improved quality of diets plus increased feed amounts. Because of the two options considered in Ruminant model, estimations of economic and environmental impacts were conducted separately for 1) improved feeding quality only and 2) improved feeding quality with increased livestock feed quantity. The analysis was then extended to include five additional scenarios. In scenario 2, farm households in all the three strata received an improved cow breed and the cost was subsidized at 100 percent, that is, farm households did not pay the purchasing price for the cow. Scenario 3 involved the provision of an improved cow breed to farm households and requiring them to pay 25 percent of the purchase price. Similar to scenario 3, scenario 4 and 5 provided farm households with an improved cow breed for which they paid one-half and three-quarters of the purchase price, respectively. The last scenario (scenario 6) provided an improved cow breed to farm households in all the three strata for which they paid full price but received a loan at 18 percent interest rate with a repayment period of three years. Table 2 presents the different scenario considered in the economic analysis. 
Table 2. Description of scenarios simulated in TOA-MD model

\begin{tabular}{|c|c|c|c|c|c|c|c|c|}
\hline \multirow[b]{2}{*}{$\begin{array}{l}\text { TOA-MD } \\
\text { scenario }\end{array}$} & \multirow[b]{2}{*}{ Scenario description } & \multirow[b]{2}{*}{ Stratum } & \multicolumn{2}{|c|}{ Baseline feeding } & \multicolumn{2}{|c|}{$\begin{array}{l}\text { Improved quality of } \\
\text { diet }\end{array}$} & \multicolumn{2}{|c|}{$\begin{array}{l}\text { Improved quality of diet } \\
\text { plus increased quantity of } \\
\text { feed }\end{array}$} \\
\hline & & & $\begin{array}{l}\text { With } \\
\text { local } \\
\text { cows }\end{array}$ & $\begin{array}{l}\text { With } \\
\text { improved } \\
\text { cows }\end{array}$ & $\begin{array}{l}\text { With } \\
\text { local } \\
\text { cows }\end{array}$ & $\begin{array}{l}\text { With } \\
\text { improved } \\
\text { cows }\end{array}$ & $\begin{array}{l}\text { With } \\
\text { local } \\
\text { cows }\end{array}$ & $\begin{array}{l}\text { With improved } \\
\text { cows }\end{array}$ \\
\hline \multirow{3}{*}{ Scenario 1} & Improved feeding for farms with local cows & Stratum 1 & yes & no & yes & no & yes & no \\
\hline & Improved feeding for farms with improved cows & Stratum 2 & no & yes & no & yes & no & yes \\
\hline & No change & Stratum 3 & no & no & no & no & no & no \\
\hline \multirow{3}{*}{ Scenario 2} & Improved feeding for farms with local cows $+1 \mathrm{IB}$ cow at zero cost & Stratum 1 & yes & no & yes & no & yes & Add $1 \mathrm{IB}$ \\
\hline & Improved feeding for farms with improved cows +1 IB cow at $0 \%$ cost & Stratum 2 & no & yes & no & yes & no & Yes, add 1IB \\
\hline & Add 1 IB cow with improved feeding. PC of cow $=0 \%$ & Stratum 3 & no & no & no & no & no & Add 1 IB cow \\
\hline \multirow{3}{*}{ Scenario 3} & Improved feeding for farms with local cows +1 IB cow at $25 \%$ cost & Stratum 1 & yes & no & yes & no & yes & Add $1 \mathrm{IB}$ \\
\hline & Improved feeding for farms with local cows +1 IB cow at $25 \%$ cost & Stratum 2 & no & yes & no & yes & no & Yes, add 1IB \\
\hline & Add 1 IB cow with improved feeding. PC of cow $=25 \%$ & Stratum 3 & no & no & no & no & no & Add 1 IB cow \\
\hline \multirow{3}{*}{ Scenario 4} & $\begin{array}{l}\text { Improved feeding for farms with local cows + one improved } 1 \text { IB cow at } \\
50 \% \text { PC }\end{array}$ & Stratum 1 & yes & no & yes & no & yes & Add 1IB \\
\hline & Improved feeding for farms with local cows +1 IB cow at 50\% PC & Stratum 2 & no & yes & no & yes & no & Yes, add $1 \mathrm{IB}$ \\
\hline & Add 1 IB cow with improved feeding. PC of cow $=50 \%$ & Stratum 3 & no & no & no & no & no & Add $1 \mathrm{IB}$ cow \\
\hline \multirow{3}{*}{ Scenario 5} & Improved feeding for farms with local cows +1 IB cow at $75 \%$ PC & Stratum 1 & yes & no & yes & no & yes & Add $1 \mathrm{IB}$ \\
\hline & Improved feeding for farms with local cows +1 IB cow at $75 \%$ PC & Stratum 2 & no & yes & no & yes & no & Yes, add $1 \mathrm{IB}$ \\
\hline & Add 1 IB cow with improved feeding. PC of cow $=75 \%$ & Stratum 3 & no & no & no & no & no & Add 1 IB cow \\
\hline \multirow{3}{*}{ Scenario 6} & $\begin{array}{l}\text { Improved feeding for farms with local cows }+1 \text { IB cow at full PC but HH } \\
\text { receives credit at } 18 \% \text { interest and with a repayment period of } 3 \text { years }\end{array}$ & Stratum 1 & yes & no & yes & no & yes & Add $1 \mathrm{IB}$ \\
\hline & $\begin{array}{l}\text { Improved feeding for farms with local cows }+1 \text { IB cow at full PC but } \mathrm{HH} \\
\text { receives credit at } 18 \% \text { interest and with a repayment period of } 3 \text { years }\end{array}$ & Stratum 2 & no & yes & no & yes & no & Yes, add 1IB \\
\hline & $\begin{array}{l}\text { Add } 1 \text { IB cow with improved feeding. PC of cow }=100 \% \text { but } \mathrm{HH} \text { receives } \\
\text { credit at } 18 \% \text { interest and with a repayment period of } 3 \text { years. }\end{array}$ & Stratum 3 & no & no & no & no & no & Add 1 IB cow \\
\hline
\end{tabular}


Notes: IB means improved breed and PC means purchase cost

\section{Results: Impact assessment of adoption of improved livestock systems}

Table 3 displays summary statistics by strata for farms in our sample. These statistics are the base for the TOA-MD model parameters. The average household size was relatively lower in stratum 3 (4.26) compared with stratum 1 (5.00) and stratum 2 (4.96). On average, stratum 3 had the highest proportion (68\%) of the population that had earned income from non-agricultural sources. Farm households in stratum 1 earned, on average, 47.5 percent more income from non-agricultural sources than those in stratum 1 and 7.2 percent higher than those in stratum 2. Net crop returns was, however, about 46 percent lower in stratum 3 compared to stratum 1 and 14.5 percent lower compared to stratum 2. Stratum two had 90 percent higher net returns from milk compared with strata one, which is expected due to the higher milk productivity from improved breeds. This stratum also had the highest net returns from other livestock products. These statistics suggest that farmers in stratum 1 focused more on crop production, farmers in stratum 2 were more involved in livestock production, while farmers in stratum 3 relied more on non-agricultural activities for a source of livelihood. 
Table 3. Summary statistics for system one, by strata

\begin{tabular}{|c|c|c|c|c|c|c|}
\hline & \multicolumn{2}{|c|}{ Stratum $1(\mathrm{~N}=28)$} & \multicolumn{2}{|c|}{ Stratum $2(\mathrm{~N}=70)$} & \multicolumn{2}{|c|}{ Stratum $3(\mathrm{~N}=66)$} \\
\hline & Mean & SD & Mean & SD & Mean & SD \\
\hline Proportion in the population & 0.17 & - & 0.43 & - & 0.40 & - \\
\hline Household size (total number of people in a household) & 5.00 & 1.56 & 4.96 & 1.79 & 4.26 & 1.90 \\
\hline Farm size (ha) & 1.02 & 0.81 & 0.89 & 0.37 & 0.91 & 0.71 \\
\hline Annual non-agricultural income (USD) & 127.33 & 197.41 & 224.89 & 375.80 & 242.33 & 498.60 \\
\hline Herd size (number of cows) & 1.50 & 0.64 & 1.70 & 1.10 & 0 & - \\
\hline Annual net returns from crops (USD ) & 580.51 & 787.16 & 364.78 & 472.07 & 312.05 & 424.51 \\
\hline Annual net returns from milk production (USD ) & 48.51 & 20.64 & 484.43 & 313.61 & 0 & - \\
\hline Annual net returns from other livestock products (USD) & 60.76 & 79.29 & 94.00 & 85.54 & 12.63 & 44.71 \\
\hline
\end{tabular}

Notes:

1) Stratum 1 comprises farm households with local cows only

2) Stratum 2 comprises farm households with improved dairy cows only

3) Stratum 3 comprises farm households without cattle

4) 1 TSh was equivalent of 0.0006 USD at the time of data collection. 
As shown in Table 3 farm households with no livestock had lower farm income compared to those with cattle. Furthermore, farms households with improved cattle had higher incomes from livestock production compared to those with local breeds, probably because of higher milk yields. As mentioned earlier, we assumed that additional inputs to livestock production (including Napier grass) would be purchased and not produced on-farm. Hence, we assume no changes in cropland allocation. Several studies have shown that if smallholder farmers face higher levels of uncertainty, they will allocate less land to a new technology (Feder, 1980; Smale et al., 1995; Pannell, 2008). The area allocated to the technology is, therefore, expected to increase if absolute risk aversion is decreasing (Feder, 1980; Smale et al., 1995; Pannell, 2008). Changes in land allocation for dominant crop enterprises can only be expected after some period of time when farmers become confident on benefits of the new technology (Feder, 1980; Smale et al., 1995; Pannell, 2008). Although we did not consider any possible feedback between livestock production and crops (e.g. increased use of manure on crops that may affect crop yields), we acknowledge that crop-livestock interactions play an important role in farming systems. However, to keep our analysis focused on the impacts of improved livestock feeding options, our approach allowed us to maintain the same crop yields and returns to crops production both under system one and system two.

\subsection{Results of the Ruminant model}

Table 4 presents results of the Ruminant model. As shown, expected milk yield was highest for farm households with improved cows that were fed improved diets. Milk yield increased by 42 percent when farm households fed their improved breeds on improved diets compared to baseline diets. Feeding local cows on improved diets also increased milk yield but the yield was about 29 percent lower compared to that obtained with improved breeds. Together, these results suggest that improved feeding is critical for increased productivity and can contribute to improved food and nutrition security. The results further confirm that payoffs are higher when improved diets are coupled with improved breeds due to increased efficiency in utilization of the feed. Table 4 also shows that methane emission intensities were higher for farm households with local cows compared to those with improved breeds of dairy cows under baseline diets. Improved feeding strategies lowered methane emission intensity of both types of breeds. 
Table 4. Daily milk production and emission (methane from enteric fermentation) across seasons for local and improved breeds with baseline and improved livestock feeding

\begin{tabular}{|c|c|c|c|c|c|c|}
\hline & \multicolumn{6}{|c|}{ Livestock type } \\
\hline & \multicolumn{3}{|c|}{ Local cow breed } & \multicolumn{3}{|c|}{ Improved cow breed } \\
\hline & Base & $\begin{array}{l}\text { Improved } \\
\text { quality }\end{array}$ & $\begin{array}{l}\text { Improved } \\
\text { quality plus } \\
\text { quantity }\end{array}$ & Base & $\begin{array}{l}\text { Improved } \\
\text { quality }\end{array}$ & $\begin{array}{l}\text { Improved } \\
\text { quality plus } \\
\text { quantity }\end{array}$ \\
\hline $\begin{array}{l}\text { Milk production } \\
\text { (I/cow/day) }\end{array}$ & 2.83 & 5.10 & 6.53 & 3.80 & 7.00 & 9.37 \\
\hline $\begin{array}{l}\text { Methane emission } \\
\text { (I/l of milk/day) }\end{array}$ & $\begin{array}{l}125 . \\
60\end{array}$ & 145.40 & 148.80 & $\begin{array}{l}162.4 \\
0\end{array}$ & 190.80 & 200.10 \\
\hline
\end{tabular}

\subsection{Results of TOA-MD modelling}

\subsubsection{Predicted adoption rates}

Figure 6.2 presents the predicted adoption rates at the population level (aggregated over the three strata) under the improved livestock diets option (i.e. livestock feeding option 1) while Figure 3 presents predicted adoption rates under the improved diets plus quantity of feed option (i.e. livestock feeding option 2). In the first case, the average projected adoption rates by the TOA-MD model ranged from about 59 to 84 percent while in the second case the average projected adoption rates by the TOA-MD model ranged from about 64 to 84 percent. These results suggest higher adoption rates when both quality and quantity of feed improves, indicating that net returns are higher compared to when only quality is improved.

Table 5 summarizes the adoption rates predicted by the TOA-MD model for each stratum of the population when the quality of the livestock diet was improved holding quantity constant. As shown, predicted adoption rate for farm households with local cows only (i.e. stratum 1) ranged between 42 percent and 65 percent. The rate was higher for farm households with improved cows only (i.e. stratum 2) and ranged from 67 percent when diets were improved holding herd sizes constant to 87 percent when diets were improved, and farm households received an improved breed of cow at zero purchase cost. These results suggest that, on average, net returns are higher when farm households in stratum 1 and stratum 2 improve the quality of livestock diets than if they rely on current feeding. The higher adoption rates for farm households in stratum 2 compared to those in stratum 1 indicate that net returns are higher for the former. As shown in Table 5, adoption rate for farm households in stratum 3 
when diets are improved (i.e. scenario 1 ) is not reported. This is because we had no ability to compare stratum 3 with a baseline. It is also for this reason that adoption rates were higher than those in stratum 1 and stratum 2 when farm households in stratum 3 received an improved breed cow. Table 6 presents the predicted adoption rates by stratum when both the quality and quantity of the diets improved. As shown, the predicted adoption rates were higher in this scenario compared to varying quality of diets alone for farm households in stratum 2 but not for those in stratum 1.

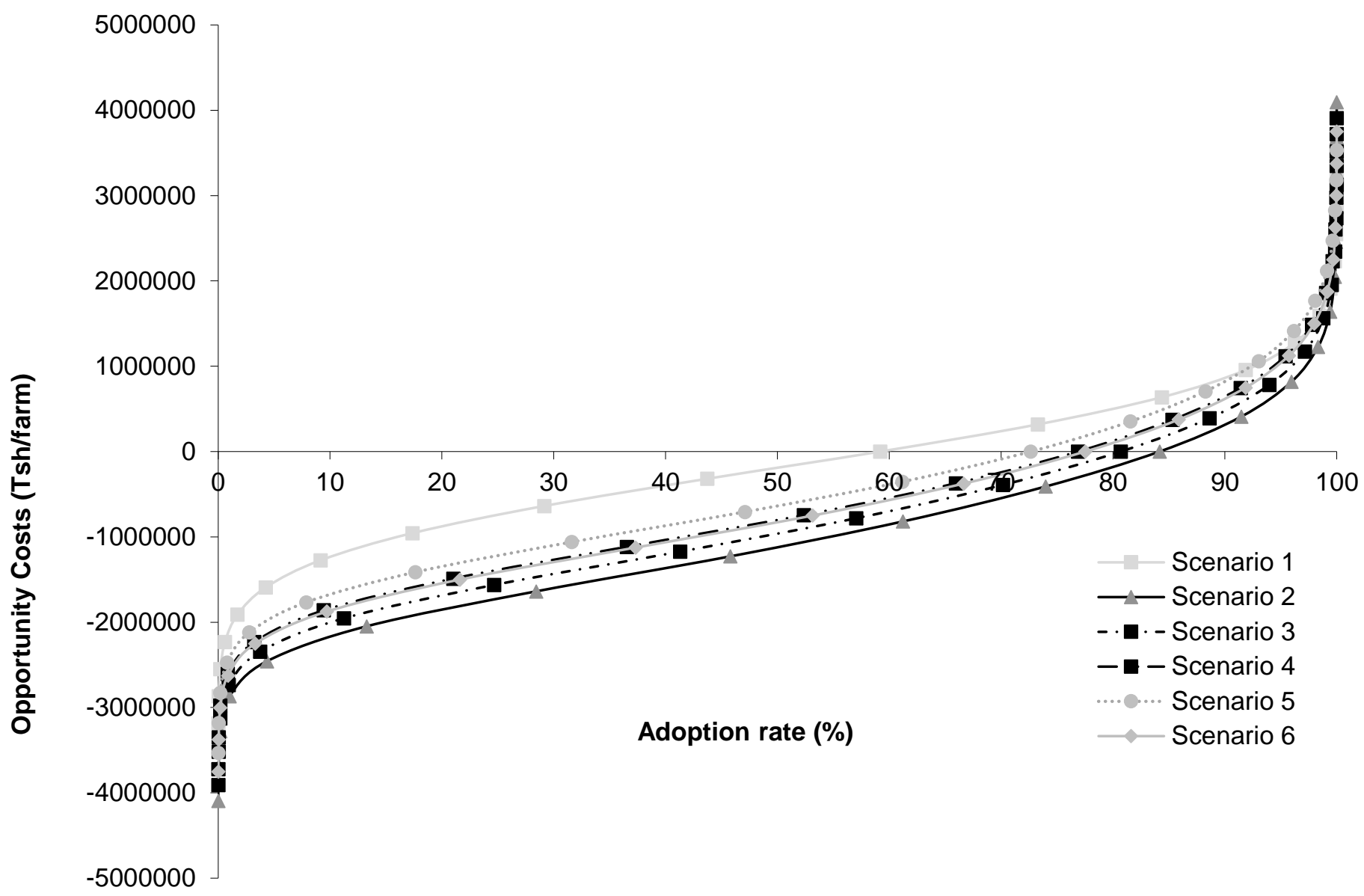

Figure 2. Predicted population adoption rates by scenario (Ruminant model scenario - improved quality of livestock diets only).

Notes:

1) A complete description of the scenarios is provided in Table 2.

2) Opportunity cost is defined here as the difference in net farm returns between the base system (current technology) and the modified system (improved technology). Adoption rate is indicated by the point where the curves cut the $x$-axis.

3) 1 TSh was equivalent of 0.0006 USD the time of data collection. 


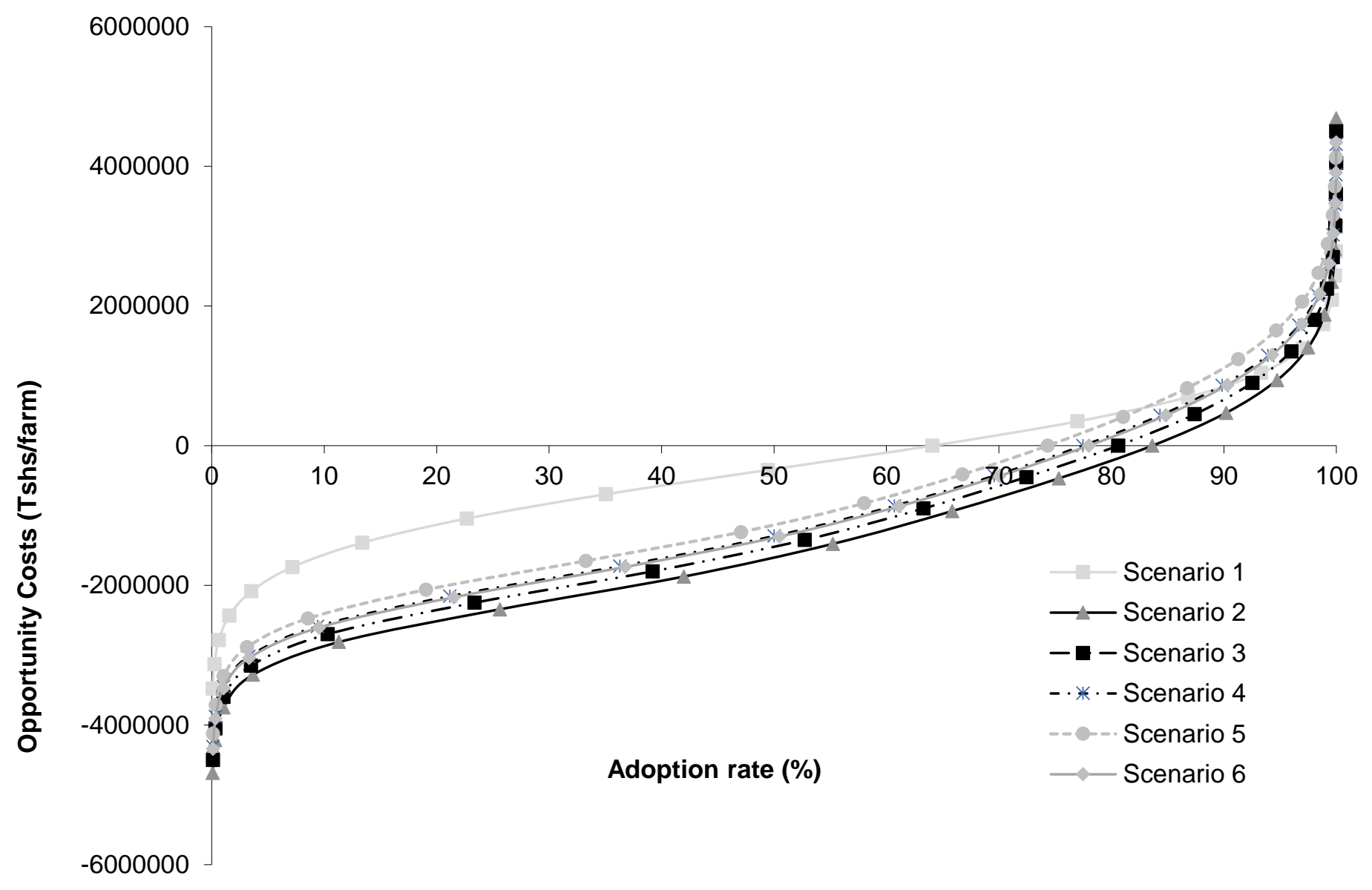

Figure 3. Predicted population adoption rates by scenario (Improved quality of livestock diets plus increased amount of feed).

Notes:

1) A complete description of the scenarios is provided in Table 2.

2) Opportunity cost is defined here as the difference in net farm returns between the base system (current technology) and the modified system (improved technology). Adoption rate is indicated by the point where the curves cut the $x$-axis.

3) 1 TSh was equivalent of 0.0006 USD at the time of data collection.

Providing an improved breed of dairy cow at zero purchase cost increased the predicted adoption rate of improved feeding by 13 percent for farms with local cows only (i.e. stratum 1 ) and 30 percent for farms with improved cattle only (i.e. stratum 2) when compared with the introduction of improved feeding only. Projected adoption rates, however, declined when farmers were required to pay part of the purchase price of the improved cow. These lower adoption rates were noteworthy for farm households in stratum 1 . On the other hand, farm households that already own improved breeds (i.e. 
those in stratum 2) might be able to afford an upfront payment hence the higher predicted adoption rates. Conditions improved when farm households had access to credit, implying that even farmers in stratum 1 might afford to cover the upfront cost of the improved cow breed. Even though the adoption rates were expected, given the design of the scenarios, it is important to highlight the importance of policies or programs that would allow farmers to adopt the proposed technologies, which as we show below, may have important consequences for food security and the environment. Given the predicted adoption rates, the projected outcomes of income, food security, poverty rate, and methane emissions for each stratum were calculated. 
Table 5. Predicted adoption rates and simulated Impacts on net returns, food insecurity, poverty rates, and methane emissions intensity, by scenario ${ }^{1}$ and stratum. Ruminant model scenario = Improved quality of diet only

\begin{tabular}{|c|c|c|c|c|c|c|c|c|}
\hline \multirow[t]{2}{*}{ Indicators } & \multirow{2}{*}{$\begin{array}{l}\text { Stratum } \\
\text { (type of farm) }\end{array}$} & \multirow[t]{2}{*}{ Base system } & \multicolumn{6}{|c|}{ Improved systems } \\
\hline & & & Scenario 1 & Scenario 2 & Scenario 3 & Scenario 4 & Scenario 5 & Scenario 6 \\
\hline \multirow[t]{3}{*}{ Predicted adoption rate (\%) } & 1-Only local cattle & $\mathrm{n} / \mathrm{a}$ & 58.00 & 65.52 & 57.93 & 50.03 & 42.12 & 51.30 \\
\hline & 2-Only improved cattle & $\mathrm{n} / \mathrm{a}$ & 67.00 & 87.03 & 84.39 & 81.41 & 78.10 & 81.91 \\
\hline & 3-No cattle & $n / a$ & $n / a$ & 99.93 & 99.75 & 99.19 & 97.69 & 99.32 \\
\hline & 1-Only local cattle & 728.00 & 33.10 & 41.20 & 33.15 & 26.11 & 20.09 & 27.17 \\
\hline \multirow{2}{*}{ (USD/year) } & 2-Only improved cattle & 1116.00 & 47.70 & 86.30 & 79.05 & 71.99 & 65.20 & 73.10 \\
\hline & 3-No cattle & 324.77 & $n / a$ & 218.00 & 190.67 & 163.08 & 135.76 & 167.49 \\
\hline \multirow[t]{3}{*}{ Food insecurity (\%) } & 1-Only local cattle & 21.66 & -30.42 & -36.15 & -30.47 & -25.07 & -20.13 & -25.90 \\
\hline & 2-Only improved cattle & 13.90 & -13.86 & -30.09 & -26.79 & -23.64 & -20.63 & -24.07 \\
\hline & 3-No cattle & 23.87 & $n / a$ & -74.28 & -69.96 & -64.68 & -58.27 & -65.60 \\
\hline \multirow[t]{3}{*}{ Poverty rate $(\%)$} & 1-Only local cattle & 92.89 & -6.40 & -8.00 & -6.36 & -4.76 & -3.50 & -4.98 \\
\hline & 2-Only improved cattle & 80.13 & -14.10 & -47.59 & -44.41 & -41.16 & -37.91 & -41.69 \\
\hline & 3-No cattle & 92.95 & $\mathrm{n} / \mathrm{a}$ & -37.20 & -31.72 & -26.19 & -20.79 & -27.07 \\
\hline \multirow{2}{*}{$\begin{array}{l}\text { Methane emission intensity (I } \\
\mathrm{CH}_{4} / \mathrm{l} \text { of milk/year) }\end{array}$} & 1-Only local cattle & 27.77 & -23.19 & -13.36 & -12.21 & -10.91 & -9.51 & -11.13 \\
\hline & 2-Only improved cattle & 24.70 & -24.00 & -52.96 & -50.94 & -48.70 & -46.28 & -49.11 \\
\hline
\end{tabular}

\section{Notes:}

1) $n / a$ means not applicable

2) For the scenarios (1, 2, 3, 4, 5, 6), average income, poverty rate, food insecurity, and average GHG emission intensity are expressed as percentage changes compared to the baseline

3) Negative figures show a percentage decrease in an indicator compared to the base scenario

4) 1 TSh was equivalent of 0.0006 USD at the time of data collection.

Table 6. Predicted adoption rates and simulated Impacts on net returns, food insecurity, poverty rates, and methane emissions intensity, by scenario ${ }^{2}$ and stratum. Ruminant model scenario = Improved quality of diet plus increased quantify of feed

\begin{tabular}{lll}
\hline \hline Indicators & Stratum & Improved systems \\
\hline
\end{tabular}

\footnotetext{
${ }^{11}$ Please refer to Table 6.2 for the definition of the scenarios.

22 Please refer to Table 2 for the definition of the scenarios.
} 


\begin{tabular}{|c|c|c|c|c|c|c|c|c|}
\hline & (type of farm) & $\begin{array}{l}\text { Base } \\
\text { system }\end{array}$ & Scenario 1 & Scenario 2 & Scenario 3 & Scenario 4 & Scenario 5 & Scenario 6 \\
\hline \multirow[t]{3}{*}{ Predicted adoption rate (\%) } & 1-Only local cattle & $\mathrm{n} / \mathrm{a}$ & 62.17 & 60.58 & 53.00 & 45.30 & 37.77 & 46.52 \\
\hline & 2-Only improved cattle & $\mathrm{n} / \mathrm{a}$ & 75.82 & 90.35 & 88.84 & 87.17 & 85.32 & 87.45 \\
\hline & 3-No cattle & $n / a$ & $n / a$ & 100.00 & 100.00 & 100 & 99.92 & 99.98 \\
\hline \multirow{3}{*}{$\begin{array}{l}\text { Average farm income } \\
\text { (USD/year) }\end{array}$} & 1-Only local cattle & 728.00 & 38.66 & 36.93 & 29.51 & 23.10 & 17.68 & 24.06 \\
\hline & 2-Only improved cattle & 1116.00 & 77.64 & 134.02 & 126.37 & 118.87 & 111.52 & 120.06 \\
\hline & 3-No cattle & 324.77 & $n / a$ & 333.16 & 305.43 & 277.70 & 249.98 & 282.15 \\
\hline \multirow[t]{3}{*}{ Food insecurity (\%) } & 1-Only local cattle & 21.66 & -31.95 & -30.79 & -25.58 & -20.73 & -16.44 & -21.51 \\
\hline & 2-Only improved cattle & 13.90 & -13.90 & -28.41 & -25.54 & -22.67 & -20.09 & -23.10 \\
\hline & 3-No cattle & 23.87 & $\mathrm{n} / \mathrm{a}$ & -83.00 & -80.77 & -78.09 & -74.86 & -78.55 \\
\hline \multirow[t]{3}{*}{ Poverty rate (\%) } & 1-Only local cattle & 92.89 & -8.28 & -9.85 & -6.04 & -4.54 & -3.34 & -4.77 \\
\hline & 2-Only improved cattle & 80.13 & -41.15 & -60.67 & -58.36 & -56.00 & -53.57 & -56.38 \\
\hline & 3-No cattle & 92.95 & $n / a$ & -57.04 & -52.82 & -48.28 & -43.44 & -49.03 \\
\hline \multirow{2}{*}{$\begin{array}{l}\text { Methane emission intensity (I } \\
\mathrm{CH}_{4} / \mathrm{l} \text { of milk/year) }\end{array}$} & 1-Only local cattle & 26.71 & -32.63 & -23.77 & -21.00 & -18.15 & -15.34 & -18.62 \\
\hline & 2-Only improved cattle & 23.90 & -28.34 & -62.98 & -61.52 & -59.97 & -58.27 & -60.21 \\
\hline
\end{tabular}

Notes:

1) $n / a$ means not applicable

2) For the scenarios $(1,2,3,4,5,6)$, average income, poverty rate, food insecurity, and average GHG emission intensity are expressed as percentage changes compared to the baseline

3) Negative figures show a percentage decrease in an indicator compared to the base scenario

4) 1 TSh was equivalent of 0.0006 USD at the time of data collection. 


\subsubsection{Simulated impacts on income, food security, poverty, and methane emissions}

Results of TOA-MD in Table 5 showed that at the predicted adoption rates for improved quality of feed, expected income would increase for farm households in stratum 1 and stratum 2. As shown, TOA-MD projected an increase in annual income from USD 728 to USD 968, representing a 33 percent increase for farm households in stratum 1. Expected economic payoffs were higher for households in stratum 2 and were projected to increase by about 48 percent from USD 1,116 to USD 1,432 with the adoption of improved diets only. Results further showed an increase in income when farm households were provided with an improved cow breed at zero purchase price. Although positive, expected gain in income was lower when households were required to pay a fraction of the purchase price and was lowest when households paid 75 percent of the purchase price. However, access to credit increased income when households paid full cost for purchase of the improved cow breed. Income level for household that accessed credit was about equal to that obtained when the purchase price was subsidized by 50 percent. These findings suggest that a policy aiming to provide access to credit may, in part, eliminate some of the constraints that small farmers have to invest in their farms. Consistent with studies that aim to understand indicators that farmers use to prioritize climate smart agricultural practices (Mwongera et al., 2015; Shikuku et al., 2015), this finding reinforces the idea that cost plays an important role in the decision making process of farm households. Projections of TOA-MD showed that, the increase in income was highest for farm households in stratum 3. As already mentioned, this stratum did not have a baseline outcome, which partly explains the high economic gains. Although it is difficult to make direct comparisons between stratum 3 and the others, the findings obtained are insightful as they suggest considerable economic gains for farm households in stratum 3 if they were to adopt an improved cow breed.

In terms of poverty rates, defined as the percentage of the population living below a poverty line of USD1.25/day, improvement in the quality of livestock diets reduced poverty both in stratum 1 (i.e. households that owned local cows only) and stratum 2 (i.e. households that owned improved breeds) but was only modest in the former. While poverty reduction remained modest when households in stratum 1 received an improved cow breed at zero purchase cost, households in stratum 2 observed a greater decline (48\%) in poverty when they received an improved cow breed. A similar pattern to that observed for income was seen in poverty when households were required to pay for the improved cow breed. Although the gains in terms of decline in poverty rates were high even when households in stratum 2 paid for the improved cow breed, these gains reduced and were lowest when households paid 
75 percent of the purchase cost. Subsidizing the cost of the improved cow breed at 50 percent yielded gains in poverty reduction equal to those achieved when farmers paid full price but accessed credit. Although the predicted adoption rate for farm households in stratum 3 was higher compared to stratum 2 , the expected decline in poverty rate was lower in stratum 3 than in stratum 2 when an improved cow breed was provided. This might be due to the distribution of income in stratum 3 that the TOA-MD could not capture.

Although households in stratum 1 gained less in terms of expected reduction in poverty, there were substantial gains in food security when they adopted improved quality of livestock feeds. Expected improvement in food security was higher for farm households in stratum 1 compared to those in stratum 2. Increased milk productivity due to better feeding and the addition of an improved breed might lead to an increase in farm income, which farms with local cows can use to satisfy their food requirements. Reducing food insecurity between 20 percent and 37 percent with these combined strategies is promising for farm households in stratum 1.

As shown in Tables 5 and 6, improved feeding and improved breeds could potentially provide mitigation co-benefits. Improved feeding strategies decreased methane emission intensity in both local and improved breeds. Consistent with the results of the Ruminant model, results of TOA-MD showed no difference in emissions reduction when farm households improved quality of diets only vis-à-vis when then they improved quality and increased quantity fed. The magnitude of reduction in emission intensity was also similar between stratum 1 and stratum 2 when improved feeding was adopted. Provision of an improved cow breed, however, on average yielded greater gains in emission intensity reduction for farm households in stratum 2 than those in stratum 1. The reason is that these results are aggregating the emissions from both the local breed cow that farmers already own and the new improved breed they would acquire under any of the scenarios.

Although results showed considerable economic gains for farm households in stratum 3 in terms of income, poverty, and food security, introducing an improved cow breed in this stratum implies shifting non-cattle producers to dairy production. Therefore, this results in an overall net increase in GHG emissions meaning that for stratum 3, adoption might create trade-offs and not a triple win.

Tables $6.7,6.8,6.9$, and 6.10 report results of a sensitivity analysis, using the adoption rate, poverty rate, threshold food security indicator, and methane emission intensity. As noted above, quantity of feed was increased and decreased by 10 percent. As shown the adoption rate, poverty, methane emissions, and food security indicators did not deviate more than 11 percent when the feed quantity was varied individually from -10 percent to 10 percent. Figure 6.4 , shows that the population adoption rates did 
not deviate more than 11 percent when feed quality and quantity was varied from -10 percent to 10 percent.

Quality improvement only

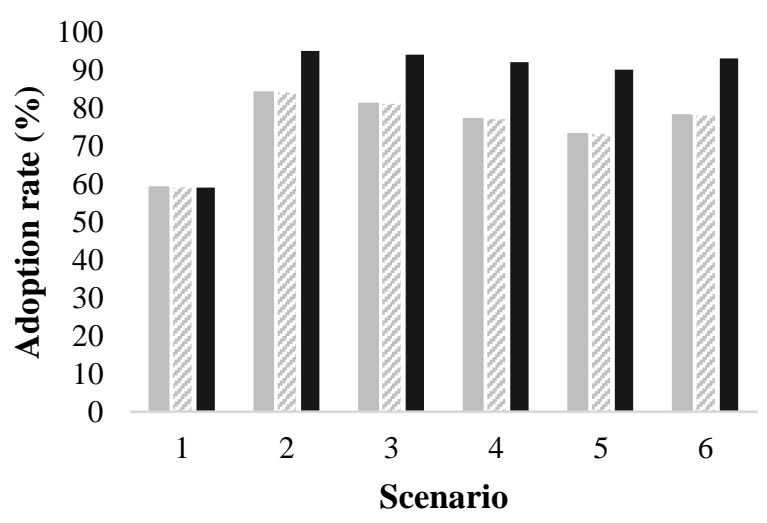

base $\quad \not-10 \% \quad \square 10 \%$
Quality + quantity improvement

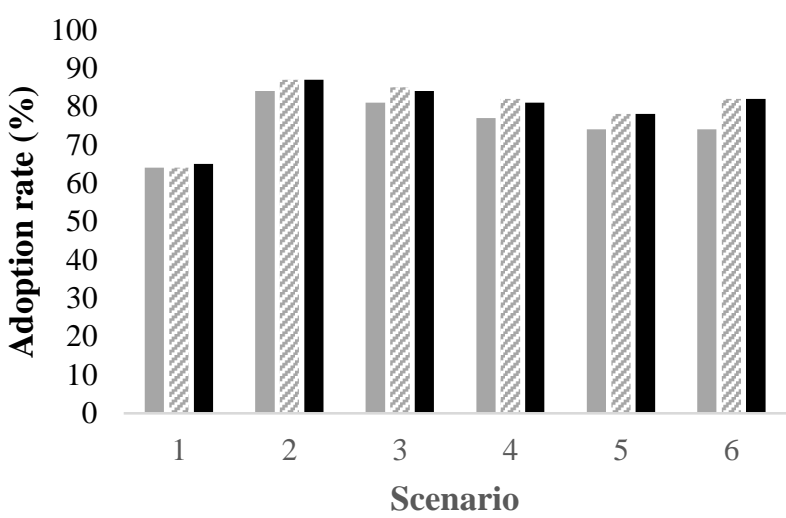

- base $\because-10 \square 10$

Figure 4: Sensitivity analysis by scenario. Base runs of baseline and scenario diets were repeated with a $+10 \%$ and $-10 \%$ variation to test sensitivity of the approach. 
Table 7. Sensitivity analysis: Increase in the quality of the feed by 10 percent (Ruminant model scenario = improved livestock diets only)

\begin{tabular}{|c|c|c|c|c|c|c|c|c|}
\hline \multirow[t]{2}{*}{ Indicators } & \multirow{2}{*}{$\begin{array}{l}\text { Stratum } \\
\text { (type of farm) }\end{array}$} & \multirow[t]{2}{*}{ Base system } & \multicolumn{6}{|c|}{ Improved systems } \\
\hline & & & Scenario 1 & Scenario 2 & Scenario 3 & Scenario 4 & Scenario 5 & Scenario 6 \\
\hline \multirow[t]{3}{*}{ Predicted adoption rate (\%) } & 1-Only local cattle & $\mathrm{n} / \mathrm{a}$ & 58.20 & 65.52 & 57.93 & 50.03 & 42.12 & 51.30 \\
\hline & 2-Only improved cattle & $\mathrm{n} / \mathrm{a}$ & 66.44 & 86.65 & 83.87 & 80.75 & 77.28 & 81.28 \\
\hline & 3-No cattle & $n / a$ & $\mathrm{n} / \mathrm{a}$ & 99.91 & 99.65 & 98.90 & 97.01 & 99.08 \\
\hline \multirow{3}{*}{$\begin{array}{l}\text { Average farm income } \\
\text { (USD/year) }\end{array}$} & 1-Only local cattle & 728.00 & 33.48 & 41.20 & 33.15 & 26.11 & 20.09 & 27.17 \\
\hline & 2-Only improved cattle & 1116.00 & 45.58 & 83.05 & 75.79 & 68.78 & 62.05 & 69.89 \\
\hline & 3-No cattle & 324.77 & $n / a$ & 210.70 & 183.03 & 155.49 & 128.30 & 159.89 \\
\hline \multirow[t]{3}{*}{ Food insecurity (\%) } & 1-Only local cattle & 21.66 & -30.56 & -27.11 & -20.22 & -14.12 & -9.01 & -15.04 \\
\hline & 2-Only improved cattle & 13.90 & -13.90 & -30.23 & -26.79 & -23.64 & -20.63 & -24.07 \\
\hline & 3-No cattle & 23.87 & $\mathrm{n} / \mathrm{a}$ & -73.19 & -68.62 & -63.05 & -56.35 & -64.01 \\
\hline \multirow[t]{3}{*}{ Poverty rate (\%) } & 1-Only local cattle & 92.89 & -6.47 & -8.00 & -6.36 & -4.76 & -3.50 & -4.98 \\
\hline & 2-Only improved cattle & 80.13 & -27.85 & -46.42 & -43.16 & -39.85 & -36.55 & -40.39 \\
\hline & 3-No cattle & 92.95 & $\mathrm{n} / \mathrm{a}$ & -35.72 & -30.18 & -22.92 & -19.34 & -25.54 \\
\hline \multirow{2}{*}{$\begin{array}{l}\text { Methane emission intensity (I } \\
\mathrm{CH}_{4} / \mathrm{l} \text { of milk/year) }\end{array}$} & 1-Only local cattle & 27.77 & -24.08 & -13.36 & -12.21 & -10.91 & -9.51 & -11.13 \\
\hline & 2-Only improved cattle & 24.70 & -21.53 & -52.25 & -50.20 & -47.87 & -45.39 & -48.28 \\
\hline
\end{tabular}

Notes:

1) $n / a$ means not applicable

2) For the scenarios $(1,2,3,4,5,6)$, average income, poverty rate, food insecurity, and average GHG emission intensity are expressed as percentage changes compared to the baseline

3) Negative figures show a percentage decrease in an indicator compared to the base scenario

4) 1 TSh was equivalent of 0.0006 USD at the time of data collection.

Table 8. Sensitivity analysis: Decrease in the quality of the feed by 10 percent (Ruminant model scenario = Improved livestock diets only)

\begin{tabular}{|c|c|c|c|c|c|c|c|c|}
\hline \multirow[t]{2}{*}{ Indicators } & \multirow{2}{*}{$\begin{array}{l}\text { Stratum } \\
\text { (type of farm) }\end{array}$} & \multirow[t]{2}{*}{ Base system } & \multicolumn{6}{|c|}{ Improved systems } \\
\hline & & & Scenario 1 & Scenario 2 & Scenario 3 & Scenario 4 & Scenario 5 & Scenario 6 \\
\hline \multirow[t]{3}{*}{ Predicted adoption rate (\%) } & 1-Only local cattle & $\mathrm{n} / \mathrm{a}$ & 57.88 & 65.31 & 57.70 & 49.80 & 41.90 & 51.07 \\
\hline & 2-Only improved cattle & $\mathrm{n} / \mathrm{a}$ & 67.92 & 87.43 & 84.92 & 82.09 & 78.94 & 82.56 \\
\hline & 3-No cattle & $\mathrm{n} / \mathrm{a}$ & $\mathrm{n} / \mathrm{a}$ & 99.84 & 99.51 & 98.68 & 96.88 & 98.87 \\
\hline
\end{tabular}




\begin{tabular}{|c|c|c|c|c|c|c|c|c|}
\hline Average farm income & 1-Only local cattle & 728.00 & 33.10 & 40.97 & 32.94 & 25.92 & 19.94 & 26.97 \\
\hline \multirow[t]{2}{*}{ (USD/year) } & 2-Only improved cattle & 1116.00 & 50.09 & 90.00 & 82.66 & 75.55 & 68.70 & 76.68 \\
\hline & 3-No cattle & 324.77 & $n / a$ & 226.83 & 199.17 & 171.67 & 144.52 & 176.06 \\
\hline \multirow[t]{3}{*}{ Food insecurity (\%) } & 1-Only local cattle & 21.66 & -30.42 & -36.01 & -30.29 & -24.88 & -19.94 & -25.76 \\
\hline & 2-Only improved cattle & 13.90 & -13.32 & -30.09 & -26.65 & -23.64 & -20.63 & -24.07 \\
\hline & 3-No cattle & 23.87 & $n / a$ & -72.14 & -67.66 & -62.21 & -55.76 & -63.13 \\
\hline \multirow[t]{3}{*}{ Poverty rate (\%) } & 1-Only local cattle & 92.89 & -6.35 & -8.26 & -6.31 & -4.72 & -3.43 & -4.94 \\
\hline & 2-Only improved cattle & 80.13 & -29.93 & -48.85 & -45.73 & -42.56 & -39.35 & -43.07 \\
\hline & 3-No cattle & 92.95 & $n / a$ & -39.19 & -33.98 & -28.73 & -23.55 & -29.56 \\
\hline \multirow{2}{*}{$\begin{array}{l}\text { Methane emission intensity (I } \\
\mathrm{CH}_{4} / \mathrm{l} \text { of milk/year) }\end{array}$} & 1-Only local cattle & 27.77 & -22.98 & -12.40 & -11.34 & -10.15 & -8.84 & -10.33 \\
\hline & 2-Only improved cattle & 24.70 & -10.38 & -53.56 & -51.63 & -49.48 & -47.14 & -49.86 \\
\hline
\end{tabular}

Notes:

1) $n / a$ means not applicable

2) For the scenarios $(1,2,3,4,5,6)$, average income, poverty rate, food insecurity, and average GHG emission intensity are expressed as percentage changes compared to the baseline

3) Negative figures show a percentage decrease in an indicator compared to the base scenario

4) 1 TSh was equivalent of 0.0006 USD at the time of data collection.

Table 9. Sensitivity analysis: Increase in the quality of the feed by 10 percent (Ruminant model scenario = Improved livestock diets plus increased feed amounts)

\begin{tabular}{|c|c|c|c|c|c|c|c|c|}
\hline \multirow[t]{2}{*}{ Indicators } & \multirow{2}{*}{$\begin{array}{l}\text { Stratum } \\
\text { (type of farm) }\end{array}$} & \multirow{2}{*}{$\begin{array}{l}\text { Base } \\
\text { system }\end{array}$} & \multicolumn{6}{|c|}{ Improved systems } \\
\hline & & & Scenario 1 & Scenario 2 & Scenario 3 & Scenario 4 & Scenario 5 & Scenario 6 \\
\hline \multirow[t]{3}{*}{ Predicted adoption rate (\%) } & 1-Only local cattle & $\mathrm{n} / \mathrm{a}$ & 62.17 & 71.60 & 64.72 & 57.32 & 49.66 & 58.53 \\
\hline & 2-Only improved cattle & $\mathrm{n} / \mathrm{a}$ & 75.82 & 89.95 & 88.29 & 86.45 & 84.42 & 86.76 \\
\hline & 3-No cattle & $\mathrm{n} / \mathrm{a}$ & $\mathrm{n} / \mathrm{a}$ & 100.00 & 99.98 & 99.94 & 99.81 & 99.95 \\
\hline \multirow{3}{*}{$\begin{array}{l}\text { Average farm income } \\
\text { (USD/year) }\end{array}$} & 1-Only local cattle & 728.00 & 38.66 & 50.47 & 41.56 & 33.59 & 26.61 & 34.81 \\
\hline & 2-Only improved cattle & 1116.00 & 77.64 & 125.23 & 117.62 & 110.17 & 102.89 & 111.36 \\
\hline & 3-No cattle & 324.77 & $\mathrm{n} / \mathrm{a}$ & 310.67 & 282.94 & 255.21 & 227.51 & 259.66 \\
\hline \multirow[t]{3}{*}{ Food insecurity (\%) } & 1-Only local cattle & 21.66 & -31.95 & -39.47 & -33.89 & -28.49 & -23.41 & -29.32 \\
\hline & 2-Only improved cattle & 13.90 & -13.90 & -28.28 & -25.82 & -22.30 & -19.66 & -23.39 \\
\hline & 3-No cattle & 23.87 & $\mathrm{n} / \mathrm{a}$ & -81.27 & -78.72 & -75.62 & -71.89 & -76.16 \\
\hline Poverty rate (\%) & 1-Only local cattle & 92.89 & -8.28 & -11.35 & -9.01 & -7.02 & -5.35 & -7.32 \\
\hline
\end{tabular}




\begin{tabular}{|c|c|c|c|c|c|c|c|c|}
\hline & 2-Only improved cattle & 80.13 & -41.15 & -58.66 & -56.22 & -53.71 & -51.12 & -54.12 \\
\hline & 3-No cattle & 92.95 & $n / a$ & -53.65 & -49.17 & -44.38 & -39.35 & -45.16 \\
\hline \multirow{2}{*}{$\begin{array}{l}\text { Methane emission intensity (I } \\
\mathrm{CH}_{4} / \mathrm{l} \text { of milk/year) }\end{array}$} & 1-Only local cattle & 26.71 & -32.63 & -27.71 & -25.31 & -22.65 & -19.81 & -23.08 \\
\hline & 2-Only improved cattle & 23.90 & -28.43 & -61.61 & -60.09 & -58.40 & -56.60 & -58.68 \\
\hline
\end{tabular}

Notes:

1) $n / a$ means not applicable

2) For the scenarios (1, 2, 3, 4, 5, 6), average income, poverty rate, food insecurity, and average GHG emission intensity are expressed as percentage changes compared to the baseline

3) Negative figures show a percentage decrease in an indicator compared to the base scenario

4) 1 TSh was equivalent of 0.0006 USD at the time of data collection.

Table 10. Sensitivity analysis: Decrease in the quality of the feed by 10 percent (Ruminant model scenario = Improved livestock diets plus increased feed amounts)

\begin{tabular}{|c|c|c|c|c|c|c|c|c|}
\hline \multirow[t]{2}{*}{ Indicators } & \multirow{2}{*}{$\begin{array}{l}\text { Stratum } \\
\text { (type of farm) }\end{array}$} & \multirow{2}{*}{$\begin{array}{l}\text { Base } \\
\text { system }\end{array}$} & \multicolumn{6}{|c|}{ Improved systems } \\
\hline & & & Scenario 1 & Scenario 2 & Scenario 3 & Scenario 4 & Scenario 5 & Scenario 6 \\
\hline \multirow[t]{3}{*}{ Predicted adoption rate (\%) } & 1-Only local cattle & $\mathrm{n} / \mathrm{a}$ & 62.17 & 71.41 & 64.52 & 57.11 & 49.43 & 58.32 \\
\hline & 2-Only improved cattle & $\mathrm{n} / \mathrm{a}$ & 74.66 & 90.58 & 89.15 & 87.57 & 85.84 & 87.84 \\
\hline & 3-No cattle & $\mathrm{n} / \mathrm{a}$ & $\mathrm{n} / \mathrm{a}$ & 100.00 & 100.00 & 99.98 & 99.93 & 99.98 \\
\hline \multirow{3}{*}{$\begin{array}{l}\text { Average farm income } \\
\text { (USD/year) }\end{array}$} & 1-Only local cattle & 728.00 & 38.66 & 50.20 & 41.32 & 33.38 & 26.43 & 34.59 \\
\hline & 2-Only improved cattle & 1116.00 & 82.25 & 139.58 & 131.91 & 124.38 & 117.00 & 125.58 \\
\hline & 3-No cattle & 324.77 & $n / a$ & 336.73 & 308.96 & 281.23 & 253.50 & 285.67 \\
\hline \multirow[t]{3}{*}{ Food insecurity (\%) } & 1-Only local cattle & 21.66 & -31.95 & -39.34 & -33.70 & -28.35 & -23.27 & -29.18 \\
\hline & 2-Only improved cattle & 13.90 & -9.06 & -28.16 & -25.29 & -22.41 & -19.83 & -22.84 \\
\hline & 3-No cattle & 23.87 & $n / a$ & -83.20 & -81.02 & -78.38 & -75.24 & -76.84 \\
\hline \multirow[t]{3}{*}{ Poverty rate (\%) } & 1-Only local cattle & 92.89 & -8.28 & -7.85 & -8.96 & -6.97 & -5.31 & -7.27 \\
\hline & 2-Only improved cattle & 80.13 & -42.38 & -60.67 & -59.65 & -57.38 & -55.04 & -57.76 \\
\hline & 3-No cattle & 92.95 & $\mathrm{n} / \mathrm{a}$ & -57.04 & -53.37 & -48.88 & -44.09 & -49.62 \\
\hline \multirow{2}{*}{$\begin{array}{l}\text { Methane emission intensity (I } \\
\mathrm{CH}_{4} / \mathrm{l} \text { of milk/year) }\end{array}$} & 1-Only local cattle & 26.71 & -32.48 & -23.77 & -24.61 & -22.00 & -19.28 & -22.44 \\
\hline & 2-Only improved cattle & 23.90 & -28.29 & -62.98 & -62.23 & -60.74 & -59.09 & -60.99 \\
\hline
\end{tabular}

Notes:

1) $n / a$ means not applicable 
2) For the scenarios $(1,2,3,4,5,6)$, average income, poverty rate, food insecurity, and average GHG emission intensity are expressed as percentage changes compared to the baseline

3) Negative figures show a percentage decrease in an indicator compared to the base scenario

4) 1 TSh was equivalent of 0.0006 USD at the time of data collection. 
Although results predict that adoption of improved livestock feeding and improved breeds might improve food security and reduce poverty with net reductions in methane emission intensity, barriers to adoption might hinder uptake. As shown, for example, economic and environmental gains were lower when farm households in all the strata paid for the purchase price of the improved cow breed. Providing access to credit, however, seemed to reduce the barrier to adoption and hence improved the economic and environmental impacts. Similarly, although our study assumes that land allocation remains unchanged, the amount of land owned by households might determine the ability of the household to keep an additional cow. As shown in Table 3, the average farm size is about one hectare. Furthermore, whether farmers will fully gain from improved livestock feeding and breeding will depend on their access to markets.

\section{Discussion and Conclusions}

This study highlighted the utility of the TOA-MD model plus Ruminant model to examine the three pillars of CSA and assess the trade-offs and synergies associated with adoption of improved livestock feeding strategies across diverse farming systems in Lushoto district, Tanzania. We stratified our sample into the following: 1) households that owned local cows only; 2 ) households that owned improved cow breed only; and 3) households that did not own cows. Using our stratification strategy, we combined the Ruminant and TOA-MD model to assess how improved livestock management options can increase productivity hence income, improve food security, and reduce GHG emission intensity.

Our results predicted that adoption of improved quality of livestock diet would increase income for farm households both in stratum 1 and stratum 2. Our prediction showed that while the increase in income substantially reduced poverty for households with improved cow breeds, gains in poverty reduction were modest for households that only owned local cows. Households with only local cows, however, received considerable gains in food security when they improved the quality of the livestock diets. Furthermore, results indicated that expected emissions intensity declined with adoption of improved quality feed with both local and improved breed cows. This finding has important implications for introducing incremental adaptation strategies. Economic gains, in terms of income, poverty, and food security were higher when households improved both the quality and quantity of the feed compared to when only quality was improved. However, no significant difference in emissions intensity was observed between improved quality and improved quality plus increased quantity of feed. We also did not observe significant difference in methane emissions between stratum 1 and stratum 2 with improved 
quality or quality plus quantity. Providing an improved cow breed had greater impacts on methane emissions reduction when farm households improved the quality of livestock diets and increased the amount fed to the livestock. Although there were gains in income, food security, poverty reduction, and methane emission, when households acquired an improved cow breed, impacts were lower when households paid for the cow. Providing access to credit, however, reduced financial constraint. Our results have several important policy implications. First, the evidence presented here suggests the need to promote improved feeding strategies and introduction of more efficient breeds of livestock in order to achieve improved food security, increased productivity, reduced poverty, and reduced methane emissions intensities. Specifically, policies targeting to increase income and improve food security can be beneficial to farm households that own local cows if such households are encouraged to adopt improved livestock diets while those targeting to further reduce poverty should aim to promote adoption of improved cow breeds. Secondly, promotion of improved livestock feeding strategies need to be accompanied by policies or programs that facilitate the adoption of improved breeds. Policies that focus on providing access to credit markets are required in order to ease liquidity constraints that often limit smallholder farmers from adopting improved technologies. However, this does not necessarily imply a complete shift to improved breeds as evidence from literature shows that local breeds are better adapted to drought conditions (Scarpa et al., 2003). Thirdly, for farm households that do not own cattle, there are trade-offs involved because shifting non-cattle producers to dairy production implies a net increase in GHG emissions. At the same time, introducing improved breeds to non-cattle producers has a considerable positive impact on income. It seems, therefore, that while shifting non-cattle producers to dairy production might not present a triple win, it is a path to reach the triple win if accompanied by other interventions.

Furthermore, there are other barriers to adoption, like farm size. Although our analysis did not account for issues of carrying capacity, we know that small farms may have issues with increasing herd sizes due to the limited land available. Future research should, therefore, incorporate the effects of changing land allocation as a key aspect when simulating impacts of improved feeding and breeding strategies. Our study provides a first attempt to combine economic and livestock simulation methods in prioritizing climate smart feeding strategies using a minimum data approach. A few points are, however, worth pointing out. First, we acknowledge that although parsimonious, accurate data to fully characterize farming systems is important in estimating ex-ante impacts using TOA-MD. Specifically, capturing heterogeneity in net-returns remains an important requirement of the model. Future data collection efforts and research should work towards an improved approach to capture the heterogeneity of milk 
production in a population of farms to allow estimation of the distribution of greenhouse gas produced in the same population and, therefore, estimate the economic versus environmental tradeoffs more accurately. Secondly, our study makes several assumptions in simulating impacts of improved livestock feeding strategies. It is, therefore, important to interpret our results within the assumptions that we make. We acknowledge, for example, that smallholder farmers might not always behave to maximize economic returns, and that crop-livestock interactions are an important component of farming systems in SSA. In conclusion, we believe this study can help to assess the multiple trade-offs of selected CSA practices and sustainable intensification options to identify triple win situations. 
Chapter 5

Agricultural intensification scenarios, household food availability and greenhouse gas emissions in Rwanda: Ex-ante impacts and trade-offs

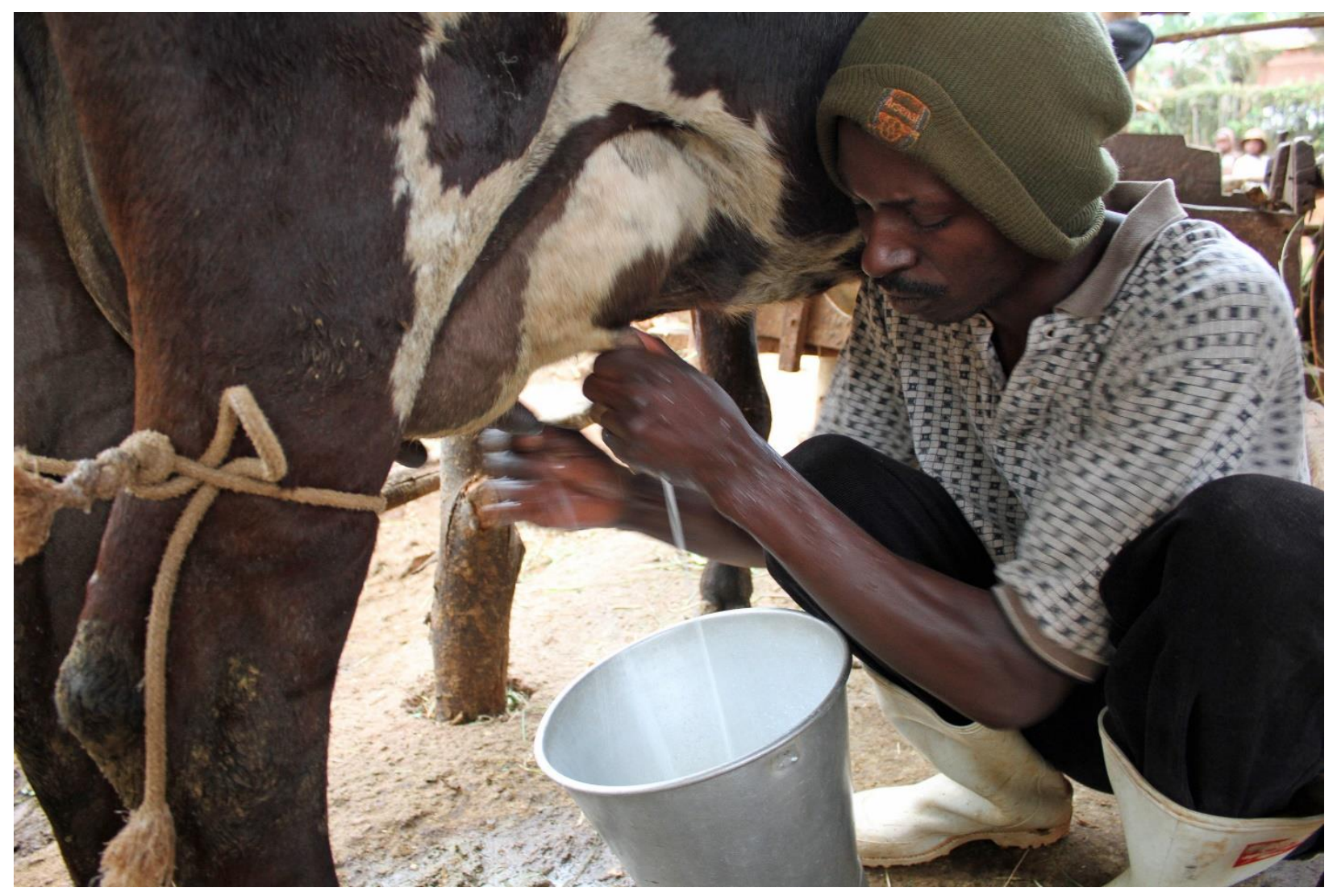

This chapter is published as:

Paul, B.K., Frelat, R., Birnholz, C., Ebong, C., Gahigi, A., Groot, J.C.J., Herrero, M., Kagabo, D., Notenbaert, A., Vanlauwe, B., van Wijk, M. (2018). Agricultural intensification scenarios, household food availability and greenhouse gas emissions in Rwanda: ex-ante impacts and trade-offs. Agricultural Systems, 163, 1626. 


\section{Introduction}

Agriculture is the backbone of Rwanda's economy, involving more than $80 \%$ of the population, and contributing 30\% to the country's Gross Domestic Product (GDP). In Rwanda's Vision 2020, agriculture is considered one of the major potential catalysts for employment creation and transformative growth (MINECOFIN, 2000). 46.3\% of the country's total land area (2.6 million ha) is arable, and main crops include beans, cassava, wheat, maize and rice. Permanent crops such as citrus, coffee and rubber, flowering shrubs, fruit trees, nut trees and vines occupy 9.5\% of the country's surface (NISR, 2014). However, Rwanda's agricultural sector is facing challenges of increasing environmental degradation, resulting in declining productivity. $34 \%$ of surveyed households said they are facing problems caused by environmental degradation, with erosion, reduced agricultural production and destructive rains being mentioned most often (NISR, 2011). The problem would be further aggravated by the growing population. If the current population growth rate of $2.8 \%$ sustains, Rwanda will reach 26 million inhabitants by 2050, translating to a population pressure of 1000 people per $\mathrm{km}^{2}$.

Globally, agriculture is a principal source of climate change, directly contributing $14 \%$ of anthropogenic greenhouse gas (GHG) emissions and another 17\% through land use change. The majority of future increases in agricultural emissions are expected to take place in low- to middle-income countries (Smith et al. 2007). While industrialized countries have to dramatically reduce current levels of GHG emissions, developing countries face the challenge of finding alternative, low carbon development pathways. Climate-smart agriculture (CSA) is seen as one of these pathways, aiming at transforming agricultural systems towards the triple win of increased food security, climate change adaptation, and mitigation. However, it has been recognized that in developing countries, mitigation should be considered as a cobenefit while priority lies with food security and adaptation (Campbell et al., 2014; Lipper et al., 2014). CSA is complementary with sustainable intensification (SI), which aims at increasing agricultural productivity from existing agricultural land while lowering its environmental impact. Increased resource use efficiency contributes to SI as well as CSA through increased productivity and reduced GHG emissions per unit output (Campbell et al., 2014). CSA and SI both acknowledge the importance of potential trade-offs between agricultural production and environmental integrity. A better understanding of these trade-offs is needed to reach a more productive and sustainable agricultural sector (Kanter et al., 2016; Klapwijk et al., 2014a; Steenwerth et al., 2014).

The government of Rwanda has recognized the dual challenge of food security and environmental sustainability and has, therefore, put emphasis on generating an integrated suite of agricultural and 
environmental strategies, policies, institutions and funds. The Strategic Plans for the Transformation of Agriculture (PSTA-III, 2014 - 2017) (MINAGRI, 2009a) and Rwanda's Vision 2020 (MINECOFIN, 2000) are designed to guide the fundamental transformation of Rwanda into a middle-income country by 2020. One of the six pillars of Vision 2020 is a Productive and Market Oriented Agriculture, with Sustainable Natural Resource Management as cross-cutting theme (MINECOFIN, 2000). The cross-sector national strategy on Green Growth and Climate Resilience adds the environmental dimension, calling to address poverty and climate change concurrently (MINIRENA, 2011). Well-known agricultural policy programs aiming to implement the strategic aspirations are the Crop Improvement Program (CIP), which supports access to mineral fertilizer and improved seeds (MINAGRI, 2011); the Girinka program which provides crossbred cows to poor farmers under a pass-on system of payment and wealth transfer (MINAGRI, 2006); and the strategy for animal nutrition improvement which calls for adequate on-farm mix of forage legumes and grasses and concentrate feeds under zero grazing (MINAGRI, 2009b).

Ex-ante impact assessment can help decision-makers in targeting and upscaling technological interventions. Farm household models have often been used for this purpose, although integrated analyses of food security at household level are still scarce (Van Wijk et al., 2014). A standard approach is to capture the diversity of farming systems with a limited number of farm types, often using resource endowment or production goals as clustering factors (e.g. Tittonell et al., 2010). Potential impacts are quantified for these farm types, and scaled up to population level by using information on the relative importance of each type. This study takes an alternative approach to assess potential impacts of policyoriented scenarios on food availability and GHG emissions across different agro-ecologies in Rwanda. Instead of focusing on a few representative farm types, we apply relatively quick and simple calculations across a large number of households. The objectives of this study are therefore to i) quantify the baseline contribution of crops, livestock and off-farm activities to household food availability and GHG; ii) assess differences in contributions within and between locations and food availability classes; iii) and determine the impact, synergies and trade-offs of crop and livestock intensification policies on food availability and GHG.

\section{Materials and Methods}

\subsection{Baseline household survey and study sites}


A household survey was conducted in June - December 2006 by the Consortium for Improvement of Agriculture-based Livelihoods in Central Africa (CIALCA) in Rwanda, DR Congo, and Burundi. In Rwanda, 911 households were surveyed across different administrative units and agro-ecologies (Figure 1). The Birunga and Congo Nile Watershed Divide (CNWD) are highland areas between 1,900-2,500m, with abundant rainfall, highly weathered soils, and expansive forest cover. The Bubereka highlands are a plateau at 2,300 m altitude, and soils are generally more fertile than in the CNWD. The Central Plateau is a large region of hills and valleys of an average altitude of 1,700 $\mathrm{m}$ and annual rainfall of 1,200 mm, and its soils are suitable for a wide range of crops. The Eastern Plateau \& Peripheral Bugesera are the extensions of the Central Plateau into the drier East, with a hilly topography and moderate agricultural potential. The Eastern Savanna \& Central Bugesera include the lowlands in the East $(1,250-1,600 \mathrm{~m})$ with $850-1,000 \mathrm{~mm}$ annual rainfall, and the agricultural potential is lower. The Imbo area is characterized by high temperatures, abundant rainfall, good quality alluvial soils and possibilities for irrigation, which makes it conducive for intensive agriculture (Figure 1; Verdoodt and Ranst, 2003). The survey collected quantitative information on the socio-economic status of households, agronomic characteristics of the farming system, market access and commercialization of crops, food security status and nutrition, and health of the household members (Ouma et al., 2012). 27 outliers were excluded from the analysis due to unrealistic fertilizer and crop production values, or missing cropland area data. The final database contained data of 884 households: 190 households in Bugesera, 200 in Kirehe, 196 in Nyagatare (all Eastern Province), 99 in Karongi, 50 in Rubavu, 50 in Rusizi (all Western Province), and 99 in Ruhango (Southern Province). 


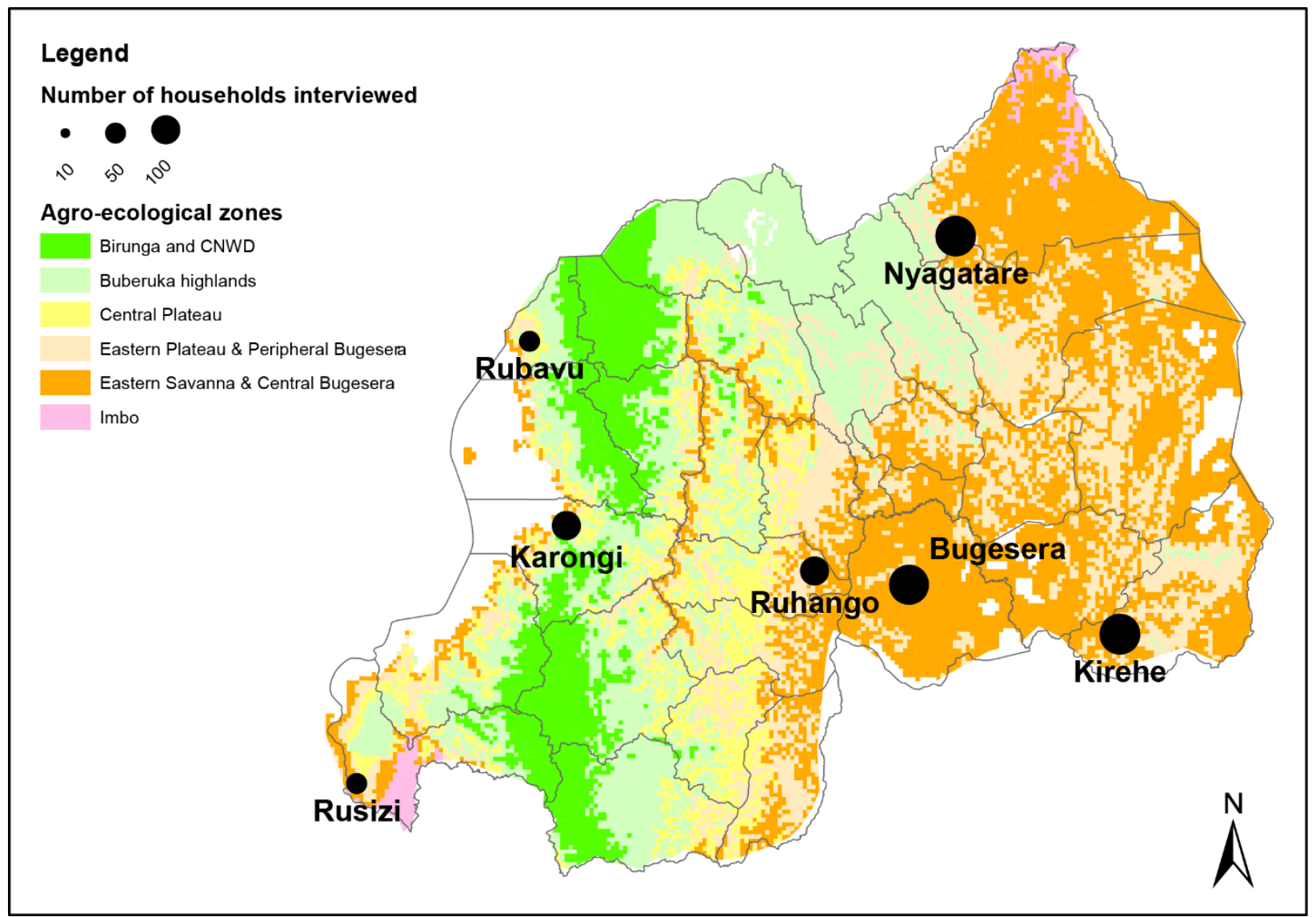

Figure 1: Map of household survey sites across agro-ecological zones in Rwanda. The map is based on Verdoodt and Ranst (2013). See Materials \& Methods (2.1) for a description of the zones which differ in altitude, rainfall and soil properties.

\subsection{Food availability calculation}

Food security encompasses various dimensions including food availability, food access, food utilization and food stability. Food availability, in general, refers to both caloric intake as well as nutritional requirements (Carletto et al., 2013a). In this study, we used a simple proxy for food security, which exclusively focusses on the energy component of food availability. The food availability (FA) indicator was developed from initial work by Hengsdijk et al. (2014), and first published by Frelat et al. (2016) who calculated FA for $>13,000$ households across sub-Sahara Africa. Ritzema et al. (2017) applied it to data from 1,800 households in West and East Africa, illustrating its usefulness for potential impact assessment. FA is a potential supply indicator, representing the daily food energy availability per household member from consumption of farm produce and food purchases with on-farm and off-farm income. The FA indicator does not intend to fully account for all household expenses or nutritional requirements. For this study, seven livelihood components were delineated that contribute to FA within 
and across sites: food crop products (consumed and sold), cash crop products, livestock products (cattle, sheep and goats, poultry), and off-farm income (Figure 2a).

FA is expressed in Potential Food Equivalent energy in kcal (PFE energy) per capita per day and is calculated as

$$
P F E=\frac{E_{\text {cons }}+E_{\text {income }}}{365 \times n_{h h}}
$$

where $E_{\text {cons }}$ is the direct consumption of the PFE energy from on farm food produce in kcal (calculated from Eq. 2), $E_{\text {income }}$ is the indirect consumption of the PFE energy from income (farm sales, off farm) in kcal (calculated from Eq. 3 ) and $n_{h h}$ is the household size in Male Adult Equivalent (MAE; see Equation 5).

The PFE energy from direct consumption of on farm produce is calculated as

$$
E_{\text {cons }}=\sum_{c} E_{c} \times m_{c} \times \theta_{c}+\sum_{l} E_{l} \times m_{l} \times \theta_{l}
$$

where $E_{c}$ is the energy content of the yield of crop $c, m_{c}$ is the yield of crop $c$ in $k g$, and $\theta_{c}$ is the percentage of the yield of crop $c$ consumed. For livestock $E_{l}$ is the energy content of livestock product $I$, $\mathrm{m}_{\mathrm{l}}$ is the produced amount of product $/ \mathrm{in} \mathrm{kg}$, and $\theta_{\mathrm{l}}$ is the percentage of livestock produce / consumed. Energy contents were based on a standard product list developed by the US Department of Agriculture USDA (source: http://ndb.nal.usda.gov/ndb/search/list).

The PFE energy from indirect consumption of food purchased with income is calculated as

$$
E_{\text {income }}=I_{U S D} \times \frac{E_{\text {staple }}}{P_{\text {staple }}}
$$

$I_{u s d}$ is the money earned by the household (by selling farm production and off farm income) in USD (calculated from Eq. 4), $E_{\text {staple }}$ is the PFE energy content of the staple crop (kcal/ $\left.\mathrm{kg}\right), P_{\text {staple }}$ is the price per $\mathrm{kg}$ of the staple crop (USD/kg).

The income earned by the household is calculated as 


$$
I_{U S D}=\sum_{c} \mathrm{P}_{c} \times \mathrm{m}_{\mathrm{c}} \times\left(1-\theta_{\mathrm{c}}\right)+\sum_{\mathrm{l}} \mathrm{P}_{\mathrm{l}} \times \mathrm{m}_{\mathrm{l}} \times\left(1-\theta_{\mathrm{l}}\right)+\Phi
$$

where $P_{c}$ and $P_{I}$ are the price of the crop yield $c$ or livestock product I in USD.kg ${ }^{-1}$, and $\Phi$ is the off farm income (in USD).

Household members were disaggregated by gender and age brackets following FAO (2011) to quantify household size in Male Adult Male Equivalents (MAE), based on energy requirements for members of each age bracket

$$
n_{h h}=\sum_{i} n_{i} \times \alpha_{i}
$$

where $n_{i}$ is number of person in class $\mathrm{I}$, and $\alpha_{i}$ : percentage of energy requirement of class I (compare to the average energy requirement of a male adult, $2500 \mathrm{kcal}$ per day).

The annual production of crops and their use (consumption and sale) were reported by farmers. Cash crops were defined as crops of which more than $90 \%$ of the annual produce is sold. Median price values per crop were used, thus all households were assumed to sell crops at the same price. The survey results showed that beans were the main staple crop in the area, having an energy content of $3400 \mathrm{kcal} / \mathrm{kg}$ ( $E_{\text {staple }}$ in Eq. 3) and a national price of $0.27 \mathrm{USD} / \mathrm{kg}\left(P_{\text {staple }}\right.$ in Eq. 3). Production and consumption of livestock products were not reported in the survey. Instead, we used average production and off-take numbers from Frelat et al. (2016) to estimate milk, meat and egg production per livestock head and year: cattle meat $0.875 \mathrm{~kg}$ (local breed and crossbred); cow milk $340 \mathrm{I}$ (local breed); $680 \mathrm{I}$ (brossbred); sheep and goat milk $0.3 \mathrm{I}$ (local breed and crossbred); sheep and goat meat $1.250 \mathrm{~kg}$ (local breed and crossbred); poultry eggs $0.9 \mathrm{~kg}$; and poultry meat $0.375 \mathrm{~kg}$. $50 \%$ of all livestock produce is assumed to be sold, $50 \%$ to be consumed. It is further assumed that households use the income generated from sales of farm produce or off-farm activities to first cover their reported expenses of crop production, and then to purchase the main staple crop of beans. Due to the lack of reliable data, other household expenses, e.g. for school fees, clothes, or medicine, are not taken into account.

The FA calculation was applied to all 884 households individually. Three FA classes were defined, following Frelat et al. (2016) who showed that the base level of food crop consumption was 1,500 kcal $M A E^{-1}$ day $^{-1}$, while the overall median of FA was roughly 4,000 kcal MAE ${ }^{-1}$ day $^{-1}$. Households with $<1,500$ kcal MAE ${ }^{-1}$ day $^{-1}$ were deemed to have insufficient food available ('low FA class'); households with 1,500 $-4,000 \mathrm{kcal} \mathrm{MAE}^{-1}$ day $^{-1}$ were considered to have sufficient food available ('medium FA class'); and 
households with $>4,000 \mathrm{kcal} \mathrm{MAE}^{-1}$ day $^{-1}$ were seen as having more than sufficient food available ('high FA class'). Results were reported in three different ways: a) FA per individual household (kcal $\mathrm{MAE}^{-1} \mathrm{day}^{-}$ $\left.{ }^{1}\right)$ with percentage of households below the $2500 \mathrm{kcal} \mathrm{MAE}^{-1}$ day $^{-1}$ line (average energy requirement of a male adult); b) median FA ( $\mathrm{kcal} \mathrm{MAE}^{-1} \mathrm{day}^{-1}$ ) per site and/or per FA class; c) contributions (\%) of crop, livestock and off-farm activities to FA.

\subsection{Calculation of greenhouse gas emissions}

The International Panel on Climate Change (IPCC) guidelines contain the most widely accepted scientific methods to quantify GHG emissions. They are divided into hierarchical Tiers $(1,2,3)$ according to methodological complexity and data requirements (IPCC, 2006). The IPCC guideline calculations have previously been used to calculate whole-farm GHG emissions using smallholder household survey data, for example by Seebauer (2014) in Kenya. Figure $2 \mathrm{~b}$ provides an overview of household data used and emission sources considered. Given the limited household data available in this study, the GHG emission calculations followed Tier 1 guidelines for emissions from manure $\left(\mathrm{CH}_{4}\right.$ and direct and indirect $\left.\mathrm{N}_{2} \mathrm{O}\right)$ and soils (direct and indirect $\mathrm{N}_{2} \mathrm{O}$ ). Fertilizer quantities were not directly recorded in the survey, so fertilizer application rates were calculated from annual fertilizer expenses per household, using a cost of 2.4 USD per $\mathrm{kg} \mathrm{N}$ from 2006. Emissions from manure were calculated using default $\mathrm{N}$ excretion rates per livestock species and body weight. Body weight was set to $350 \mathrm{~kg}$ for local cattle, $450 \mathrm{~kg}$ for crossbred cattle, and $400 \mathrm{~kg}$ for other livestock. It was assumed that $80 \%$ of the manure produced was collected, and all applied to fields for fertilization. Manure and fertilizer application rates were used to multiply with default emission factors extracted from the IPCC guidelines (IPCC, 2006). The available survey data was sufficient to follow Tier 2 guidelines for emissions from enteric fermentation $\left(\mathrm{CH}_{4}\right)$ for cattle, and Tier 1 for other livestock. Tier 2 takes into account the gross energy requirements of cattle with an annual milk production of $340 \mathrm{I} \mathrm{yr}^{-1}$ for local cattle breeds and $680 \mathrm{I} \mathrm{yr}^{-1}$ for crossbred cattle. This resulted in calculated emission factors of $20 \mathrm{~kg} \mathrm{CH}_{4}$ head $^{-1} \mathrm{yr}^{-1}$ for local cattle, and $26 \mathrm{~kg} \mathrm{CH}_{4}$ head $^{-1} \mathrm{yr}^{-1}$

for crossbred cattle. Tier 1 default emission factors were used for other animals: $5 \mathrm{~kg} \mathrm{CH}_{4} \mathrm{head}^{-1} \mathrm{yr}^{-1}$ for sheep and goats, $1 \mathrm{~kg} \mathrm{CH}_{4}$ head $^{-1} \mathrm{yr}^{-1}$ for pigs, and no emissions for poultry. We did not compute methane emissions from rice, nor emission from burning residue since both activities were not common among the survey respondents. Given the low levels of fertilizer and industrial feed use, off-farm GHG emissions were not taken into account. Further, we excluded changes in soil organic $\mathrm{C}$ (SOC) stocks from the GHG calculations, assuming a steady-state. Firstly, changes in soil C stocks are slow and only visible in the long-term. Even potentially soil conserving agricultural practices have minimal impacts on SOC 
stocks across many tropical soils in Sub-Saharan Africa (SSA), at least partly due to high decomposition rates (Palm et al., 2014; Powlson et al., 2016). Moreover, modeling of SOC changes is still challenging, especially with limited input data availability. SOC sequestration is a complex process, and any potential increase rates will slow down and cease over time, reaching a new equilibrium state. Therefore, the role of SOC sequestration in GHG balances and global mitigation efforts is limited (Sommer and Bossio, 2014). The GHG calculation was applied to all 884 households individually. Results were reported in three different ways: a) GHG per individual household (calculating $\left.\mathrm{kg} \mathrm{CO}^{\mathrm{e}} \mathrm{hh}^{-1} \mathrm{yr}^{-1}\right)$; b) median GHG (kg

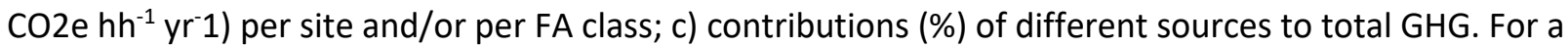
detailed description of the calculations, see Supplementary Material.

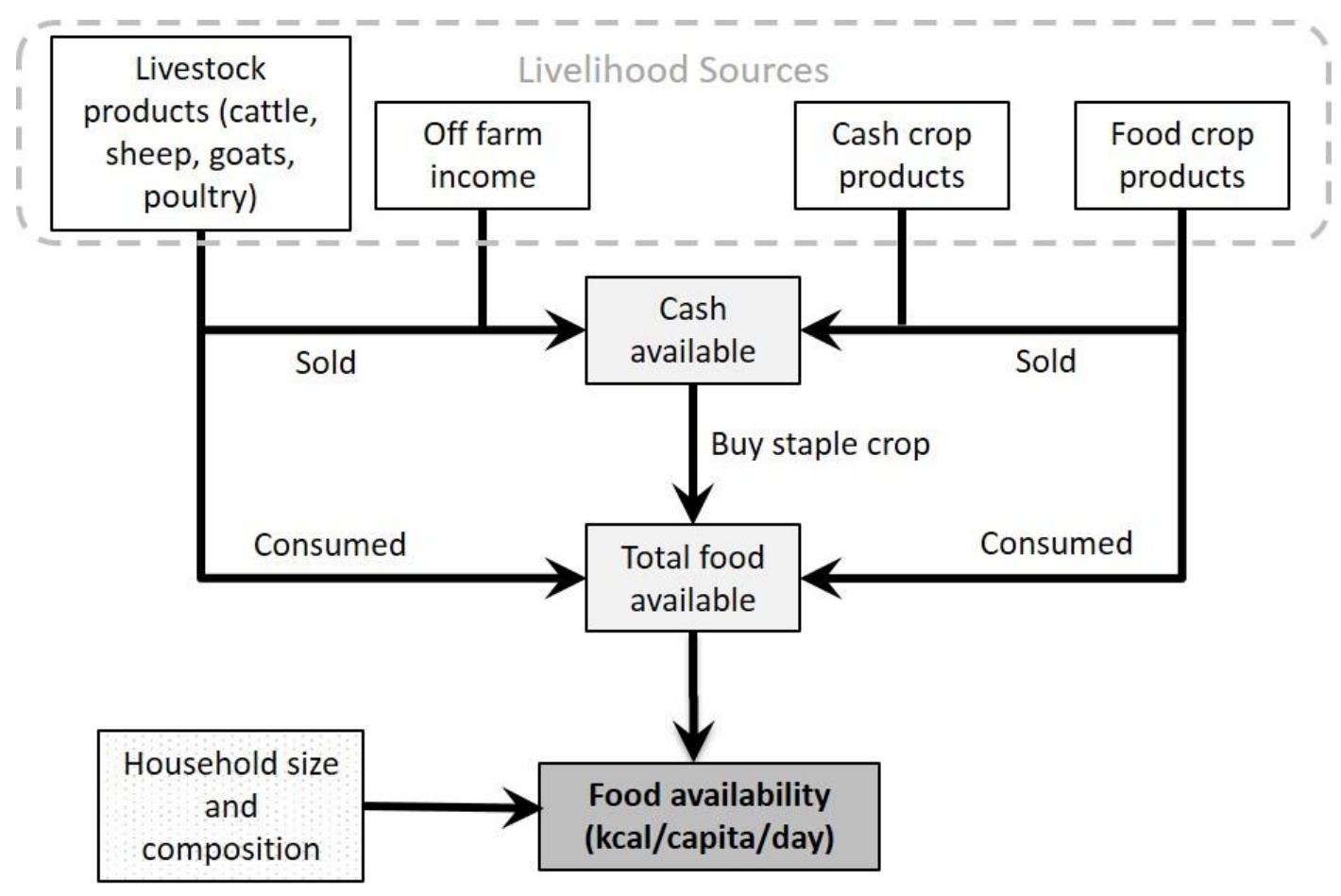






Figure 2: (a) Schematic representation of the FA calculations at household level in energy (kcal) $\mathrm{MAE}^{-1} \mathrm{day}^{-1}$, adapted from Frelat et al. (2016); (b) Schematic representation of GHG calculations at household level in $\mathrm{CH}_{4}$ and $\mathrm{N}_{2} \mathrm{O}$ from enteric fermentation, manure and soil emissions, converted to $\mathrm{CO}_{2} \mathrm{e}$ in the sum.

\subsection{Agricultural intensification scenarios}

The scenarios in this study were closely modeled after key national policy programs, and effect sizes informed by published literature and expert estimations. Table 1 summarizes the key parameters and assumptions for each scenario.

A) Girinka: In 2006, the Government of Rwanda initiated the Girinka program (One Cow per Poor Family) (MINAGRI, 2006). Under Girinka, in-calf crossbred heifers are distributed to vulnerable farmers who pass on the first female calf to a poor neighbor. The program seeks to address malnutrition by increasing rural milk consumption, which currently lies with 13 I person $^{-1} \mathrm{yr}^{-1}$ far below FAO recommended rate of 220 I. Participating households are selected by the community and should own no livestock and less than 0.75 ha land (MINAGRI, 2006). Local cows produce around 2 I day ${ }^{-1}$ during lactation, while crossbreed cows can potentially reach $6 \mathrm{I} \mathrm{day}^{-1}$ (Kamanzi et al., 2012). However, in reality, the poorest Girinka farmers have difficulty feeding their cow, mainly relying on low quality feeds such as collected natural grasses, banana pseudostems, and crop residues. This limits the productivity of crossbred cows 
to $2-4$ I cow $^{-1}$ day $^{-1}$ (Klapwijk et al., 2014b). The Girinka scenario added one crossbred cow to each farm household without cattle and with less than 0.75 ha land. Milk production of the Girinka cows (as for all other crossbred cows) was set to $680 \mathrm{I} \mathrm{cow}^{-1} \mathrm{yr}^{-1}$, using the estimations of Klapwijk et al. (2014b) and Lukuyu et al. (2009), while taking into account gestation and dry periods (Table 1).

B) Improved livestock feeding: Creating a resilient feed resource base and systematic crop-livestock integration are seen as major building stones to reach Vision 2020 (MINAGRI, 2009a). In 2009, the strategic plan for livestock nutrition improvement called for adequate on-farm mix of forage legumes and grasses and concentrate feeds under zero grazing (MINAGRI, 2009a). Restricted grazing has been confined to areas in Nyagatare and Gishwati, and otherwise, only zero grazing or fenced grazing are allowed. Despite these efforts, most of the livestock herd is currently still inadequately fed (Lukuyu et al., 2009; Mutimura et al., 2013). To make optimal use of the limited land resources, high productivity fodder species such as Napier grass (Pennisetum purpureum) and high-quality species such as Brachiaria cv. Mulato /l have been promoted. Mulato // has 12 - 14\% crude protein content, and can be grown on soils with lower fertility and is drought tolerant (Mutimura et al., 2012; 2015). Other options include leguminous forage shrubs such as Leucaena diversifolia. Supplementation with $2.2 \mathrm{~kg}$ leaf meal was shown to increase daily milk yield from 6 to $8 \mathrm{~kg} \mathrm{milk} \mathrm{cow}^{-1}$ day $^{-1}$ (Myambi and Mutimura, 2012). Although land availability for additional forage production is limited in Rwanda, different forage species can be targeted to specific cropping system niches (Umenezero et al., 2016). The improved livestock feeding scenario assumed that local and crossbred milk production increased by 50\% (from 340 to 510 I $\mathrm{yr}^{-1}$ ) and $81 \%$ (from 680 to $1230 \mathrm{I} \mathrm{yr}^{-1}$ ). Implicit in this scenario is that farmers grew the additional fodder necessary without changing current land use and expenses, thus integrating as intercrop or rotation or on previously unused areas of their farm such as boundaries and contours.

C. Soil and crop improvement: In 2007, the Government of Rwanda commenced the Crop Intensification Program (CIP), aiming to increase productivity of six priority annual crops (maize, wheat, rice, potato, beans and cassava) for improved food security and self-sufficiency (MINAGRI, 2011). A major activity under CIP is importation and distribution of subsidized farm inputs through public-private partnerships. In addition, the National Fertilizer Strategy aims to reach an average mineral fertilizer application of 45 $\mathrm{kg} \mathrm{ha}^{-1} \mathrm{yr}^{-1}$ in 2017/18, increasing from an average fertilizer application level of $4.2 \mathrm{~kg} \mathrm{ha}^{-1}$ in $1969-1993$ (MINAGRI, 2014). The soil and crop improvement scenario assumed that $45 \mathrm{~kg} \mathrm{ha}^{-1}$ fertilizer application increases crop yields of CIP priority crops 1) by $100 \%$ for those farm households with no fertilizer expenditure in the baseline study; 2 ) by $50 \%$ for those households that spent $1-6700 \mathrm{RWF} \mathrm{ha}^{-1} \mathrm{yr}^{-1}$ on 
fertilizer; and 3) by $25 \%$ for those households that spent more than $6700 \mathrm{RWF} \mathrm{ha}^{-1} \mathrm{yr}^{-1}$ on fertilizer. Since the most commonly used fertilizers for food crops in Rwanda are NPK (17-17-17), urea (46-0-0) and DAP (46-0-18), we assumed an average overall $\mathrm{N}$ fertilizer content of $35 \%$, thus the $45 \mathrm{~kg}$ fertilizer ha-1 correspond to $16 \mathrm{~kg} \mathrm{~N} \mathrm{ha}^{-1}$. Additional fertilizer expenses for the household were calculated using the conversion of at 2.4 USD per kg N.

Table 1: Key parameters and assumptions of the three study scenarios.

\begin{tabular}{|c|c|c|c|}
\hline & A. Girinka & $\begin{array}{l}\text { B. Improved livestock } \\
\text { feeding }\end{array}$ & C. Soil and crop improvement \\
\hline Parameters & $\begin{array}{l}+1 \text { crossbred cow for } \\
\text { households without cattle } \\
\text { and less than } 0.75 \text { ha of } \\
\text { land at milk production of } \\
680 \mathrm{I} \mathrm{yr}^{-1} \text {. }\end{array}$ & $\begin{array}{l}\text { Milk production increases by } \\
50 \% \text { for local cattle (from } 340 \\
\text { to } 510 \mathrm{I} \mathrm{yr}^{-1} \text { ) and } 81 \% \text { for } \\
\text { crossbred cattle (from } 680 \text { to } \\
1230\left(\mathrm{yr}^{-1} \text { ). }\right.\end{array}$ & $\begin{array}{l}\text { Increase of crop production for maize, } \\
\text { wheat, rice, potato, beans and cassava } \\
\text { due to additional } 45 \mathrm{~kg} \text { fertilizer ha }{ }^{-1} \\
\text { across all households, corresponding to } \\
16 \mathrm{~kg} \mathrm{~N} \mathrm{ha}^{-1} \text {. The crop yield response } \\
\text { depends on baseline fertilizer } \\
\text { application: }+100 \% \text { for households } \\
\text { without previous fertilizer use; }+50 \% \text { for } \\
\text { households with } 1-6700 \mathrm{RWF} \mathrm{ha}^{-1} \mathrm{yr}^{-1} \\
\text { fertilizer expenses; }+25 \% \text { if expenses } \\
\text { exceed } 6700 \mathrm{RWF} \mathrm{ha}^{-1} \mathrm{yr}^{-1} \text {. }\end{array}$ \\
\hline
\end{tabular}

The gift cow can be fed to the extent that it produces $680 \mathrm{I} \mathrm{yr}^{-1}$ at no additional Assumptions costs or change in crop production. The additional milk produced is half sold, half consumed by the household.
The increase of feed does not affect the production of food crops and does not imply additional expenses. The extra milk is half sold, half consumed by the household.
Buying better seeds does not generate extra expenses, but fertilizer purchase results in additional expenses of 2.4 USD $\mathrm{kg}^{-1} \mathrm{~N}$. The extra crop produced follows the same pattern of crop sold vs. crop consumed.

\section{Results}

\subsection{Diversity of farm households}

Median family size varied between 3.8 - 5.0 household members. Median cropping area ranged between 0.6 - 1.3 ha per household, with smallest areas in Rusizi (0.63 ha) and Bugesera (0.79 ha). Median livestock herd size was smallest in Kirehe (0.2 Tropical Livestock Units - TLU) and largest in 
Ruhango (0.93 TLU). Households in Gatsibo and Rubavu did not have any annual expenses for purchase of agricultural inputs, while in Ruhango and Rusizi the median value varied between 380 to 1400 Rwandan Francs (RWF). In all sites, off-farm income was small, with only Rubavu having relatively higher median values (Table 2).

Table 2. Agro-ecological and socio-economic characteristics of the survey districts. Annual rainfall and altitude data was obtained from the closest weather station of the Rwanda Meteorology Agency. Population density for each district was extracted from the 2012 Population and Housing Census and the National Institute of Statistics of Rwanda. All other data was calculated from the household survey and given in median with inter-quartile ranges in brackets. MAE refers to Male Adult Equivalent.

\begin{tabular}{|c|c|c|c|c|c|c|c|}
\hline & Bugesera & Nyagatare & Karongi & Kirehe & Rubavu & Ruhango & Rusizi \\
\hline $\begin{array}{l}\text { Population } \\
\text { density } \\
\left(\text { people } / \mathrm{km}^{2} \text { ) }\right.\end{array}$ & 280 & 242 & 334 & 287 & 1039 & 510 & 418 \\
\hline $\begin{array}{l}\text { Annual rainfall } \\
(\mathrm{mm})\end{array}$ & 854 & 633 & 1089 & 913 & 1205 & 1070 & 1419 \\
\hline Altitude (m) & 1450 & 1450 & 1470 & 1500 & 1554 & 1700 & 1591 \\
\hline $\begin{array}{l}\text { Family size } \\
\text { (MAE) }\end{array}$ & $3.8(2.2)$ & $4.4(2.1)$ & $4.1(2.8)$ & $4.1(2.2)$ & $5(2.9)$ & $4.1(2.1)$ & $4.8(3.4)$ \\
\hline Crop land (ha) & $\begin{array}{l}0.79 \\
(1.6)\end{array}$ & $1(1.2)$ & $1.1(2.1)$ & $1.1(1.6)$ & $1.2(1.7)$ & $1.3(2.3)$ & $\begin{array}{l}0.63 \\
(1.5)\end{array}$ \\
\hline Number of crops & $5(3)$ & $4(3)$ & $5(1)$ & $5(3)$ & $4(2)$ & $6(2)$ & $5(2)$ \\
\hline $\begin{array}{l}\text { Livestock herd } \\
\text { size (TLU) }\end{array}$ & $\begin{array}{l}0.76 \\
(1.2)\end{array}$ & $0.46(1.5)$ & $0.8(1.4)$ & $0.2(0.8)$ & $\begin{array}{l}0.5 \\
(0.67)\end{array}$ & $\begin{array}{l}0.93 \\
(1.8)\end{array}$ & $\begin{array}{l}0.51 \\
(0.95)\end{array}$ \\
\hline $\begin{array}{l}\text { Crop input } \\
\text { expenses (RWF) }\end{array}$ & $0(3900)$ & $0(0)$ & $0(5200)$ & $0(5200)$ & $0(0)$ & $\begin{array}{l}380 \\
(11000)\end{array}$ & $\begin{array}{l}1400 \\
(7300)\end{array}$ \\
\hline $\begin{array}{l}\text { Off farm income } \\
\text { (RWF) }\end{array}$ & $0(15)$ & $0(67)$ & $0(85)$ & $0(39)$ & $46(280)$ & $0(58)$ & $0(27)$ \\
\hline
\end{tabular}

\subsection{Baseline food availability}

The FA indicator, calculated for all individual households, showed a positive relationship with selfassessed status of food security. Respondents of the same household survey were asked to classify their 
own food security status as i) often insufficient food quantity; ii) sometimes insufficient food quantity; iii) sufficient quantity but not the desired type; or iv) sufficient quantity and desired type (Figure 3). Overall, $46 \%$ of all households had less than 2,500 kcal available $\mathrm{MAE}^{-1} \mathrm{day}^{-1}$. Rubavu (30\%) and Ruhango (34\%) had fewest households below the 2,500 kcal line, while Rusizi (52\%) and Bugesera (53\%) had the highest percentages. Ruhango (3600 kcal MAE ${ }^{-1}$ day $^{-1}$ ) and Rubavu (3400 kcal MAE ${ }^{-1}$ day $^{-1}$ ) had the highest median FA, and Bugesera, Kirehe and Rusizi had the lowest (all $3200 \mathrm{kcal} \mathrm{MAE}^{-1}$ day $^{-1}$ ). The main contribution to FA originated from consumed and sold food crops $-81.2 \%$ in the low FA class, $64.3 \%$ in the medium FA class, and $53.1 \%$ in the high FA class. The share of cash crops increased from $2.5 \%$ for the low FA class to $3.5 \%$ for the high FA class. While the contribution of poultry was higher in the low FA class (3.2\%) than in the high FA class $(0.7 \%)$, the contribution of cattle showed the reverse pattern (26.8\% in high FA class, and $5.9 \%$ in low FA class). Off-farm income was more important in the high FA class (15.5\%) than in the low FA class (5.2\%). Off-farm income contributed more to FA in the high FA class in Rubavu (32.0\%) and Kirehe (22.5\%) than in other sites. Cash crops contributed more to FA in Rubavu (6.1 - 7.9\%) than in other sites (Fig. 4a, Fig. 5a). FA was not correlated to land size (Fig. 1 Supplementary Material).

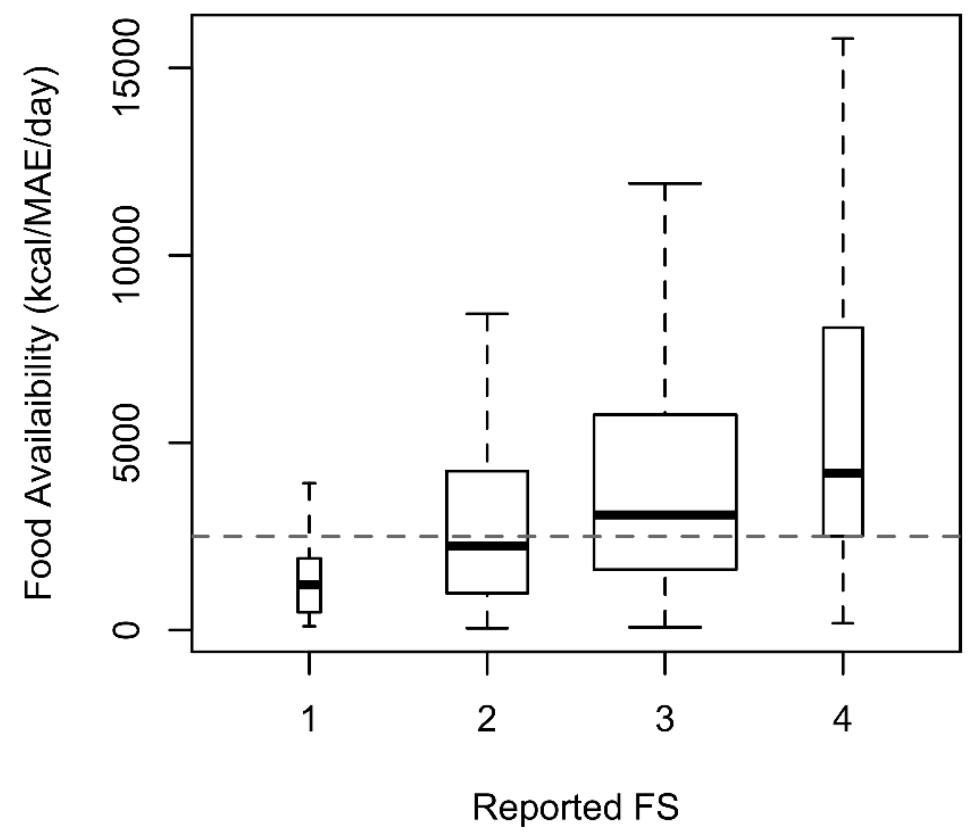


Figure 3: $\mathrm{FA}$ in $\mathrm{kcal}_{\mathrm{MAE}}^{-1}$ day $^{-1}$ compared to self-assessed food security from the same survey to explore confidence of the FA indicator. Respondents were asked to classify their own food security status as: i) often insufficient food quantity; ii) sometimes insufficient food quantity; iii) sufficient quantity but not the desired type; or iv) sufficient quantity and desired type. The red dashed line represents a FA level of 2,500 $\mathrm{kcal}_{\mathrm{MAE}}^{-1} \mathrm{day}^{-1}$, the daily energy need of a male adult.

\subsection{Baseline GHG emissions}

GHG emissions were correlated to livestock, with, on average, 1,360 kg CO${ }_{2}$ e per TLU (Fig. 2

Supplementary Material). Across all sites, the largest contributor to GHG emissions was enteric fermentation (48.7\% low FA, 48.9 medium FA, 47.6\% high Fa), followed by emissions from manure (31.8\%, 27.4\%, 26.7\%), and then direct and indirect emissions from soils (19.5\%, 23.7\%, 25.7\%). 138 households (15.6\% of the study population) did not emit any GHG emissions and are represented by the blank space in Figure 4b. These households did not own ruminants and did not report applying fertilizer or manure to their fields. 53 households (6\% of the population) had very low GHG emissions, remaining $<10 \mathrm{~kg} \mathrm{CO}_{2} \mathrm{e} \mathrm{hh}^{-1} \mathrm{yr}^{-1}$ (Fig 4b). The highest median emissions were calculated for households in Ruhango

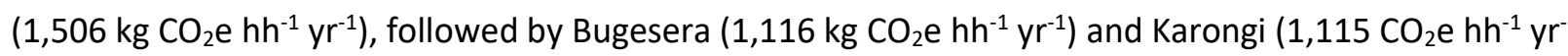
$\left.{ }^{1}\right)$. Lowest median emissions were derived for Kirehe and Rusizi with 395 and $663 \mathrm{~kg} \mathrm{CO}_{2} \mathrm{e} \mathrm{hh}^{-1} \mathrm{yr}^{-1}$ respectively. GHG emissions increased from low FA class to high FA class, with $50 \%$ of the total GHG being emitted by $22 \%$ of the households with the highest FA scores (Figure $4 b, 5 b$ ).

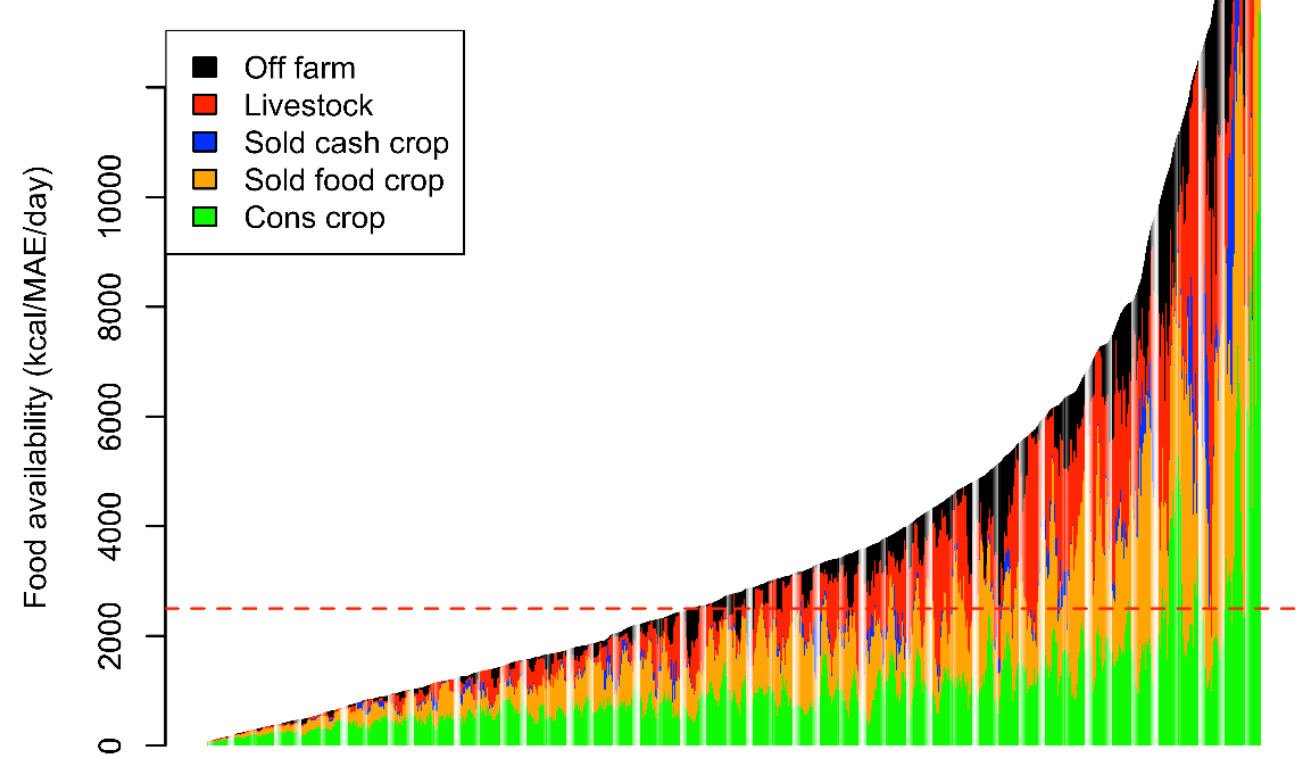




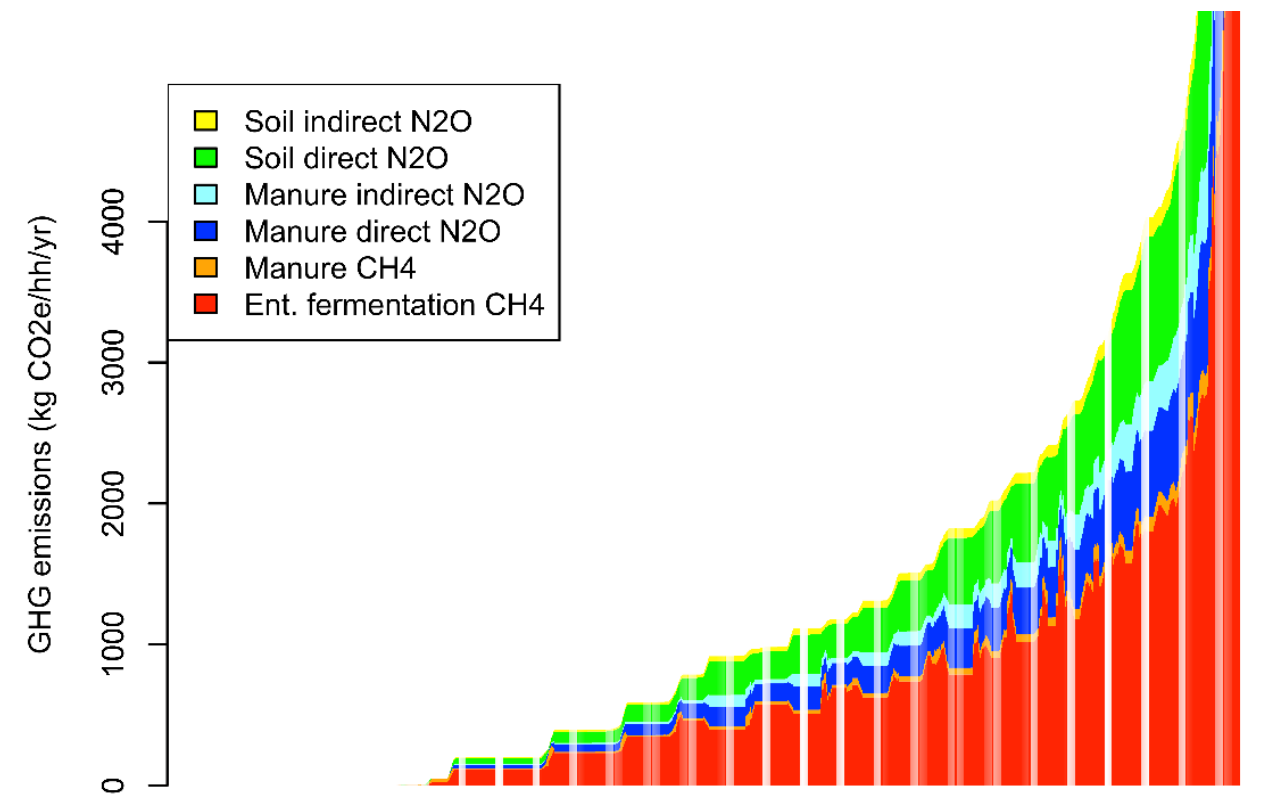

Figure 4: (a) Overall distribution of FA across all study households in Rwanda. Each vertical bar represents one household, the colors represent its sources of energy, and the height represents total FA in $\mathrm{kcal}^{\mathrm{MAE}} \mathrm{M}^{-1} \mathrm{day}^{-1}$. The red dashed line depicts a food availability level of 2,500 kcal MAE $\mathrm{May}^{-1}$, the daily energy need of a male adult; (b) Overall distribution of GHG emissions in $\mathrm{kg} \mathrm{CO}_{2} \mathrm{e} \mathrm{hh}^{-1} \mathrm{yr}^{-1}$ across all sites in Rwanda. Each vertical bar represents one household, the colors represent the sources of GHG emissions, and the height represents the total amount of $\mathrm{GHG}$ in $\mathrm{CO}_{2} \mathrm{e}$.
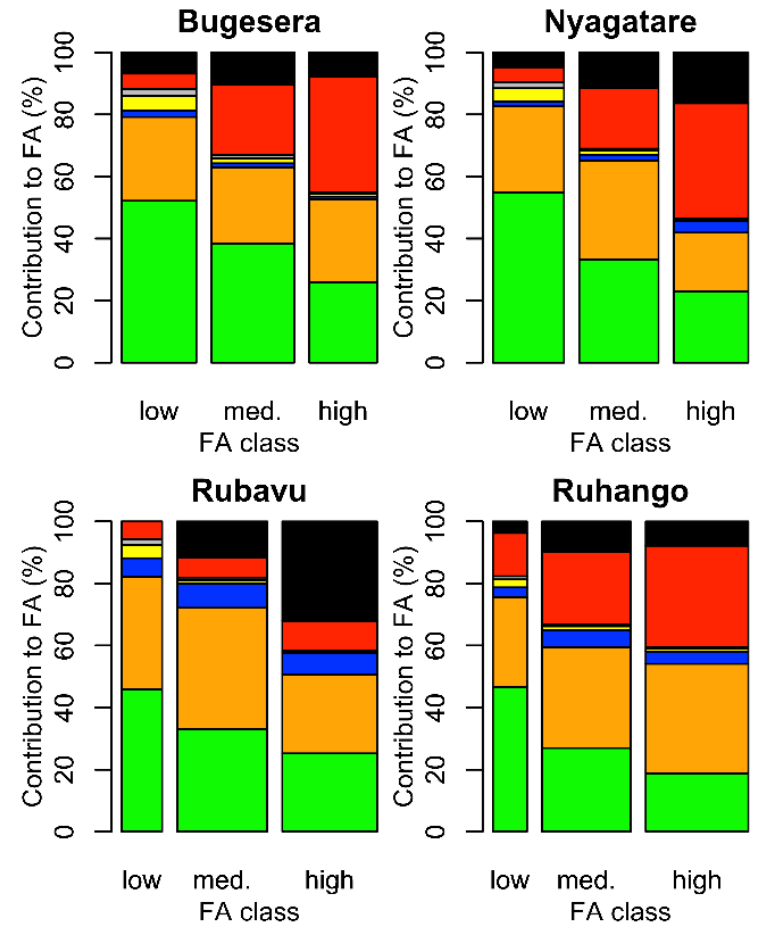
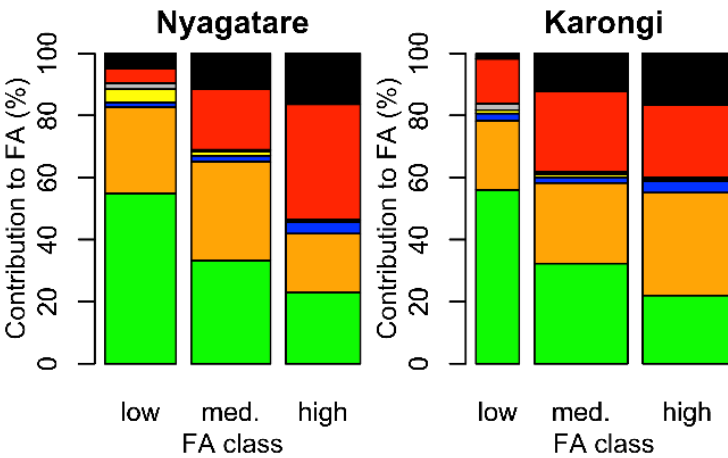

Rusizi



Kirehe



Sources of energy

- Off farm

$\square$ Cattle

$\square$ Sheep and goats

$\square$ Poultry

- Sold cash crop

$\square$ Sold food crop

$\square$ Cons. crop 

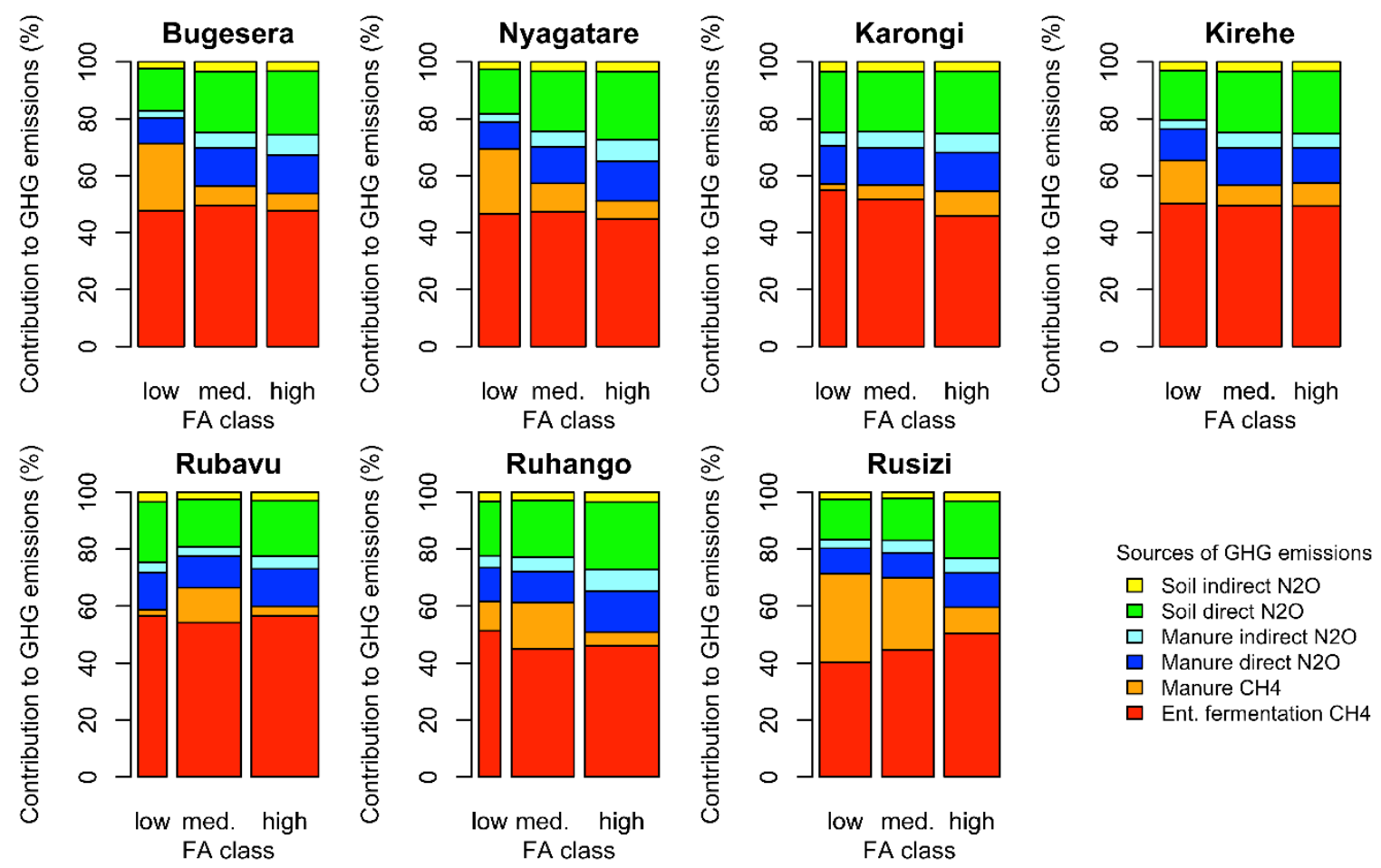

Figure 5: (a) Relative contribution (\%) of household activities to $\mathrm{FA}\left(\mathrm{kcal} \mathrm{MAE}^{-1} \mathrm{yr}^{-1}\right.$ ) per district and FA class. FA classes are defined as follows: low FA class with $<1,500 \mathrm{kcal} \mathrm{MAE}^{-1} \mathrm{yr}^{-1}$, medium FA class with 1,500 $-4,000 \mathrm{kcal}$ $\mathrm{MAE}^{-1} \mathrm{yr}^{-1}$, high FA class with $>4,000 \mathrm{kcal} \mathrm{MAE}^{-1} \mathrm{yr}^{-1}$; (b) Relative contribution (\%) of GHG emission sources to overall GHG per district and FA class. FA classes are defined as follows: low FA class with $<1,500 \mathrm{kcal} \mathrm{MAE}^{-1} \mathrm{yr}^{-1}$, medium FA class with $1,500-4,000 \mathrm{kcal} \mathrm{MAE}^{-1} \mathrm{yr}^{-1}$, high FA class with $>4,000 \mathrm{kcal} \mathrm{MAE}^{-1} \mathrm{yr}^{-1}$. Households with no GHG emissions were omitted from this graph.

\subsection{Scenario assessment and trade-offs}

The effects of the three policy scenarios on FA and GHG emissions varied between sites and FA classes. Girinka only affected $26 \%$ of all households, but $49 \%$ within the low FA class. The scenario decreased households below the $2,500 \mathrm{kcal} \mathrm{MAE}^{-1} \mathrm{yr}^{-1}$ line from $46 \%$ to $35 \%$, leading to a median net increase of $1843 \mathrm{kcal} \mathrm{MAE}^{-1} \mathrm{yr}^{-1}$. At the same time, GHG emissions increased by $1174 \mathrm{~kg} \mathrm{CO}_{2} \mathrm{e} \mathrm{hh}^{-1} \mathrm{yr}^{-1}$. Improved livestock feeding reached $42 \%$ of all households, though only $10 \%$ in the low FA class and $66 \%$ in the high FA class. The scenario decreased the overall proportion of households below 2,500 kcal MAE $\mathrm{Mr}^{-1}$ from $46 \%$ to $43 \%$, leading to a median net increase of $755 \mathrm{kcal} \mathrm{MAE}^{-1} \mathrm{yr}^{-1}$. GHG emissions increased by $50 \mathrm{~kg} \mathrm{CO}_{2} \mathrm{e} \mathrm{hh} \mathrm{yr}^{-1}$. Soil and crop improvement affected $94 \%$ of all households with equally high shares $(91-96 \%)$ in all FA classes. The scenario reduced the percentage of population below the 2,500 kcal line from $46 \%$ to $40 \%$, leading to a median net increase of $322 \mathrm{kcal} \mathrm{MAE}^{-1} \mathrm{yr}^{-1}$. GHG emissions increased by $23 \mathrm{~kg} \mathrm{CO}_{2} \mathrm{e} \mathrm{hh}{ }^{-1} \mathrm{yr}^{-1}$ (Figure 6). Figure 7 underlines trade-offs between FA and GHG emissions, which 
varied across scenarios. Households that were not affected by a scenario are displayed as dots, while changes from baselines to scenario outcomes are denoted as arrows. While Girinka did not affect the majority of the households, it sharply increased both FA and GHG emissions for the impacted households, which originally had low GHG emissions (long and steep arrows). Improved livestock feeding did not affect many of the low FA households, but it increased FA for those impacted accompanied by only a minimal increase in GHG emissions (short and flat arrows). Soil and crop improvement affected almost all households (hardly any dots) with highly variable responses in FA and GHG (short and long arrows, and steep and flat arrows) (Figure 7).
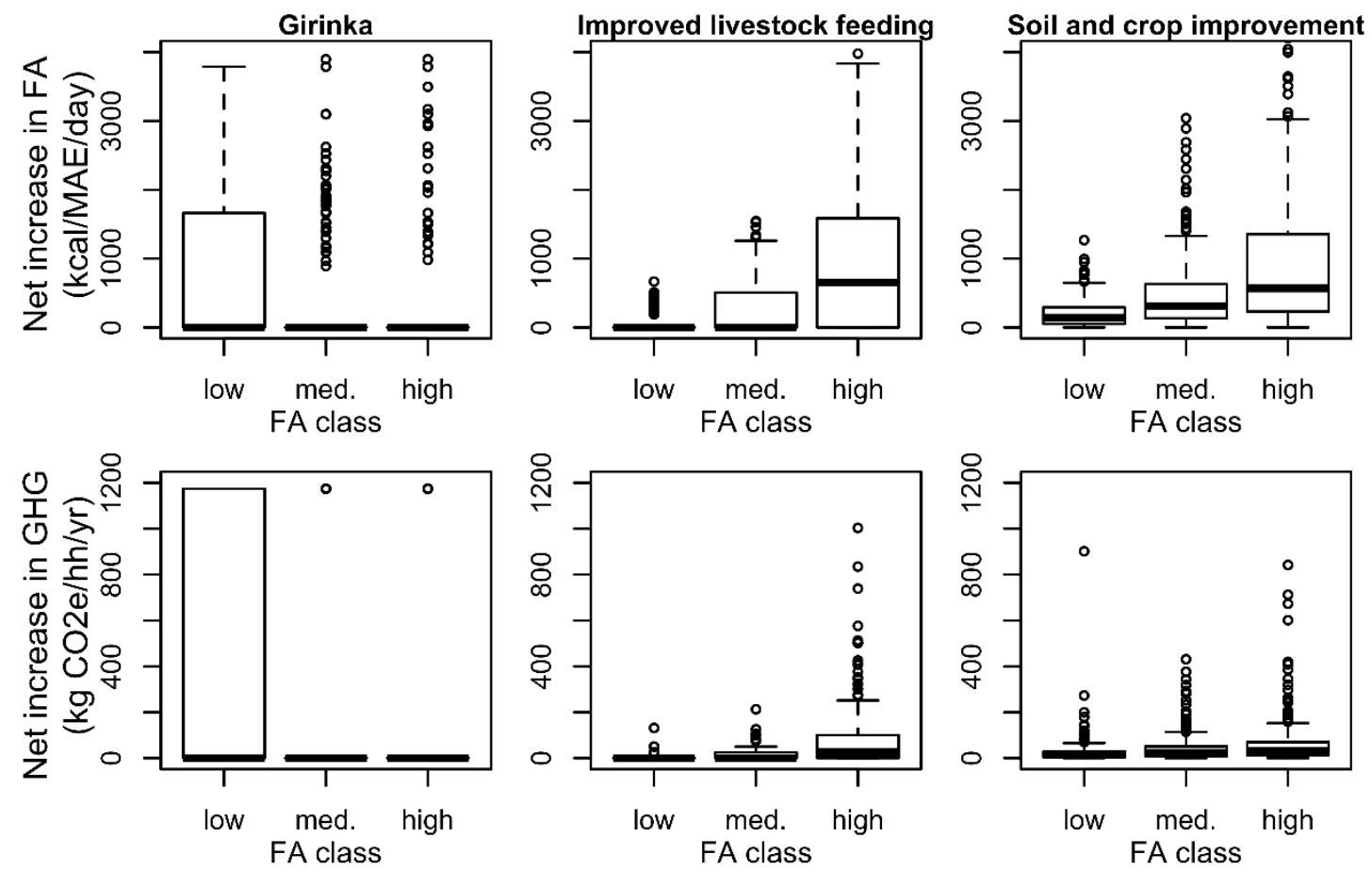

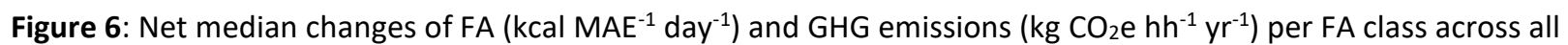
districts for the different policy scenarios Girinka, improved livestock feeding, and soil and crop improvement. FA classes are defined as follows: low FA class with $<1,500 \mathrm{kcal} \mathrm{MAE}^{-1} \mathrm{yr}^{-1}$, medium FA class with 1,500 - 4,000 kcal $\mathrm{MAE}^{-1} \mathrm{yr}^{-1}$, high FA class with $>4,000 \mathrm{kcal} \mathrm{MAE}^{-1} \mathrm{yr}^{-1}$. 

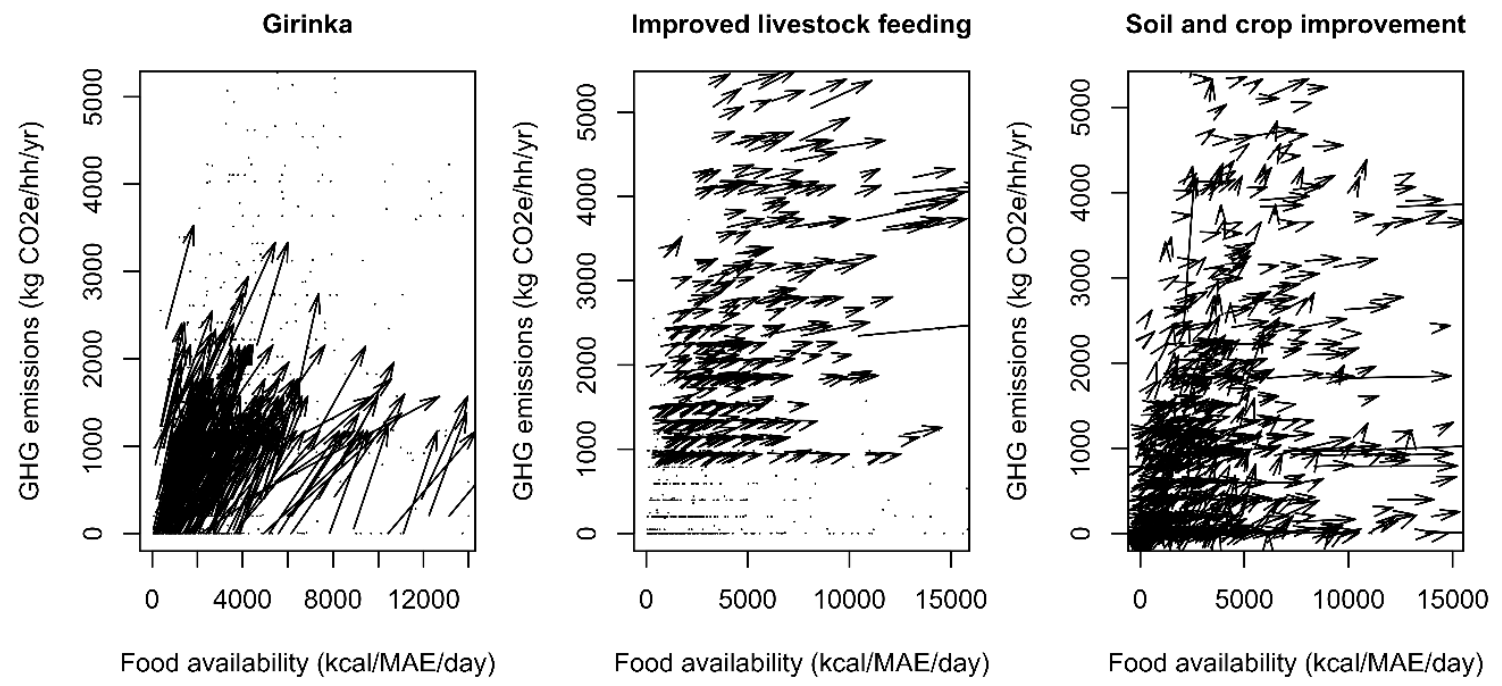

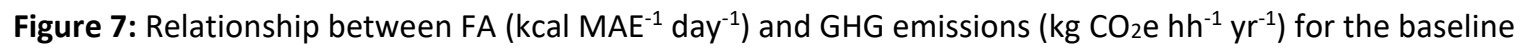
(beginning of the arrow) and the different policy scenarios Girinka, improved livestock feeding, and soil and crop improvement (end point of the arrows).

\section{Discussion}

\subsection{Data limitations}

Farmer-reported data, as used for this analysis, has its inherent limitations. Carletto et al. (2013b) compared farmer-reported farm sizes with empirical measurements. They showed that farmers with small land holdings ( $<5$ acres) tended to overestimate their land size, while farmers with larger land holdings ( $>5$ acres) underestimated the same. However, the differences balanced out, resulting in an only $3 \%$ overall discrepancy. Similar effects could be expected for farmer-reported crop and livestock yields that we used in this study. Although errors in farmer-reported data are high, it is the best method available to date to analyze large household populations.

\subsection{Determinants of food availability}

Following the correlation between calculated FA and self-assessed food security from the same survey (Figure 3), we conclude that the FA indicator gives reasonable insight into variations in overall food security status across individual farm households, despite the strong underlying assumptions and simplifications. This corroborates findings of Frelat et al. (2016) and Hammond et al. (2017) who showed that the FA indicator correlated well with self-scoring of food security, the USAID Hunger and Food Insecurity Status indicator and household level diet diversity. Although FA is a potential supply indicator 
only and not necessarily reflecting full food security status, Hammond et al. (2017) also illustrated how households with at least 4,000 $\mathrm{kcal}_{\mathrm{MAE}}^{-1} \mathrm{day}^{-1}$ can qualify to be effectively food secure. The FA indicator has been found useful for quantifying key determinants of food availability in systems where agricultural productivity is one of the key limiting factors (Frelat et al., 2016; Ritzema et al,. 2017).

The small land sizes and low livestock ownership were reflected in low FA scores (Figure 4a, 5a). 46\% of the population remained below the $2500 \mathrm{kcal} \mathrm{MAE}^{-1} \mathrm{day}^{-1}$ line, which is comparable to other sites in East and West Africa like Lushoto (Tanzania), Wote (Kenya), Lawra (Ghana) or Borana (Ethiopia) (Ritzema et al., 2017). However, $46 \%$ is higher than $37 \%$ obtained from analyzing more than 13,000 households across sub-Saharan Africa (Frelat et al., 2016). However, the dataset used for this study originates from 2006, and food availability has likely been changing since then. Between 2006 and 2011, the standard of living for Rwandans has considerably improved, with the most drastic poverty reduction in the Northern Province (NISR, 2011). Rwanda's Vision 2020 aspires to reduce the poverty rate to $30 \%$ in 2020, and increase caloric consumption to $2200 \mathrm{kcal} \mathrm{day}^{-1}$ person $^{-1}$ (MINECOFIN, 2000).

The Southern (Rusizi) and Eastern (Bugesera, Kirehe, Gatsibo) parts of the country showed lower FA than the North (Rubavu) and South-West (Karongi, Ruhango) (Figure 5a). Ruhango benefits from its proximity to Kigali as well as its central location, opening up economic opportunities such as trade. Karongi has access to income from fishing in Lake Kivu. Bugesera, Kirehe and Gatsibo suffer from low soil fertility, acidic soils and pronounced dry spells. These findings are largely in line with research from the National Institute for Statistics in Rwanda (NISR, 2011), which reported the highest poverty levels in the Southern province and lowest close to Kigali. Despite the differences between the regions, we found consistent patterns in the factors determining FA: Food crops, consumed or sold, were the mainstay of food availability in Rwanda, regardless of FA class or site. Higher FA positively correlated with livestock owning, off-farm income, and cattle numbers, pointing to potential pathways out of poverty. Cash crops played a negligible role in Rwanda's FA, and possible reasons could include lack of land and investments in value chain development that would be needed to let them play a comparable role as in Western Kenya and North Eastern Tanzania (Ritzema et al., 2017). The NISR survey (2011) further confirmed the crucial role of off-farm job creation for poverty reduction, measuring highest poverty among those exclusively relying on agricultural income. It also showed that increases in agricultural productivity and livestock ownership in especially the Northern, Eastern and Western provinces contributed considerably to poverty reduction. Little progress was made in the poor Southern Province (NISR, 2011).

\subsection{GHG emission determinants}


Farm level GHG emissions in Rwanda were highly correlated with livestock ownership (Fig. 2 Supplementary Material). Households in sites with the highest cattle numbers, therefore, showed the highest $\mathrm{CO}_{2}$ e emissions (Figure 5b). Valentini et al. (2014) assign $61 \%$ of total emissions from SSA to agriculture, forestry and other land use, with $\mathrm{CH}_{4}$ emissions from ruminant enteric fermentation being responsible for a large share of agricultural emissions. A study from Western Kenya confirmed the high contribution of livestock to the overall GHG balance of such smallholder systems (Seebauer, 2014). Also, a rapid assessment for Rwanda found that enteric fermentation was one of the largest contributors to GHG emissions at the national level (Dfid et al., 2009).

However, GHG assessment results need to be interpreted with caution. Firstly, comparability between different assessments is low. Colomb et al. (2013) investigated 18 landscape-scale GHG calculators and although all of them were based on the IPCC guidelines, they differed in scope, calculation method and reporting units (Colomb et al., 2013). Secondly, IPCC Tier 1 was developed for national scale inventories but came into use at farm scale when more data was unavailable. Tier 1 emission factors are mostly derived from OECD country data as empirical measurements from SSA are rare. Due to differences in breeds, climates, feeding and management systems, it became generally acknowledged that IPCC Tier 1 and 2 methods overestimate livestock-related emissions (enteric fermentation, manure) from SSA (Herrero et al., 2013). Recent empirical measurements of $\mathrm{CH}_{4}$ and $\mathrm{N}_{2} \mathrm{O}$ emissions from livestock excreta in Kenya confirmed that IPCC Tier 1 methods overestimate fecal $\mathrm{CH}_{4}$ and urine $\mathrm{N}_{2} \mathrm{O}$ by a factor two, and fecal $\mathrm{N}_{2} \mathrm{O}$ even 10 - 20-fold (Pelster et al., 2016). Therefore, close relation between TLU and total GHG emissions from agricultural activity in Rwanda, therefore, could be, at least partly, a consequence of methodological shortcomings. Until more studies are available to re-define emission factors across different tropical climates and for all GHG emission sources over longer periods, the IPCC guidelines are the best available method to estimate whole farm GHG budgets.

\subsection{Scenario assessment}

Although policy impacts are dynamic and can differ in short and long term, the modeling approach we used is a static, short term exploration of potential impacts of policy scenarios that have no financial or logistical constraints to reach its target group. Our analysis illustrates how intensification scenarios result in different potential impacts and trade-offs between food availability and GHG emissions across the population. 
Girinka reached the smallest number of overall households (26\%), but it specifically impacted the low FA class. Therefore, it achieved the most drastic decrease in households below $2500 \mathrm{kcal} \mathrm{MAE}^{-1} \mathrm{yr}^{-1}(11 \%)$. However, this came at the largest cost in GHG increase due to the increase in animal numbers. While Girinka strongly acted pro-poor, it could hardly be considered climate smart due to the steep increase in GHG emissions. In addition, adding cows to the poorest households would have strong implications for feed availability and labor demands (Klapwijk et al., 2014b).

Improved livestock feeding impacted more households overall (42\%), but mainly within the medium and high FA classes where cattle ownership is more concentrated. Consequently, the decrease of households below $2500 \mathrm{kcal} \mathrm{MAE}^{-1} \mathrm{yr}^{-1}$ was only $3 \%$, making it is the least equitable scenario. The increase in GHG emissions is relatively small, thereby decreasing emission intensity per produced energy. This is in line with another study that showed how improved livestock feeding strategies in Tanzania can decrease $\mathrm{CH}_{4}$ emission intensities while increasing income and food security (Shikuku et al., 2017). Improved livestock feeding is currently considered one of the most promising climate-smart practices. With an accelerated adoption rate, it could considerably contribute towards reaching a triple win between food security, adaptation, and mitigation (Campbell et al., 2014; Lipper et al., 2014).

Soil and crop improvement is the most equitable strategy, affecting almost all households (94\%) equally distributed across all FA classes. Although it decreased households below $2500 \mathrm{kcal} \mathrm{MAE}^{-1} \mathrm{yr}^{-1}$ by $6 \%$, the net median increase in energy availability was lowest of all scenarios ( $322 \mathrm{kcal} \mathrm{MAE}^{-1} \mathrm{yr}^{-1}$ ). The scenario also resulted in the smallest increase in GHG emissions.

These results were obtained by using relatively simple calculation schemes for both food availability and GHG emissions, two of the three pillars of CSA. More detailed model analyses could give more accurate numbers, but this study gives a first insight into the main patterns and major effects of the different intensification scenarios. The approach is also easily applicable across large numbers of farm households and uses relatively easily available information, thereby allowing rapid impact assessment across contrasting systems. This type of analysis is needed for comparative assessment and prioritization of policy options, and scale-up of possible farm household level responses to regional or country levels (e.g. van Wijk, 2014).

\section{Conclusions}

Across all sites, $46 \%$ of households were below the $2500 \mathrm{kcal} \mathrm{MAE}^{-1} \mathrm{yr}^{-1}$ line, with lower food availability in the Southern and Eastern Rwanda. Consumed and sold food crops were the mainstay of food 
availability, contributing between $81.2 \%$ (low FA class) to $53.1 \%$ (high FA class). Livestock and off-farm income were the most important pathways to higher FA. Baseline GHG emissions were low, ranging between 395 - $1506 \mathrm{~kg} \mathrm{CO}_{2} \mathrm{e} \mathrm{hh}^{-1} \mathrm{yr}^{-1}$ per site, and livestock-related emissions from enteric fermentation $(47.6-48.9 \%)$ and manure (26.7 - 31.8\%) were the largest contributors to total GHG emissions across sites and FA classes. GHG emissions increased with FA, with $50 \%$ of the total GHG being emitted by $22 \%$ of the households with the highest FA scores. Scenario assessment of the three policy options showed strong differences in potential impacts: Girinka only reached one-third of the household population but acted highly pro-poor by decreasing the households below the $2,500 \mathrm{kcal} \mathrm{MAE}^{-1} \mathrm{yr}^{-1}$ line from $46 \%$ to $35 \%$. However, Girinka also increased GHG by $1174 \mathrm{~kg} \mathrm{CO}_{2} \mathrm{e} \mathrm{hh}^{-1} \mathrm{yr}^{-1}$, and can therefore not be considered climate-smart. Improved livestock feeding was the least equitable strategy, decreasing food insufficient households by only 3\%. However, it increased median FA by $755 \mathrm{kcal} \mathrm{MAE}^{-1} \mathrm{yr}^{-1}$ at a small GHG increase (50 kg CO $2 \mathrm{e} \mathrm{hh}^{-1} \mathrm{yr}^{-1}$ ). Therefore, it is a promising option to reach the CSA triple win. Crop and soil improvement resulted in the smallest increase in median FA (FA by $755 \mathrm{kcal} \mathrm{MAE}^{-1} \mathrm{yr}^{-1}$ ), and decreasing the proportion of households below 2,500 $\mathrm{kcal}_{\mathrm{MAE}}^{-1} \mathrm{yr}^{-1}$ by $6 \%$. This came only at a minimal increase in GHG emissions ( $23 \mathrm{~kg} \mathrm{CO}_{2} \mathrm{e} \mathrm{hh}^{-1} \mathrm{yr}^{-1}$ ). All policy programs had different potential impacts and trade-offs on different sections of the farm household population. Quick calculations like the ones presented in this study can assist in policy dialogue and stakeholder engagement to better select and prioritize policies and development programs, despite the complexity of its impacts and trade-offs. 
Chapter 6

Agro-environmental trade-offs across smallholder livestock systems in Babati, Northern Tanzania



This chapter is under review as:

Paul, B.K., Groot, J.C.J., Birnholz, C.A., Nzogela, B., Herrero, M., Woyessa, K., Nijbroek, R., A. Notenbaert, Sommer, R., Tittonell, P. Agro-environmental trade-offs across smallholder livestock systems in Babati, Northern Tanzania. International Journal for Agricultural Sustainability. 


\section{Introduction}

Two-thirds of smallholders in eastern and central Africa rely on mixed crop-livestock systems as a source of income and nutrition, employment, insurance, traction or clothing (Herrero et al., 2012). The rise in population and urbanization is expected to result in larger demands for livestock products, which increases pressure on natural resources. Environmental impacts include effects on climate, water, nutrient cycling, biodiversity, land degradation and deforestation (Herrero et al., 2015). In particular, livestock production systems in the region have one of the highest greenhouse gas (GHG) emission intensities, thus GHG per unit livestock product, worldwide (Herrero et al., 2013). Climate-smart agriculture (CSA) is seen as one of the pathways to transform agricultural systems, aiming to sustain food security under climate change, while reducing GHG emissions. Although CSA strives to improve food security, adaptation and climate change mitigation, it acknowledges that not every recommended practice applied in every place can be a triple win. Mitigation in developing countries is seen as a cobenefit, while food security and adaptation are the main priorities (Lipper et al., 2014).

Tanzania has the third largest cattle population in Africa (25 million heads) after Ethiopia and Sudan. $50 \%$ of Tanzanian households keep livestock, contributing 14\% to their income. However, livestock productivity remains low. 98\% of the total cattle herd is indigenous Tanzania Shorthorn Zebu whose adult body weight lies at only $200-350 \mathrm{~kg}$, annual off-take rate at $8-10 \%$, and $400 \mathrm{I}$ milk is yielded per lactation. Milk production in the dry season is only half of the amount produced in the rainy season. Tanzania's current milk consumption of 45 liters person ${ }^{-1}$ year $^{-1}$ is low when compared to Kenya (80 liters), India (68 liters), USA (261 liters), and the FAO recommendation (200 liters) (Katjiuongua and Nelgen, 2014; Kurwijila et al., 2012). Following the ratification of the Paris Climate Agreement in November 2016, Tanzania has committed to reduce GHG emissions by $10-20 \%$ by 2013 , conditional on sufficient financial support. This commitment is anchored in the National Climate Change Strategy (2012) and the Zanzibar Climate Change Strategy (2014) which elaborate adaptation and mitigation options. Agriculture and livestock are sectors for intended adaptation contributions including increasing crop yields and sustainable pasture management systems (United Republic of Tanzania, 2015). Agricultural research for development needs to align closely to policy interests on climate and agriculture at the national and sub-national level. In doing so, research can critically support evidencebased design and implementation of policy, leading to climate-smart development outcomes and impacts (Thornton et al., 2017). 
Several livestock intensification options have been proposed to increase climate-smartness. Feed use efficiency, the amount of dry matter feed required to produce a unit output such as milk or meat, has been identified as key to both increasing livestock productivity and reducing GHG emission intensities. Provision of higher quality and more digestible feed will lower emissions per unit output. Feed rations can be improved through planted forages, energy-dense concentrates, and treatment of low quality feeds such as crop residues. Improved animal management, including improved breeds, animal health, and reproductive management, can drastically increase herd productivity. Manure management and safe storage could reduce emissions as well (Herrero et al., 2016). Planted forage options have been developed and adapted to various agro-ecologies, farming systems and production objectives. In addition to improving feed digestibility, they can increase soil organic carbon (Peters et al., 2013). A combination of such approaches - improved nutrition, management and manure - would result in an increase in productivity, decrease in herd size, and lower overall emissions (Herrero et al., 2016).

Finding a balance between multiple objectives and potential trade-offs, and forging synergies between agricultural production and environmental quality, lies at the heart of CSA (Campbell et al., 2014). The field of agricultural trade-off analysis is growing, for trade-offs operating on many different scales, and affecting different stakeholders (Klapwijk et al., 2014). Since smallholder farming systems in sub-Saharan Africa (SSA) are highly diverse and dynamic, trade-offs play out differently. Understanding and classifying such complexity and diversity is the basis for understanding impacts and trade-offs (Giller et al., 2011; Tittonell et al., 2010). There is a wide array of indicators and metrics to assess productive, economic, environmental and social functions of farming systems, and to evaluate trade-offs between them (Smith et al., 2017). To address those multiple dimensions in one approach, trade-off analysis often employs interdisciplinary, bio-economic models. Multi-objective optimization, in particular, is considered a useful approach as farmers are not ultimate profit maximizers (Kanter et al., 2016). Integrated, systems-oriented impact assessments and realistic consideration of adoption constraints are crucial to informing decisions for improved adaptation and mitigation of mixed crop-livestock systems in Sub-Saharan Africa (SSA) (Descheemaeker et al., 2016).

This study aims to explore climate-smart livestock intensification options that reduce agroenvironmental trade-offs across different smallholder livestock systems in Babati, Northern Tanzania. Specifically, its objectives are to:

i) Describe and classify diversity of livestock feeding and husbandry systems; 
ii) Quantify environmental efficiencies and agro-environmental trade-offs for different livestock systems;

iii) Explore livestock intensification options that reduce agro-environmental trade-offs.

\section{Materials \& Methods}

\subsection{Study area}

Babati is one of the five districts in Manyara region, Northern Tanzania, representing a high agroecological and socio-economic diversity. Altitude ranges from 950 to $2450 \mathrm{~m}$ asl, and precipitation varies between 500 and $1200 \mathrm{~mm}$ year ${ }^{-1}$ (Figure 1). Soils include sandy loams to clay alluvials, have a pH around 6.5, and $\mathrm{P}, \mathrm{S}$ and $\mathrm{Zn}$ availability is generally low. Mineral fertilizer application in the area is insignificant (Kihara et al., 2015). Maize is intercropped with pigeon peas and beans in the long rains from February to May, and beans are planted in the short rains from November to January. A wide range of cash crops are grown, including coffee, sugarcane, cotton, rice, wheat, potatoes, sunflowers, and pyrethrum. In 2012, Babati district had almost 64,000 farming households and 420,000 heads of cattle. $40 \%$ of the population are ethnic Iraqw, and 30-35\% Gorowa, and both communities count as indigenous nowadays. The Iraqw settled in the area 200 years ago from Kenya, when population pressure was low in Babati. Availability of fertile land attracted more in-migration in the 1950s, leading to the high current ethnic diversity. More recently, population pressure has been increasing up to 180200 people per $\mathrm{km}^{2}$, limiting availability of farming land and pasture (Bishop-Sambrook et al., 2004; Hillbur, 2013).

\subsection{Data collection}

Data was collected on three occasions between 2013 and 2017, starting with a rapid household survey among 96 households, followed by a detailed characterization of 12 farming households including tree and soil measurements, and ending with in-depth follow-up discussions with four households that were selected as case studies for the bio-economic modeling:

i) A rapid household survey was conducted from 23 to 26 April 2013 in the villages of Hallu (1224 m asl), Mafuta (1022 $\mathrm{m}$ asl), Shaurimoyo (1002 $\mathrm{m}$ asl), Seloto (1646 $\mathrm{m}$ asl), Sabilo (1664 $\mathrm{m}$ asl), and Long (2154 $\mathrm{m}$ asl) (Figure 1). 96 households (16 per village) were interviewed by eight trained enumerators. The survey focused on assessing farm resources, management strategies, farm productivity and household 
economy, aiming to identify initial entry points for sustainable intensification in Tanzania (Timler et al., 2014).
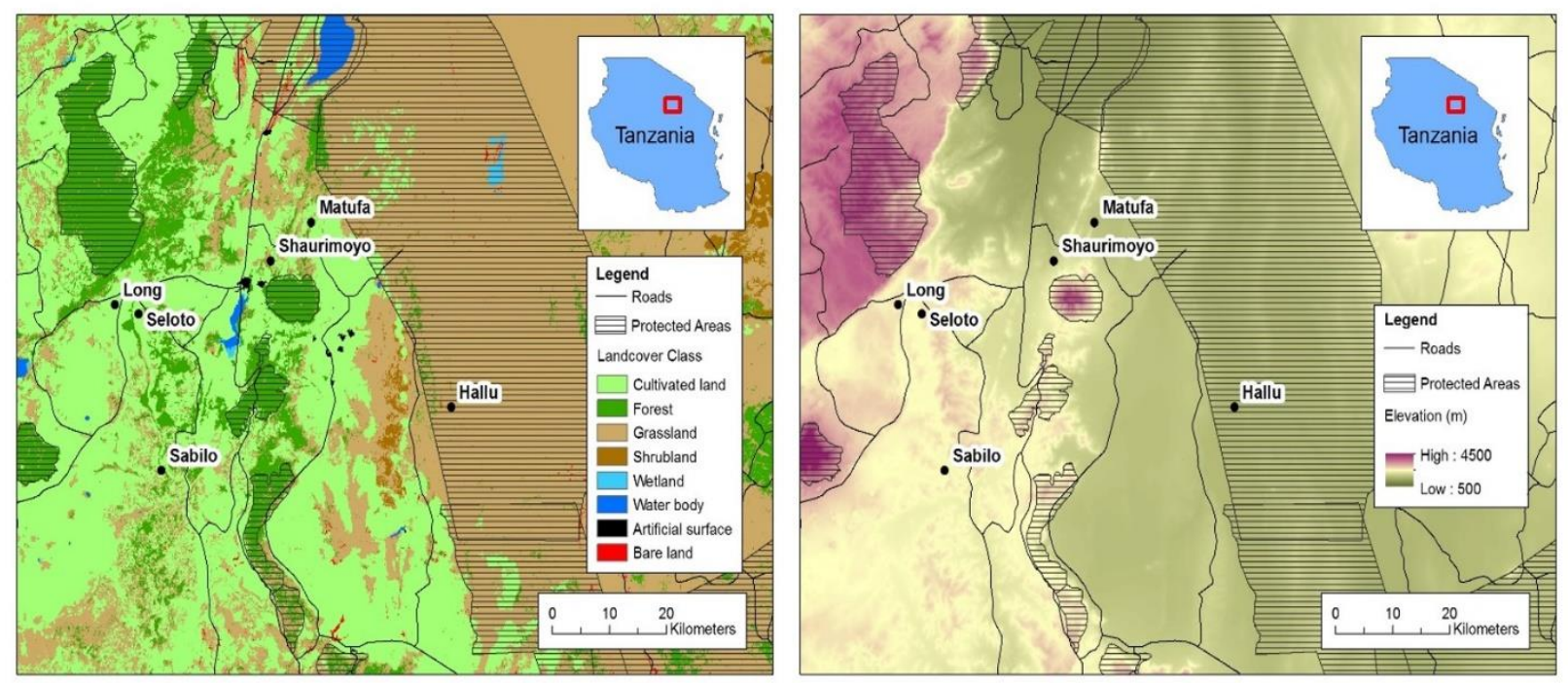

Figure 1: Maps of the six study villages with land cover (left) and elevation (right). Data sources: Land cover (Chen et al., 2014), district boundaries (GADM, 2018), elevation (Jarvis et al., 2008), protected areas (UNEP-WCMC and IUCN, 2016).

ii) A detailed household characterization was implemented from 17 to 27 February 2015. The typology (Section 2.3) was discussed with extension officers in Babati, and found to be adequately representing the existing livestock system diversity. The POULTRY type was omitted as the focus of this study lay on ruminants. From the 96 households of step i), 12 farms were randomly chosen to represent the remaining four types (six households SMALLEST, two DAIRY, two SHOATS, two LARGE LIVESTOCK) across four villages (Hallu, Long, Sabilo, Seloto). Interviews were conducted using the IMPACTlite survey tool (Rufino et al., 2012). A total of 26 topsoil $(0-20 \mathrm{~cm}$ ) composite samples were taken at all 12 farms from different land uses (cropland, grassland and fallow). Trees on the farms were counted and diameter at breast height (DBH) measured if $>2.5 \mathrm{~cm}$. In the case that trees were too remote to measure, only the number of trees was recorded and the average DBH of the farm applied.

iii) Follow-up visits and in-depth discussions took place with one farmer of each type in Hallu (LARGE LIVESTOCK), Long (SMALLEST) and Sabilo (DAIRY and SHOATS), which were purposively chosen among the 12 farmers from step ii) to represent the different types. The discussions followed a semi-structured list of questions and were conducted together with Babati extension officers from the $8^{\text {th }}$ to the $13^{\text {th }}$ of January 2017 , and again from the $13^{\text {th }}$ to the $14^{\text {th }}$ of February 2017 . In addition to evaluating modeling input data, general farming objectives and constraints, and alternative farming technologies were 
discussed that formed narratives around farmers' perspectives on climate-smart livestock intensification options (see Section 2.5).

\subsection{Household data analysis and typology}

Exploratory statistics with the R statistical programming software (R core team, 2013) were conducted on the rapid characterization dataset to describe the general farming systems. A quantitative, multivariate statistics method was used to construct a livestock and feed based typology (Alvarez et al., 2014). Expert knowledge and a literature review resulted in the selection of 12 variables for the typology construction which were extracted or calculated from the dataset (Table 1). Cattle number was closely correlated with total Tropical Livestock Units (TLU) $(R 2=0.93)$ and therefore not included. As multivariate analyses are sensitive to exceptional observations, the dataset was curated for missing and outlying data (Alvarez et al., 2014). The following farms were removed: five farms without livestock (TLU=0), two farms with missing data, and six farms with exceptional data (two farms with $>4$ improved cattle, two farms with >25,000 kg cereal residue fed, one farm with >1000 kg other residue fed, and one farm with $>3000 \mathrm{~kg}$ legume residue fed). A total of 83 out of the original 96 households were retained for analysis. We first ran a principal component analysis (PCA) to reduce the dimension of the dataset, and then used the scores of the PCA to obtain homogeneous groups of farms using hierarchical cluster analysis (Ward method) (e.g. Tittonell et al., 2010). All analyses were executed in R, using the ade4 package (Dray et al., 2007, version 1.6-2) and the cluster package (Maechler et al., 2016).

Table 1: Variables with units used in typology construction. Livestock family labor referred to the total daily family labor required for the livestock herd per farm, excluding hired labor. Purchased concentrates were the sum of locally available, purchased supplements for any livestock type, e.g. maize bran, sunflower cake and maclick. Cereal, legume and other residue fed was computed by multiplying the crop areas per farm with average crop yields, the harvest index per crop, and the farmer-reported percentage of residue fed to livestock.

\begin{tabular}{ll}
\hline Variable & Unit \\
\hline Household size & number \\
Farm size & ha \\
Livestock herd size & TLU \\
Improved cattle & number \\
Local cattle & number \\
Small ruminants & number \\
Poultry & number \\
Cereal residue used as feed & kg FW year ${ }^{-1}$ \\
Legume residue used as feed & kg FW year \\
Other residue used as feed & kg FW year $^{-1}$ \\
Livestock family labor & hours day ${ }^{-1}$
\end{tabular}


Grazing time $\quad$ hour day ${ }^{-1}$

Purchased concentrates $\quad$ kg year $^{-1}$

\subsection{Tree and soil data analysis}

Aboveground biomass of live trees was estimated using the following empirically derived allometric equation from Kuyah et al. (2012):

$$
\mathrm{AGB}=0.091 * D B H^{2.472}
$$

Where AGB is the aboveground biomass in kg dry weight (DW), and $D B H$ tree diameter at breast height in $\mathrm{cm}$. The carbon content of woody biomass was assumed to be $0.48 \mathrm{~kg} \mathrm{C} \mathrm{kg} \mathrm{DW}^{-1}$ (Thomas and Martin, 2012) with which the total carbon (C) stock of trees on farms and per hectare was computed. Annual growth and removal of $\mathrm{C}$ stocks were not taken into account.

The soil samples were air dried and transported to the CIAT soil laboratories in Nairobi, Kenya for analysis. Total $\mathrm{C}$ and nitrogen $(\mathrm{N})$ were analyzed by total combustion technique using an elemental macro-analyzer (Elementar Vario Max Cube). pH was measured in water (1:2.5), soil particle size (sand, silt, clay) by the hydrometer method, and extractable phosphate was determined by Bray-P.

\subsection{Bio-economic modeling}

Four case study farms were simulated with FarmDESIGN, a bio-economic farm model that calculates the impacts of various farm configurations on a large set of agro-environmental and socio-economic performance indicators. Applications of FarmDESIGN in the Netherlands (Mandryk et al., 2014), Zambia (Timler et al., 2017), and Mexico (Cortez-Arriola et al., 2014, 2016; Flores-Sanchez et al., 2011, 2015; Groot et al., 2016) have suggested the model is robust enough to accommodate contrasting farming systems and agro-ecologies. FarmDESIGN has been evaluated in terms of design-, output- and end-user validity. However, uncertainty lies in the quality of input data, as well as parameterization of degradation, nutrient losses and OM breakdown (Groot et al., 2012). The inputs required for the model can be grouped into: i) biophysical environment (e.g. soils, climate); ii) socio-economics (e.g. input costs, labor price); iii) crops and crop products yield, composition and use; iv) livestock and livestock products yield, composition and use; v) manure types and degradation, and mineral fertilizer use; vi) household members and labor availability. We collected input data for the four case study farms during the detailed household characterization (Section 2.3, step ii) and follow-up interviews (Section 2.3, step iii) (Tables A2, A3, A4, A5, A6, Appendix 3), as well as literature-derived or expert-estimated parameters 
(Tables A7, A8, A9, A10, A11, Appendix 4). We aimed to increase quality and validate input data by triangulation through several visits, as well as discussion of data with local experts and extension officers. Farm performance was evaluated in terms of livestock feed balance, organic matter (OM) balance, farm N balance and cycle, GHG emissions, species richness, income, and labor requirements. Species richness relied on the Margalef index (M) by Oyarzun et al. (2013), which was computed from the number of crops and the farm area. Feed balances were calculated for energy and protein by matching available feeds with animal requirements and dry matter intake capacity. Animal requirements were related to body maintenance, growth, pregnancy and milk production. Feed intake was determined by the feed intake capacity saturation value of feeds. We used the Dutch VEM (feed unit milk) and DVE (intestinally degradable protein) systems (Tamminga et al., 1994; van Es, 1975). Household net income calculations included revenues from all crop and livestock production, based on their production and prices minus production costs such as feeding, inputs, hired labor and land (Groot et al., 2012). Prices and costs were reported in Tanzanian Shilling (TSh), and converted to US dollar (USD), using an exchange rate of 2235 TSh. Off-farm income was not taken into account.

A GHG emission estimation module was added to FarmDESIGN, including the following sources: i) methane $\left(\mathrm{CH}_{4}\right)$ from livestock enteric fermentation, ii) $\mathrm{CH}_{4}$ and direct and indirect nitrous oxide $\left(\mathrm{N}_{2} \mathrm{O}\right)$ from manure storage and application, iii) $\mathrm{N}_{2} \mathrm{O}$ from mineral fertilizer application; iv) direct and indirect $\mathrm{N}_{2} \mathrm{O}$ from soils through $\mathrm{N}$ input from crop residue retention, $\mathrm{N}$ fixation and atmospheric deposition, $\mathrm{v}$ ) $\mathrm{CO}, \mathrm{CO}_{2}, \mathrm{~N}_{2} \mathrm{O}, \mathrm{NO}_{\mathrm{x}}$ and $\mathrm{CH}_{4}$ from burning of organic material. Input data on livestock numbers, manure production, crop residue use, and fertilizer and manure application were multiplied with IPCC Tier 1 emission factors (IPCC, 2006) (Table 2). N manure excretion rate was calculated by the model taking into account protein intake by livestock and protein digestibility of the feed basket, so that manure related $\mathrm{N}_{2} \mathrm{O}$ emissions can be considered an IPCC Tier 2 method. Calculated $\mathrm{N}_{2} \mathrm{O}$ and $\mathrm{CH}_{4}$ emissions were converted into $\mathrm{CO}_{2}$ equivalents $\left(\mathrm{CO}_{2} \mathrm{e}\right)$ by multiplying by their respective global warming potentials (GWP) -21 for $\mathrm{CH}_{4}$ and 310 for $\mathrm{N}_{2} \mathrm{O}$.

Table 2: GHG emission factors on an annual production basis. Factors taken from IPCC 2006.

\begin{tabular}{lll}
\hline Emission source & Unit & Factor \\
\hline i) Enteric fermentation & & \\
Crossbred dairy cow & $\mathrm{kg} \mathrm{CH}_{4}$ animal & \\
Local dairy cow & $\mathrm{kg} \mathrm{CH}_{4}$ animal $^{-1}$ & 41 \\
Local adult bull & $\mathrm{kg} \mathrm{CH}_{4}$ animal $^{-1}$ & 31 \\
Steers and heifers & $\mathrm{kg} \mathrm{CH}_{4}$ animal $^{-1}$ & 20
\end{tabular}




\begin{tabular}{|c|c|c|}
\hline Calves & $\mathrm{kg} \mathrm{CH}_{4}$ animal $^{-1}$ & 16 \\
\hline Sheep and goats & $\mathrm{kg} \mathrm{CH}_{4}$ animal $^{-1}$ & 5 \\
\hline Pigs & $\mathrm{kg} \mathrm{CH}_{4}$ animal $^{-1}$ & 1 \\
\hline Poultry & $\mathrm{kg} \mathrm{CH}_{4}$ animal $^{-1}$ & 0 \\
\hline \multicolumn{3}{|l|}{ ii) Manure production } \\
\hline All cattle, pigs & $\mathrm{kg} \mathrm{CH}_{4}$ animal $^{-1}$ & 1 \\
\hline Sheep & $\mathrm{kg} \mathrm{CH}_{4}$ animal $^{-1}$ & 0.15 \\
\hline Goats & $\mathrm{kg} \mathrm{CH}_{4}$ animal $^{-1}$ & 0.17 \\
\hline Poultry & $\mathrm{kg} \mathrm{CH}_{4}$ animal $^{-1}$ & 0.02 \\
\hline \multicolumn{3}{|l|}{ iii) Manure storage and deposition/application } \\
\hline Direct emissions stable and yard manure storage & $\mathrm{kg} \mathrm{N}_{2} \mathrm{O} \mathrm{kg} \mathrm{N}{ }^{-1}$ & 0.01 \\
\hline Indirect emissions stable and yard manure storage & $\mathrm{kg} \mathrm{N}_{2} \mathrm{O} \mathrm{kg} \mathrm{NH}{ }_{3}-\mathrm{N}^{-1}$ & 0.01 \\
\hline Manure deposition during grazing & $\mathrm{kg} \mathrm{N}_{2} \mathrm{O} \mathrm{kg} \mathrm{N}^{-1}$ & 0.02 \\
\hline Manure application to fields & $\mathrm{kg} \mathrm{N}_{2} \mathrm{O} \mathrm{kg} \mathrm{N} \mathrm{kg}^{-1}$ & 0.01 \\
\hline \multicolumn{3}{|l|}{ iv) Soil emissions } \\
\hline Inorganic fertilizer application & $\mathrm{kg} \mathrm{N}_{2} \mathrm{O} \mathrm{kg} \mathrm{N}^{-1}$ & 0.01 \\
\hline Crop residue, $\mathrm{N}$ fixation, atmospheric $\mathrm{N}$ deposition & $\mathrm{kg} \mathrm{N}_{2} \mathrm{O} \mathrm{kg} \mathrm{N}{ }^{-1}$ & 0.01 \\
\hline \multicolumn{3}{|l|}{ v) Burning } \\
\hline Residue burning & $\mathrm{kg} \mathrm{N}_{2} \mathrm{O} \mathrm{kg} \mathrm{DM}^{-1}$ & 0.00007 \\
\hline Residue burning & $\mathrm{kg} \mathrm{CH}_{4} \mathrm{~kg} \mathrm{DM}^{-1}$ & 0.0027 \\
\hline Residue burning & $\mathrm{kg} \mathrm{CO}_{2} \mathrm{~kg} \mathrm{DM}^{-1}$ & 1.515 \\
\hline
\end{tabular}

FarmDESIGN also contains a multi-objective Pareto-based optimization algorithm that can evaluate and minimize trade-offs between several production objectives. Based on available resources and provided with a delimited room to reallocate these resources, the model generates clouds of alternative farm configurations. For this study, the objectives were set to: a) maximize annual income (USD farm ${ }^{-1}$ ); $b$ ) maximize the annual farm $\mathrm{N}$ balance $\left.\left(\mathrm{kg} \mathrm{N} \mathrm{ha}^{-1}\right) ; \mathrm{c}\right)$ minimize annual greenhouse gas emissions $\left(\mathrm{t} \mathrm{CO}_{2} \mathrm{e}\right)$. These indicators were chosen to represent the three pillars of CSA - food security, adaptive capacity or resilience, and mitigation of climate change. In a systematic review of impacts of CSA technologies, Rosenstock et al. (2016) acknowledge that for each of the three pillars, there are many possible dimensions and indicators. Income and GHG emissions are included as indicators for food security and climate change mitigation respectively, while adaptive capacity is arguably more difficult to approximate. Higher farm $\mathrm{N}$ balances were chosen to represent increased farm and soil resources, and they increase the buffer capacity of households against shocks. Constraints were set to not exceed the current farm size, observe livestock feed balances, and keep the organic matter balance within ranges. Decision variables were based on options for climate-smart intensification of livestock, namely a) varying numbers of livestock species, and option of introducing improved dairy breeds; b) choice in crop 
residue use between livestock feeding and soil cover, and c) room for changes in livestock feeding, including Napier grass (Pennisetum purpureum) as introduced forage and local concentrates (Table A11, Appendix 5). The optimization was run for 1000 iterations to attain a stable model outcome. From the obtained trade-off curves for GHG vs. N balance, 4 alternative configurations per farm type were selected for further investigation and comparison to the baseline (B), representing very high (V), high $(\mathrm{H})$, medium $(\mathrm{M})$ and low $(\mathrm{L})$ income and $\mathrm{GHG}$ emissions.

\section{Results}

\subsection{Smallholder livestock systems typology}

Livestock feeding and husbandry in Babati was predominantly extensive with relatively large local cattle herd sizes, few improved breeds, day-time grazing, little purchased feed, wide-spread crop residue feeding and low productivity (Figures A1, A2, A3, A4, Appendix 1). Soils exhibited a moderate to good level of fertility. Differences between villages were apparent, reflecting varying agro-ecologies. Hallu had the lowest level of soil fertility, and Long the highest (Table A1, Appendix 1).

The multivariate analysis identified five principal components (PCs) with an eigenvalue higher than 1.0, of which four were retained to maintain interpretability (Figure A5, Appendix 2). Together, these four PCs explained $63.9 \%$ of the variability within the dataset.

Table 3: Correlation matrix between survey variables and the four retained PCs. In bold, the strongest correlations per component.

\begin{tabular}{lllll}
\hline Variable & PC1 & PC2 & PC3 & PC4 \\
\hline Farm size & $\mathbf{- 0 . 8 9}$ & -0.20 & -0.09 & -0.15 \\
Legume residue used as feed & $\mathbf{- 0 . 8 0}$ & -0.22 & -0.12 & -0.19 \\
Cereal residue used as feed & $\mathbf{- 0 . 7 9}$ & -0.26 & 0.10 & -0.15 \\
Livestock herd size & $\mathbf{- 0 . 7 3}$ & 0.31 & -0.01 & 0.21 \\
Other residue used as feed & -0.62 & -0.16 & -0.42 & -0.04 \\
Household size & -0.53 & 0.46 & 0.32 & -0.14 \\
Small ruminants & -0.47 & 0.27 & 0.09 & $\mathbf{0 . 5 7}$ \\
Improved cattle & -0.22 & -0.32 & $\mathbf{0 . 6 3}$ & 0.06 \\
Grazing time & -0.21 & $\mathbf{0 . 7 1}$ & 0.17 & -0.34 \\
Poultry & -0.02 & -0.31 & $\mathbf{0 . 7 7}$ & 0.15 \\
Livestock family labor & -0.01 & $\mathbf{0 . 5 5}$ & 0.10 & $\mathbf{0 . 1 4}$ \\
Purchased concentrates & 0.18 & $\mathbf{0 . 0 7}$ & 0.22 & $\mathbf{- 0 . 6 9}$ \\
\hline
\end{tabular}


Farm area, cereal and legume residues fed, and livestock herd size were negatively correlated with PC1, explaining $30 \%$ of the variability in the dataset; grazing time and livestock family labor were positively correlated with PC2 (13\%); improved cattle and poultry were positively correlated with PC3 (11\%); and purchased feed negatively and small ruminants positively with PC4 (10\%) (Table 3$)$. The subsequent cluster analysis (Figure A6, Appendix 2) resulted in the selection of five clusters, whose meanings were interpreted together with the PCs (Figures A7, A8, A9, Appendix 2). The five types, and the representative case study farms for the subsequent bio-economic modeling could be summarized as follows:

SMALLEST (44.6\%) was the smallest by area (1.3 ha), had the second smallest livestock herd (2.9 TLU), did not own improved cattle and only few small ruminants, but had the highest median amount of purchased concentrates (83.5 $\mathrm{kg}$ year $^{-1}$ ) (Table 4). The case study farm was located in Long and had 1.6 ha divided in various fields under maize and beans, potatoes, eucalyptus and pasture. The household had two local cows, four goats and three sheep which grazed six hours day ${ }^{-1}$ off-farm and two hours day ${ }^{1}$ on farm and otherwise stayed in the yard or stable (Tables A2, A3, Appendix 3).

DAIRY (16.9\%) had a medium farm (2.4 ha) and livestock herd size (4.6 TLU). It had the highest median number of improved cattle (1.5 heads), and relatively high purchased feed (52.4 kg year ${ }^{-1}$ ) (Table 4). The case study farm was located in Sabilo and cultivated 3.6 ha, of which one field was intercropped with maize, bean, and pigeon pea, 0.53 ha under Napier grass, and 1.5 ha under local pasture. The four crossbred dairy cows were kept inside, while the six local cattle, five goats, and two sheep grazed ten $\mathrm{h}$ day $^{-1}$ on-farm (Tables A2, A3, Appendix 3).

SHOAT (26.5\%) had a medium farm size (1.8 ha), the second largest livestock herd (7.3 TLU) with 14.6 small ruminants, the longest grazing time $\left(8.9\right.$ hours day $\left.^{-1}\right)$, and purchased the lowest amount of feed concentrates (4.5 $\mathrm{kg} \mathrm{year}^{-1}$ ) (Table 4). The case study farm was located in Sabilo and farmed on 8.4 ha, of which 3.1 ha were under several crops (maize, bean, pigeon pea, sunflower), 1.6 ha under wheat, and the remainder under natural pasture. The case study farm was considerably larger than the median value from the typology construction, as the household has misestimated its farm size during the initial characterization which could only be verified and collected during the in-depth follow-up visit. The household owned 20 goats, seven sheep, and seven local cattle that all grazed exclusively on-farm on the pasture or in the open yard around the homestead (Tables A2, A3, Appendix 3). 
POULTRY (7.2\%) owned a relatively small farming area (1.6 ha), had the smallest herd (1.1 TLU) and most chicken of all types (20 heads). It had one of the lowest family labor requirements for livestock (6.5 hours day ${ }^{-1}$ ) and relatively high purchased concentrates (Table 4). This type was omitted for household modeling.

LARGE LIVESTOCK (4.8\%) had the largest number of household members (10), the largest farming area (7.8 ha) and the largest livestock herd size (13.7 TLU) (Table 5.4). The case study farm was located in Hallu and had 11.1 ha with a fully mechanized maize, pigeon pea and sunflower field (10.1 ha), and an Acacia and Senna tree plot of 1 ha around the house. The 15 local cattle and five calves grazed off-farm for 9 hours day $^{-1}$, and otherwise stayed in the open yard around the house. None of the farms applied mineral fertilizer (Tables A2, A3, Appendix 3).

Table 4: Description of livestock system types. Values are expressed in median over the year. The variables are described in Table 3.

\begin{tabular}{|c|c|c|c|c|c|c|c|c|c|c|}
\hline & $\begin{array}{l}\text { Share of } \\
\text { farm } \\
\text { population }\end{array}$ & $\begin{array}{l}\text { Farm } \\
\text { size }\end{array}$ & $\begin{array}{l}\text { Household } \\
\text { members }\end{array}$ & $\begin{array}{l}\text { Livestock } \\
\text { herd size }\end{array}$ & $\begin{array}{l}\text { Small } \\
\text { ruminants }\end{array}$ & Poultry & $\begin{array}{l}\text { Improved } \\
\text { cattle }\end{array}$ & $\begin{array}{l}\text { Grazing } \\
\text { time }\end{array}$ & $\begin{array}{l}\text { Livestock } \\
\text { family } \\
\text { labor }\end{array}$ & $\begin{array}{l}\text { Purchased } \\
\text { concentrates }\end{array}$ \\
\hline & $\%$ & ha & number & TLU & number & number & number & h day ${ }^{-1}$ & h day ${ }^{-1}$ & kg year $^{-1}$ \\
\hline SMALLEST & 44.6 & 1.3 & 6.4 & 2.9 & 4.7 & 5.7 & 0.0 & 7.8 & 8.5 & 83.5 \\
\hline DAIRY & 16.9 & 2.4 & 7.2 & 4.6 & 7.4 & 19.2 & 1.5 & 8.3 & 8.9 & 52.4 \\
\hline SHOAT & 26.5 & 1.8 & 8.6 & 7.3 & 14.6 & 11.2 & 0.0 & 8.9 & 9.8 & 4.5 \\
\hline POULTRY & 7.2 & 1.6 & 4.3 & 1.1 & 3.0 & 20.2 & 0.5 & 0.0 & 6.5 & 56.6 \\
\hline $\begin{array}{l}\text { LARGE } \\
\text { LIVESTOCK }\end{array}$ & 4.8 & 7.8 & 10.3 & 13.7 & 20.3 & 5.0 & 0.5 & 7.5 & 6.7 & 25.0 \\
\hline
\end{tabular}




\subsection{Bio-economic performance of different types}

Feed baskets of the four case study farms contained four to eight on- and off-farm items per household. Total dry matter (DM) intake per farm varied between 6,619 $\mathrm{kg}$ (SMALLEST) to 28,065 kg (LARGE LIVESTOCK), corresponding to average daily values of 18 - $77 \mathrm{~kg}$ DM. SMALLEST and LARGE LIVESTOCK relied on off-farm grazing for more than $50 \%$, while DAIRY fetched around $40 \%$ by cutting and carrying natural grasses outside of the farm. DAIRY was the only farm to cultivate on-farm forages (Napier grass), constituting $15 \%$ of its feed basket. SHOAT exclusively fed on-farm resources, with $41 \%$ constituted by its own pasture. SHOAT and LARGE LIVESTOCK farms were feeding higher proportions of various crop residues $(40-50 \%)$ when compared to SMALLEST and DAIRY $(20-30 \%)$ due to their larger farm sizes and crop production. Concentrate feed such as sunflower cake, maize bran and maize grain only made a marginal contribution to the SHOAT farm feed basket in terms of DM (Figure 2a), but contributed 22\% of proteins to the diet (Figure $2 \mathrm{~b}$ ). Although DAIRY only had the $2^{\text {nd }}$ highest TLU and fed the $3^{\text {rd }}$ largest DM amount, it fed most proteins of all farms.
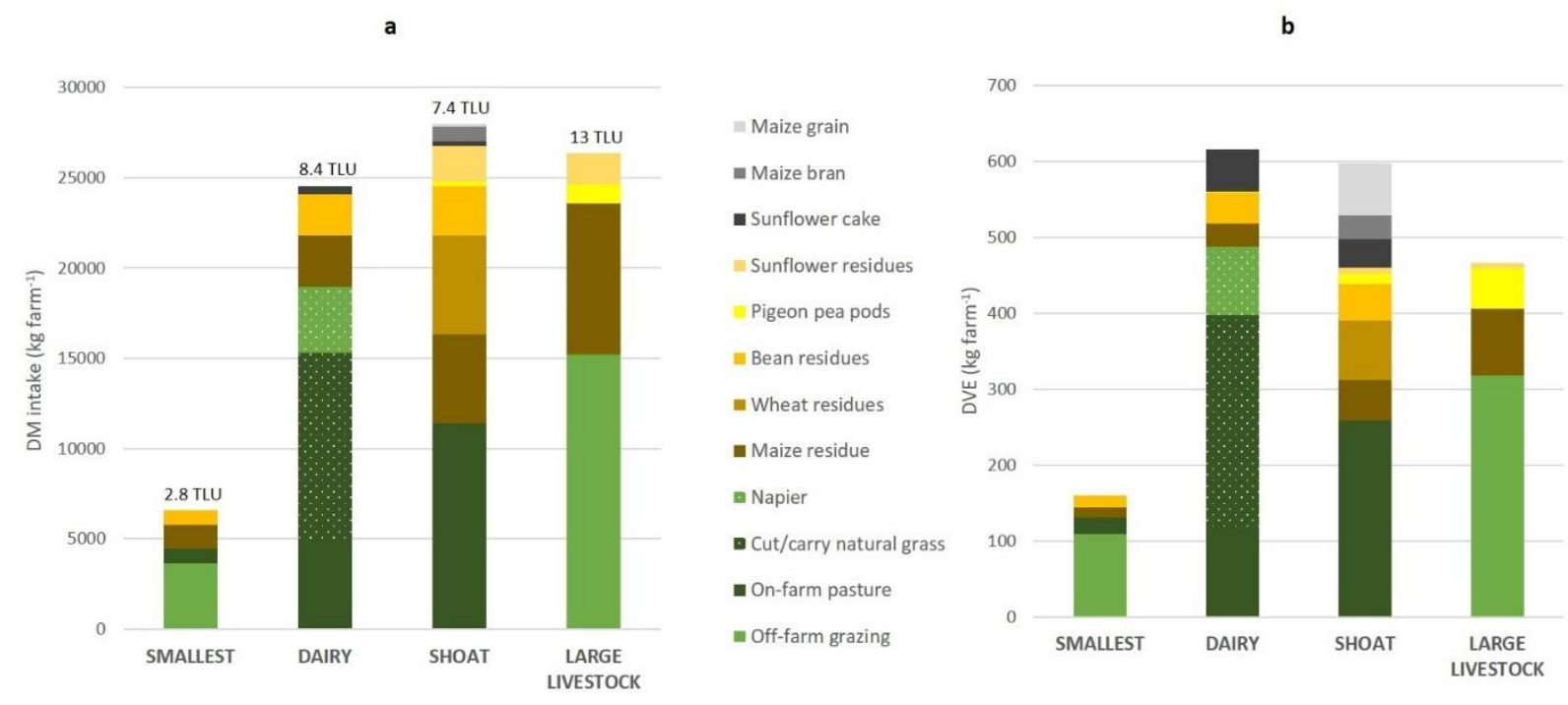
Figure 2: Livestock feed baskets of the four case study farms in (a) total dry matter (DM) intake and (b) intestinally digestible protein (DVE) per livestock system. Fresh grasses are denoted in green colors, crop residues in brown/yellow/orange colors, and grain/seed feed in grey colors. Cut-and-carry fodders were marked with the white dotted pattern.

Annual income per household was between 997 USD (SMALLEST) and 2977 USD (LARGE LIVESTOCK). Except LARGE LIVESTOCK, all farms lay below the poverty line. One third to half of all produce was consumed by the households themselves. When family labor was costed, SMALLEST was operating at a loss, and SHOAT just ran even. Despite its much lower farm area, DAIRY was generating higher income than SHOAT (Figure 3a). Total annual labor hours (Figure 3b) required were 3,262 hours (SMALLEST), 6,327 (SHOAT), 6,634 (DAIRY) and 8,296 hours (LARGE LIVESTOCK). In total, livestock activities required more labor than crop activities, mainly due to grazing time. SMALLEST hired the least labor, while LARGE LIVESTOCK and SHOAT hired considerable amounts of labor for crop and livestock activities. Livestock labor intensity (hours TLU ${ }^{-1}$ ) was highest for SMALLEST and lowest for LARGE LIVESTOCK, as herding a small herd is less labor-efficient than herding a large livestock herd. DAIRY needed the second highest amount of labor for livestock due to cut and carry feeding. Crop labor intensities were similar across farms.
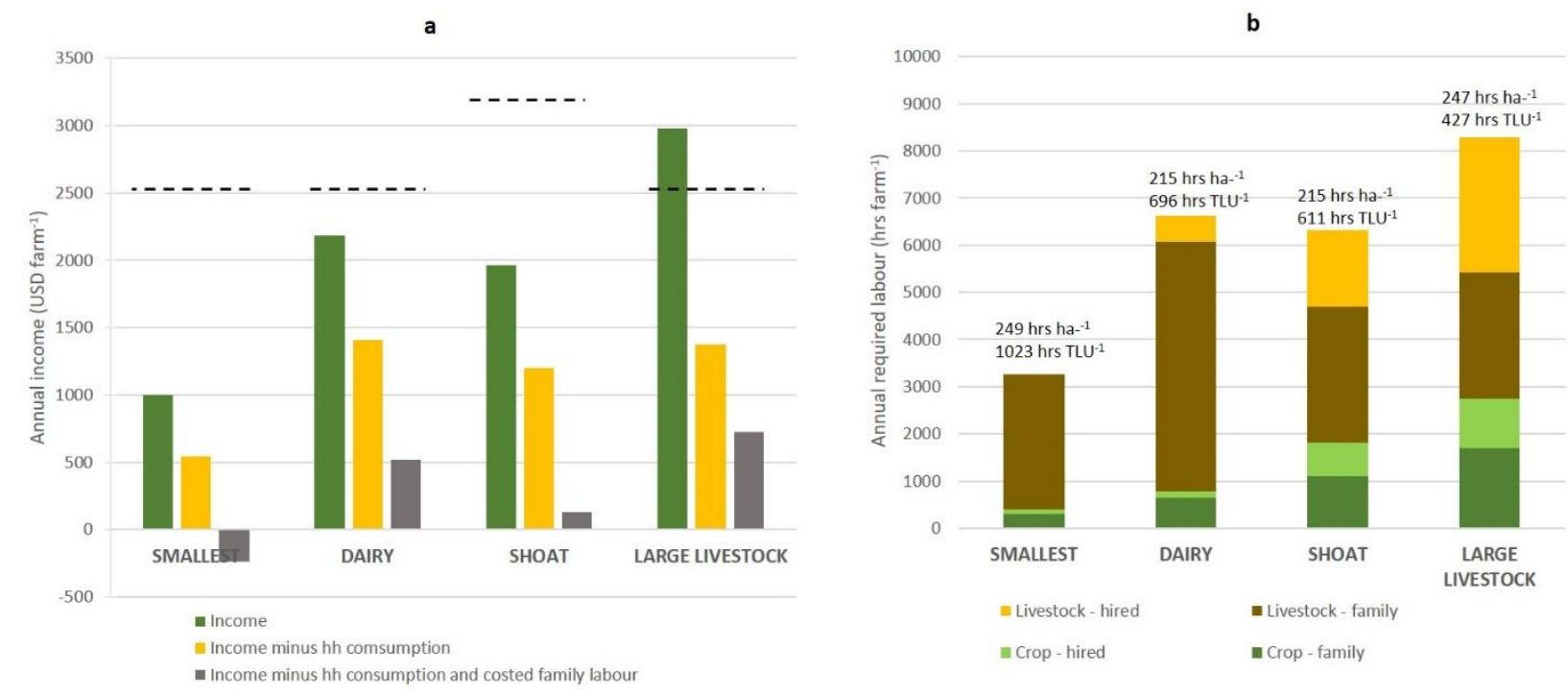

Figure 3: Socio-economic indicators of farm performance per livestock system: Annual income (a); annual required labor (b). The dashed line illustrates the poverty line at 1 USD per household member and day (a), and the numbers above bars denote labor efficiencies - for crop activities per area, and for livestock activities per TLU 9b).

Enteric fermentation and manure together were responsible for $>90 \%$ of total farm-level emissions. Therefore, emissions increased with livestock herd size, ranging between 2.9 t $\mathrm{CO}_{2} \mathrm{e}$ (SMALLEST) and 
16.2 t CO $\mathrm{CO}_{2} \mathrm{e}$ (LARGE LIVESTOCK). Only LARGE LIVESTOCK also had significant crop-related $\mathrm{N}_{2} \mathrm{O}$ emissions due to $\mathrm{N}$ inputs from crop residue retention on the field and $\mathrm{N}$ fixation by legumes. LARGE LIVESTOCK was also the only farm that burned on-farm products such as timber and pigeon pea stalks for firewood. Emission intensity per liter of milk produced was highest for SHOAT $\left(15.3 \mathrm{~kg} \mathrm{CO}_{2} \mathrm{e}^{-1}\right)$ and SMALLEST $(9.4$ $\left.\mathrm{kg} \mathrm{CO}_{2} \mathrm{el}^{-1}\right)$ due to low production levels, and lowest for DAIRY $\left(2.1 \mathrm{~kg} \mathrm{CO}_{2} \mathrm{el}^{-1}\right)$. Emission intensity per hectare was highest for DAIRY $\left(2.6 \mathrm{t} \mathrm{CO}_{2} \mathrm{e} \mathrm{ha}{ }^{-1}\right)$ due to relatively higher stocking rate, and lowest for SHOATS (1.1 $\mathrm{t} \mathrm{CO}_{2} \mathrm{e} \mathrm{ha}{ }^{-1}$ ) because of the large farm size (Figure 4a). SHOAT had the lowest $\mathrm{N}$ balance with $0 \mathrm{~kg} \mathrm{~N} \mathrm{ha}^{-1}$ as it was the only farm with no nutrient influx from off-farm feeds. All other farms achieved positive farm-level $\mathrm{N}$ balances due to the import of grass from outside the farms. DAIRY exported the largest amount of $\mathrm{N}$ through milk sale, and SHOAT and LARGE LIVESTOCK through crop sales. None of the farms imported $\mathrm{N}$ in the form of manure or mineral fertilizers (Figure $4 \mathrm{~b}$ ).
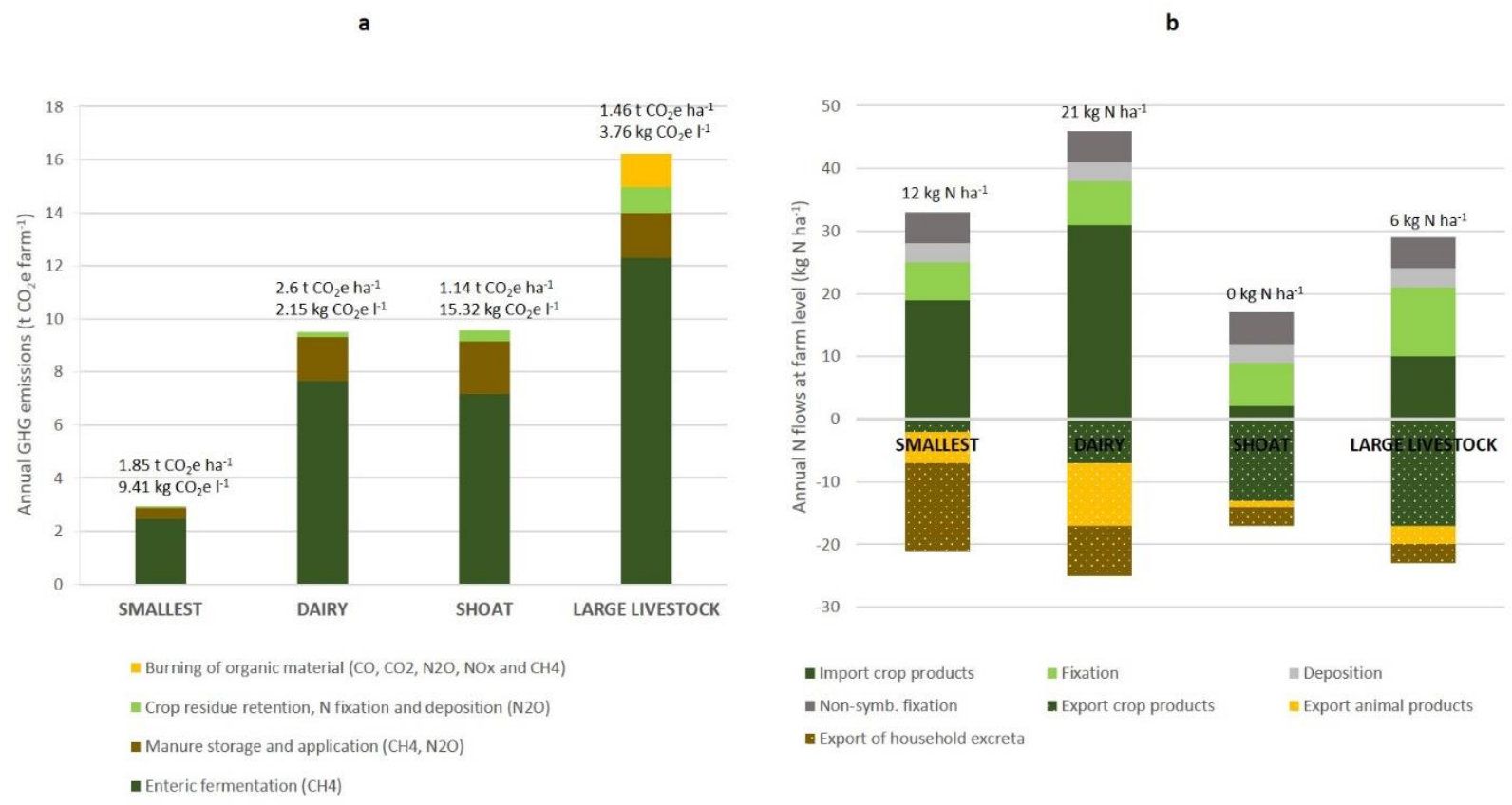

Figure 4: Environmental indicators of farm performance per livestock system: Greenhouse gas emissions (a) and annual $\mathbf{N}$ flows at farm level (b). Numbers above bars emission intensities per land area and milk produced (a), and positive values represent imports, and negative value denotes exports while numbers above bars denoted the annual $\mathrm{N}$ balance per land area (b).

Overall relative scoring of agro-environmental and socio-economic indicators clearly illustrated differences in performance between the livestock systems. SMALLEST came out favorably in terms of environmental quality with highest species richness, low $\mathrm{GHG}$, and good $\mathrm{C}$ and $\mathrm{N}$ balances but it also generated the lowest income. DAIRY produced high income, highest $\mathrm{C}$ and $\mathrm{N}$ balances and only medium GHG, but had relatively high feed and labor demands. SHOATS had medium income and highest tree C 
stock, but the lowest $\mathrm{C}$ and $\mathrm{N}$ balances, high GHG emissions, and high feed and labor requirements. LARGE LIVESTOCK had the highest income, but low $\mathrm{C}$ and $\mathrm{N}$ balances, high GHG emissions, low species richness, and high feed and labor requirements (Figure 5).


Figure 5: Scoring of SMALLEST (a), DAIRY (b), SHOAT (c) and LARGE LIVESTOCK (d) along socio-economic and agro-environmental indicators. Variables were standardized between 0 and 1 , defining the highest value for each variable among the four farmers as 1.

\subsection{Agro-environmental trade-offs}

The model optimization runs illustrated that all farms faced trade-offs between income and GHG emissions. However, all types had alternative options available to increase income while reducing GHG when compared to the baseline, with DAIRY and to a lesser extent SHOAT and LARGE LIVESTOCK having most options available (Figure 6a). When looking at the relationship between income and annual $\mathrm{N}$ balance, a trade-off was visible for SMALLEST and DAIRY while for SHOATS and LARGE LIVESTOCK there were only a few options to increase their $\mathrm{N}$ balance (Figure $6 \mathrm{~b}$ ). 


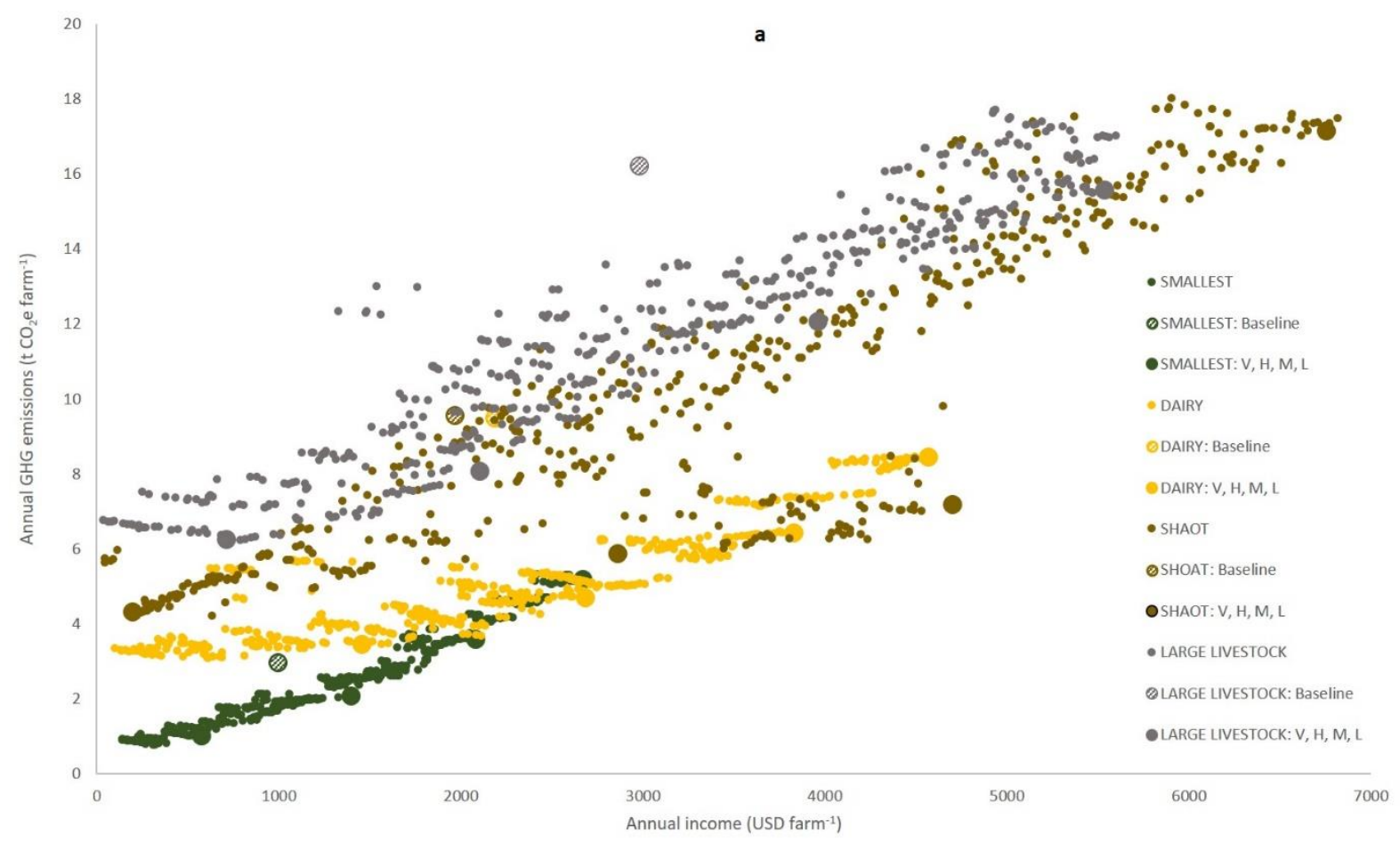

b

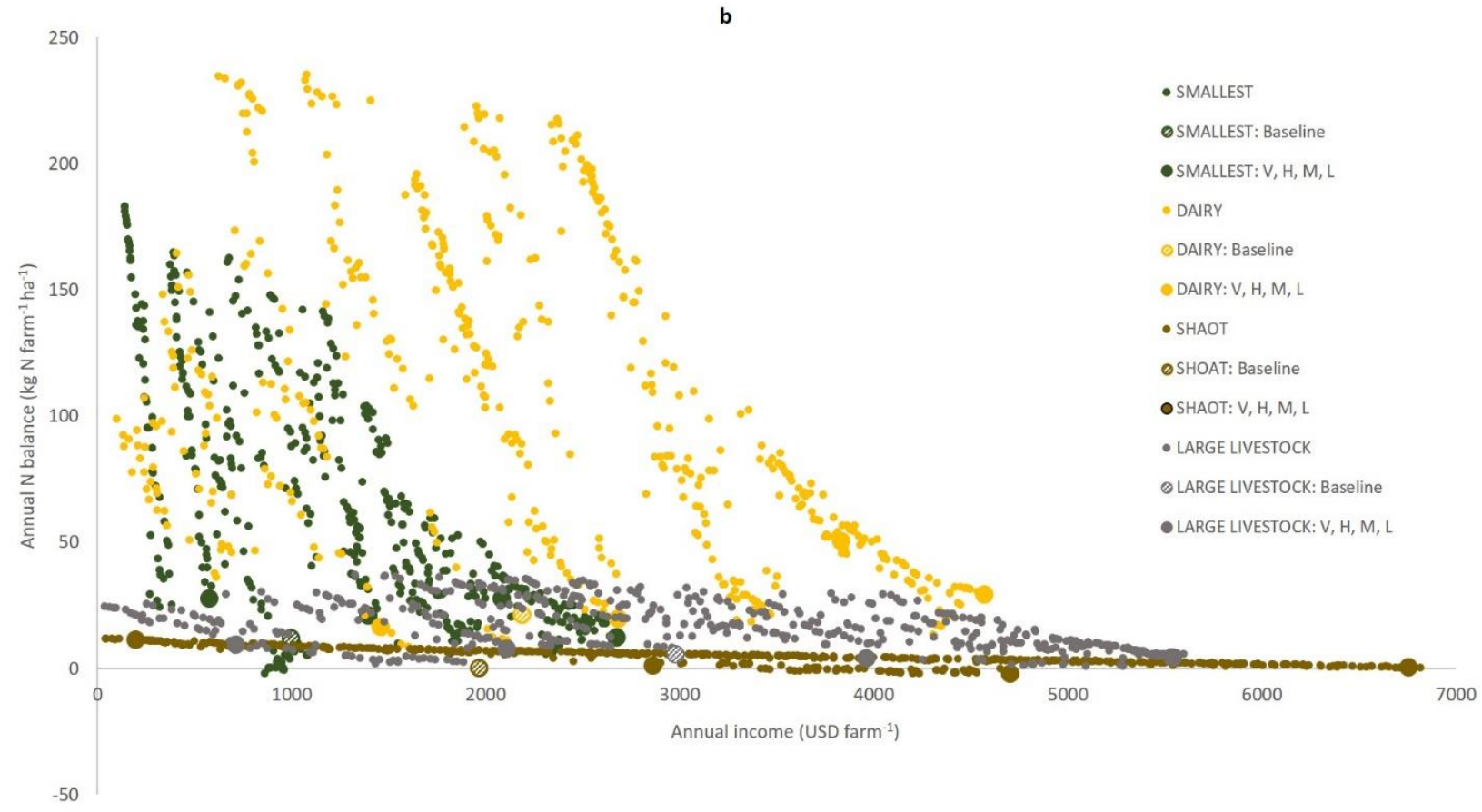

Figure 6: Trade-offs between annual income and GHG emissions (a) and annual income and farm $\mathbf{N}$ balances (b) across smallholder livestock systems. The large dots with pattern denote the baseline position, whereas all other dots 377 are model-generated. The large dots denote model-generated farm constellations that are further examined in Table 6. $V=$ very high income and $G H G, H=$ high, $M=$ medium, $L=$ low. 
Only a few of the chosen alternatives represented a triple win, thus an improvement on all three objectives when compared to the baseline. Farm constellation M (medium) for SMALLEST increased income by $40 \%$, decreased GHG emissions by $30 \%$ and increased $\mathrm{N}$ balance by $76 \%$. The overall cattle number was reduced from six to three, and goats and sheep from seven to one. Less maize and bean residues were fed but sunflower cake added, which enabled higher milk production for local and improved cows. The on-farm pasture was eliminated, potato and maize and bean fields slightly reduced and more residues retained in the field instead of fed. Farm alternatives $\mathrm{V}$ and $\mathrm{H}$ were triple-wins for DAIRY when compared to the baseline. Option $\vee$ (high income and increased GHG emissions) increased DAIRY income by $109 \%$, decreased GHG by $11 \%$ and increased $\mathrm{N}$ balance by $38 \%$. This was reached through eliminating the local goats and cows, but increasing improved cows to seven, and raising their milk production to $4.9 \mathrm{~kg} \mathrm{day}^{-1}$ by increasing the Napier grass field, decreasing on-farm pasture, and doubling the sunflower cake fed. Less maize and bean residues were fed but more retained on the field. Option M increased SHOAT income by $46 \%$, decreased GHG by $39 \%$ and increased $\mathrm{N}$ balance by $1144 \%$. This was obtained by eliminating local cows and goats, reducing sheep to one, and adding three improved cows with higher milk production of $5.4 \mathrm{~kg} \mathrm{day}^{-1}$. A Napier grass field of 0.4 ha was introduced, the on-farm pasture and crop fields reduced so that the total farming area decreased to $5.4 \mathrm{ha}$. Less maize and bean residues were fed and more retained on the soil. Option $\mathrm{H}$ was not a triple-win for LARGE LIVESTOCK but came closest as it increased income by $33 \%$, decreased GHG by $26 \%$, but decreased $\mathrm{N}$ balance by $28 \%$. Local cattle were reduced from 15 to eight, and one improved cow at high $\left(5.8 \mathrm{~kg} \mathrm{day}^{-1}\right)$ milk production added. Off-farm grazing was reduced, but sunflower cake feeding (354 kg DM year ${ }^{-1}$ ) and a Napier grass field of 1.8 ha were introduced. Crop residue feeding was reduced but more retained on the field (Table 5). 
Table 5: Outcomes, constraints and decision variables for baselines (B) and four alternative farm configurations from optimization run output. $V=$ very high income and $G H G, H=$ high, $M=$ medium, $L=$ low.

\begin{tabular}{|c|c|c|c|c|c|c|c|c|c|c|c|c|c|c|c|c|c|c|c|c|}
\hline \multirow[b]{2}{*}{ Outcome variables } & \multicolumn{5}{|c|}{ SMALLEST } & \multicolumn{5}{|c|}{ DAIRY } & \multicolumn{5}{|c|}{ SHOAT } & \multicolumn{5}{|c|}{ LARGE LIVESTOCK } \\
\hline & B & $\mathrm{v}$ & $\mathrm{H}$ & M & $\mathrm{L}$ & B & v & $\mathrm{H}$ & M & $\mathrm{L}$ & B & $v$ & $\mathrm{H}$ & M & L & B & $\mathrm{v}$ & $\mathrm{H}$ & M & $\mathrm{L}$ \\
\hline Annual income (USD farm ${ }^{-1}$ ) & 997 & 2670 & 2081 & 1394 & 574 & 2186 & 4565 & 3828 & 2680 & 1455 & 1965 & 6754 & 4701 & 2860 & 198 & 2977 & 5535 & 3959 & 2104 & 711 \\
\hline Greenhouse gas emissions $\left(\mathrm{CO}_{2} \mathrm{e}_{\text {farm }}{ }^{-1}\right)$ & 3.0 & 5.2 & 3.6 & 2.1 & 1.0 & 9.5 & 8.5 & 6.4 & 4.7 & 3.4 & 9.6 & 17.2 & 7.2 & 5.9 & 4.3 & 16.2 & 15.6 & 12.1 & 8.1 & 6.3 \\
\hline Annual $\mathrm{N}$ balance $\left(\mathrm{kg} \mathrm{N} \mathrm{farm}^{-1}\right)$ & 12.1 & 12.5 & 28.1 & 21.3 & 27.9 & 21.2 & 29.4 & 50.6 & 19.8 & 16.7 & 0.1 & 0.4 & -2.0 & 1.3 & 11.6 & 5.7 & 4.7 & 4.2 & 8.0 & 9.5 \\
\hline \multicolumn{21}{|l|}{ Constraint variables } \\
\hline Organic matter balance $\left(\mathrm{kg} \mathrm{farm}^{-1}\right)$ & -0.2 & 503.0 & 549.1 & 109.0 & 453.0 & 0.1 & 147.9 & 314.6 & 239.4 & 171.9 & 0.1 & 209.0 & 115.7 & 133.4 & 140.1 & 0.3 & 37.4 & 19.6 & 14.5 & 16.0 \\
\hline Labor balance (hours year ${ }^{-1}$ ) & 3620 & 4948 & 5542 & 5638 & 5837 & 585 & 2789 & 3499 & 3755 & 4102 & 1174 & 606 & 2217 & 3103 & 3857 & 1639 & 447 & 673 & 822 & 3228 \\
\hline Farm area (ha) & 1.6 & 1.6 & 0.8 & 1.2 & 0.3 & 3.7 & 3.1 & 1.8 & 1.7 & 1.4 & 8.4 & 8.4 & 8.4 & 5.4 & 3.2 & 11.1 & 11.0 & 10.7 & 9.6 & 5.0 \\
\hline \multicolumn{21}{|l|}{ Decision variables } \\
\hline Local cows (number) & 2.0 & 2.0 & 2.0 & 1.0 & 1.0 & 3.0 & 0.0 & 0.0 & 0.0 & 2.0 & 3.0 & 6.0 & 1.0 & 0.0 & 0.0 & 11.0 & 11.0 & 6.0 & 0.0 & 0.0 \\
\hline Improved cows (number) & 0.0 & 3.0 & 2.0 & 1.0 & 0.0 & 3.0 & 7.0 & 5.0 & 3.0 & 1.0 & 0.0 & 10.0 & 3.0 & 3.0 & 1.0 & 1.0 & 2.0 & 2.0 & 2.0 & 1.0 \\
\hline Local bulls (number) & 3.0 & 0.0 & 0.0 & 1.0 & 0.0 & NA & NA & NA & NA & NA & 3.0 & 2.0 & 2.0 & 2.0 & 2.0 & 4.0 & 2.0 & 2.0 & 2.0 & 2.0 \\
\hline Local young male cattle (number) & 1.0 & 1.0 & 0.0 & 0.0 & 0.0 & NA & NA & NA & NA & NA & NA & NA & NA & NA & NA & NA & NA & NA & NA & NA \\
\hline Local goat (number) & 4.0 & 0.0 & 0.0 & 1.0 & 2.0 & 5.0 & 0.0 & 0.0 & 0.0 & 0.0 & 20.0 & 0.0 & 1.0 & 0.0 & 0.0 & NA & NA & NA & NA & NA \\
\hline Sheep (number) & 3.0 & 0.0 & 0.0 & 0.0 & 0.0 & NA & NA & NA & NA & NA & 7.0 & 0.0 & 0.0 & 1.0 & 7.0 & NA & NA & NA & NA & NA \\
\hline Off-farm grazing ( $\left(\mathrm{kg}\right.$ DM year ${ }^{-1}$ ) & 3850 & 3592 & 3828 & 3282 & 1752 & NA & NA & NA & NA & NA & NA & NA & NA & NA & NA & 13350 & 12028 & 7673 & 8464 & 5598 \\
\hline Maize + bean (+ pigeon pea + sunflower) field (ha) & 1.0 & 0.3 & 0.0 & 0.9 & 0.0 & 1.6 & 1.6 & 1.4 & 1.5 & 1.3 & 3.1 & 0.5 & 4.9 & 2.2 & 0.0 & 10.1 & 7.2 & 7.1 & 8.2 & 3.2 \\
\hline Potato field (ha) & 0.3 & 0.3 & 0.3 & 0.2 & 0.1 & NA & NA & NA & NA & NA & NA & NA & NA & NA & NA & NA & NA & NA & NA & NA \\
\hline Wheat field (ha) & NA & NA & NA & NA & NA & NA & NA & NA & NA & NA & 1.6 & 0.0 & 0.3 & 0.0 & 0.0 & NA & NA & NA & NA & NA \\
\hline Napier field (ha) & 0.0 & 0.9 & 0.4 & 0.0 & 0.0 & 0.5 & 0.6 & 0.4 & 0.1 & 0.0 & 0.0 & 4.9 & 0.2 & 0.4 & 0.4 & 0.0 & 2.0 & 1.8 & 0.0 & 0.4 \\
\hline On-farm pasture (ha) & 0.2 & 0.0 & 0.0 & 0.0 & 0.0 & 1.5 & 0.9 & 0.0 & 0.0 & 0.1 & 3.7 & 3.0 & 3.0 & 2.8 & 2.8 & NA & NA & NA & NA & NA \\
\hline Bean residues fed (fraction) & 1.0 & 0.9 & 0.9 & 0.4 & 1.0 & 1.0 & 0.6 & 0.1 & 0.0 & 0.1 & 1.0 & 0.7 & 0.1 & 0.6 & 0.7 & NA & NA & NA & NA & NA \\
\hline Bean residues retained (fraction) & 0.1 & 0.2 & 0.0 & 0.1 & 0.5 & 0.0 & 0.6 & 0.3 & 0.6 & 0.6 & 0.0 & 0.6 & 1.0 & 0.3 & 0.8 & NA & NA & NA & NA & NA \\
\hline Maize residues fed (fraction) & 1.0 & 0.1 & 0.4 & 0.0 & 0.5 & 1.0 & 0.0 & 0.1 & 0.2 & 0.3 & 1.0 & 0.4 & 0.8 & 0.3 & 0.8 & 0.4 & 0.0 & 0.0 & 0.0 & 0.0 \\
\hline Maize residues retained (fraction) & 0.1 & 1.0 & 0.6 & 0.7 & 0.3 & 0.0 & 0.3 & 0.9 & 0.8 & 0.6 & 0.0 & 0.3 & 1.0 & 1.0 & 0.2 & 0.6 & 0.6 & 0.7 & 0.5 & 0.9 \\
\hline Sunflower residues fed (fraction) & NA & NA & NA & NA & NA & NA & NA & NA & NA & NA & 1.0 & 0.3 & 0.0 & 0.2 & 0.6 & 0.4 & 0.1 & 0.1 & 0.1 & 0.4 \\
\hline Sunflower residues retained (fraction) & NA & NA & NA & NA & NA & NA & NA & NA & NA & NA & 0.0 & 1.0 & 0.5 & 0.3 & 0.8 & 0.6 & 0.8 & 0.9 & 0.7 & 0.6 \\
\hline Sunflower cake fed $\left(\mathrm{kg} \mathrm{DM}\right.$ year $\left.{ }^{-1}\right)$ & 0 & 415 & 342 & 473 & 7 & 900 & 1936 & 1931 & 44 & 39 & NA & NA & NA & NA & NA & 0 & 178 & 354 & 912 & 116 \\
\hline Wheat residue fed (fraction) & NA & NA & NA & NA & NA & NA & NA & NA & NA & NA & 1.0 & 0.5 & 0.3 & 0.5 & 0.6 & NA & NA & NA & NA & NA \\
\hline Wheat residue retained (fraction) & NA & NA & NA & NA & NA & NA & NA & NA & NA & NA & 0.0 & 0.4 & 0.3 & 0.3 & 0.1 & NA & NA & NA & NA & NA \\
\hline
\end{tabular}




\subsection{Farmers' perspectives on livestock intensification}

When asked about the relative importance of crop and livestock activities, all four farmers from data collection step iii) underlined cropping as the priority activity for income generation. Livestock was mainly seen as a backup asset, insurance or risk buffer for funding events and emergencies such as travel, schooling and medical expenses. Except for DAIRY, farmers also expressed the importance of livestock numbers, and not productivity, to elevate status and prestige within their community. DAIRY was the only farm that had experience with improved cattle at the time of data collection in 2015, and was planning to replace the remaining local cattle with improved cows (except one bull for draught power) when the children left home as there would be no herding labor available anymore. All farmers underlined the main advantage of improved cattle, being higher milk and manure production. Several challenges with improved cattle rearing were quoted, especially by SHOAT and SMALLEST: a) they required a high amount and different type of labor as fetching of cut-and-carry feed and drinking water (around $80 \mathrm{I} \mathrm{day}{ }^{-1}$ ) was physically demanding and could not be exercised by children or old people who normally herded local cattle; b) they were susceptible to diseases and decease especially under hard conditions; c) they could not provide draught power which was essential in the area; d) they were not easy to sell as they had higher body weight and were more expensive; e) they were difficult to impregnate naturally, and artificial insemination services and cooling facilities were difficult to access; $f$ ) they required more and higher quality feed which is not sufficiently available from the local pastures; $g$ ) lack of training and successful examples among their neighbors. After the detailed characterization in 2015 (thus not reflected in this study), SMALLEST started experimenting with Napier grass on a small plot, and LARGE LIVESTOCK commenced with one improved dairy cow, which was managed separately from the other cattle. Another commonly mentioned theme was the disappearance of off-farm, communal grazing areas. In Sabilo, there was already no grazing areas available anymore as they had disappeared over the last decade; in Long only the nearby forest could be grazed during parts of the year; only in Hallu, large communal grazing areas were available as recently the community received land from the neighboring Tarangire National Park in exchange for strictly keeping their cattle outside of its boundaries. Part of this land was used for communal grazing, while other parts were distributed to households as cropping land.

\section{Discussion}

\subsection{Livestock system diversity, and drivers of change}


Livestock feeding and husbandry in Babati was predominantly extensive, with relatively large livestock herds, local cattle breeds, heavy reliance on grazing and crop residue feeding, small amounts of feed concentrates, and low productivity. Only few cattle of improved breeds were kept separately from the local cattle herds in zero-grazing units. The quantified feed baskets in Babati are in line with results from Mangesho et al. (2013) from the same area. According to Hillbur (2013), the cultural history of the Iraqw and Gorowa as pastoralists and later agro-pastoralists can partly explain the current extensive livestock keeping. The experience of zero-grazing is still mainly limited to areas with high population pressure and Heifer Project International (HPI) intervention areas from the 1980s and 1990s (Hillbur, 2013). However, increasing land pressure and degradation is changing the context, leading to disappearance of grazing land, sub-division of farms, and increased conflicts between herders and farmers. Where communal grazing exists, there are by-laws in place within villages. All villages now have defined boundaries, and village land use plans are underway (Bishop-Sambrook et al., 2004; Hillbur 2013).

In many regions of SSA, the reported diversity of agro-ecological environment and socio-economic characteristics is widespread. It is of key importance to capture and classify such farming system diversity to conduct meaningful ex-ante exploration of alternative management (Tittonell et al., 2010). Different approaches can be used to construct farm typologies, such as qualitative, participatory, expertbased and quantitative typologies (Alvarez et al., 2014; Kuivanen et al., 2016; Tittonell et al., 2010). In this study, we chose a predominantly structural, quantitative approach for the farm typology, relying on land size, livestock species and numbers, and crop residue and concentrate feeding. The method has its inherent challenges: livestock holdings turned out to be highly fluctuating, with numbers doubling or halving between the farm visits in February 2015 and February 2017. This reflects findings from Western Kenya which documented farmers' trajectories over ten years. Improving livelihoods in the area was called a "moving target" as farmers coped and adapted quickly to the fast-changing local and regional environment (Valbuena et al., 2014).

\subsection{Improved dairy breeds and feeding as climate-smart livestock intensification options}

All farm types had options to increase income while decreasing GHG emissions and increasing $\mathrm{N}$ balance. These options mainly consisted of reducing general ruminant numbers but increasing their milk production by introducing improved breeds and planted fodder, while feeding fewer crop residues but keeping them on the field. DAIRY came out favorably in terms of income when considering the relatively small farm size and had relatively few environmental trade-offs. However, it needs to be noted that data reported by smallholder farmers is especially prone to estimation errors. For example, $\mathrm{N}$ surpluses 
between $0-21 \mathrm{~kg} \mathrm{~N}^{-1}$ like in this study are low and differences could be caused by such error margins. Fewer improved dairy breeds which are better managed and fed has often been presented as promising climate-smart livestock intensification options (CIAT and World Bank, 2017; Herrero et al., 2016). Smallholder dairy systems would not only have the lowest GHG emission intensities per kg milk produced, but also the lowest trade-offs with other farm performance dimensions. External drivers like increasing land pressure and policy reform might further favor transition towards dairy systems.

This study also demonstrated that with diminishing off-farm grazing and remaining large livestock and crop sales, nutrient mining is of potential concern. Unless cattle feed is imported from outside the farm, fodder and crop residue feeding are not sufficient nutrient replenishment. In low population pressure areas, potential trade-offs can be managed through temporal or spatial arrangements while in areas with high land pressures, these traditional nutrient transfer systems collapse (Vanlauwe et al., 2017). Babati illustrates this shift in systems, with Hallu (LARGE LIVESTOCK) representing the vanishing nutrient import systems. The village lies in an area that only recently received land from the Tarangire National Park, and farm areas are large and communal grazing abundant. Long (SMALLEST) and Sabilo (DAIRY, SHOAT) represent the increasing reliance on on-farm resources, reducing farm sizes and zero-grazing systems. Already now, at least $52 \%$ of the fields in Babati had negative nutrient balances (Kihara et al., 2015). However, planted forages can also have other environmental benefits that were beyond this study. A study from Long in the 2014 rainy season demonstrated that although $75 \%$ of rainfall water was lost by evapotranspiration, runoff levels were significantly lower under forage grass-legume intercrop, resulting in $30 \%$ higher soil moisture (Kizito et al., 2016).

\subsection{Social context inhibiting adoption of improved breeds and feeds}

Despite its bio-economic potential as a climate smart livestock intensification pathway, improved dairy breed, feed and husbandry have inherent characteristics that inhibit rapid adoption. Smallholder dairying has been presented as fast-tracking development, and an advanced, 'modern' technology but Green (2017) argues that livestock modeling neglects the social context of smallholder dairying. Three main adoption obstacles can be distinguished: Firstly, the introduction of improved dairy breeds is not as simple as inserting a singular technological object, but a change or re-organization of the entire production system. This re-organization in time and space requires skill and experience that might not be present among poor smallholders. The introduction of dairy breeds in Tanzania cannot be seen as a consistent shift, and ventures into dairying are at times short-lived, following project cycles, or ending with sale, loss or death of dairy cattle (Green, 2017). This argumentation is reflected in the perceptions 
of farmers in Babati. If improved breeds were introduced in farming systems, they were kept as a completely separate and re-organized enterprise, and not integrated with the local cattle herds: different feeds and feeding system (zero grazing), and different and high labor demands for fetching water and fodder. Farmers were reluctant to venture in improved dairy cows due to lack of training and experience. The second obstacle to adopting fewer improved dairy breeds and increasing productivity through better feeds is the partial loss of the multi-functionality of livestock (Descheemaeker et al., 2016). Sumberg and Lankoande (2013) showed in their study from Tanzania that income and nutritious food is only one function of livestock. Intermediary products such as manure and draught, plus saving and insurance functions, are not to be underestimated. New animals can be seen as deposits, their growth as interest, and sale or death as withdrawal or loss. Livestock are also important for social dynamics and identity. Moving towards improved dairy for income and food, some farmers would be reluctant to accept the trade-offs of losing the savings, cultural and draught functions (Sumberg and Landoande, 2013). This is reflected in farmers' quotes in Babati, mentioning the role of local cattle in social status, as well as draught power and asset and insurance function. The last major obstacle to adoption would be increased risk (Green, 2017; Sumberg and Landoande, 2013). Farmers reported high mortality, low fertility, sensitivity to heat, sun and tropical diseases, and high costs for disease prevention and veterinary care.

\subsection{Policy relevance for CSA in Tanzania}

This study confirms what has been reported before: livestock is the main contributor to agricultural greenhouse gas emissions in Tanzania (CIAT and World Bank, 2017) and other countries in East Africa (Paul et al., 2018; Ortiz-Gonzalo et al., 2017). Per farm emissions in Babati were higher than in other sites in the region due to the relatively large livestock herds, ranging from 2.9 t $\mathrm{CO}_{2} \mathrm{e}$ (SMALLES) to 16.2 t $\mathrm{CO}_{2} \mathrm{e}$ (LARGE LIVESTOCK). In Rwanda, for example, average annual GHG emissions per household only lay between $0.4 \mathrm{t}$ and $1.5 \mathrm{t} \mathrm{CO}_{2} \mathrm{e}$ (Paul et al., 2018). In Central Kenya, whole farm GHG emissions amounted to an average of $1.05 \mathrm{~kg} \mathrm{CO}_{2} \mathrm{e} \mathrm{kg} \mathrm{milk-1}$ (Ortiz-Gonzalo et al., 2017), while in this study they ranged from 2.1 to $15.3 \mathrm{~kg} 1.05 \mathrm{~kg} \mathrm{CO}_{2} \mathrm{e} \mathrm{kg} \mathrm{milk}{ }^{-1}$. However, it needs to be taken into account that although the GHG emission estimations in this study are comprehensive, changes in soil organic carbon (SOC) and aboveground biomass $\mathrm{C}$ were not taken into account. Moreover, calculation of enteric fermentation relies on IPCC Tier 1 factors that have been shown to overestimate emissions (Herrero et al., 2013), and do not reflect changes in quality of feed. 
While the developed world has higher total agricultural emissions, the developing world has higher GHG emission intensities per livestock output due to poor diets, genetics, health, and husbandry (Herrero et al., 2016). In line with this, Tanzania has negligible total and per capita $\mathrm{GHG}$ emissions $\left(0.2 \mathrm{t} \mathrm{CO}_{2}\right.$ e per capita) and taking into account the 48.1 Mio. ha forests, Tanzania is a net carbon sink. Tanzania has committed to reducing GHG economy-wide by $10-20 \%$ in 2030 , although agriculture is not a focus area for mitigation (Republic of Tanzania, 2015). This underlines that mitigation cannot be an objective in this environment, but only a co-benefit. If financing mechanisms, through carbon credits, for example, become available this might become interesting. But if there is synergy with productivity increase and improved production coefficients, it would be beneficial.

\section{Conclusions}

Five distinct smallholder livestock systems could be identified: SMALLEST represented $45 \%$ of the study sample, DAIRY 17\%, SHOAT 26\%, POULTRY 7\%, and LARGE LIVESTOCK 5\%. Only DAIRY cultivated fodder and fed cross-bred cows in zero-grazing units, while the other farm types mainly relied on on-farm and off-farm grazing and crop residues for their local cattle. Increasing population pressure and policy changes make future moves into dairy systems likely. Farm $\mathrm{N}$ balances were positive when large amounts of $\mathrm{N}$ could be imported with off-farm grazing, but this traditional nutrient transfer system is likely to collapse due to increasing population pressure and policy changes. More than $90 \%$ of on-farm


other smallholder systems in East Africa due to relatively large herd sizes. Emission intensity per kg milk was lowest for DAIRY $\left(2.1 \mathrm{~kg} \mathrm{CO}_{2} \mathrm{e} \mathrm{kg}^{-1}\right)$ when compared to SHOAT $\left(15.3 \mathrm{~kg} \mathrm{CO}_{2} \mathrm{e} \mathrm{I}^{-1}\right)$ and SMALLEST (9.4 $\mathrm{kg} \mathrm{CO}_{2} \mathrm{e} \mathrm{kg}^{-1}$ ). DAIRY also showed the lowest trade-offs with other farm performance indicators as it resulted in highest income, highest $\mathrm{C}$ and $\mathrm{N}$ balances, but still had relatively high feed and labor demands. All livestock systems had alternatives available to increase income while decreasing GHG emissions and increasing $\mathrm{N}$ balance, thereby reducing agro-environmental trade-offs. These options included reducing ruminant numbers, replacing local cattle with improved dairy breeds, improve feeding through on-farm Napier grass (Pennisetum purpureum) cultivation to reach higher milk production levels, and reducing crop residue feeding to leave them on the field. However, intensive discussions with farmers revealed three main obstacles to adoption of these climate-smart livestock intensification technologies: they require a skillful re-organization of the entire production system, resulting in loss of some multi-functionality of livestock, and incur higher production risks. Low baseline farm emissions in 
Tanzania underline that mitigation cannot be a main objective but rather a co-benefit. If climate change mitigation is synergetic with much-needed productivity improvements, and if possible opening avenues to potential financing options e.g. through C credits, climate-smart livestock intensification options should still be an important building block of Tanzania's climate policies. More research is needed on the effects of climate change on smallholder livestock systems, and the potential role of planted forages in buffering climate-induced fluctuation in crop production. 
Chapter 7

\section{General discussion}



A synthesis of this chapter will be submitted as:

Paul, B.K, Maass, B.L., Groot, J.C.J., Notenbaert, A.M.O., Herrero, M., Tittonell, P.A. Improved feeding and forages at crossroads: farming systems modeling for low emission livestock development in East Africa. Outlook on Agriculture. 


\subsection{Introduction}

Sustainable intensification of livestock production systems has been a global research priority. In SubSaharan Africa (SSA), the primary aim is to improve smallholder livelihoods while mitigating negative environmental impacts. The main objective of this thesis was to explore potential impacts and trade-offs associated with the implementation of improved livestock feeding and forage technologies at farm scale, across a diversity of smallholder crop-livestock systems in East Africa. First, I quantified multidimensional benefits of forage technologies in terms of forage productivity and quality, livestock productivity, soil quality, economic performance and food crop productivity in SSA from published literature. In doing so, it makes the case for the potential contribution of forages to sustainable intensification (Chapter 2). Subsequently, the thesis zooms into the challenge by assessing the status quo of current feeding systems and feed limitations in smallholder farms of East Africa. Using a relatively simple approach to quantify feed gaps in data-scarce smallholder systems, existing feed gaps in various smallholder crop-livestock systems were quantified, resulting in low dairy productivity (Chapter 3). Based on this understanding, I analyzed current performance and efficiencies of various smallholder crop-livestock farming systems. We explored potential impacts and trade-offs of improved livestock feeding and forages from different perspectives and scientific disciplines, considering productivity, environmental and livelihood dimensions. I loosely coupled an economic model with a livestock simulation model to simulate impacts of improved livestock feeding strategies across a household population in Lushoto, Tanzania (Chapter 4). Then, I calculated two relatively simple whole-farm indicators for food security and greenhouse gas (GHG) emissions across a large household dataset from Rwanda (Chapter 5). Lastly, I took a more comprehensive approach studying a variety of productive, environmental and socio-economic indicators for a small number of smallholder livestock systems in Tanzania using household surveys, semi-structured interviews, on-farm measurements and observations to perform multiple-objective optimization modeling (Chapter 6).

Livestock feeding and forages were shown to be at multiple crossroads: at a point where crucial decisions regarding future pathways are made, where productivity and environmental impacts meet, and where scientific disciplines including agronomy, soil and animal science intersect. In this general discussion chapter, I will bring together main findings of my thesis, and reflect on their implications for current societal and scientific debates. First, I explore how improved forages could close the existing feed gaps in SSA, and which obstacles to adoption exist. Then, I discuss the importance of fitting forage 
technologies in agro-ecological and socio-economic context of farming systems, and which agronomic research that requires. Third, I discuss the importance of improved feeding and forages for low emission livestock development, thus reducing environmental trade-offs. Fourth, I am reflecting on farming systems research methods and approaches, and their meaning towards reaching development impact. Lastly, I am ending with suggestions and recommendations for further research, and potential institutional and policy implications.

\subsection{Can planted forages close feed gaps in East Africa?}

Various studies from East Africa have reported inadequate supply of quality feed particularly in the dry season(s) or during prolonged dry spells (e.g. Kabirizi et al., 2006; Mtengeti et al., 2008; Lukuyu et al., 2009; Mutimura et al., 2013). Using a relatively simple approach to quantify feed gaps in data-scarce smallholder systems, we quantified that $61 \%$ of herds in all sites across Tanzania faced a ME feed gap, and 55\% a CP feed gap towards locally attainable milk production levels (Chapter 3 ). Feed gaps have also been reported from other areas. In semi-arid Zimbabwe, dry-season feed gaps in terms of energy and protein supply were especially severe in farms with high stocking rates (Descheemaeker et al., 2018). In seven sites across West and East Africa (Nyando and Wote in Kenya; Hoima in Uganda; Lushoto in Tanzania; Borana in Ethiopia; Yatenga in Burkina Faso; Kaffrine in Senegal), livestock yield gaps were derived from stochastic frontier analysis. Technical efficiency scores were converted the percentage increases required to reach aggregate efficiency scores of 1 in each site. The yield gaps for livestock products ranged from $28-168 \%$, requiring a doubling of output in some cases. For milk, the yield gap in Lushoto was 45\%, in Nyando 55\%, and in Wote 40\% (Henderson et al., 2016). In Mexico, grazing areas provided insufficient metabolizable energy, and milk production could only be sustained through provision of concentrates and conserved forage. Milk production was $78.4 \%$ lower on family-based farms, and $57.9 \%$ lower on semi-specialized farms when compared to a reference farm with best crop production practices and improved herd management (Cortez-Arriola et al., 2014).

Improved livestock feeding and forages potentially have an important role to play in closing such feed gaps (Chapter 2). Tropical forages include a wide variety of sown or planted grasses, herbaceous or dualpurpose legumes and shrubs (also mostly legumes) that are integrated in agro-pastoral, silvo-pastoral and intensive or extensive mixed agricultural systems for grazing or cut-and-carry. Grasses have been more popular than legumes amongst farmers due to lower maintenance requirements for planting and weeding, less pest and disease pressure, their perennial nature, and soil protection properties (Rao et 
al., 2015). Napier grass (Pennisetum purpureum) is a C4 grass native to SSA, and widely used in cut-andcarry systems in East Africa due to its high herbage yields per unit area, and relative tolerance to intermittent drought. However, it requires high soil fertility and is subject to disease pressure including stunt and smut diseases (Negawo et al., 2017). There are other well-documented forage technologies: fodder shrubs including Calliandra calothyrus, Sesbania sesban, Leucaena trichanda in East Africa (Franzel et al., 2003; Place et al., 2009), and herbaceous legumes (Stylosanthes guianensis, S. hamata, Mucuna pruriens) and dual-purpose legumes such as cowpea (Vigna unguiculata) in West Africa (Elbesha et al. 1999; Tarawali et al. 1999; Kristjanson et al. 2005). Increased forage availability (Pennisetum purpureum, Brachiaria hybrid cv. Mulato II, Desmodium uncinatum, D. intortum) has been a welcomed byproduct of the well-documented push-pull system in SSA (Kassie et al., 2018). Several forage grasses, legumes and shrubs have been globally promoted for increased livestock productivity in cut-and-carry systems and have reached a point of commercial importance. These include Brachiaria hybrid cv. Mulato II and other hybrids such as cvs. Cayman and Cobra, Panicum maximum cv. Mombasa and Tanzania, Lablab purpureus cv. Rongai, Desmodium uncinatum and D. intortum, and fodder shrubs including Calliandra calothyrsus, Gliricidia sepium and Leucaena leucocephala (Rao et al., 2015).

Using the feeding system classification and feed gap data presented in Chapter 3, exploratory calculations can elucidate how much forage and land would be required to close the existing feed gaps across different crop-livestock systems (Table 1). 
Table 1: Exploratory analysis of forage and land requirements to close feed gaps in metabolizable (ME) and crude protein (CP) across three crop-livestock systems. ME and CP gaps refer to the definition provided in Chapter 3. Data from Chapter 3 is used: Mvomero for extensive livestock, Babati for mixed semiintensive dairy, and Lushoto for small intensive dairy. Napier refers to Pennisetum purpureum, Brachiaria Cobra to Brachiaria hybrid cv. Cobra, Panicum Tanzania to Panicum maximum cv. Tanzania, and Desmodium Silverleaf to Desmodium uncinatum cv. Silverleaf. Parameters used for this calculation include ME content of forages in Mj/kg (Napier 9.9, Brachiaria Cobra 7, Pancimum Tanzania 8, Desmodium Silverleaf 7.4 Mj/kg); CP content of forages in \% of DM content (Napier 11, Brachiaria Cobra 14, Panicum Tanzania 12, Desmodium Silverleaf 18\%); and herbage production of forages in t DM/year (Napier 10, Brachiaria Cobra 6, Panicum Tanzania 7, Desmodium Silverleaf $4 \mathrm{t} \mathrm{DM/ha).} \mathrm{A} \mathrm{negative} \mathrm{feed} \mathrm{gap} \mathrm{indicates} \mathrm{excess} \mathrm{feeding,} \mathrm{thus} \mathrm{resulting} \mathrm{forage} \mathrm{and} \mathrm{land}$ requirements are not applicable. Bold numbers indicate the forage and land requirements for the most limiting factor (ME or CP).

\begin{tabular}{|c|c|c|c|c|c|}
\hline & & & Extensive livestock & Mixed semi-intensive dairy & Small intensive dairy \\
\hline \multirow{3}{*}{$\begin{array}{l}\text { Farming } \\
\text { system }\end{array}$} & \multicolumn{2}{|l|}{ Cattle herd } & 17 local cattle & 10 local cattle, 3 improved breeds & 1 adult and 1 heifer improved breeds \\
\hline & \multicolumn{2}{|l|}{ Feeding } & Grazing on natural pastures & Grazing plus maize and bean residues & $\begin{array}{l}\text { Natural vegetation cut-and-carry, some } \\
\text { Napier grass }\end{array}$ \\
\hline & \multicolumn{2}{|l|}{ Land availability } & 18 ha & 4 ha & 1 ha \\
\hline \multirow{2}{*}{ Feed gap } & \multicolumn{2}{|l|}{ ME gap (MJ/herd/day) } & 355 & -170 & 27.6 \\
\hline & \multicolumn{2}{|l|}{ CP gap (g/herd/day) } & 1358 & 5406 & 471.9 \\
\hline \multirow{9}{*}{$\begin{array}{l}\text { Forage } \\
\text { required } \\
\text { to fill gap }\end{array}$} & & Forage option & & & \\
\hline & \multirow{4}{*}{$\begin{array}{l}\text { Required forage (kg } \\
\text { DM/day) for filling ME gap }\end{array}$} & Napier & 44.4 & - & 3.5 \\
\hline & & Brachiaria Cobra & 50.8 & - & 3.9 \\
\hline & & Panicum Tanzania & 39.5 & - & 3.1 \\
\hline & & Desmodium Silverleaf & 48.0 & - & 3.7 \\
\hline & \multirow{4}{*}{$\begin{array}{l}\text { Required forage (DM/day) } \\
\text { for filling CP gap }\end{array}$} & Napier & 13.6 & 54.1 & 4.7 \\
\hline & & Brachiaria Cobra & 9.7 & 38.6 & 3.4 \\
\hline & & Panicum Tanzania & 12.3 & 49.1 & 4.3 \\
\hline & & Desmodium Silverleaf & 7.5 & 30.0 & 2.6 \\
\hline \multirow{8}{*}{$\begin{array}{l}\text { Land } \\
\text { required } \\
\text { to fill gap }\end{array}$} & \multirow{4}{*}{$\begin{array}{l}\text { Required land to fill ME } \\
\text { gap (ha) with forage }\end{array}$} & Napier & 1.6 & - & 0.1 \\
\hline & & Brachiaria Cobra & 3.1 & - & 0.2 \\
\hline & & Panicum Tanzania & 2.1 & - & 0.2 \\
\hline & & Desmodium Silverleaf & 4.4 & - & 0.3 \\
\hline & \multirow{4}{*}{$\begin{array}{l}\text { Required land to fill CP gap } \\
\text { (ha) with forage }\end{array}$} & Napier & 0.5 & 2.0 & 0.2 \\
\hline & & Brachiaria Cobra & 0.6 & 2.3 & 0.2 \\
\hline & & Panicum Tanzania & 0.6 & 2.6 & 0.2 \\
\hline & & Desmodium Silverleaf & 0.7 & 2.7 & 0.2 \\
\hline
\end{tabular}


Depending on farming system and forage species, between $17-68 \%$ of the total farmland would need to be dedicated to additional forage cultivation to fill the feed gap (Table 1). The results depend on assumptions made regarding herbage production and crude protein (CP) and metabolizable energy (ME) content of forages, which can be highly variable depending on agro-ecology, season and management. Therefore, these calculations can only be viewed as exploratory, but they illustrate the challenge of land requirements for sufficiently feeding cattle with on-farm cultivated forages. Especially in areas where agro-ecological potential and population pressure is high, farmers need to weigh between various land uses and associated opportunity costs. Food crops will often be prioritized to ensure food selfsufficiency, and cash crops are an attractive income-generating activity, especially if markets are available (Makoni et al., 2013). Bosire et al. (2016) confirmed that technically, milk and meat production in Kenya could be increased by $51 \%$ and $71 \%$ respectively, without encroaching natural areas. However, competition for land would be intense as the cropland area that needs to be converted to feed crops had to increase by 50-300\%. Other studies have underlined the challenge of land requirements for forage cultivation in densely populated areas such as Rwanda (Umunezero et al., 2016; Klapwijk et al., 2014b). This points to the importance of spatial and temporal integration of tropical forages into cropping systems to reduce competition with food crops (Section 7.3).

In addition to lack of available land for forage cultivation, other reasons for lack of adoption of forage technologies have been discussed in the literature. Adoption has remained below expectation, despite proven potential benefits (Pengelly et al., 2003; Owen et al., 2012; Hall et al., 2007; de Haan et al., 2006).

1) There is a lack of awareness and knowledge, low support and investment from national and local authorities, lack and cost of planting material, and lack of market linkages for inputs and outputs (Ndah et al., 2017; Owen et al., 2012; Peters et al., 2003; Romney et al., 2004).

2) Lack of land tenure has been shown to discourage forage cultivation in Kenya (Njarui et al., 2017). Different intra-household access to land and division of labor by women and men can also influence adoption, especially in pastoral and agro-pastoral systems (Omollo et al., 2018).

3) Improved feeding needs to go hand in hand with a range of other technological changes, otherwise production responses can be disappointing. For example, a farmer would have to improve the animal breed, provide drinking water, ensure veterinary services, and improve animal husbandry in order to reap benefits of higher milk production from improving the feed 
(Chapters 3 and 4; Ndah et al., 2017). The adoption of several technologies at the same time is a challenge to smallholder farmers lacking investment capacity.

4) It requires a substantive farming system and cultural shift to replace (parts of) free grazing with cut-and-carry feeding of cultivated forages (Chapter 6). Farmers who are unfamiliar with the concept of investing labor (planting, management and harvesting) and capital (seeds, land) in producing feed that was previously acquired "for free" are more reluctant to start growing forages. Such investment is mostly common for food crops but not for feed (Thomas and Sumberg, 1995).

5) Most fundamentally, an obstacle to adoption might be that a farmer's objective has not been well defined (Sumberg, 2002). Farmers manage livestock according to the weighing of their functions (Rufino, 2007). Livestock intensification is not the main priority for farmers that primarily keep livestock for providing drought power, as assets and risk management strategy, or for cultural reasons (Sumberg and Lankoande, 2013; Thomas and Sumberg, 1995). These functions provide incentives for keeping large livestock herds at low productivity levels, instead of reducing stocking rates and investing in increased productivity (Descheemaeker et al., 2016).

\subsection{Where to fit? Tropical forages matching agro-ecological and socio-economic contexts}

Improved forages have been shown to potentially contribute to sustainable intensification in SSA. Improved forages had on average a 2.6 times higher biomass production than local controls. Soil losses on average almost halved when forages were intercropped with food crops, and food grain yields increased by $60 \%$. Milk production increased by an average $35 \%$ when forages were part of improved feeding regimes (Chapter 2). Forages range from annual and perennial herbaceous and dual-purpose legumes to fodder shrubs and grasses, and each can occupy a different spatial and temporal niche and fulfill a different objective in a given farming system. Skillful spatial and temporal integration into cropping systems, especially with food crops, is key in not compromising smallholders' food security and deliver multiple benefits. Tropical forage technologies can therefore be considered knowledge-intensive technologies (Ates et al., 2018; Maass et al., 2015; Rudel et al., 2015). Highly participatory approaches to research for development (R4D) have shown higher success in forage adoption, working together with farmers to find solutions (Stür et al., 2002). In Rwanda, several cropping system niches for additional forage cultivation could be identified. Shade-tolerant grasses and legumes such as Brachiaria spp., Desmodium intortum and $D$. uncinatum, and Mucuna pruriens could be suitable for planting below public and private woodlots and bananas. Farm boundaries, roadsides terraces and contours have been 
popular niches for grasses such as Napier grass fodder shrubs, especially in erosion-prone areas (Figure 1a). Integration of forage grasses with food legume on cropping land is another niche, such as Napier grass with green peas in highland areas (Pisum sativum) (Figure 1b). Suitability of those niches depends on bio-physical conditions and tolerance of forage species to e.g. soil acidity, slope, and shade, as well as socio-economic factors such as land tenure, distance to farms and policy regulations (Umunezero et al., 2016). In highland areas in Madagascar, Brachiaria hybrid cv. Mulato has been used as cover crop in Conservation Agriculture (CA) systems to improve soil structure and soil organic matter, for example as intercrop with cassava (Maass et al., 2015). Further experimentation and model exploration included integration of dual-purpose legumes with rice and maize under CA, such as Lablab purpureus, Vetch villosa, Arachis pintoi, and Stylosanthes guianensis. A 30-60\% residue retention rate was shown to be beneficial for soil fertility without compromising dairy cow feeding (Naudin et al., 2012). On-farm participatory research from DR Congo has shown that $43 \%$ of farmers decided to grow forages intercropped with food crops such as maize and cassava, especially legumes such as Stylosanthes guianensis, Canavalia brasiliensis and Desmodium uncinatum. Choice of forage species and integration into farming systems depended on many factors, including soil fertility, land tenure, safety, and predominant livestock management system (Paul et al., 2016). One of the best documented examples of successful cropping systems integration is the push-pull system. It integrates forage grasses and legumes with maize, sorghum and millet to decrease Striga and stemborer infestation, thereby increasing cereal yields. Napier grass, and Brachiaria hybrid cv. Mulato II in drier areas, is planted around the cereal crop to attract and trap stemborer moth. Desmodium uncinatum (cv. Silverleaf), and Desmodium intortum (cv. Greenleaf) in drier areas, is intercropped with the cereal and causes abortive germination of Striga due to root exudates (Khan et al., 2014). Despite the high initial investment especially for Desmodium seed and establishment, farmers appreciate higher feed availability and quality, and improved milk productivity, especially in areas with a good dairy market (De Groote et al., 2010). Thus, forage technologies do not only need to fit cropping systems and agro-ecologies, but also socio-economic environments. The concept of socio-ecological niches summarizes this notion, referring to best-fit agricultural improvements that are adapted to the agro-ecological, socio-cultural, economic and institutional context (Descheemaeker et al., 2016; Ojiem et al., 2017). 


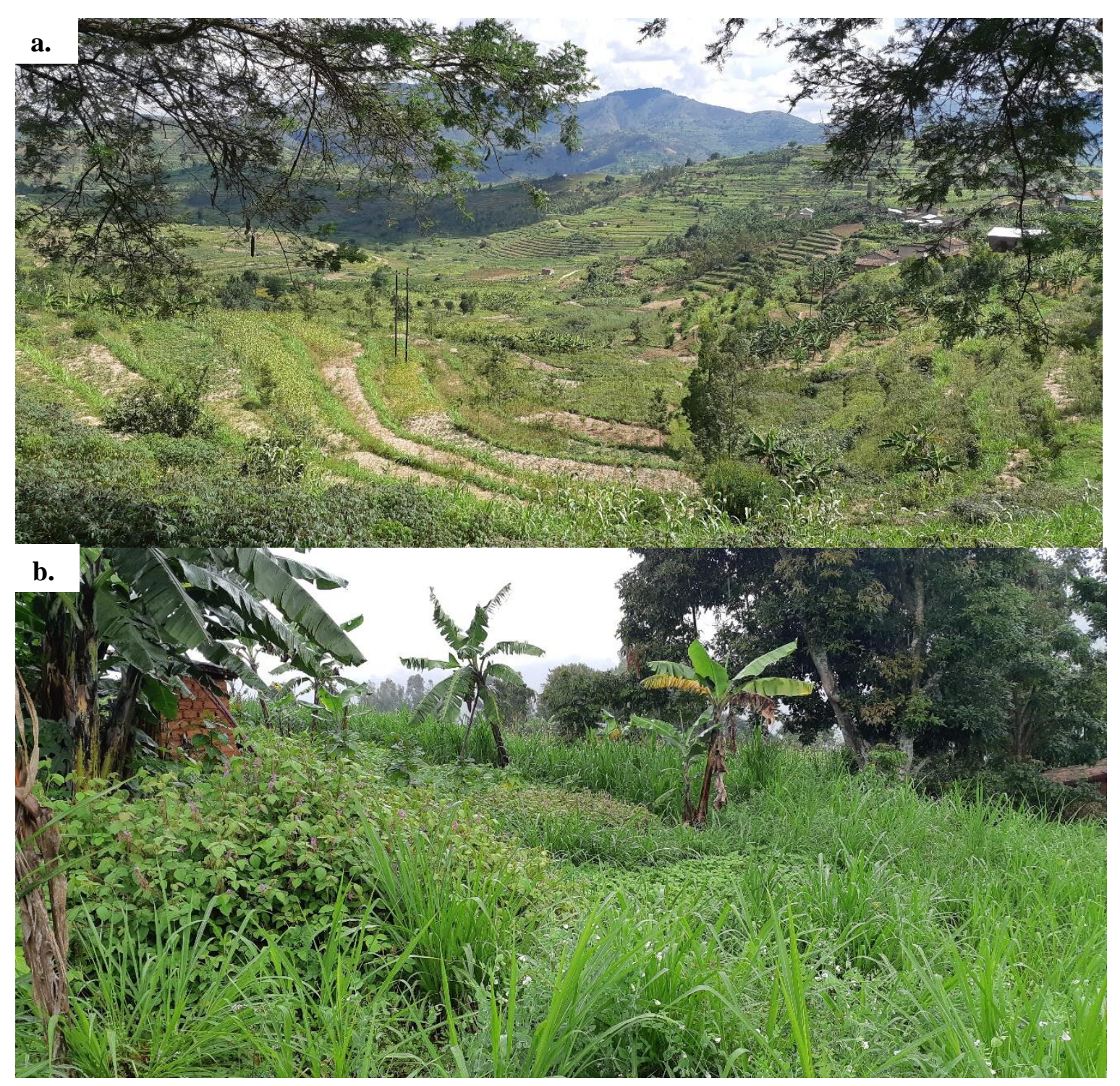

Figure 1: Napier grass grown on contours and terraces in Butare, Rwanda (a), and Napier intercropped with peas in front, and Desmodium distortum with Napier grass in the background in Burera, Rwanda (b). Photos credits: Birthe Paul.

However, agronomy research has been criticized as lacking 'scalability', emphasizing local relevance of research results. Few randomized and researcher-controlled trials, mostly on research stations but increasingly farmers' fields, help in identifying single factors influencing yield and elucidating underlying mechanisms. However, they fail to predict realistic performance under farmers' conditions, as the interplay of factors of environment, genotype and management determine yields, not single factors. The average yield under experimentation will only be reached by a small proportion of farmers, owing to the large variability of agro-ecological conditions and management that affect performance. 'Agronomy at 
scale', or a large number of small, un-replicated trials in farmers' fields under their own management could help unravel determining factors that cause variability in crop productivity. Statistical methods continue evolving to consider and embrace this variability (Vanlauwe et al., 2016). Moreover, participatory on-farm trials can support experiential learning by farmers to adapt and fit forages into their own systems (Paul et al., 2014).

Multi-locational, consistent, high quality and inter-operational data is crucial for forage agronomy to keep pace with the challenge of scalability, and the evolution of (big) data science, geospatial analytics and decision support tools. However, variability in forage agronomy data from SSA is remarkably high, for example in Napier grass as presented in Chapter 2. This can partly be explained by its wide adaptation to a range of agro-ecological conditions, and yield variation depending on cultivar and its interaction with cutting regime and fertilization. However, there is also a lack of application of standardized methods in forage agronomy data collection and analysis, which reduces comparability across sites (Chapter 2). Forage agronomy has been less resourced than other field crops, resulting in fewer publications and less established evaluation methods. Only few journals are specialized in forage agronomy, such as Crop and Pasture Science, Tropical Grasslands - Forrajes Tropicales, Grass and Forage Science, and Grassland Science. Some agronomy related journals also accept forage publications, although their numbers are comparably low, including Journal of Experimental Agriculture, Field Crop Research, and European Journal of Agronomy. Sufficient multi-locational, high-quality data is a main bottleneck to calibrate crop simulation models for main forages in East Africa. Until date, adaptation of mechanistic crop models to tropical forages have been limited and are mostly location or region specific (Andrade et al., 2016). The CROPGRO Perennial Forage Model was brought into the Decision Support System for Agrotechnology Transfer (DSSAT) 4.7 release in 2017 by including a storage organ (rhizome/stolon) as well as dormancy and partitioning to allow for periodic defoliation and re-growth. It has been parameterized and calibrated for Brachiaria brizantha cv. Marandu (Pequeno et al., 2014), Brachiaria brizantha cv. Xaraes (Pedreira et al., 2011), Brachiaria hybrid cv. Mulato II (Pequeno et al., 2017), and Panicum maximum cv. Tanzania (Lara et al., 2012) in Brazil. Other empirical models that predict the growth and biomass accumulation of tropical forages include APSIM, ALMANAC, Century and Orchidee-GM that have been calibrated to the genera of Paspalum, Cynodon, Brachiaria and Panicum (Andrade et al., 2016). To date, no testing or adaptation has been done with data from East Africa. Such calibrated perennial forage simulation model could help with targeting and scaling suitable forage technologies to various agro-ecological conditions, quantify forage yield gaps and highlight improved management strategies, estimate soil organic carbon accumulation, and test adaptability of forage crops 
to future climate change scnearios. Similar to crop yield gap analysis, calibrated perennial forage models could quantify the forage yield gap and highlight improved management strategies.

\subsection{Greening the white gold - implications for low emission livestock development}

Livestock and its role in global environmental change has been an actively discussed topic in science and policy arenas (e.g. Willett et al. 2019; The Economist 2019). Some argue that the public discussion has been simplistic and over-emphasizing the 'bad' of livestock, mainly the environmental impact, neglecting the 'good' of livestock keeping in smallholder systems. The debate needs to differentiate between industrialized systems, where consumption levels of animal source foods have exceeded boundaries of human and planetary health, and developing countries, where current consumption is only a fraction and the role of livestock in agricultural sustainability is more complex. Animal products are excellent sources of proteins, iron, zinc, and essential vitamins and minerals that can prevent stunting of physical and cognitive development. They are essential for a healthy diet where the variety of foods is seasonally and locally determined. In addition, livestock are paramount to nutrient cycling, wealth storage and risk management, insurance, draft, and income of smallholder farmers (Ayantunde et al., 2018; Herrero et al., 2012; Salmon et al., 2018). In SSA, yield gaps of most products are so large that intensification is a necessity, regardless of whether it is conventional, sustainable or ecological (Tittonell and Giller, 2013). De-intensification is needed in high-external input, industrial agricultural systems, and intensification in low-input systems with large yield gaps. Society needs different conceptualizations of sustainable intensification for different parts of the world. There are different ways to 'green' agriculture, and the term of sustainable intensification is contested and complex (Struik and Kuyper, 2017).

Improved livestock feeding and forages can contribute to a 'greening' of livestock. Enteric fermentation and manure management are the main contributors to whole-farm GHG emissions in East Africa, which makes livestock is a key entry point for climate change mitigation (Chapters 5 and 6; Seebauer, 2014). However, baseline emissions are low when compared to industrialized countries, which has been confirmed by the results presented in Chapter 5, 6 and 7. In contrast to industrialized countries that need to reduce absolute emissions, the focus in East Africa should be on reducing emission intensities through efficiency gains (Salmon et al., 2018). Through taking different modeling approaches, this thesis has shown that livestock feeding can decrease GHG emission intensities without compromising income and food security of smallholder farmers in East Africa. Multi-objective optimization of various smallholder livestock systems in Tanzania revealed how reducing ruminant numbers, replacing local 
cattle with improved dairy breeds, and improving feeding through on-farm Napier grass (Pennisetum purpureum) cultivation were synergetic options (Chapter 6). Simulation results illustrated that households with improved cattle would be able to achieve higher income and lower methane emission intensity with improving quality and quantity of their feed than households with local cattle in Tanzania (Chapter 4). The improved livestock feeding scenario in Rwanda increased food security at only a small GHG trade-off, although it was the least equitable strategy reaching more well-off farmers (Chapter 5). This corresponds to literature that have presented livestock feeding as triple-win climate smart technology (Bryan et al. 2013; Thornton \& Herrero, 2010). However, GHG emission measurement and quantification approaches are continuously evolving, and differences in methods complicate comparability of results (Denef et al., 2012; Richards, 2016). Limited data availability is a main constraint to GHG emission accounting in SSA, thus most approaches (as employed in this thesis) rely on IPCC Tier 1 and 2 emission factors which have often been shown to be inaccurate for SSA but remain the best available approach (Mushi et al., 2015). Harmonized, low-cost methods are needed to establish locally suitable emission factors (EF) (Rosenstock et al., 2013), and empirical measurements have recently been published that improve emission factors for East Africa (Goopy et al., 2018; Ndung'u et al., 2019; Pelster et al., 2016).

Improved livestock feeding and forages are therefore key to low emission livestock development, a concept that was coined by the CGIAR Research Program on Climate Change, Agriculture and Food Security (CCAFS), the Global Research Alliance on Greenhouse Gases (GRA), and the Food and Agriculture Organization of the United Nations (FAO). Low emission livestock development aims to avoid pathways and pitfalls, 'leapfrogging' industrialized countries. It can also open new avenues to finance agricultural development. Just over 100 countries refer to agriculture as one domain of action to deliver on their Nationally Determined Contributions (NDCs) under the Paris Agreement, the landmark agreement signed by the UNFCCC (United Nations Framework Convention on Climate Change) parties on 12 December 2015 to accelerate actions and investments needed for a low carbon future. All 54 African countries have signed the Paris Agreement, and 44 countries have submitted Nationally Determined Contributions (NDCs) to the UNFCCC. In general, development and environmental goals targeting livestock and dairy are gaining more traction in East Africa. For example, dairy development is one of the main mechanisms to reach Rwanda's vision 2020, and Ethiopia's Growth and Transformation program has dairy anchored in pro-poor development policies (Makoni et al., 2013). Measurement, reporting and verification (MRV) approaches are becoming more important to unlock such finance. Capacity building is needed to improve countries' reporting to the UNFCCC, and quantify mitigation 
contributions from technologies such as livestock feeding and forages towards NDCs. Improving collection of high-quality feed data at national level is essential for accurate estimations (Harinder and Philippe, 2014).

Improved forages can also generate other environmental benefits such as soil conservation or improvement (Chapter 2). In contrary to grain-based intensification, which has been the dominant model in industrializing livestock development, grass-fed livestock intensification might have positive impacts in terms of land restoration (Godde et al., 2018). In Colombia, productive pastures were found to have higher soil aggregate stability, $20 \%$ more soil C and N, and nearly $40 \%$ higher organic phosphorus than degraded pastures (Fonte et al., 2014). Land degradation includes soil erosion, soil compaction, soil sealing, change in soil and nutrient content, salinization, acidification, change in runoff and infiltration regimes of water, nutrients and agrochemicals, invasive species, loss of native vegetation, loss of net primary productivity (NPP), loss of biotic diversity, and loss of ecosystem services. In SSA, the first problem has been reported to be soil erosion, followed by loss of soil organic carbon (SOC), nutrient imbalances and loss of soil biodiversity (Montanarella, 2016). Improved tropical forage grasses can directly increase SOC and decrease soil erosion (Chapter 2), while indirectly increasing organic matter input to soils through decreasing pressure on crop residues for livestock feeding (Chapter 6). Similar to NDC contributions, developing countries need robust evidence to show contributions to Land Degradation Neutrality (LDN) targets under the UNCCD (UN Convention to Combat Desertification) to access land restoration finance. Greater policy impact might be achieved if model results of priority areas for land restoration are combined with stakeholder prioritization, as areas of overlap can drive motivation, commitment and ultimately action (Willemen et al., 2018).

\subsection{Bringing research to impact - reflections on the use of farming systems modeling approaches and tools}

Ex-ante impact assessment and prioritization studies are increasingly important to target scarce research and development resources, and support decisions for improved adaptation and mitigation of mixed crop-livestock systems in SSA (van Wijk et al., 2014; Descheemaeker et al., 2016). This thesis aimed to generate results that can inform policy makers, project designers, investors, donors and other decision-makers on prioritizing options towards low emission livestock, despite the complexity of potential impacts and trade-offs. Different metrics, approaches and tools are needed for ex-ante impact assessment, including simulation modeling, optimization modeling, cost-benefit analysis, meta-analysis, integrated assessment, and spatial analysis. All approaches and tools satisfy different objectives and 
have different requirements, functionalities, strengths and disadvantages (Thornton et al., 2018). Metaanalysis techniques were employed in Chapter 2 to quantify average multi-dimensional impacts of forage technologies in SSA. However, meta-analyses are time-consuming, and it is difficult to draw conclusions on underlying processes (Thornton et al., 2018). Simulation modeling was used in Chapter 4, combining a livestock model (Ruminant) and an economic model (TOA-MD) to assess the impacts of improved feeding scenarios on various strata of the household population. Simulation modeling is widely used but often complex, calibration and validation are challenging and high uncertainty is associated with results, and the models have high data demands (Thornton et al., 2018). Multi-objective optimization modeling was employed in Chapter 6 to identify livestock technologies that can maximize income while decreasing GHG emissions. Even more so than other modeling, optimization modeling is complex, data intensive and time consuming (Thornton et al., 2018) and could only be applied to few farming systems for intensive exploration.

Understanding, considering, capturing and classifying the heterogeneity and diversity of smallholder farming systems in SSA is the basis to understanding the dynamics and exploring responses to interventions (Giller et al., 2011; Tittonell et al., 2010). Two basic contrasting approaches to whole-farm modeling of smallholder systems can be distinguished (Table 2). Firstly, modeling few farming systems, types or classes that are considered representative is a well-established approach. Farming system types are a population of individual farm systems that have broadly similar resource bases, enterprise patterns, household livelihoods and constraints, and for which similar development strategies and interventions would be appropriate (Dixon et al., 2001). Methods for constructing farming systems typologies include multivariate statistics (e.g. principal component analysis, clustering techniques), decision trees, and expert-based and participatory typologies. An integration of qualitative stakeholder views and quantitative, statistical analysis of one-off surveys promises to result in typologies that are stable and valid in the longer term, despite the rapidly changing and dynamic environment (Alvarez et al., 2018). Methods for selecting farming system types for whole-farm modeling can be classified as 'real' farm versus a 'constructed' farm. A real representative farm can be identified within a wider household dataset through multivariate statistics (e.g. Alary et al., 2016; Cortez-Arriola et al., 2014; Rigolot et al., 2017; Waithaka et al., 2006), or through participatory Focus Group Discussions (Michalscheck et al., 2018). A farm can also be purposively selected for modeling to test and illustrate functionalities of a new model or modules (Ditzler et al., 2019; Parsons et al., 2011). Generic, 'synthetic' farming systems have been defined for large geographic areas using various data sources including 
literature, policy documents, census data and expert knowledge (Mayberry et al., 2017; 2018) or from mean values of household survey data for each particular type (Descheemaeker et al., 2018). Komarek et al. (2012) employed a hybrid method where they selected representative farms for each type, and used mean values for each class to calibrate the farms. Between three to nine farming systems were modeled in the above-mentioned studies without within-type replication, and only Alary et al. (2016) modeled two farms per type to explore impacts of Conservation Agriculture technologies. Secondly, modeling entire farm has become increasingly popular. Relatively simple indicators, such as land productivity, food availability and self-sufficiency, greenhouse gas emissions (IPCC Tier 1), household income, or dietary diversity score can be calculated for all households of a household survey. Although not necessary in this approach, results are often presented in strata following the particular research question. Strata could be based on research questions (Shikuku et al., 2017), classes identified in the outcome variables such as food availability or greenhouse gas emissions (e.g. Frelat et al., 2016; Paul et al., 2018; Ritzema et al., 2017), or types identified through multivariate statistics (Douxchamps et al., 2016; Falconnier et al., 2015; Lopez-Ridaura et al., 2018). Household populations for which this approach was implemented ranged from 32 households (Falconnier et al., 2015) to 13,000 (Frelat et al., 2016) households (Table 2). 
Table 2: Approaches to whole-farm modeling of smallholder mixed crop-livestock systems, including geographic scope, number of households or farming systems modeled, and data source or method. ImpactLite stands for Integrated Modelling Platform for Mixed Animal Crop Systems, a commonly used survey tool.

\begin{tabular}{|c|c|c|c|c|}
\hline & Geographic scope & $\begin{array}{l}\text { Number of } \\
\text { households/ } \\
\text { farming } \\
\text { systems }\end{array}$ & Data source/method & Reference \\
\hline \multirow{9}{*}{$\begin{array}{l}\text { Farming system population } \\
\text { modeling }\end{array}$} & $\begin{array}{l}\text { Mali: Koutiala } \\
\text { India: Uttarakhand }\end{array}$ & 30 & $\begin{array}{l}\text { Dataset of } 17 \text { years by Malian Institute for Rural } \\
\text { Economy (IER), participants purposively selected } \\
\text { according to oxen endowment typology } \\
\text { Household survey, participants purposively } \\
\text { selected to reflect various nutrient management } \\
\text { systems }\end{array}$ & Falconnier et al. 2015 \\
\hline & Tanzania: Lushoto district & 164 & CCAFS ImpactLite data & Chapter 4: Shikuku et al. 2017 \\
\hline & India: Bihar & 269 & $\begin{array}{l}\text { Cereal Systems Initiative for South Asia (CSISA) } \\
\text { survey, random sampling }\end{array}$ & Lopez-Ridaura et al. 2018 \\
\hline & Burkina Faso, Ghana, Senegal & 600 & CCAFS ImpactLite data, stratified sampling & Douxchamps et al. 2016 \\
\hline & Rwanda: different districts & 884 & CIALCA baseline survey & Chapter 5: Paul et al. 2018 \\
\hline & $\begin{array}{l}\text { Kenya, Tanzania, Uganda, } \\
\text { Ethiopia, Senegal, Burkina }\end{array}$ & & & \\
\hline & Faso & 1019 & CCAFS ImpactLite data, stratified sampling & Henderson et al. 2016 \\
\hline & $\begin{array}{l}\text { East and West Africa: } 7 \\
\text { countries }\end{array}$ & 1800 & CCAFS ImpactLite data, stratified sampling & Ritzema et al. 2017 \\
\hline & Sub-Saharan Africa & 13000 & Collated dataset of various household surveys & Frelat et al. 2018 \\
\hline \multirow{3}{*}{$\begin{array}{l}\text { Farming system } \\
\text { type modeling }\end{array}$} & India, Ethiopia & 4 & $\begin{array}{l}\text { Constructed from ImpactLite survey, government } \\
\text { census, OPEC database and other databases and } \\
\text { expert knowledge and policy documents }\end{array}$ & Mayberry et al. 2018 \\
\hline & & & $\begin{array}{l}\text { Constructed from ImpactLite survey, government } \\
\text { census, OPEC database and other databases and }\end{array}$ & \\
\hline & India, Ethiopia & 5 & expert knowledge and policy documents & Mayberry et al. 2017 \\
\hline
\end{tabular}


Mexico: Yucatan

Zimbabwe: Nkayi

Tanzania: Babati

Burkina Faso: Yatenga

China: Gansu

Real

Kenya: Vihiga

Mexico: Michoacan

Ghana: three regions

Vietnam: Son La

Brazil: Cerrados
Constructed from averages from household

survey ( $\mathrm{n}=91$ ) for 2 types (poor and non-poor, 3 stocking densities)

Descheemaeker et al. 2018

Multvariate statistics typology on household

survey data $(n=94)$

Chapter 6: Paul et al. in review

Real farms selected from CCAFS baseline

$(n=200)$; selected two contrasting systems (small

and large) based on previously published

multivariate statistics typology

Rigolot et al. 2017

Real farms selected with PCA and clustering from household survey $(n=90)$. A representative for

each cluster was then calibrated with

average/means from the cluster.

Komarek et al. 2012

Real farms, pilot farms chosen to be

representative for subsistence, semi-subsistence,

semi-commercial

Waithaka et al. 2006

Real farms identified by multi-variate statistics from survey data of around 90 households

3 types in 3 regions (low, medium, high resources) - Focus Group Discussions to identify types and representative households for visits

Michaelscheck et al. 2018

Purposively selected from ImpactLite survey of 17 hhs (but this is also a paper that presents new model modules)

Ditzler et al. 2019

3 types, 2 farms for each. Typology based on multivariate statistics in a separate study 
This thesis has employed different ways to deal with farming systems complexity - working with populations of households (Chapters 4 and 5), and modeling few representative farming systems derived from participatory and multivariate statistics typologies (Chapters 3 and 6). Both approaches have their inherent advantages and disadvantages: Modeling entire farm populations can analyze variability and spread across many households and is not challenged with representativeness when selecting farming systems for modeling. Approaches tend to me more rapid as only one-off household data is required. Often, results are perceived as being more widely applicable, more 'scientific' and more relevant to decision and policy makers. However, calculations have to be relatively simple to be applied to household survey data, and can only deliver a first picture or snapshot of the situation that can pave the way for more detailed, nuanced and fine-grained household analysis, as well as experimentation and monitoring/evaluation (Hammond et al., 2017). Moreover, quality of outputs entirely depends on the quality of survey data which has often been questioned (Carletto et al., 2013a; Fraval et al., 2018). Household surveys are one of the most commonly used data sources for farming system modeling, and were employed in Chapters 4, 5 and 6. Surveys rely on farmer recall instead of more time and resource intensive monitoring and measurement. Carletto et al. (2013b) compared farmer-reported farm sizes with empirical measurements. They showed that farmers with small land holdings ( $<5$ acres) tended to overestimate their land size, while farmers with larger land holdings ( $>5$ acres) underestimated the same. Fraval et al. (2018) compared standard data derived from three multi-purpose farming systems survey tools - Integrated Modelling Platform for Mixed Animal Crop Systems (ImpactLite), the Rural Household Multiple Indicator Survey (RHoMIS) and the Living Standards Measurement Survey program (LSMS). Yields and land areas were found to be less reliable than other variables, although they are key to any productivity and poverty estimations. Farmer reported data has its inherent weaknesses, and validation and triangulation with mixed data collection methods is essential (e.g. Chapter 6). Modeling few farming systems on the other hand enables more in-depth understanding of complexities, underlying dynamics and relationships between farming systems components. Working with real farms allows for feedback loops and participatory modeling that can improve modeling quality and outputs, and allows mutual learning processes. However, selecting few farms to represent types risks to lose the unavoidable intra-type variability or heterogeneity (Alvarez et al., 2018). Extrapolation of results from analyzing case study farms to farming systems and types might become difficult as there are many factors at play including land sizes, management, off-farm activities and farmers' objectives (RipollBosch et al., 2012). The outscaling potential of results, underpinning analysis with changes in policy, institutions and markets, and the science-policy interface are areas that need more future attention 
(Groot et al., 2017). Mixed methods data collection and modeling can also be more time and resource intensive. It is a balancing act to obtain a sufficiently accurate picture without being overly simplifying, using the least resource-intensive approach available. Perfectly representing the system reality is not desirable, but appropriate imprecision and simplification of realities' complexity is needed (Chambers, 2017).

The increased pressure for more impact by research funders has intensified the identity crisis the international R4D community is facing. Some argue that research should not try to do development, but try and produce results that are relevant to development. More than the number of farmers that research reaches directly, it is about the uptake of research products which happens in partnership with development actors and funders (Leeuwis et al., 2017a, 2017b). CCAFS recently published a framework (Thornton et al., 2017) and case studies (Dinesh et al., 2018; Westermann et al., 2018) on making agricultural research for development outcome based. They illustrate three different scaling pathways value chains and private sector, information and communication technologies and agro-advisory services, and policy engagement (Westernmann et al., 2018). Dinesh et al. (2018) analyze 34 case studies of science-policy engagement, explaining the three/thirds principle of allocating resources in equal proportions to not only evidence but also outreach and engagement. Another way of how research can make impact is influencing and shaping public discourse, yet it is much more difficult to document, and has therefore often been overlooked. The question of how evidence is, can or should be translated to inform policy and decision making is not new. Access to research results seems to not be the decisive factor, but Sutherland and Wordley (2017) argued that "evidence complacency" is at play. Practitioners prefer anecdotes over evidence, leading to poor practice and inefficiencies. Reasons include that policy makers or practitioners think they already have enough knowledge, evidence is not relevant to their context, too much effort is needed to check evidence, reliance on evidence reduces professional autonomy in decision making, people are more accessible and useful information sources than evidence, inadequate training in using evidence, competing demands on their time, and short-term pressure to deliver strong policy/project independent of its success (Sutherland and Wordley, 2017). There is also an inherent tension between the complexity of smallholders' realities, and simplicity of guidance that decision makers require. Re-defining the balance between doing justice to complexity of farming systems and translating results into simplicity and 'digestibility' requested by decision-makers is an area that deserves future research attention. 


\subsection{At a crossroads - the way forward}

In this thesis, we have quantified the crucial importance of livestock for food security and income, but also livestock's major contribution to total agricultural GHG emissions across a diversity of crop-livestock systems in East Africa. We showed how feed gaps in quantity and quality currently result in low dairy productivity. Improved livestock feeding practices can affect farming systems in various key ways, closing feed gaps and increasing livestock productivity, food availability and household income, while reducing GHG emission intensities and improving soil quality. This thesis argues that improved livestock feeding and forages are at a crossroad: they link crop, livestock and soil components of farming systems, and are a potentially crucial entry point to low emission livestock, mitigating agro-environmental tradeoffs. Data-scarce environments such as East Africa pose special challenges to research, necessitating the development of minimum-data approaches. Triangulation with methods from different scientific disciplines, and on-farm participatory research, improves data quality as well as local relevance and experiential learning of research.

Suggestions and recommendations for future research include the following three broad areas: First, research in this thesis calls for next-level forage agronomy. Agronomy is challenged to develop 'scalable' approaches and results that can be translated into targeting and decision support tools. Agronomy at scale can identify factors influencing site-year variability and adaptability of forages in farmers' fields. Forage crop modeling, as well as big data approaches could support this, including data mining, metaanalysis and geospatial analytics. However, high-quality, multi-locational, inter-operable, standardized and consistent forage agronomic data has to become available. Systems agronomy approaches and the socio-ecological niche concept can further our understanding of spatial and temporal integration of forages into complex cropping and farming systems to reduce land requirements and deliver multiple benefits. Second, this thesis made a step, but also highlights an urgent need for further multi-disciplinary and systems-level approaches to quantify synergies and trade-offs between different productivity, environmental and livelihood dimensions. Low emission livestock for smallholder systems in East Africa is only viable if it does not come with livelihood trade-offs. Validation has been a tricky area in farming systems modeling, and linking ex-ante estimations to on-farm measurements and ex-post impact assessment could improve model predictions. Re-defining the balance between doing justice to complexity of farming systems and translating results into simplicity and 'digestibility' requested by decision-makers is another area that deserves future research attention. Third, potential country-level contributions of improved feeding and forages to GHG mitigation and land restoration policy targets is an emerging research demand. The current methods often rely on coarse estimations, and can be 
improved with better feeding data and locally derived parameters. Only little research is available from SSA that reports the contribution of improved forages to soil quality and restoration, including soil organic carbon and physical soil quality.

Improved livestock feeding practices could play a key role towards low emission livestock development and potentially land restoration at scale. More investment in research and capacity building is needed to quantify and synthesize potential contributions of livestock feeding and forages to NDC and LDN commitments by countries without risking trade-offs in smallholder livelihoods. If linked to such policy processes, funding avenues for implementing these practices at scale could be unlocked. Ex-ante impact estimations can assist in policy dialogue and stakeholder engagement to better select and prioritize policies and development programs, despite the complexity of its impacts and trade-offs. 


\section{References}

Alary, V., Corbeels, M., Affholder, F., Alvarez, S., Soria, A., Valadares Xavier, J.H., da Silva, F.A.M., Scopel, E., 2016. Economic assessment of conservation agriculture options in mixed crop-livestock systems in Brazil using farm modeling. Agricultural Systems 144, 33-45.

Alexandratos, N., Bruinsma, J., 2012. World agriculture towards 2030/2050: The 2012 revision. ESA Working Paper No. 12-03. Food and Agriculture Organization of the United Nations (FAO), Rome, Italy.

Alvarez, S., Paas, W., Descheemaeker, K., Tittonell, P., \& Groot, J., 2014. Typology construction, a way of dealing with farm diversity. Report for the CGIAR Research Program on Integrated Systems for the Humid Tropics, Wageningen, the Netherlands 1-37.

Alvarez, S., Timler, C.J., Michalschek, M., Paas, W., Descheemaeker, K., Tittonell, P., Andersson, J.A., Groot, J.C.J., 2018. Capturing farm diversity with hypothesis-based typologies: An innovative methodological framework for farming system typology development. PLoS ONE 13(5).

Andrade, A.S., Santos, P.M., Pezzopane, J.R.M., de Araujo, L.C., Pedreira, B.C., Pedreira, C.G.S., Marin, F.R., Lara, M.A.S., 2016. Simulating tropical forage growth and biomass accumulation: an overview of model development and application. Grass and Forage Science, 71 (1), 54-65.

Antle, J.M., Valdivia, R.O., 2006. Modelling the supply of ecosystem services from agriculture: a minimumdata approach. Australian Journal of Agricultural and Resource Economics 50 (1), 1-15.

Antle, J. M., Diagana, B., Stoorvogel, J.J.,Valdivia, R.O., 2010. Minimum-data analysis of ecosystem service supply in semi-subsistence agricultural systems. Australian Journal of Agricultural and Resource Economics 54 (4), 601-617.

Antle, J.M., Valdivia, R.O., 2011. TOA-MD 5.0: Trade-off Analysis Model for Multi-Dimensional Impact Assessment. http://trade-offs.oregonstate.edu.

Antle, J.M., Stoorvogel, J.J., Valdivia, R.O., 2014. New parsimonious simulation methods and tools to assess future food and environmental security of farm populations. Philos. Trans. R. Soc. Lond. B. Biol. Sci. $1639,369$.

Antle, J., Adhikari, S., Price, S., 2015a. An Income-based food security indicator for agricultural technology impact assessment, in Andrew Schmitz , P. Lynn Kennedy, Troy G. Schmitz (ed.) Food Security in an Uncertain World (Frontiers of Economics and Globalization) Emerald Group Publishing Limited 15, $81-96$.

Antle, J., Valdivia R., Booten K., Hatfield J., Janssen S., Jones J., Porter C., Rosenzweig C, Ruane A., Thorburn P.., 2015b. AgMIP's Trans-disciplinary Approach to Regional Integrated Assessment of Climate Impact, Vulnerability and Adaptation of Agricultural Systems. Handbook of Climate Change and Agroecosystems: The Agricultural Model Intercomparison and Improvement Project (AgMIP). C. Rosenzweig, and D. Hillel, Eds., ICP Series on Climate Change Impacts, Adaptation, and Mitigation. Imperial College Press. 4. 
Ates, S., Cicek, H., Bell, L.W., Norman, H.C., Mayberry, D.E., Kassam, S., Hannaway, D.B., Louhaichi, M., 2018. Sustainable development of smallholder crop-livestock farming in developing countries. IOP Conference Series: Earth and Environmental Science 142 (1), 012076. IOP Publishing.

Ayantunde, A.A., Duncan, A.J., van Wijk, M.T., Thorne, P., 2018. Review: Role of herbivores in sustainable agriculture in Sub-Saharan agriculture. Animal 12 (s2), 1-11.

Ayele, S., Duncan, A., Larbi, A., Khanh, T.T., 2012 Enhancing innovation in livestock value chains through networks: Lessons from fodder innovation case studies in developing countries. Science and Public Policy 39 (3), 333-346.

Bacigale, S. B., Paul, B. K., Muhimuzi, F. L., Mapenzi, N., Peters, M. \& Maass, B. L., 2014. Characterizing feeds and feed availability in Sud-Kivu province, DR Congo. Tropical Grasslands - Forrajes Tropicales 2, 9-11.

Bebe, B.O., Udo, H.M.J., Thorpe, W., 2002. Development of smallholder dairy systems in the Kenyan Highlands. Outlook on Agriculture 31 (2), 113-220.

Bebe, B.O., Udo, H.M.J., Thorpe, W., 2008. Characteristics of feeding and breeding practices for intensification of smallholder dairy systems in the Kenya Highlands. Livestock Research for Rural Development 82 (2-3), 117 \& 127.

Bell, L., 2009. Building better feed systems. Tropical Grasslands 43, 199-206.

Bell, L.W., Moore A.D., and Thomas D.T., 2017. Integrating diverse forage sources reduces feed gaps on mixed crop-livestock farms. Animal 12 (9), 1-14.

Bishop-Sambrook, C., Kienzle, J., Mariki, W., Owenya, M., Ribeiro, F., 2004. Conservation agriculture as a labor saving practice for vulnerable households. International Fund for Agricultural Development (IFAD), Food and Agriculture Organization of the United Nations (FAO). Rome, Italy.

Bosire, C.K., Krol, M.S., Mekonnen, M.M., Ogutu, J.O., de Leeuw, J., Lannerstad, M., Hoekstra, A.Y., 2016. Meat and milk production scenarios and associated land footprints in Kenya. Agricultural Systems $145,64-75$.

Boval, M., Angeon, V., Rudel, T., 2017. Tropical grasslands: A pivotal place for a more multi-functional agriculture. Ambio 46 (1), 48-56. https://doi.org/10.1007/s13280-016-0806-5.

Bryan, E., Ringler, C., Okoba, B., Koo, J., Herrero, M., Silvestri, S., 2013. Can agriculture support climate change adaptation, greenhouse gas mitigation and rural livelihoods? Insights from Kenya. Climatic Change 118 (2), 151-165.

Bucagu, C., Vanlauwe, B., Van Wijk, M. T., Giller, K. E., 2014. Resource use and food self-sufficiency at farm scale within two agro-ecological zones of Rwanda. Food Security 6 (5), 609-628. 
Campbell, B. M., Thornton, P., Zougmoré, R., van Asten, P., Lipper, L., 2014. Sustainable intensification: What is its role in climate smart agriculture? Current Opinion in Environmental Sustainability 8, 3943.

Carletto, C., Zezza, A., Banerjee, R., 2013a. Towards better measurement of household food security: Harmonizing indicators and the role of household surveys. Global Food Security 2 (1), 30-40.

Carletto, C., Savastano, S., Zezza, A., 2013b. Fact or artifact: The impact of measurement errors on the farm size-productivity relationship. Journal of Development Economics 103 (1), 254-261.

Chambers, R., 2017. Can We Know Better? Reflections for Development. Practical Action Publishing, Warwickshire, UK 202.

Chen, J., Chen, J., Liao, A., Cao, X., Chen, L., Chen, X., He, C., Han, G., Peng, S., Lu, M., Zhang, W., Tong, X., Mills, J., 2014. Global land cover mapping at 30m resolution: A POK-based operational approach. ISPRS Journal of Photogrammetry and Remote Sensing 103, 7-27.

CIAT \& World Bank, 2017. Climate-Smart Agriculture in Tanzania. CSA Country Profiles for Africa Series. International Center for Tropical Agriculture (CIAT), World Bank, Washington, D.C. 25.

Claessens, L., Antle J.M., Stoorvogel, J.J., Valdivia R.O., Thornton, P.K., Herrero, M.., 2012. A method for evaluating climate change adaptation strategies for small-scale farmers using survey, experimental and modeled data. Agricultural systems Systems 111, 85-95.

Colomb, V., Touchemoulin, O., Bockel, L., Chotte, J.-L., Martin, S., Tinlot, M., \& Bernoux, M., 2013. Selection of appropriate calculators for landscape-scale greenhouse gas assessment for agriculture and forestry. Environmental Research Letters 8 (1), 015029.

Cook, B.G., Schultze-Kraft R., 2015. Botanical name changes - nuisance or a quest for precision? Tropical Grasslands-Forrajes Tropicales 3, 34-40.

Cortez-Arriola, J., Groot, J. C. J., Améndola Massiotti, R. D., Scholberg, J. M. S., Valentina Mariscal Aguayo, D., Tittonell, P., Rossing, W. a. H., 2014. Resource use efficiency and farm productivity gaps of smallholder dairy farming in North-west Michoacán, Mexico. Agricultural Systems 126, 15-24.

Cortez-Arriola, J., Groot, J. C. J., Rossing, W. A. H., Scholberg, J. M. S., Améndola Massiotti, R. D., Tittonell, P., 2016. Alternative options for sustainable intensification of smallholder dairy farms in NorthWest Michoacán, Mexico. Agricultural Systems 144, 22-32.

Critical Ecosystem Partnership Fund, 2005. Eastern Arc Mountains and Coastal Forests of Tanzania and Kenya: Ecosystem Profile. Cape Town 162.

CSIRO (Commonwealth Scientific and Industrial Research Organization) 2007. Nutrient requirements of domesticated ruminants. CSIRO publishing. Collingwood, Australia.

De Haan, N.C., Romney, D., Bezkorowajnyj, P., Olufajo, O., 2006. Feeding livestock through partnerships. Knowledge Management for Development Journal, 2 (3), 123-135. 
Delaquis E., de Haan S., Wyckhuys KAG, 2018. On-farm diversity offsets environmental pressures in tropical agro-ecosystems: A synthetic review for cassava-based systems. Agriculture, Ecosystems \& Environment 251 (2), 226-235.

Delgado C., Rosegrant M., Steinfeld H., Ehui S., Courbois C., 1999. Livestock to 2020 - The Next Food Revolution. Food, Agriculture, and the Environment Discussion Paper No. 28. IFPRI, FAO, ILRI.

Denef, K., Paustian, K., Archibeque, S., Biggar, S., Pape, D., 2012. Report of Greenhouse Gas Accounting Tools for Agriculture and Forestry Sectors. Interim Report to USDA under Contract No. GS-23F$8182 \mathrm{H}$.

Descheemaeker, K., Oosting, S. J., Homann-Kee Tui, S., Masikati, P., Falconnier, G. N., Giller, K. E., 2016. Climate change adaptation and mitigation in smallholder crop-livestock systems in sub-Saharan Africa: a call for integrated impact assessments. Regional Environmental Change 16 (8), 23312343.

Descheemaker, K., Zilstra, M., Masikati, P., Crespo, O., Homann-Kee Tui, S., 2018. Effects of climate change and adaptation on the livestock component of mixed farming systems: A modeling study from semi-arid Zimbabwe. Agricultural Systems 159, 282-295.

De Vries, M., de Boer, I.J.M., 2010. Comparing environmental impacts for livestock products: A review of life cycle assessments. Livestock Science 128, 1-11.

Dfid, DEW Point, SEI (Stockholm Environment Institute), 2009. A Rapid Assessment of a National Energy and Low Carbon Path for Rwanda.

Dinesh, D., Zougmore, R.B.,Vervoort, J., Totin, E., Thornton, P.K., Solomon, D., Shirsath, P.B., Pede, V.O., Lopez Noriega, I., Laderach, P., Korner, J., Hegger, D., Girvetz, E.H., Friis, A.E., Driessen, P.P.J., Campbell, B.M., 2018. Facilitating Change for Climate-Smart Agriculture through Science-Policy Engagement. Sustainability, 10, 2616.

Ditzler, L., Komarek, A.M., Chiang, T.W., Alvarez, S., Chatterjee, S.A., Timler, C., Raneri, J.E., Estrada Carmona, N., Kennedy, G., Groot, J.G.J., 2019. A model to examine farm household trade-offs and synergies with an application to smallholders in Vietnam. Agricultural Systems 173, 49-63.

Dixon, J., Gulliver, A., Gibbon, D., 2001. Farming Systems and Poverty - Improving farmers' livelihoods in a changing world. Experimental Agriculture 39 (1), 109-110.

Douxchamps, S., van Wijk, M.T., Silvestri, S., Moussa, A.S., Quiros, C., Ndour, N.Y.B., Buah, S., Some, L., Herrero, M., Kristjanson, P., Ouedraogo, M., Thornton, P.K., van Asten, P., Zougmore, R., Rufino, M.C., 2016. Linking agricultural adaptation strategies, food security and vulnerability: evidence from West Africa. Regional Environmental Change 16, 1305-1317.

Dray, S., Dufour, A.B., Chessel, D., 2007: The ade4 package-II: Two-table and K-table methods. R News 7 (2), 47-52. 
Duncan, A.J., Lukuyu, B., Stuer, W., 2012. Feed Assessment Tool (FEAST). Nairobi, Kenya: International Livestock Research Institute (ILRI).

Duncan, A.J., Teufel, N., Mekonnen, K., Singh, V.K., Bitew, A., Gebremedhin, B., 2013. Dairy intensification in developing countries: effects of market quality on farm-level feeding and breeding practises. Animal 7 (12), 2054-2062.

Duncan, A.J., Bachewe, F., Mekonnen, K., Valbuena, D., Rachier, G., Lule, D., Bahta, M., Erenstein, O., 2016. Crop residue allocation to livestock feed, soil improvement and other uses along a productivity gradient in Eastern Africa. Agriculture, Ecosystems and Environment 228, 101-110.

Easterling, W., Aggarwal, P., Batima, P., Brander, K., Erda, L., Howden, M., Kirilenko, A.,Morton, J., Soussana, J.F., Schmidhuber, J., et al., 2007. Food, fibre, and forest products. In: Parry, M.L., Canziani, O.F., Palutikof, J.P., Linden, P.J., Hanson, C.E. (Eds.), Climate Change 2007: Impacts, Adaptation and Vulnerability. Cambridge University Press, Cambridge, UK 273-313.

Elbesha, E., Thornton, P.K., Tarawali, G., 1999. An ex-post economic impact assessment of planted forages in West Africa. Impact Assessment Series. 2. ILRI (International Livestock Research Institute), Nairobi, Kenya.

Falconnier, G.N., Descheemaeker, K., van Mourik, T.A., Sanogo, O.M., Giller, K.E., 2015. Understanding farm trajectories and development pathways: Two decades of change in southern Mali. Agricultural Systems 139, 210-222.

FAO (Food and Agriculture Organization of the United Nations), 2009. The State of Food and Agriculture. FAO, Rome and World Bank, Rome, Italy, and Washington, D.C., United States of America.

FAO (Food and Agriculture Organization of the United Nations), 2011. Human Energy Requirements. Food and Nutrition Technical Report Series 1. Rome, Italy 1-103.

FAO (Food and Agriculture Organization of the United Nations), 2013. Climate-smart agriculture sourcebook. Rome, Italy.

Feedipedia, 2012-2017. Animal Feed Resources Information System. INRA, CIRAD, AFZ and FAO. https://www.feedipedia.org.

Flores-Sanchez, D., Koerkamp-Rabelista, J. K., Navarro-Garza, H., Lantinga, E. A., Groot, J. C. J., Kropff, M. J., Rossing, W. A. H., 2011. Diagnosis for ecological intensification of maize-based smallholder farming systems in the Costa Chica, Mexico. Nutrient Cycling in Agroecosystems 91 (2), 185-205.

Foerch, W., Patti, K., Thornton P., Kiplimo. J., 2011. Initial Sites in the CCAFS Regions: Eastern Africa, West Africa and Indo-Gangetic Plains, Version 2. CGIAR Research Program on Climate Change, Agriculture and Food Security (CCAFS). Copenhagen, Denmark.

Fonte, S., Nesper, M., Hegglin, D., Velasquez, J.E., Ramirez, B., Rao, I.M., Bernasconi, S.M., Buenemann, E.K., Frossard, E., Oberson, A., 2014. Pasture degradation impacts soil phosphorus storage via 
changes to aggregate-associated soil organic matter in highly weathered tropical soils. Soil Biology \& Biochemistry 68, 150-157.

Franzel, S., Wambugu, C., Stewart, J., \& Sande, B. D., 2003. Fodder shrubs for improving incomes of dairy farmers in the East African highlands.

Franzel, S., Carsan, S., Lukuyu, B., Sinja, J., Wambugu, C., 2014. Fodder trees for improving livestock productivity and smallholder livelihoods in Africa. Current Opinion in Environmental Sustainability 6, 98-103.

Fraval, S., Hammond, J., Wichern, J., Oosting, S.J., de Boer, I.J.M., Teufel, N., Lannerstad, M., Waha, K., Pagella, T., Rosenstock, T.S., Giller, K.E., Herrero, M., Harris, D., van Wijk, M.T., 2018. Making the most of imperfect data: A critical evaluation of standard information collected in farm household surveys. Experimental Agriculture 1-21.

Frelat, R., Lopez-Ridaura, S., Giller, K.E., Herrero, M., Douxchamps, S., Djurfeldt, A.A., Erenstein, O., Henderson, B., Kassie, M., Paul, B.K., Rigolot, C., Ritzema, R.S., Rodriguez, D., Van Asten, P.J.A., van Wijk, M.T., 2016. What drives household food availability in sub-Saharan Africa? Evidence using big data from small farms. Proceedings of the National Academy of Science 113 (2), 458-463.

Funk, C., Peterson, P., Landsfeld, M., Pedreros, D., Verdin, J., Shukla, S., Husak, G., Rowland, J., Harrison, L., Hoell, A., Joel, M., 2015. The climate hazards infrared precipitation with stations-a new environmental record for monitoring extremes. Scientific Data 2, 1-21.

GADM (Database of Global Administrative Areas), 2018. GADM database of Global Administrative Areas. University of Berkeley, Museum of Vertebrate Zoology and the International Rice Research Institute (http://www.gadm.org).

Galiè, A., Mulema, A., Mora Benard, M.A., Onzere, S.N., Colverson, K.E., 2015. Exploring gender perceptions of resource ownership and their implications for food security among rural livestock owners in Tanzania, Ethiopia, and Nicaragua. Agriculture \& Food Security 4 (1), 2.

Giller, K. E., Tittonell, P., Rufino, M. C., van Wijk, M. T., Zingore, S., Mapfumo, P., Adjei-Nsiah, S., Herrero, M., Chikowo, K.R., Corbeels, M., Rowe, E.C., Baijukya, F., Mwijage, A., Smith, J., Yeboah, E., van de $r$ Burg, W.J., Sanogo, O.M., Misiko, M., de Ridder, M., Karanja, S., Kaizzi, C., K'ungu, J., Mwale, M., Nwaga, D., Pacini, C., Vanlauwe, B., 2011. Communicating complexity: Integrated assessment of trade-offs concerning soil fertility management within African farming systems to support innovation and development. Agricultural Systems 104 (2), 191-203.

Godde, C.M., Garnett, T., Thornton, P.K., Ash, A.J., Herrero, M., 2018. Grazing systems expansion and intensification: Drivers, dynamics and trade-offs. Global Food Security 16, 93-105.

Goopy, J.P., Onyango, A.A., Dickhoefer, U., Butterbach-Bahl, K., 2018. A new approach for improving emission factors for enteric methane emissions of cattle in smallholder systems of East Africa Results for Nyando, Western Kenya. Agricultural Systems, 161, 72-80. 
Green, M., 2017. Dairying as Development: Caring for 'Modern' Cows in Tanzania. Human Organization 76, 109-120.

Groot, J. C. J., Oomen, G. J. M., Rossing, W. A. H., 2012. Multi-objective optimization and design of farming systems. Agricultural Systems 110, 63-77.

Groot, J., Cortez-Arriola, J., Rossing, W., Améndola Massiotti, R., Tittonell, P., 2016. Capturing Agroecosystem Vulnerability and Resilience. Sustainability 8 (11), 1206.

Groot, J.C.J., Kennedy, G., Remans, R., Estrada-Carmona, N., Raneri, J., Declerck, F., Alvarez, S., Mashingaidze, N., Timler, C., Stadler, M., del Rio Mena, T., Horlings, L., Brouwer, I., Cole, S.M., Descheemaeker, K., 2017. Integrated systems research in nutrition-sensitive landscapes: A theoretical methodological framework. In Oborn, I., Vanlauwe, B., Phillips, M., Thomas, R., Brooijmans, W., Atta-Krah, K. (Eds.), 2017. Sustainable intensification in smallholder agriculture an integrated systems research approach. 259-274. Routledge, London and New York.

Hall, A., Sulaiman, R., Bezkorowajnyj, P., 2007. Reframing Technical Change: Livestock Fodder Scarcity Revisited as Innovation Capacity Scarcity. A Conceptual Framework. ILRI, ICRISAT, IITA, UNU-MERIT.

Hammond, J., Fraval, S., van Etten, J., Suchini, J. G., Mercado, L., Pagella, T., Frelat, R., Lannerstad, M., Douxchamps, S., Teufel, N., Valbuena, D. and van Wijk, M. T., 2017. The Rural Household MultiIndicator Survey (RHoMIS) for rapid characterisation of households to inform Climate Smart Agriculture interventions: description and applications in East Africa and Central America. Agricultural Systems 151, 225-233.

Harinder, M.P. S., Philippe. A., 2014. A need for generating sound quantitative data at national levels for feed-efficient animal production. Animal Production Science 54: 1569-1574.

HarvestChoice, 2011. "AEZ (16-class)." International Food Policy Research Institute, Washington, DC., and University of Minnesota, St. Paul, MN. Available online at http://harvestchoice.org/node/4988.

Hassanali, A., Herren, H., Khan, Z.R., Pickett, J.A., Woodcock, C.M., 2008. Integrated pest management: the push-pull approach for controlling insect pests and weeds of cereals, and its potential for other agricultural systems including animal husbandry. Philosophical Transactions of the Royal Society B: Biological Sciences 363 (1491), 611-621.

Hedges, L.V., Gurevitch, J., Curtis, P.S., 1999. The meta-analysis of response ratios in experimental ecology. Ecology 80, 1150-1156.

Henderson, B., Godde, C., Medina-Hidalgo, D., van Wijk, M., Silvestri, S., Douxchamps, S., Stephenson, M., Power, B., Rigolot, C., Cacho, O., Herrero, M.., 2016. Closing system-wide yield gaps to increase food production and mitigate GHGs among mixed crop - livestock smallholders in Sub-Saharan Africa. Agricultural Systems 143, 106-113.

Hengsdijk, H., Franke, A. C., van Wijk, M. T., Giller, K. E., 2014. How small is beautiful? Food self-sufficiency and land gap analysis of smallholders in humid and semi-arid sub Saharan Africa. Plant Research International, part of Wageningen UR (Report 562). Wageningen, the Netherlands. 
Herrero, M., 1997. Modelling dairy grazing systems: an integrated approach. Ph.D. thesis, University of Edinburgh, Edinburgh, Scotland.

Herrero, M., Thornton, P.K., Notenbaert, A.M., Wood, S., Msangi, S., Freeman, H.A., Bossio, D., Dixon, J., Peters, M., van de Steeg, J., Lynam, J., Rao, P.P., Macmillan, S., Gerard, B., McDermott, J., Sere, C., Rosegrant, M., 2010. Smart Investments in Sustainable Food Production: Revisiting Mixed CropLivestock Systems. Science 327, 822-825.

Herrero, M., Gerber, P., Vellinga, T., Garnett, T., Leip, A., Opio, C., Westhoek, H.J., Thornton, P.K., Olesen, J., Hutchings, N., Montogomery, H., Soussana, J.F., Steinfeld, H., McAllister, T.A., 2011. Livestock and greenhouse gas emissions: the importance of getting the numbers right. Animal Feed Science and Technology 116-67, 770-782.

Herrero, M., Grace, D., Njuki, J., Johnson, N., Enahoro, D., Silvestri, S., Rufino, M. C., 2012. The roles of livestock in developing countries. Animal, 7 (1), 3-18.

Herrero, M., Havlík, P., Valin, H., Notenbaert, A., Rufino, M. C., Thornton, P. K., Blümmel, M., Weiss, F., Grace, D., Obersteiner, M., 2013. Biomass use, production, feed efficiencies, and greenhouse gas emissions from global livestock systems. Proceedings of the National Academy of Sciences of the United States of America 110 (52), 20888-93.

Herrero, M., Thornton, P., 2013. Livestock and global change: emerging issues for sustainable food systems. Proceedings of the National Academy of Sciences (PNAS) 110, 20878-20881.

Herrero, M., Henderson, B., Havlík, P., Thornton, P. K., Conant, R. T., Smith, P., Wirsenius, S., Hristov, A.N., Gerber, P., Gill, M. Butterbach-Bahl, K., Valin, H., Garnett, T., Stehfest, E., 2016. Greenhouse gas mitigation potentials in the livestock sector. Nature Climate Change 6 (5), 452-461.

Herrero, M., Thornton, P., Reid, R.., Kruska, R., 2008. Systems dynamics and the spatial distribution of methane emissions from African domestic ruminants in 2013 Agriculture, Ecosystems and Environment. 126, 122-137.

Herrero, M., Wirsenius, S., Henderson, B., Rigolot, C., Thornton, P., Havlík, P., de Boer, I., Gerber, P.J., 2015. Livestock and the Environment: What Have We Learned in the Past Decade? Annual Review of Environment and Resources 40 (1), 177-202.

Hieronymi, A., 2013. Understanding Systems Science: A Visual and Integrative Approach. Systems Research and Behavioral Science 30, 580-595. https://doi.org/10.1002/sres.

Hijmans, R.J., Cameron, S.E., Parra, J.L., Jones, P.G., Jarvis, A., 2005. Very high resolution interpolated climate surfaces for global land areas. International Journal of Climatology 25, 1965-1978.

Hillbur, P., 2013. The Africa RISING research sites in Tanzania - Opportunities and challenges to sustainable intensification and institutional innovation. IITA report. 
Hillier, J., Walter, C., Malin, D., Garcia-Suarez, T., Mila-i-Canals, L., Smith, P., 2011. A farm-focused calculator for emissions from crop and livestock production. Environmental Modelling \& Software 26 (9), 1070-1078.

Homann-Kee Tui, S., Valbuena, D., Masikati, P., Descheemaeker, K., Nyamangara, J., Claessens, L., Erenstein, O., Van Rooyen, A., Nkomboni, D., 2015. Economic trade-offs of biomass use in croplivestock systems: Exploring more sustainable options in semi-arid Zimbabwe. Agricultural Systems $13,48-60$.

Homann-Kee Tui, S., Descheemaeker, K., Masikati, P., Chibwana Gama, A., Crespo, O., Claessens, L., Valdivia, R., 2016. Re-designing smallholder farming futures for reduced vulnerability to climate change in semi-arid southern Africa. Submitted to European Journal of Agronomy.

ILCA (International Livestock Centre for Africa), 1990. Livestock systems research manual. ILCA Working Paper 1, Volume 1. Addis Ababa, Ethiopia. 399.

IPCC (International Panel on Climate Change), 2006. IPCC Guidelines for National Greenhouse Gas Inventories, Prepared by the National Greenhouse Gas Inventories Programme, Eggleston H.S., Buendia, L., Miwa, K., Ngara, T., Tanabe, K. (eds). Published: IGES, Japan.

Jambiya, G., 1998. The Dynamics of Population, Land Scarcity, Agriculture and Non-Agricultural Activities: West Usambara Mountains, Lushoto District, Tanzania. ASC Working Paper 28. Dar es Salaam 42.

Jarvis, A., Reuter, H.I., Nelson A., and Guevara E., 2008. Hole-filled SRTM for the globe Version 4, available from the CGIAR-CSI SRTM 90m Database. http://srtm.csi.cgiar.org.

Jones, J. W., Antle, J. M., Basso, B., Boote, K. J., Conant, R. T., Foster, I., Godfray, H.C.J., Herrero, M., Howitt, R.E., Janssen, S., Keating, B.A., Munoz-Carpena, R., Porter, C.H., Rosenzweig, C., Wheeler, T.R., 2017. Toward a new generation of agricultural system data, models, and knowledge products: State of agricultural systems science. Agricultural Systems 155, 269-288.

Kamanzi, M., Mapiye, C., 2012. Feed inventory and smallholder farmers' perceived causes of feed shortage for dairy cattle in Gisagara District, Rwanda. Tropical Animal Health and Production 44, 1459-1468.

Kanter, D. R., Musumba, M., Wood, S. L. R., Palm, C., Antle, J., Balvanera, P., Dale, V.H., Havlik, P., Kline, K.L., Scholes, R.J., Thornton, P., Tittonell, P., Andelman, S., 2016. Evaluating agricultural trade-offs in the age of sustainable development. Agricultural Systems in press.

Kassie M., Stage J., Diiro G., Muriithi B., Muricho G., Ledermann S.T., Pittchar J., Midega C., Khan Z., 2018. Push-pull farming system in Kenya: Implications for economic and social welfare. Land Use Policy 77, 186-198.

Katjiuongua, H., Nelgen, S., 2014. Tanzania smallholder dairy value chain development: Situation analysis and trends. ILRI Project Report. Nairobi, Kenya: ILRI. 
Kebebe, E.G., Oosting, S.J., Baltenweck, I., Duncan, A.J., 2017. Characterisation of adopters and nonadopters of dairy technologies in Ethiopia and Kenya. Tropical Animal Health and Production 49 (4), 681-690.

Kihara, J., Tamene, L. D., Massawe, P., Bekunda, M., 2015. Agronomic survey to assess crop yield, controlling factors and management implications: a case-study of Babati in northern Tanzania. Nutrient Cycling in Agroecosystems 102 (1), 5-16.

Kizito, F., Lukuyu, B., Sikumba, G., Kihara, J., Bekunda, M., Nganga, K.W., Kimaro, A., Haroon, S., 2016. The role of forages in sustainable intensification of crop-livestock agro-ecosystems in the face of climate change: The case for landscapes in Babati, Northern Tanzania. In R. Lal, D. Kraybill, D. O. Hansen, B. R. Singh, T. Mosogoya, \& L. O. Eik (Eds.), Climate Change and Multi-Dimensional Sustainability in African Agriculture 411-430.

Klapwijk, C., van Wijk, M., Rosenstock, T., van Asten, P., Thornton, P., Giller, K., 2014a. Analysis of tradeoffs in agricultural systems: current status and way forward. Current Opinion in Environmental Sustainability 6, 110-115.

Klapwijk, C. J., Bucagu, C., van Wijk, M. T., Udo, H. M. J., Vanlauwe, B., Munyanziza, E., Giller, K. E., 2014b. The "One cow per poor family" programme: Current and potential fodder availability within smallholder farming systems in southwest Rwanda. Agricultural Systems 131, 11-22.

Komarek, A.M., McDonald, C.K., Bell, L.W., Whish, J.P.M., Robertson, M.J., MacLeod, N.D., Bellotti, W.D., 2012. Whole-farm effects of livestock intensification in smallholder systems in Gansu, China. Agricultural Systems 109, 16-24.

Kristjanson, P., Neufeldt, H., Gassner, A., Mango, J., Kyazze, F.B., Desta, S., Sayula, G., Thiede, B., Förch, W., Thornton, P.K. and Coe, R., 2012. Are food insecure smallholder households making changes in their farming practices? Evidence from East Africa. Food Security 4 (3), 318-397.

Kristjanson, P., Okike, I., Tarawali, S., Singh, B.B., Manyong, V.M., 2005. Farmers' perceptions of benefits and factors affecting the adoption of improved dual-purpose cowpea in the dry savannas of Nigeria. Agricultural Economics 32, 195-210.

Kristjanson, P., Tarawali, S., Okike, I., Singh, B.B., Thornton, P.K., Manyong, V.M., Kruska, R.L., Hoogenboom, G., 2002. Genetically Improved Dual-purpose Cowpea: Assessment of Adoption and Impact in the Dry Savannah of West Africa. Impact Assessment Series No. 9. ILRI (International Livestock Research Institute), Nairobi, Kenya.

Kuivanen, K. S., Alvarez, S., Michalscheck, M., Adjei-Nsiah, S., Descheemaeker, K., Mellon-Bedi, S., Groot, J. C. J., 2016. Characterising the diversity of smallholder farming systems and their constraints and opportunities for innovation: A case study from the Northern Region, Ghana. NJAS - Wageningen Journal of Life Sciences 78, 153-156.

Kurwijila, R. L., Omore, A., Grace, D., 2012. The Tanzania Dairy Industry. Sokoine University of Agriculture. Retrieved from: 
https://cgspace.cgiar.org/bitstream/handle/10568/33865/TanzaniaDairyIndustryOverview2012.pd f?sequence=1.

Kuyah, S., Dietz, J., Muthuri, C., Jamnadass, R., Mwangi, P., Coe, R., Neufeldt, H. 2012. Allometric equations for estimating biomass in agricultural landscapes: I. Aboveground biomass. Agric. Ecosyst. Environ. $158,216-224$.

Lara, M.A.S., Pedreira, C.G.S., Boote, K.J., Pedreira, B.C., Moreno, L.S.B., Alderman, P.D., 2012. Predicting growth of Panicum maximum: An adaptation of the CROPGRO-Perennial Forage Model. Agronomy Journal, 104 (3), 600-611.

Leeuwis, C., Klerkx, L., Schut, M., 2017a. Reforming the research policy and impact culture in the CGIAR: Integrating science and systemic capacity development. Global Food Security April, 0-1.

Leeuwis, C., Schut, M., Klerkx, L., 2017b. Systems research in the CGIAR as an arena of struggle: competing discourses on the embedding of research in development. In: Sumberg, J., Andersson, J., Thompson, J. (Eds.), Agronomy for Development: The Politics of Knowledge in Agricultural Research. Routledge. 59-78.

Lenné, J.M., Fernandez-Rivera, S., Blümmel, M., 2003. Approaches to improve the utilization of food-feed crops - synthesis. Field Crop Research 84, 213-222.

Lenné, J.M., Wood, D., 2004. Is there a 'logic of fodder legumes' in Africa?. Food Policy 29, 565-585.

Linard, C., Gilbert, M., Snow, R.W., Noor, A.M., Tatem, A.J., 2012. Population distribution, settlement patterns and accessibility across Africa in 2010. PLOS ONE 7(2): e31743 (http://www.worldpop.org.uk).

Linquist, B. a., Liu, L., van Kessel, C., van Groenigen, K. J., 2013. Enhanced efficiency nitrogen fertilizers for rice systems: Meta-analysis of yield and nitrogen uptake. Field Crops Research 154, 246-254.

Lipper, L., Thornton, P., Campbell, B.M., Baedeker, T., Braimoh, A., Bwalya, M., Caron, P., Cattaneo, A., Garrity, D., Henry, K., Hottle, R., Jackson, L., Jarvis, A., Kossam, F., Mann, W., McCarthy, N., Meybeck, A., Neufeldt, H., Remington, T., Sen, P.T., Sessa, R., Shula, R., Tibu, A., Torquebiau, E. F., 2014. Climate-smart agriculture for food security. Nature Climate Change. 4, 1068-1072.

Lisson, S., MacLeod, N., McDonald, C., Corfield, J., Pengelly, B., Wirajaswadi, L., Rahman, R., Bahar, S., Padjung, R., Razak, N., Puspadi, K., Dahlanuddin, Sutaryono, Y., Saenong, S., Panjaitan, T., Hadiawati, L., Ash, A., Brennan, L., 2010. A participatory, farming systems approach to improving Bali cattle production in the smallholder crop-livestock systems of Eastern Indonesia. Agricultural Systems 103 (7), 486-497.

Lopez-Ridaura, S., Frelat, R., van Wijk, M.T., Valbuena, D., Krupnik, T.J., Jat, M.L., 2018. Climate smart agriculture, farm household typologies and food security. An ex ante assessment from Eastern India. Agricultural System. 159, 57-68. 
Lukuyu, B. A., Kitalyi, A., Franzel, S., Duncan, A., Baltenweck, I., 2009. Constraints and options to enhancing production of high quality feeds in dairy production in Kenya, Uganda and Rwanda. ICRAF Working Paper No. 95. ICRAF, ILRI, Nairobi, Kenya.

Lukuyu, B., Franzel, S., Ongadi, P.M., Duncan, A., 2011. Livestock feed resources: Current production and management practices in central and northern Rift Valley Provinces. Livestock Research for Rural Development 5 (2) 30-35.

Lukuyu, M., Njehu, A., Mwilawa, A., Lukuyu, B., Omore, A., Rao J., 2016. A study to understand fodder markets and fodder trading patterns in MoreMilkiT sites and other selected regions in Tanzania. CGIAR Research Program on Livestock and Fish. Nairobi, Kenya: ILRI.

Lyamchai, C., Yanda, P., Sayula, G., Kristjanson, P., 2011. Summary of Baseline Household Survey Results: Lushoto, Tanzania. Copenhagen.

Maass, B., Midega, C.A.O., Mutimura, M., Rahetlah, V.B., Salgado, P., Kabirizi, J.M., Khan, Z.R., Ghimire, S.R., Rao, I.M., 2015. Homecoming of Brachiaria: Improved Hybrids Prove Useful for African Animal Agriculture. East Africa Agricultural and Forestry Journal 81 (1), 71-78.

Maechler, M., Rousseeuw, P., Struyf, A., Hubert, M., Hornik, K., 2016. cluster: Cluster Analysis Basics and Extensions. $\mathrm{R}$ package version 2.0.5.

Mandryk, M., Reidsma, P., Kanellopoulos, A., Groot, J. C. J., van Ittersum, M. K., 2014. The role of farmers' objectives in current farm practices and adaptation preferences: A case study in Flevoland, the Netherlands. Regional Environmental Change 14 (4), 1463-1478.

Mangesho, W., Loina, R., Diyu, J., Urassa, V., Lukuyu, B., 2013. Report of Feed Assessment in Babati District, Manyara Region. Africa RISING, Arusha, Tanzania.

Mangesho, W., Loina, R., Bwire, J., in collaboration with Maass, B.L., Lukuyu, B., Wassena, F.J., 2015. Feed Assessment 3 - Lushoto District, Tanga Region, the United Republic of Tanzania. Report. International Center for Tropical Agriculture (CIAT), Nairobi, Kenya; Tanzania Livestock Research Institute (TALIRI), Tanga, Tanzania; International Livestock Research Institute (ILRI), Nairobi, Kenya. 16.

Makoni, N., Mwai, R., Redda, T., van der Zijpp, A., van der Lee, J., 2013. White Gold; Opportunities for Dairy Sector Development Collaboration in East Africa. Centre for Development Innovation, Wageningen UR (University \& Research centre). CDI report CDI-14-006. Wageningen, the Netherlands.

Mayberry, D., Ash, A., Prestwidge, D., Godde, C.M., Henderson, B., Duncan, A., Blummel, M., Reddy, Y.R., Herrero, M., 2017. Yield gap analyses to estimate attainable bovine milk yields and evaluate options to increase production in Ethiopia and India. Agricultural Systems 155, 43-51.

Mayberry, D., Ash, A., Prestwidge, D., Herrero, M., 2018. Closing yield gaps in smallholder goat production systems in Ethiopia and India. Livestock Science 214, 238-244. 
McDermott, J.J., Staal, S.J., Freeman, H.A., Herrero, M., van de Steeg, J.A., 2010. Sustaining intensification of smallholder livestock systems in the tropics. Livestock Science 130 (1-3), 95-109.

McIntire, J., Bourzat, D., Pingali, P., 1992. Crop - Livestock Interaction in Sub-Saharan Africa. World Bank Regional and Sectoral Studies. Washington, DC.

Michalscheck, M., Groot, J.G.J., Kotu, B., Hoeschle-Zeledon, I., Kuivanen, K., Descheemaeker, K., Tittonell, P., 2018. Model results versus farmer realities. Operationalizing diversity within and among smallholder farm systems for a nuanced impact assessment of technology packages. Agricultural Systems 162, 164-178.

Millar, J., Connell, J., 2010. Strategies for scaling out impacts from agricultural systems change: the case of forages and livestock production in Laos. Agriculture and Human Values 27 (2), 213-225.

MINECOFIN (Rwanda Ministry of Finance and Economic Planning), 2000. Rwanda Vision 2020. Government of Rwanda, Kigali, Rwanda.

MINAGRI (Rwanda Ministry of Agriculture and Animal Resources), 2006. 'A Cow to Each Poor Family in Rwanda'. Government of Rwanda, Kigali, Rwanda.

MINAGRI (Rwanda Ministry of Agriculture and Animal Resources), 2009a. Strategic Plan for the Transformation of Agriculture in Rwanda - Phase II (PSTA II). Final Report. Government of Rwanda, Kigali, Rwanda.

MINAGRI (Rwanda Ministry of Agriculture and Animal Resources), 2009b. Strategic Plan for Animal Nutrition Improvement Programme for Rwanda. Final Report of Technical Assistance for Institutional Component of Support Project to the Strategic Plan for the Transformation of Agriculture in Rwanda (PAPSTA). Government of Rwanda, Kigali, Rwanda.

MINAGRI (Rwanda Ministry of Agriculture and Animal Resources), 2011. Strategies for Sustainable Crop Intensification in Rwanda - Shifting focus from producing enough to producing surplus. Government of Rwanda, Kigali, Rwanda.

MINAGRI (Rwanda Ministry of Agriculture and Animal Resources), 2014. National Fertilizer Policy. Ministry of Agriculture and Animal Resources. Government of Rwanda, Kigali, Rwanda.

MINIRENA (Ministry of Natural Resources), 2011. Green Growth and Climate Resilience - National Strategy for Climate Change and Low Carbon Development. Government of Rwanda, Kigali, Rwanda.

Montanarella, L., Pennock, D.J., McKenzie, N., Badraoui, M., Chude, V., Baptista, I., Mamo, T., Yemefack, M., Aulakh, M.S., Yagi, K., Hong, S.Y., Vijarnsorn, P., Zhang, G., Arrouays, D., Black, H., Krasilnikov, P., Sobocka, J., Alegre, J., Henriquez, C.R., Mendonca-Santos, M.L., Taboada, M., Espinosa-Victoria, D., AlShankiti, A., AlaviPanah, S.K., Elsheikh, E.A., Hempel, J., Arbestain, M.C., Nachtergaele, F., Vargas, R., 2016. World's soils are under threat. SOIL, 2, 79-82.

Moore, A.D., Bell, L.W., Revell, D.K., 2009. Feed gaps in mixed-farming systems: insights from the Grain \& Graze program. Animal Production Science 49 (10), 736. 
Morris, J., Fraval, S., Githoro, E., Mugatha, S., \& Ran, Y., 2014. Participatory GIS expert workshop report. ILRI, SEI. Nairobi, Kenya.

Mtengeti, E.J., Phiri, E.C.J.H., Urio, N.H., Mhando, D.G., Mvena, Z., Ryoba, R., Mdegela, R., Singh, B.R., Mo, M., Wetlesen, A., Lorken, T., Reksen, O., 2008. Forage availability and its quality in the dry season on smallholder dairy farms in Tanzania. Acta Agriculturae Scand Section A, 58 (4), 196-204.

Murithi, F., Minayo, C., 2011. Staff aging, turnover in African Agricultural Research. In: A case study on Kenya Agricultural Research Institute in: Agricultural R\&D: Investing in Africa Future. Analyzing trends, Challenges and opportunities. IFPRRI-FARA Conference, Ghana. URL: https://www.asti.cgiar.org/pdf/conference/Theme2/CaseStudies/Murithi.pdf

Muriuki, H., Thorpe, W., 2001. Smallholder dairy production and marketing in eastern and southern Africa: Regional synthesis. Proceedings of South-South Workshop on Smallholder Dairy Production and Marketing. 13-16 March 2001, National Dairy Development Board (NDDB), Anand, India.

Mushi, D. E., Eik, L. O., Bernués, A., Ripoll-Bosch, R., Sundstøl, F., \& Mo, M., 2015. Reducing GHG emissions from traditional livestock systems to mitigate changing climate and biodiversity. In: Sustainable Intensification to Advance Food Security and Enhance Climate Resilience in Africa (pp. 343-365). Springer, Cham.

Mutimura, M., Everson, T. M., 2011. Assessment of livestock feed resource-use patterns in low rainfall and aluminium toxicity prone areas of Rwanda. African Journal of Agricultural Research 6 (15), 34613469.

Mutimura, M., Everson, T. M., 2012. On-farm evaluation of improved Brachiaria grasses in low rainfall and aluminium toxicity prone areas of Rwanda. International Journal of Biodiversity and Conservation 4 (3), 137-154.

Mutimura, M., Lussa, A.B., Mutabazi, J., Myambi, C.B., Cyamweshi, R.A., Ebong, C., 2013. Status of animal feed resources in Rwanda. Tropical Grasslands-Forrajes Tropicales 1 (1), 109-110.

Mutimura, M., Ebong, C., Rao, I. M., Nsahlai, I. V., 2015. Nutritional values of available ruminant feed resources in smallholder dairy farms in Rwanda. Tropical Animal Health and Production 47 (6), 1131-1137.

Mwongera, C., Shikuku, K.M, Winowiecki, L., Twyman, J., Läderach, P., Ampaire, E., van Asten P., Twomlow S., 2015. Climate-smart agriculture rapid appraisal (CSA-RA): A prioritization tool for outscaling CSA. Step-by-step guidelines.

Myambi, C. B., Mutimura, M., 2012. Effect of Supplementing Different Levels of Leucaena diversifolia Leaf Meal on Milk Yield of Crossbred Dairy Cows. Research Journal of Dairy Sciencies 6 (3-4), 19-21.

Naudin, K., Scopel, E., Andriamandroso, A. L. H., Rakotosolofo, M., Andriamarosoa Ratsimbazafy, N. R. S., Rakotozandriny, J. N., Salgado, P., Giller, K. E., 2012. Trade-Offs Between Biomass Use and Soil Cover. the Case of Rice-Based Cropping Systems in the Lake Alaotra Region of Madagascar. Experimental Agriculture 48 (02), 194-209. 
Ndah, T., Schuler, J., Nkwain, V.N., Nzogela, B., Paul, B.K., 2017. Factors affecting the adoption of forage technologies in smallholder dairy production systems in Lushoto, Tanzania. CIAT Working Paper. International Center for Tropical Agricutlure (CIAT), Cali, Colombia. 38.

Ndung'u, P.W., Bebe, B.O., Ondiek, J.O., Butterbach-Bahl, K., Merbold, L., Goopy, J.P., 2019. Improved region-specific emission factors for enteric methane emissions from cattle in smallholder mixed crop-livestock systems in Nandi County, Kenya. Animal Production Scienc, 59 (6), 1136.

Negawo, A., Teshome, A., Kumar, A., Hanson, J., Jones, C., 2017. Opportunities for Napier Grass (Pennisetum purpureum) Improvement Using Molecular Genetics. Agronomy 7 (2), 28. https://doi.org/10.3390/agronomy7020028.

Niang, A., Styger, E., Gahamanyi, A., Hoekstra, D., Coe, R., 1998. Fodder-quality improvement through contour planting of legume-shrub / grass mixtures in croplands of Rwanda highlands. Agroforestry Systems 39, 263-274.

NISR (National Institute of Statistics of Rwanda), 2011. The Third Integrated Household Living Conditions Survey (EICV3). Main Indicators Report. Government of Rwanda, Kigali, Rwanda.

NISR (National Institute of Statistics of Rwanda), 2014. Seasonal Agricultural Survey 2014. Government of Rwanda, Kigali, Rwanda.

Njarui, D.M., Gatheru, M., Gichangi, E.M., Nyambati, E.M., Ondiko, C.N., Ndungu-Magiroi, K.W., 2017. Determinants of forage adoption and production niches among smallholder farmers in Kenya. African Journal of Range \& Forage Science 34 (3), 157-166.

Nkonya, E., Johnson, T., Kwon, H.Y., Kato, E., 2016. Economics of Land Degradation in Sub-Saharan Africa. In: Nkonya, E., Mirzabaev, A., von Braun, J. (Eds). Economics of Land Degradation and Improvement -A Global Assessment for Sustainable Development. Springer, Cham.

NRC (National Research Council), 2001. Nutrient requirements of dairy cattle. Seventh revised edition. National Academic Press, Washington, D.C., United States of America.

Nyiransengimana, E., Mbarubukeye, S., 2005. Peri- urban livestock production in Rwanda. African Crop Science Conference Proceedings 7 (1997), 825-826.

Ojiem, J. O., Vanlauwe, B., de Ridder, N., \& Giller, K. E., 2007. Niche-based assessment of contributions of legumes to the nitrogen economy of Western Kenya smallholder farms. Plant and Soil 292(1-2), 119-135.

Okoba, B.O., Tenge, A.J., Sterk, G., Stroosnijder, L., 2007. Participatory Soil and Water Conservation Planning using an Erosion Mapping Tool in the Central Highlands of Kenya. Land Degradation and Development 18 (3), 330-319.

Omollo, E.O., Wasonga ,O.V., Elhadi, M.Y., Mnene, W.N., 2018. Determinants of pastoral and agro-pastoral households' participation in fodder production in Makueni and Kajiado Counties, Kenya. Pastoralism: Research, Policy and Practice 8 (1), 9. 
Ortiz-Gonzalo, D., Vaast, P., Oelofse, M., de Neergaard, A., Albrecht, A., Rosenstock, T. S., 2017. Farm-scale greenhouse gas balances, hotspots and uncertainties in smallholder crop-livestock systems in Central Kenya. Agriculture, Ecosystems and Environment 248 (January), 58-70.

Ortiz-Gonzalo, D., de Neergaard, A., Vaast, P., Suarez-Villanueva, V., Oelofse, M., Rosenstock, T.S., 2018. Multi-scale measurements show limited soil greenhouse gas emissions in Kenyan smallholder coffee-dairy systems. Science of the Total Environment 626, 328-339.

Ouma, E., Birachi, E., Pypers, P., Vanlauwe, B., Ekesa, B., Blomme, G., ... van Asten, P., 2012. CIALCA Baseline Survey. CIALCA Technical Report No. 17. CIAT, IITA and Bioversity International Nairobi, Kenya.

Owen, E., Smith, T., Makkar, H., 2012. Successes and failures with animal nutrition practices and technologies in developing countries: A synthesis of an FAO e-conference. Animal Feed Science and Technology 174 (3-4), 211-226.

Oyarzun, P.J., Borja, R.M, Sherwood, S., Parra, V., 2013. Making Sense of Agrobiodiversity, Diet, and Intensification of Smallholder Family Faring in the Highland Andes of Ecuador. Ecol. Food Nutr. 52 (6), 515-541.

Palacios-Lopez A., Christiaensen L., Kilic T., 2017. How much of the labor in African agriculture is provided by women? Food Policy 67, 52-63.

Palm, C., Blanco-Canqui, H., DeClerck, F., Gatere, L., Grace, P., 2014. Conservation agriculture and ecosystem services: An overview. Agriculture, Ecosystems \& Environment 187, 87-105.

Parsons, D., Nicholson, C.F., Blake, R.W., Ketterings, Q.M., Ramirez-Aviles, L., Fox, D.G., Tedeschi, L.O., Cherney, J.H., 2011. Development and evaluation of an integrated simulation model for assessing smallholder crop-livestock production in Yucatan, Mexico. Agricultural Systems 104, 1-12.

Paul, B.K., Pypers, P., Sanginga, J.M., Bafunyembaka, F., Vanlauwe, B., 2014. ISFM Adaptation Trials: Farmer-to-Farmer Facilitation, Farmer-Led Data Collection, Technology Learning and Uptake. In: B. Vanlauwe et al. (eds.). Challenges and Opportunities for Agricultural Intensification of the Humid Highland Systems of Sub-Saharan Africa. Springer International, Switzerland.

Paul, B.K., Muhimuzi, F.L., Bacigale, S.B., Wimba, B.M.M., Chiuri, W.L., Amzati, G.S., Maass, B.L., 2016. Towards an assessment of on-farm niches for improved forages in Sud-Kivu, DR Congo. Journal of Agriculture and Rural Development in the Tropics and Subtropics 177 (2).

Paul, B.K., Frelat, R., Birnholz, C., Ebong, C., Gahigi, A., Groot, J.C.J., Herrero, M., Kagabo, D.M., Notenbaert, A., Vanlauwe, B., van Wijk, M.T., 2018. Agricultural intensification scenarios, household food availability and greenhouse gas emissions in Rwanda: Ex-ante impacts and trade-offs. Agricultural Systems 163, 16-26.

Paul, S.S., Mandal A.B., Mandal G.P., Kannan A., Pathak, N.N., 2004. Deriving nutrient requirements of lactating Indian cattle under tropical condition using performance and intake data emanated from 
feeding trials conducted in different research institutes. Asian-Australasian Journal of Animal Sciences 17 (6), 769-776.

Pedreira, B.C., Pedreira, C.G.S., Boote, K.J., Lara, M.A.S., Alderman, P.D., 2011. Adapting the CROPGRO perennial forage model to predict growth of Brachiaria brizantha. Field Crop Research, 120, 370379.

Pelster, D. E., Gisore, B., Koske, J. K., Goopy, J., Korir, D., Rufino, M. C., Butterbach-Bahl, K., 2016. Methane and Nitrous Oxide Emissions from Cattle Excreta on an East African Grassland. Journal of Environmental Quality 45 (5), 1531.

Pengelly, B.C., Whitbread, A., Mazaiwana, P.R., Mukombe, N., 2003. Tropical forage research for the future-better use of research resources to deliver adoption and benefits to farmers. Tropical Grasslands 37 (4), 207-216.

Pequeno, D.N.L., Pedreira, C.G.S., Boote, K.J., 2014. Simulating forage production of Marandu palisade grass (Brachiaria brizantha) with the CROPGRO-Perennial Forage model. Crop \& Pasture Science, $65,1335-1348$.

Peters, M., Herrero, M., Fisher, M., Erb, K., Rao, I., Subbarao, G.V., Castro, A., Chara, J., Murgueitio, E., van der Hoek, R., Läderach, P., Hyman, G., Tapasco, J., Strassburg, B., Paul, B.K., Rincon, A., SchultzeKraft, R., Fote, S., Searchinger, T., 2013. Challenges and opportunities for improving eco-efficiency of tropical forage-based systems to mitigate greenhouse gas emissions. Tropical Grasslands Forrajes Tropicales 1, 137-149.

Peters, M., Rao, I., Fisher, M., Subbarao, G., Martens, S., Herrero, M., van der Hoek, R., Schultze-Kraft, R., Miles, J., Castro, A., Graefe, S., Tiemann, t., Ayarza, M., Hyman, G., 2012. Chapter 11: Tropical Forage-based Systems to Mitigate Greenhouse Gas Emissions. In Eco-Efficiency: From Vision to Reality. Cali, Colombia: CIAT 1-20.

Peters, M., Lascano, C. E., Roothaert, R., De Haan N. C., 2003. Linking research on forage germplasm to farmers: the pathway to increased adoption-a CIAT, ILRI and IITA perspective. Field Crops Research 84 (1), 179-188.

Peters, M., Horne, P., Schmidt, A., Holmann, F., Kerridge, P.C., Tarawali, S.A., Schlutze- Kraft, R., Lascano, C., Argel, P., Stur, W., Fujisaka, S., Muller-Samann, K., Wortmann, C., 2001. The role of forages in reducing poverty and degradation of natural resources in tropical production systems. AgREN Network Paper No. 117, ODI Agricultural Research and Extension Network.

Philibert, A., Loyce, C., Makowski, D., 2012. Assessment of the quality of meta-analysis in agronomy. Agriculture, Ecosystems and Environment 148, 72-82.

Place, F., Roothaert, R., Maina, L., Franzel, S., Sinja, J., Wanjiku, J., 2009. The impact of fodder trees on milk production and income among smallholder dairy farmers in East Africa and the role of research. Occasional Paper 12, World Agroforestry Center (ICRAF), Nairobi, Kenya. 
Powlson, D. S., Stirling, C. M., Thierfelder, C., White, R. P., Jat, M. L., 2016. Does conservation agriculture deliver climate change mitigation through soil carbon sequestration in tropical agro-ecosystems? Agriculture, Ecosystems and Environment 220, 164-174.

Rao, I., Peters, M., Castro, A., Schultze-Kraft, R., White, D., Fisher, M.J., Lascano, C., Blummel, M., Bungenstab. D., Tapasco, J., Hyman, G., Bolliger, A., Paul, B., van der Hoek, R., Maass, B.L., Tiemann, T., Cuchillo, M., Douxchamps, S., Villanueva, C., Rincon, A., Avarza, M., Rosenstock, T., Subbarao, G., Arango, J., Cardoso, J.A., Worthington M., Chrinda, N., Notenbaert, A., Jenet, A., Schmidt, A., Vivas, N., Lefroy, R., Fahrney, K., Guimaraes, E., Tohme, J., Cook, M., Herrero, M., Chacon, M., Searchinger, T., Rudel, T., 2015. LivestockPlus - The sustainable intensification of forage-based agricultural systems to improve livelihoods and ecosystem services in the tropics. Tropical Grasslands - Forrajes Tropicales 3 (2), 59.

R Core Team, 2013. R: A language and environment for Statistical Computing. R Foundation for Statistical Computing, Vienna, Austria. http://www.R-project.org/.

Richards, M., Metzel, R., Chirinda, N., Ly, P., Nyamadzawo, G., Duong Vu, Q., de Neergaard, A., Oelofse, M., Wollenberg, E., Keller, E., Malin, D., Olesen, J.E., Hillier, J., Rosenstock, T.S., 2016. Limits of agricultural greenhouse gas calculators to predict soil $\mathrm{N}_{2} \mathrm{O}$ and $\mathrm{CH}_{4}$ fluxes in tropical agriculture. Scientific Reports, 6, 26279.

Rigolot, C., de Voil, P., Douxchamps, S., Prestwidge, D., van Wijk, M., Thornton, P., Rodriguez, D., Henderson, B., Medina, D., Herrero, M. (2017). Interactions between intervention packages, climatic risk, climate change and food security in mixed crop-livestock systems in Burkina Faso. Agricultural Systems 151, 217-224.

Ripoll-Bosch, R., Diez-Unquera, B., Ruiz, R., Villalba, D., Molina, E., Joy, M., Olaizola, A., Bernues, A., 2012. An integrated sustainability assessment of Mediterranean sheep farms with different degrees of intensification. Agricultural Systems, 105, 46-56.

Ritzema, R., Frelat, R., Douxchamps, S., Silvestri, S., Rufino, M.C., Herrero, M., Giller, K., Lopez-Ridaura, S., Teufel, N., Paul, B.K., van Wijk, M., 2017. Is production intensification likely to make farm households food-adequate? A simple food availability analysis across smallholder farming systems from East and West Africa. Food Security 9 (1),115-131.

Robinson, T.P., Thornton, P.K., Franceschini, G., Kruska, R.L., Chiozza, F., Notenbaert, A., Cecchi, G., Herrero, M., Epprecht, M, Fritz, S., You, L., Conchedda, G., See, L., 2011. Global livestock production systems. Rome, Italy: Food and Agriculture Organization of the United Nations (FAO) and Nairobi, Kenya: International Livestock Research Institute (ILRI) 1-152.

Robinson, T. P., Wint, G. R. W., Conchedda, G., Van Boeckel, T. P., Ercoli, V., Palamara, E., ... Gilbert, M., 2014. Mapping the Global Distribution of Livestock. PLoS ONE. 9 (5), e96084.

Romney, D., Utiger, C., Kaitho, R., Thorne, P., Wokabi, A., Njoroge, L., Chege, L., Kirui, J., Kamotho, D., Staal, S., 2004. Effect of intensification on feed management of dairy cows in the Central Highlands of Kenya. In E. Owen, T. Smith, M. A. Steele, S. Anderson, A. J. Duncan, M. Herrero, J.D. Leaver, C.K. Reynolds, J.I. Richards, J. C. Ku-Vera (Eds.), Responding to the livestock revolution: the role of 
globalization and implications for poverty alleviation. British Society of Animal Science Publication. Nottingham, UK 33, 3-8.

Rosenstock, T. S., Lamanna, C., Chesterman, S., Bell, P., Arslan, A., Richards, M., Rioux, J., Aknleye, A.O., Champalle, C., Cheng, Z., Corder-Dolloff, C., Dohn, J., English, W., Eyrich, A., Girvetz, E.H., Kerr, A., Lizarazo, M., Madalinska, A., McFatridge, S., Morris, K.S., Namoi, N., Poultouchidou, A., Ravina da Silva, M., Rayess, S., Ström, H., Tully, K.L., Zou, W., 2016. The scientific basis of climate-smart agriculture - A systematic review protocol (No. 138). Working Paper No. 138. Copenhagen, Denmark: CGIAR Research Program on Climate Change, Agriculture and Food Security (CCAFS). http://www.ccafs.cgiar.org.

Rosenstock, T. S., Lamanna, C., Chesterman, S., Bell, P., Arslan, A., Richards, M., Rioux, J., Aknleye, A.O., Champalle, C., Cheng, Z., Corder-Dolloff, C., Dohn, J., English, W., Eyrich, A., Girvetz, E.H., Kerr, A., Lizarazo, M., Madalinska, A., McFatridge, S., Morris, K.S., Namoi, N., Poultouchidou, A., Ravina da Silva, M., Rayess, S., Ström, H., Tully, K.L., Zou, W., 2016. The scientific basis of climate-smart agriculture - A systematic review protocol (No. 138). Working Paper No. 138. Copenhagen, Denmark: CGIAR Research Program on Climate Change, Agriculture and Food Security (CCAFS). http://www.ccafs.cgiar.org.

Rosenstock, T.S., Rufino, M.C., Butterbach-Bahl, K., Wollenberg, E., 2013. Toward a protocol for quantifying the greenhouse gas balance and identifying mitigation options in smallholder farming systems. Environmental Research Letters 8, 21003.

Rudel, T.K., Paul, B., White, D., Rao, I.M., van der Hoek, R., Castro, A., Boval, M., Lerner, A., Schneider, L., Peters, 2015. LivestockPlus: Forages, sustainable intensification, and food security in the tropics. Ambio 44, 685-693.

Rudel, T.K., Kwon, O.J., Paul, B.K., Boval, M., Rao, I.M., Burbano, D., McGroddy, M., Lerner, A.M., White, D., Cuchillo, M., Luna, M., Peters, M. 2016. Do Smallholder, Mixed Crop-Livestock Livelihoods Encourage Sustainable Practices? A Meta-Analysis. Land 5, 6.

Rufino, 2007. Quantifying the contribution of crop-livestock integration to African farming. PhD thesis, Wageningen University, the Netherlands.

Rufino, M.C., Quiros, C., Boureima ,M., Desta, S., Douxchamps, S., Herrero, M., Kiplimo, J., Lamissa, D., Joash, M., Moussa, A.S., Naab, J., Ndour, Y., Sayula, G., Silvestri, S., Singh, D., Teufel, N., Wanyama, I., 2012. Developing generic tools for characterizing agricultural systems for climate and global change studies (IMPACTlite-phase 2). Copenhagen: CGIAR Research Program on Climate Change, Agriculture and Food Security (CCAFS).

Salmon, G., Teufel, N., Baltenweck, I., van Wijk, M., Claessens, L., Marshall, K., 2018. Trade-offs in livestock development at farm level: Different actors with different objectives. Global Food Security 17, 103112.

Scarpa, R., Eric, E.S.K., Kristjanson, P., Radeny, M., Drucker, A.G., Rege, J.E.O., 2003. Valuing indigenous cattle breeds in Kenya: an empirical comparison of stated and revealed preference value estimates. Ecological Economics 45, 409-426. 
Schultze-Kraft, R., Rao, I.M., Peters, M., Clements, R.J., Bai, C., Liu, G., 2018. Tropical forage legumes for environmental benefits: An overview. Tropical Grasslands-Forrajes Tropicales 6 (1), 1-14.

Seebauer, M., 2014. Whole farm quantification of GHG emissions within smallholder farms in developing countries. Environmental Research Letters 9 (3), 1-19.

SEI (Stockholm Institute of Environment), 2009. Economics of Climate Change in Rwanda. Stockholm, Sweden.

Sere, C., Steinfeld, H., 1996. World Livestock Production Systems. Current Status, Issues, Trends. FAO Animal Production and Health Paper No. 127. FAO, Rome.

Shelton, H. M., Franzel, S., Peters, M., 2005. Adoption of tropical legume technology around the world: analysis of success. Tropical Grasslands 39, 198-209.

Shepherd, K.D., Soule MJ, 1998. Soil fertility management in west Kenya: dynamic simulation of productivity, profitability and sustainability at different resource endowment levels. Agriculture, Ecosystems and Environment 71 (1-3), 131-145.

Shikuku, K.M, Mwongera, C., Winowiecki, L., Twyman, J., Atibo, C., Läderach, P., 2015. Understanding farmers' indicators in climate-smart agriculture prioritization in Nwoya District, Northern Uganda. International Center for Tropical Agriculture (CIAT). Cali, Colombia 46.

Shikuku, K. M., Valdivia, R. O., Paul, B. K., Mwongera, C., Winowiecki, L., Läderach, P., Herrero, M., Silvestri, S., 2017. Prioritizing climate-smart livestock technologies in rural Tanzania: A minimum data approach. Agricultural Systems 151, 204-2016.

Sidahmed, A., 2008. Livestock and climate change: coping and risk management strategies for a sustainable future. In livestock and global climate change conference proceeding, May 2008, Tunisia.

Silvestri, S., Douxchamps S., Kristjanson P., Förch W., Radeny M., Mutie I., Quiros F. C., Herrero M., Ndungu A., Ndiwa N., Mango J., Claessens L., Rufino MC., 2015. Households and food security: lessons from food secure households in East Africa. Agriculture and Food Security 4, 23.

Simon, H.A., 1957. Models of Man: Social and Rational. New York: John Wiley \& Sons.

Smith, P., Martino, D., Cai, Z. et al., 2007. Agriculture. In: Chapter 8 of Climate change 2007; Mitigation. Contribution of Working Group III to the Fourth Assessment Report of the Intergovernmental Panel on Climate Change. B Metz, O R Davidson, P R Bosch, R Dave and L A Meyer (Eds). Cambridge University Press, Cambridge, UK and New York, USA 497-540.

Smith, A., Snapp, S., Chikowo, R., Thorne, P., Bekunda, M., Glover, J., 2017. Measuring sustainable intensification in smallholder agroecosystems : A review. Global Food Security 12, 127-138.

Snyder, K.A., Miththapala, S., Sommer, R., Braslow, J., 2016. The Yield Gap: Closing the Gap by Widening the Approach. Experimental Agriculture 53, 445-459. 
Sommer, R., Bossio, D., 2014. Dynamics and climate change mitigation potential of soil organic carbon sequestration. Journal of Environmental Management 144, 83-87.

Staal, S., Owango, M., Muriuki, H., Kenyanjui, M., Lukuyu, B., Njoroge, L., Njubi, D., Baltenweck, I., Musembi, F., Bwana, O., Muriuki, K., Gichungu, G., Omore, A., Thorpe, W., 2001. Dairy Systems Characterisation of the Greater Nairobi Milk Shed: Smallholder Dairy (R\&D) Project. KARI/MoA/ILRI Collaborative Dairy Research Programme. ILRI, Nairobi, Kenya 68. (http://www.cgiar.org/ilri/info/databases.cfm).

Steenwerth, K. L., Hodson, A. K., Bloom, A. J., Carter, M. R., Cattaneo, A., Chartres, C. J., Hatfield, L., Henry, J., Hopmans, W., Horwath, B., Jenkins, E., Kebreab, R., Leemans, R., Lipper, L., Lubell, M.N., Msangi, S., Prabhu, R., Reynolds, M.P., Sandoval Solis, S., Sischo, W.M., Springbor, M., Tittonell, P., Wheler, S.M., Vermeulen, S.J., Wollenberg, E.K., Jarvis, L.S., Jackson, L. E., 2014. Climate-smart agriculture global research agenda: scientific basis for action. Agriculture \& Food Security 3 (1), 11.

Steinfeld, H., Gerber, P., Wassenaar, T., Castel, V., Rosales, M., de Haas, C., 2006. Livestock's Long Shadow. Environmental issues and options. LEAD-FAO, Food and Agriculture Organization, Rome, Italy 390.

Stoorvogel, J. J., Smaling, E. M. A., Janssen, B. H., 1993. Calculating soil nutrient balances in Africa at different scales - I. Supra-national scale. Fertilizer Research 35, 227-235.

Struik, P.C., Kuyper, T.W., 2017. Sustainable intensification in agriculture: the richer shade of green. A review. Agronomy for Sustainable Development, 37 (5).

Stür, W. W., Horne, P. M., Gabunada Jr, F. A., Phengsavanh, P., Kerridge, P. C., 2002. Forage options for smallholder crop-animal systems in Southeast Asia: working with farmers to find solutions. Agricultural Systems 71 (1), 75-98.

Stür, W., Khanh, T. T., \& Duncan, A., 2013. Transformation of smallholder beef cattle production in Vietnam. International Journal of Agricultural Sustainability 11 (4), 363-381.

Sumberg, J., 2002. The logic of fodder legumes in Africa. Food Policy 27 (3), 285-300.

Sumberg, J., 2002b. Livestock nutrition and foodstuff research in Africa: when is a nutritional constraint not a priority research problem? Animal Science 75 (3), 332-338.

Sumberg, J., 2003. Toward a dis-aggregated view of crop-livestock integration in Western Africa. Land Use Policy 20, 253-264.

Sumberg, J., Lankoande, G.D., 2013. Heifer-in-trust, Social Protection and Graduation: Conceptual Issues and Empirical Questions. Development Policy Review 31 (3), 255-27.

Sutherland, W. J., Wordley, C. F. R., 2017. Evidence complacency hampers conservation. Nature Ecology \& Evolution, 1. (September), 1215-1216. 
Tarawali, G., Manyong, V.M., Carsky, R.J., Vissoh, P.V., Osei-Bonsu, P., Galiba, M., 1999. Adoption of improved fallows in West Africa: lessons from Mucuna and stylo studies. Agroforestry Systems 47, 93-122.

Tarawali, S.A., Singh, B.B., Gupta, S.S., Tabo, R., Harris, F., Nokoe, S., Fernandez-Rivera, S., Bationo, A., Manyong, V.M., Makinde, K., Odion, E.C., 2003. Cowpea as a key factor for a new approach to integrated crop-livestock systems research in the dry savannas of West Africa. In: Challenges and opportunities for enhancing sustainable cowpea production, 4-7 September 2000, (International Institute for Tropical Agriculture (IITA), Ibadan, Nigeria.

Tarawali, S.A., Tarawali, G., Larbi, A., Hanson, J., 1995. Methods for the evaluation of forage legumes, grasses and fodder trees for use as livestock feed (Vol. 1). ILRI (International Livestock Research Institute), Nairobi, Kenya.

Tamminga, S., Van Straalen, W.M., Subsnel, A.P.J., Meijer, R.G.M., Steg, A., Wever, C.J.G., Blok, M.C., 1994. The Dutch protein evaluation system: the DVE/OEB-system. Livestock Production Science 40 (2), $139-155$.

Tenge, J., De Graaff, J., Hella, J.P, 2005. Financial efficiency of major soil and water conservation measures in West Usambara highlands, Tanzania. Applied Geography 25, 348-366.

The Economist, $4^{\text {th }}$ of May 2019. A Meaty Planet. International section 57-59.

Thomas, D., Sumberg, J. E., 1995. A review of the evaluation and use of tropical forage legumes in subSaharan Africa. Agriculture, Ecosystems \& Environment 54 (3), 151-163.

Thornton, P., Herrero, M., Freeman, A., Mwai, O., Rege, E., Jones, P., McDermott, J., 2007. Vulnerability, Climate change and Livestock - Research Opportunities and Challenges for Poverty.

Thornton, P.K., van de Steeg, J., Notenbaert, A.M., Herrero, M., 2009. The impacts of climate change on livestock and livestock systems in developing countries: A review of what we know and what we need to know. Agricultural Systems 101, 113-127.

Thornton, P. K., 2010. Livestock production: recent trends, future prospects. Philosophical Transactions of the Royal Society of London. Series B, Biological sciences 365 (1554), 2853-67.

Thornton, P.K., Herrero, M., 2010. Potential for reduced methane and carbon dioxide emissions from livestock and pasture management in the tropics. Proceedings of the National Academy of Sciences (PNAS), 107 (46), 19667-19672.

Thornton, P. K., Schuetz, T., Förch, W., Cramer, L., Abreu, D., Vermeulen, S., Campbell, B. M., 2017. Responding to global change : A theory of change approach to making agricultural research for development outcome-based. Agricultural Systems 152, 145-153.

Thornton, P.K., Whitbread, A., Baedeker, T., Cairns, J., Claessens, L., Baethgen, W., Bunn, C., Friedmann, M., Giller, K.E., Herrero, M., Howden, M., Kilcline, K., Nangia, V., Ramirez-Villega, J., Kumar, S., West, 
P.C., Keating, B., 2018. A framework for priority setting in climate smart agriculture research. Agricultural Systems 167, 161-175.

Thorpe, W.R., Muriuki, H.G., Omore, A.O., Owango, M.O., Staal, S.J., 2000. Dairy development in Kenya: the past, the present and the future. Presented at 'Challenges to Animal Production in this Millennium', Annual Symposium of the Animal Production Society of Kenya (APSK), Nairobi, 22-23 March, 2000. ILRI, Nairobi, Kenya. URL: https://cgspace.cgiar.org/handle/10568/1723

Timler, C., Michalscheck, M., Klapwijk, C., Mashingaidze, N., Ollenburger, M., Falconnier, G., Kuivanen, K., Descheemaeker, K., Groot, J., 2014. Characterization of farming systems in Africa RISING intervention sites. International Institute of Tropical Agriculture (IITA). Wageningen, the Netherlands.

Timler, C., Michalscheck, M., Alvarez, S., Descheemaeker, K., Groot, J.C.J., 2017. Exploring options for sustainable intensification through legume integration in different farm types in Eastern Zambia. In: I. Oborn, B. Vanlauwe, M. Phillips, R. Thomas, W. Brooijmans, K. Atta-Krah. Sustainable Intensification in Smallholder Agriculture - an integrated systems research approach. Routledge, New York.

Tittonell, P., Muriuki, A., Shepherd, K.D., Mugendi, D., Kaizzi, K. C., Okeyo, J., Verchot, L., Coe, R., Vanlauwe, B., 2010. The diversity of rural livelihoods and their influence on soil fertility in agricultural systems of East Africa - A typology of smallholder farms. Agricultural Systems 103 (2), 83-97.

Tittonell, P., Giller, K.E., 2013. When yield gaps are poverty traps: The paradigm of ecological intensification in African smallholder agriculture. Field Crops Research 143, 76-90.

Tittonell, P., Gérard, B., Erenstein, O., 2015. Tradeoffs around crop residue biomass in smallholder croplivestock systems - What's next? Agricultural Systems 134, 119-128.

Thomas, S. C., Martin, A. R., 2012. Carbon content of tree tissues: A synthesis. Forests 3 (2), 332-352.

Thornton, P.K., 2010. Livestock production: recent trends, future prospects. Philosophical Transactions of the Royal Society B. 365, 2853-2867.

't Mannetje, L., 2000. Measuring biomass of grassland vegetation. In: 't Mannetje, L, Jones RM (eds.) Field and laboratory methods for grassland and animal production research. Wallingford, $C A B I$ Publishing/CAB International 151-177.

Tongruksawattana, S., and Ngunjiri, S., 2015. Farm household typology - Lushoto, Tanzania. Report from CCAFS PEACSA project, unpublished.

Tubiello, F.N., Soussana, J.F., Howden, S.M., 2007. Crop and pasture response to climate change. Proc Natl Acad Sci. 104, 19686-19690.

Udo, H.M.J, Aklilu, . H.A., Phong, L.T., Bosma, R.H., Budisatria, I.G.S., Patil, B.R., Samdup, T., Bebe, B.O., 2011. Impact of intensification of different types of livestock production in smallholder croplivestock systems. Livestock Science 139 (1-2), 22-29. 
Umunezero, O., Mwendia, S., Paul, B. K., Maass, B. L., Ebong, C., Kagabo, D., Musana, D., Muhutu, J.C., Mutimura, M., Hirwa, C.A., Shumbushu, F., Nyiransengimana, F., Mukuralinda, A., Notenbaert, A., 2016. Identifying and Characterizing Areas for Potential Forage Production in Rwanda. CIAT Working Paper No. 417. Centro Internacional de Agricultura Tropical (CIAT), Cali, Colombia. 16.

UN, Department of Economic and Social Affairs, Population Division, 2015. World Population Prospects: The 2015 Revision, Key Findings and Advance Tables. Working Paper No. ESA/P/WP.241.

UNEP-WCMC and IUCN, 2016. Protected Planet: Tanzania; The World Database on Protected Areas (WDPA)/The Global Database on Protected Areas Management Effectiveness (GD-PAME). Cambridge, UK. Retrieved from http://www.protectedplanet.net/.

United Republic of Tanzania, 2015. Intended Nationally Determined Contributions (INDCs). Dar Es Salaam, Tanzania.

Valbuena, D., Erenstein, O., Homann-Kee Tui, S., Abdoulaye, T., Claessens, L., Duncan, A.J., Gerard, B., Rufino, M.C., Teufel, N., van Rooyen, A., van Wijk, M.T., 2012. Conservation Agriculture in mixed crop-livestock systems: Scoping crop residue trade-offs in Sub-Saharan Africa and South Asia. Field Crops Research 132, 175-184.

Valbuena, D., Groot, J. C. J., Mukalama, J., Gérard, B., Tittonell, P., 2015. Improving rural livelihoods as a "moving target": trajectories of change in smallholder farming systems of Western Kenya. Regional Environmental Change 15 (7), 1395-1407.

Valentini, R., Arneth, A., Bombelli, A., Castaldi, S., Cazzolla Gatti, R., Chevallier, F., Ciais, P., Grieco, E., Hartmann, J., Henry, M., Houghton, R.A., Jung, M., Kutch, W.L., Malhi, Y., Mayorga, E., Merbold, L., Murray-Tortarolo, G., Papale, D., Peylin, P., Poulter, B., Raymond, P.A., Santini, M., Sitch, S., Vaglio Laurin, G., van der Werf, G.R., Williams, C.A., Scholes, R. J., 2014. A full greenhouse gases budget of Africa: Synthesis, uncertainties, and vulnerabilities. Biogeosciences 11 (2), 381-407.

Vallentine JF, 1990. Grazing management. Academic Press, London.

Van der Lee, J., Klerkx, L., Bebe, B.O., Mengistu, A., Oosting, S., 2018. Intensification and Upgrading Dynamics in Emerging Dairy Clusters in the East African Highlands. Sustainability 10, 4324.

Van De Ven, G.W.J., De Ridder, N., Van Keulen, H., Van Ittersum, M. K., 2003. Concepts in production ecology for analysis and design of animal and plant-animal production systems. Agricultural Systems 76 (2), 507-525.

Van der Linden, A., Oosting, S.J., van de Ven, G.W.J., de Boer, I.J.M., van Ittersum, M.K., 2015. A framework for quantitative analysis of livestock systems using theoretical concepts of production ecology. Agricultural System 139, 100-109.

Van der Linden, A., Oosting, S.J., van de Ven, G.W.J., van Ittersum, M.K., de Boer, I.J.M., 2018. LiGAPS-Beef, a mechanistic model to explore potential and feed-limited beef production 1: model description and illustration. Animal 1-11. 
Van Es, A.J.H., 1975. Feed evaluation for dairy cows. Livestock Production Science 2, 95-107.

Van Ittersum, M.K., Cassman, K.G., Grassini, P., Wolf, J., Tittonell, P., Hochman, Z., 2013. Yield gap analysis with local to global relevance-A review. Field Crops Research 143, 4-17.

Van Kooten, G.C., Schoney, R.A., Hayward, K.A., 1986. An Alternative Approach to the Evaluation of Goal Hierarchies among Farmers. Western Journal of Agricultural Economics 11 (1), 40-49.

Vanlauwe, B., Coe, R., Giller, K.E., 2016. Beyond averages: New approaches to understand heterogeneity and risk of technology success or failure in smallholder farming. Experimental Agriculture 1-23.

Vanlauwe, B., Barrios, E., Robinson, T., van Asten, P., Zingore, S., Gerard, B., 2017. System productivity and natural resource integrity in smallholder farming. Friends or foes? In: I. Oborn, B. Vanlauwe, M. Phillips, R. Thomas, W. Brooijmans, K. Atta-Krah. Sustainable Intensification in Smallholder Agriculture - an integrated systems research approach. Routledge, New York.

Van Wijk, M.T., Tittonell, P., Rufino, M.C., Herrero, M., Pacini, C., de Ridder, N., Giller, K.E., 2009. Identifying key entry-points for strategic management of smallholder farming systems in subSaharan Africa using the dynamic farm-scale simulation model NUANCES-FARMSIM. Agricultural Systems 102m, 89-101.

Van Wijk, M.T., Rufino, M.C., Enahoro, D., Parsons, D., Silvestri, S., Valdivia, R.O., Herrero, M., 2014. Farm household models to analyse food security in a changing climate: A Review. Global Food Security 3 (2), 77-84.

Van Wijk, M.T., 2014. From global economic modelling to household level analyses of food security and sustainability: how big is the gap and can we bridge it? Food Policy 49, $378-388$

Verdoodt, A., Ranst, E. Van., 2003. Land Evaluation for Agricultural Production in the Tropics - A Large-Scale Land Suitability Classification for Rwanda. Laboratory of Soil Science, Ghent University.

Waithaka, M.M., Thornton, P.K., Herrero, M., Shepherd, K.D., 2006. Bio-economic evaluation of farmers' perceptions of viable farms in western Kenya. Agricultural Systems 90, 243-271.

Wassena, F.J., Mangesho, W.E., Chawala, A., Laswai, G.H., Bwire, J.M.N., Kimambo, A.E., Lukuyu, B., Sikumba, G., Maass, B.L., 2015. Effects of season and location on cattle milk produced and producer milk prices in selected villages of Tanga and Morogoro Regions, Tanzania. Livestock Research for Rural Development 27 (10).

Watson, John, R., 1972. Conservation Problems, Policies and the Origins of the Mlalo Basin Rehabilitation Scheme, Usambara Mountains, Tanzania. Geografiska Annaler 54 (3/4), 221-226.

Westermann, O., Forch, W., Thornton, P., Korner, J., Cramer, L., Campbell, B., 2018. Scaling up agricultural interventions: Case studies of climate smart agriculture. Agricultural Systems, 165, 183-293. 
White, D. S., Peters, M., Horne, P., 2013. Global impacts from improved tropical forages : A meta-analysis revealing overlooked benefits and costs, evolving values and new priorities. Tropical Grasslands 1, $12-24$.

Wickama J., Okoba B., Sterk G., 2014. Effectiveness of sustainable land management measures in West Usambara highlands, Tanzania. Catena 118, 91-102.

Willemen, L., Crossman, N.D., Quatrini, S., Egoh, B., Kalaba, F.K., Mbilinyi, B., de Groot, R., 2018. Identifying ecosystem hotspots for targeting land degradation neutrality investments in south-eastern Africa. Journal of Arid Environments, 159, 75-86

Willett, W., Rockström, J., Loken, B., Springmann, M., Lang, T., Vermeulen, S., Garnett, T., Tilman, D., DeClerck, F., Wood, A., Jonell, M., Clarck, M., Gordon, L.J., Fanzo, J., Hawkes, C., Zurayk, R., Rivera, J.A., De Vries, W., Sibanda, L.M., Afshin, A., Chaudhary, A., Herrero, M., Agustina, R., Branca, F., Lartey, A., Fan, S., Crona, B., Fox, E., Bignet, V., Troell, M., Lindhal, T., Singh, S., Cornell, S.E., Reddy, K.S., Narain, S., Nishtar, S., Murray, C.J.L., 2019. Food in the Anthropocene: the EAT-Lancet Commission on healthy diets from sustainable food systems. The Lancet Commissions, 393 (10170), 447-492.

Winowiecki, L., Vågen, T.-G., Massawe, B., Jelinski, N.A., Lyamchai, C., Sayula, G., Msoka, E., 2015. Landscape-scale variability of soil health indicators: Effects of cultivation on soil organic carbon in the Usambara Mountains of Tanzania. Nutrient Cycling in Agroecosystems 105 (3), 263-274.

Zingore, S., Gonzalez-Estrada, E., Delve, R.J., Herrero, M., Dimes, J.P., Giller, K.E., 2009. An integrated evaluation of strategies for enhancing productivity and profitability of resource-constrained smallholder farms in Zimbabwe. Agricultural Systems 101, 57-68. 


\section{Appendices}

\section{Chapter 2}

References of the review

\begin{tabular}{|c|c|c|c|c|c|c|c|c|c|c|}
\hline \multirow[t]{2}{*}{ Author } & \multirow[t]{2}{*}{ Year } & \multirow[t]{2}{*}{ Title } & \multirow[t]{2}{*}{ Journal } & \multirow[t]{2}{*}{ Country } & \multirow{2}{*}{$\begin{array}{l}\text { Mode of } \\
\text { study }\end{array}$} & \multicolumn{5}{|c|}{ Impact dimension } \\
\hline & & & & & & Forage & Livestock & Soil & Economics & Food crop \\
\hline $\begin{array}{l}\text { Akinlade J. , Smith J. } \\
\text { W., Raji A., Busari A., } \\
\text { Adekunle I., } \\
\text { Adewumi M. }\end{array}$ & 2005 & $\begin{array}{l}\text { Effect of Two Cowpea } \\
\text { (Vigna unguiculata) Fodder } \\
\text { Cultivars as Supplements } \\
\text { on Voluntary Intake, Milk } \\
\text { Yield and Manure } \\
\text { Production of Bunaji Cows }\end{array}$ & $\begin{array}{l}\text { Journal or Agriculture } \\
\text { and Rural Development } \\
\text { in the Tropics and } \\
\text { Subtropics }\end{array}$ & Nigeria & Feeding trial & FALSE & TRUE & FALSE & FALSE & FALSE \\
\hline $\begin{array}{l}\text { Angima, S., Stott, } \\
\text { D.E., O’Neill, M.K., } \\
\text { Ong, C.K. Weesies, } \\
\text { G.A. }\end{array}$ & 2002 & $\begin{array}{l}\text { Use of Calliandra-Napier } \\
\text { grass contour hedges to } \\
\text { control erosion in central } \\
\text { Kenya }\end{array}$ & $\begin{array}{l}\text { Agriculture, Ecosystem } \\
\text { and Environment }\end{array}$ & Kenya & On-farm trial & FALSE & FALSE & TRUE & FALSE & FALSE \\
\hline Ayoub A. & 1985 & $\begin{array}{l}\text { The potential contribution } \\
\text { of some forage crops to } \\
\text { the Nitrogen budget and } \\
\text { animal feed in the Sudan } \\
\text { Gezira farming system }\end{array}$ & $\begin{array}{l}\text { In Haque, I., Jutzi, S. and } \\
\text { Neatte, P. (eds) (1985). } \\
\text { Potentials of Forage } \\
\text { Legumes in Farming } \\
\text { Systems of Sub-Saharan } \\
\text { Africa: Proceedings of a } \\
\text { Workshop Held at ILCA, } \\
\text { Addis Ababa, Ethiopia, } \\
\text { 16-19 September } 1985\end{array}$ & Sudan & $\begin{array}{l}\text { On-station } \\
\text { trial }\end{array}$ & TRUE & FALSE & FALSE & FALSE & TRUE \\
\hline $\begin{array}{l}\text { Barahenda, M., } \\
\text { Shem, M., Kanuya, } \\
\text { N., Ntakabeza, I., } \\
\text { Gasana, J. Uwimana, } \\
\text { G., Umenezero, O., } \\
\text { Uwumikuza, D. }\end{array}$ & 2007 & $\begin{array}{l}\text { Yield potential of Grass- } \\
\text { Legume Pasture under } \\
\text { Different Management } \\
\text { Systems }\end{array}$ & $\begin{array}{l}\text { Research Journal of } \\
\text { Animal Sciences }\end{array}$ & Rwanda & $\begin{array}{l}\text { On-station } \\
\text { trial }\end{array}$ & TRUE & FALSE & FALSE & FALSE & FALSE \\
\hline $\begin{array}{l}\text { Boitumelo, W., } \\
\text { Mahabile, W. }\end{array}$ & 1992 & $\begin{array}{l}\text { Improving milk production } \\
\text { in small-scale dairy farms } \\
\text { in Botswana: Incorporating } \\
\text { legume fodder in the } \\
\text { farming systems }\end{array}$ & $\begin{array}{l}\text { In Stares, J.E. et al (eds) } \\
\text { (1992): The } \\
\text { complementarity of } \\
\text { feed resources for } \\
\text { Animal production in } \\
\text { Africa }\end{array}$ & $\begin{array}{l}\text { Botswan } \\
\text { a }\end{array}$ & On-farm trial & TRUE & FALSE & FALSE & FALSE & FALSE \\
\hline $\begin{array}{l}\text { De Groote, H., } \\
\text { Vanlauwe, B., Ruto, } \\
\text { E., Odhiambo, G., } \\
\text { Kanampiu, F., Khan, } \\
\text { Z. }\end{array}$ & 2010 & $\begin{array}{l}\text { Economic analysis of } \\
\text { different options in } \\
\text { integrated pest and soil } \\
\text { fertility management in } \\
\text { maize systems of Western } \\
\text { Kenya }\end{array}$ & Agricultural Economics & Kenya & On-farm trial & FALSE & FALSE & FALSE & TRUE & FALSE \\
\hline
\end{tabular}




\begin{tabular}{|c|c|c|c|c|c|c|c|c|c|c|}
\hline $\begin{array}{l}\text { Gbaraneh , L., Ikpe, } \\
\text { F., Larbi, A., Wahua, } \\
\text { T.,Torunana, J. }\end{array}$ & 2004 & $\begin{array}{l}\text { The Influence Of Lablab } \\
\text { (Lablab purpureus) On } \\
\text { Grain And Fodder Yield Of } \\
\text { Maize (Zea mays) In A } \\
\text { Humid Forest Region Of } \\
\text { Nigeria }\end{array}$ & $\begin{array}{l}\text { Journal of Applied } \\
\text { Sciences and } \\
\text { Environmental } \\
\text { Management }\end{array}$ & Nigeria & $\begin{array}{l}\text { On-station } \\
\text { trial }\end{array}$ & TRUE & FALSE & FALSE & FALSE & FALSE \\
\hline $\begin{array}{l}\text { Guto, S.N., Pypers, } \\
\text { P., Vanlauwe, B., de } \\
\text { Ridder, N., Giller, } \\
\text { K.E. }\end{array}$ & 2011 & $\begin{array}{l}\text { Tillage and vegetative } \\
\text { barrier effects on soil } \\
\text { conservation and short- } \\
\text { term economic benefits in } \\
\text { the Central Kenya } \\
\text { highlands }\end{array}$ & Field Crop Research & Kenya & On-farm trial & TRUE & FALSE & FALSE & TRUE & TRUE \\
\hline $\begin{array}{l}\text { Hassanali A., Herren, } \\
\text { H., Khan, Z., Pickett, } \\
\text { J., Woodcock, C. }\end{array}$ & 2008 & $\begin{array}{l}\text { Integrated pest } \\
\text { management: the push- } \\
\text { pull approach for } \\
\text { controlling insect pests } \\
\text { and weeds of cereals, and } \\
\text { its potential for other } \\
\text { agricultural systems } \\
\text { including animal } \\
\text { husbandry }\end{array}$ & $\begin{array}{l}\text { Philosophical } \\
\text { Transactions of the The } \\
\text { Royal Society Series B }\end{array}$ & Kenya & On-farm trial & FALSE & FALSE & FALSE & TRUE & FALSE \\
\hline $\begin{array}{l}\text { Hassen, A., } \\
\text { Gizachew, L., } \\
\text { Rethman, N., van } \\
\text { Niekerk, W.A. } \\
\text { Van Niekerk, W. }\end{array}$ & 2007 & $\begin{array}{l}\text { Influence of undersowing } \\
\text { perennial forages in maize } \\
\text { on grain, fodder yield and } \\
\text { soil properties in the sub- } \\
\text { humid region of western } \\
\text { Ethiopia }\end{array}$ & $\begin{array}{l}\text { African Journal of Range } \\
\text { \& Forage Science }\end{array}$ & Ethiopia & On-farm trial & TRUE & FALSE & FALSE & FALSE & TRUE \\
\hline Kabirizi, J. & 2009 & $\begin{array}{l}\text { Participatory testing of } \\
\text { forage legume innovations } \\
\text { with women farmers in } \\
\text { Masaka District, Uganda: } \\
\text { Impact on fodder } \\
\text { availability, animal } \\
\text { performance and } \\
\text { household income }\end{array}$ & $\begin{array}{l}\text { In. Urama K. et al } \\
\text { (2009). Agricultural } \\
\text { innovations for } \\
\text { sustainable } \\
\text { development.Vol. } 2 \\
\text { issue 1. African } \\
\text { Technology Policy } \\
\text { Studies Network. Pp.79 }\end{array}$ & Uganda & $\begin{array}{l}\text { Feeding trial } \\
\text { and on-farm } \\
\text { trial }\end{array}$ & TRUE & TRUE & FALSE & FALSE & TRUE \\
\hline $\begin{array}{l}\text { Kabirizi, J., Mpairwe, } \\
\text { D., Mutetikka, D. }\end{array}$ & 2006 & $\begin{array}{l}\text { Improving dairy cattle } \\
\text { productivity in smallholder } \\
\text { farms in Uganda: } \\
\text { Incorporating leguminous } \\
\text { forages in farming systems }\end{array}$ & $\begin{array}{l}\text { Uganda Journal of } \\
\text { Agricultural Sciences }\end{array}$ & Uganda & Feeding trial & FALSE & TRUE & FALSE & TRUE & FALSE \\
\hline $\begin{array}{l}\text { Kabirizi, J., Mpairwe, } \\
\text { D., Mutetikka, D. }\end{array}$ & 2006 & $\begin{array}{l}\text { Effect of intercropping } \\
\text { legumes with elephant } \\
\text { grass on fodder production } \\
\text { in intensive smallholder } \\
\text { dairy farms in Uganda }\end{array}$ & $\begin{array}{l}\text { Uganda Journal of } \\
\text { Agricultural Sciences }\end{array}$ & Uganda & On-farm trial & TRUE & FALSE & FALSE & FALSE & FALSE \\
\hline
\end{tabular}




\begin{tabular}{|c|c|c|c|c|c|c|c|c|c|c|}
\hline $\begin{array}{l}\text { Kabirizi, J., Muyekho, } \\
\text { F., Mulaa, M., } \\
\text { Kawube, G., Msangi, } \\
\text { R., Pallangyo, B., } \\
\text { Zziwa, E., Mugerwa, } \\
\text { S., Ajanga,S., } \\
\text { Lukwago, G., } \\
\text { Wamalwa N., } \\
\text { Kariuki, I., } \\
\text { Atuhairwe, A., } \\
\text { Awalla, J., Namazzi, } \\
\text { C., Nampijja, Z. }\end{array}$ & 2015 & $\begin{array}{l}\text { Dry season forages for } \\
\text { improving dairy } \\
\text { production in smallholder } \\
\text { systems in Uganda }\end{array}$ & $\begin{array}{l}\text { Napier grass feed } \\
\text { resource: production, } \\
\text { constraints and } \\
\text { implications for } \\
\text { smallholder farmers in } \\
\text { Eastern and Central } \\
\text { Africa. ISBN: } 978-9970- \\
\text { 9269-1-6 (Book) }\end{array}$ & Uganda & On-farm trial & TRUE & TRUE & FALSE & FALSE & FALSE \\
\hline $\begin{array}{l}\text { Kabirizi, J., Taabu, L., } \\
\text { Kigongo, J., Namazzi, } \\
\text { C., Ebiyau, G., } \\
\text { Oketayot, J., Ogwal, } \\
\text { S. }\end{array}$ & 2010 & $\begin{array}{l}\text { The contribution of } \\
\text { women to food and fodder } \\
\text { production in war affected } \\
\text { areas of Gulu District in } \\
\text { Uganda }\end{array}$ & $\begin{array}{l}\text { In: Proceedings of } \\
\text { Second RUFORUM } \\
\text { Biennial Meeting } 20 \text { - } \\
24 \text { September 2010, } \\
\text { Entebbe, Ug }\end{array}$ & Uganda & On-farm trial & TRUE & FALSE & FALSE & FALSE & TRUE \\
\hline $\begin{array}{l}\text { Kabirizi, J., Ziiwa, E., } \\
\text { Mugerwa, S., } \\
\text { Ndikumana, J., } \\
\text { Nanyennya, W. }\end{array}$ & 2010 & $\begin{array}{l}\text { Dry season forages for } \\
\text { improving dairy } \\
\text { production in smallholder } \\
\text { systems in Uganda }\end{array}$ & Tropical Grasslands & Uganda & On-farm trial & TRUE & TRUE & FALSE & FALSE & FALSE \\
\hline $\begin{array}{l}\text { Kakengi, A., Shem, } \\
\text { M., Mtengeti, E., } \\
\text { Otsyina, R. }\end{array}$ & 2001 & $\begin{array}{l}\text { Leucaena leucocephala } \\
\text { leaf meal as supplement to } \\
\text { diet of grazing dairy cattle } \\
\text { in semiarid Western } \\
\text { Tanzania }\end{array}$ & Agroforestry Systems & Tanzania & Feeding trial & FALSE & TRUE & FALSE & FALSE & FALSE \\
\hline $\begin{array}{l}\text { Karachi, M., Zengo, } \\
\text { M. }\end{array}$ & 1998 & $\begin{array}{l}\text { Legume forages from } \\
\text { pigeon pea, leucaena and } \\
\text { sesbania as supplements } \\
\text { to natural pastures for } \\
\text { goat production in } \\
\text { western Tanzania }\end{array}$ & Agroforestry Systems & Tanzania & Feeding trial & FALSE & TRUE & FALSE & FALSE & FALSE \\
\hline $\begin{array}{l}\text { Kariuki, J., Gitau, G., } \\
\text { Gachuiri, C., } \\
\text { Tamminga, S., Muia, } \\
\text { J. }\end{array}$ & 1999 & $\begin{array}{l}\text { Effect of supplementing } \\
\text { napier grass with } \\
\text { desmodium and lucerne } \\
\text { on DM, CP and NDF intake } \\
\text { and weight gains in dairy } \\
\text { heifers }\end{array}$ & $\begin{array}{l}\text { Livestock Production } \\
\text { Science }\end{array}$ & Kenya & Feeding trial & FALSE & TRUE & FALSE & FALSE & FALSE \\
\hline $\begin{array}{l}\text { Kariuki, J., } \\
\text { Tamminga, S., } \\
\text { Gachuri, C., Gitau, } \\
\text { G., Muia, J. }\end{array}$ & 2001 & $\begin{array}{l}\text { Intake and rumen } \\
\text { degradation in cattle fed } \\
\text { Napier grass (Pennisetum } \\
\text { purpureum) supplemented } \\
\text { with various levels of } \\
\text { Desmodium intortum and } \\
\text { Ipomoea batatus vines }\end{array}$ & $\begin{array}{l}\text { South African Journal of } \\
\text { Animal Science }\end{array}$ & Kenya & Feeding trial & FALSE & TRUE & FALSE & FALSE & FALSE \\
\hline
\end{tabular}




\begin{tabular}{|c|c|c|c|c|c|c|c|c|c|c|}
\hline $\begin{array}{l}\text { Kariuki, J., } \\
\text { Tamminga, S., Gitau, } \\
\text { G., Gachuiri, C., } \\
\text { Muia, J. }\end{array}$ & 1999 & $\begin{array}{l}\text { Performance of Sahiwal } \\
\text { and fresian heifers fed on } \\
\text { napier grass supplemented } \\
\text { with graded levels of } \\
\text { lucerne }\end{array}$ & $\begin{array}{l}\text { South African Journal of } \\
\text { Animal Science }\end{array}$ & Kenya & Feeding trial & FALSE & TRUE & FALSE & FALSE & FALSE \\
\hline $\begin{array}{l}\text { Katuromunda, S. } \\
\text { Sabiiti, E., Bekunda, } \\
\text { A. }\end{array}$ & 2012 & $\begin{array}{l}\text { Effect of legume foliage } \\
\text { supplementary feeding to } \\
\text { dairy cattle offered } \\
\text { Pennisetum purpureum } \\
\text { basal diet on feed intake } \\
\text { and manure quality }\end{array}$ & $\begin{array}{l}\text { Uganda Journal of } \\
\text { Agricultural Science }\end{array}$ & Uganda & Feeding trial & FALSE & TRUE & FALSE & FALSE & FALSE \\
\hline $\begin{array}{l}\text { Katuromunda, S., } \\
\text { Sabiiti, E., Bekunda, } \\
\text { M. }\end{array}$ & 2011 & $\begin{array}{l}\text { Effect of combined } \\
\text { application of cattle } \\
\text { manure and mineral } \\
\text { fertilizers on the growth } \\
\text { characteristics and quality } \\
\text { of pennisetum prupureum } \\
\text { fodder }\end{array}$ & $\begin{array}{l}\text { Livestock Research for } \\
\text { Rural Development }\end{array}$ & Uganda & $\begin{array}{l}\text { On-station } \\
\text { trial }\end{array}$ & TRUE & FALSE & FALSE & FALSE & FALSE \\
\hline $\begin{array}{l}\text { Kawube, G., Alicai, } \\
\text { T., Otim, M., } \\
\text { Mukwaya, A., } \\
\text { Kabirizi, J., Talwana, } \\
\text { H. }\end{array}$ & 2014 & $\begin{array}{l}\text { Resistance of Napier grass } \\
\text { clones to napier grass } \\
\text { stunt disease }\end{array}$ & $\begin{array}{l}\text { African Crop Science } \\
\text { Journal }\end{array}$ & Uganda & $\begin{array}{l}\text { On-station } \\
\text { trial }\end{array}$ & TRUE & FALSE & FALSE & FALSE & FALSE \\
\hline $\begin{array}{l}\text { Khan Z., Midega, C., } \\
\text { Wanyama, J., } \\
\text { Amudavi, D., } \\
\text { Hassanali, A., } \\
\text { Pittchar, J., Pickett, J. }\end{array}$ & 2009 & $\begin{array}{l}\text { Integration of edible beans } \\
\text { (Phaseolus vulgaris L.) into } \\
\text { the push-pull technology } \\
\text { developed for stemborer } \\
\text { and Striga control in } \\
\text { maize-based cropping } \\
\text { systems }\end{array}$ & Crop Protection & Kenya & $\begin{array}{l}\text { On-station } \\
\text { trial }\end{array}$ & FALSE & FALSE & FALSE & TRUE & TRUE \\
\hline $\begin{array}{l}\text { Khan Z., Hassanali, } \\
\text { A., Khamis, T., } \\
\text { Overholt, W. } \\
\text { Hooper, A., Pickett, } \\
\text { J., Wahams, L. and } \\
\text { Woodcock, C. }\end{array}$ & 2002 & $\begin{array}{l}\text { Control of witchweed } \\
\text { Striga hermonthica by } \\
\text { intercropping with } \\
\text { Desmodium spp., and the } \\
\text { mechanism defined as } \\
\text { allelopathic. }\end{array}$ & $\begin{array}{l}\text { Journal of Chemical } \\
\text { Ecology }\end{array}$ & Kenya & $\begin{array}{l}\text { On-station } \\
\text { trial }\end{array}$ & FALSE & FALSE & FALSE & FALSE & TRUE \\
\hline $\begin{array}{l}\text { Khan Z., Midega, C. } \\
\text { Amudavi, D., } \\
\text { Hassanali, A., } \\
\text { Pickett, J. }\end{array}$ & 2008 & $\begin{array}{l}\text { On-farm evaluation of the } \\
\text { 'push-pull' technology for } \\
\text { the control of stemborers } \\
\text { and striga weed on maize } \\
\text { in western Kenya }\end{array}$ & Field Crop Research & Kenya & On-farm trial & FALSE & FALSE & FALSE & FALSE & TRUE \\
\hline $\begin{array}{l}\text { Khan Z., Midega, C., } \\
\text { Njuguna, E., } \\
\text { Amudavi, D., } \\
\text { Wanyama, J., } \\
\text { Pickett, J. }\end{array}$ & 2008 & $\begin{array}{l}\text { Economic performance of } \\
\text { the 'push-pull' technology } \\
\text { for stemborer and Striga } \\
\text { control in smallholder } \\
\text { farming systems in } \\
\text { western Kenya }\end{array}$ & Crop Protection & Kenya & On-farm trial & FALSE & FALSE & FALSE & TRUE & TRUE \\
\hline
\end{tabular}




\begin{tabular}{|c|c|c|c|c|c|c|c|c|c|c|}
\hline $\begin{array}{l}\text { Kouame, C., Hoefs, } \\
\text { S., Powell, J., Roxas, } \\
\text { D., Renards, C. }\end{array}$ & 1991 & $\begin{array}{l}\text { Intercrop Stylosanthes } \\
\text { effects on millet yields and } \\
\text { animal performance in the } \\
\text { Sahel }\end{array}$ & $\begin{array}{l}\text { In Stares, J.E. et al (eds) } \\
\text { (1992): The } \\
\text { complementarity of } \\
\text { feed resoures for } \\
\text { Animal production in } \\
\text { Africa }\end{array}$ & Niger & $\begin{array}{l}\text { On-station } \\
\text { trial }\end{array}$ & TRUE & FALSE & FALSE & FALSE & TRUE \\
\hline $\begin{array}{l}\text { Kouame, C., Powell, } \\
\text { J., Renards, C., } \\
\text { Quesenerry, K. }\end{array}$ & 1993 & $\begin{array}{l}\text { Plant yields and fodder } \\
\text { quality related } \\
\text { characteristics of millet- } \\
\text { stylo intercropping } \\
\text { systems in the Sahel. In: } \\
\text { Shetty, S.V et al. (1995). } \\
\text { Millet and cowpea in } \\
\text { mixed farming systems of } \\
\text { the Sahel: A review of } \\
\text { strategies for increased } \\
\text { productivity and } \\
\text { sustainability. }\end{array}$ & $\begin{array}{l}\text { In Powell et al (1995). } \\
\text { Livestock and } \\
\text { sustainable nutrient } \\
\text { cycling in mixed farming } \\
\text { systems of Sub-Sahara } \\
\text { Africa. Vol. 2: }\end{array}$ & Niger & On-farm trial & TRUE & FALSE & FALSE & FALSE & FALSE \\
\hline $\begin{array}{l}\text { Kusekwa, M., } \\
\text { Kyamanywa, R., } \\
\text { Ngowi, M. }\end{array}$ & 1992 & $\begin{array}{l}\text { Fitting forage legumes into } \\
\text { the cropping systems of } \\
\text { semi-arid Tanzania }\end{array}$ & $\begin{array}{l}\text { In Stares, J.E. et al (eds) } \\
\text { (1992): The } \\
\text { complementarity of } \\
\text { feed resoures for } \\
\text { Animal production in } \\
\text { Africa }\end{array}$ & $\begin{array}{l}\text { Botswan } \\
\text { a }\end{array}$ & $\begin{array}{l}\text { On-station } \\
\text { trial }\end{array}$ & TRUE & FALSE & FALSE & FALSE & TRUE \\
\hline $\begin{array}{l}\text { Lanyasunya, T., } \\
\text { Wang, Rong H., } \\
\text { Mukisira, E. }\end{array}$ & 2006 & $\begin{array}{l}\text { Effect of Supplementation } \\
\text { on Performance of Calves } \\
\text { on Smallholder Dairy } \\
\text { Farms in Bahati Division of } \\
\text { Nakuru District, Kenya }\end{array}$ & $\begin{array}{l}\text { Pakistan Journal of } \\
\text { Nutrition }\end{array}$ & Kenya & Feeding trial & FALSE & TRUE & FALSE & FALSE & FALSE \\
\hline $\begin{array}{l}\text { Macala, J., Sebolai, } \\
\text { B., Majinda, R. }\end{array}$ & 1992 & $\begin{array}{l}\text { Colospermum mopane } \\
\text { browse plant and sorghum } \\
\text { stover as feed resources } \\
\text { for ruminants during the } \\
\text { dry season in Botswana }\end{array}$ & $\begin{array}{l}\text { In Stares, J.E. et al (eds) } \\
\text { (1992): The } \\
\text { complementarity of } \\
\text { feed resoures for } \\
\text { Animal production in } \\
\text { Africa }\end{array}$ & $\begin{array}{l}\text { Botswan } \\
\text { a }\end{array}$ & Feeding trial & TRUE & TRUE & FALSE & FALSE & FALSE \\
\hline $\begin{array}{l}\text { Mafongoya, P.L., } \\
\text { Kuntashula, E., } \\
\text { Kwesiga, F., Chirwa, } \\
\text { T., Chintu, R., Sileshi, } \\
\text { G., Matibini, J. }\end{array}$ & 2003 & $\begin{array}{l}\text { Leguminous agroforestry } \\
\text { options for replenishing } \\
\text { soil fertility in Southern } \\
\text { Africa }\end{array}$ & $\begin{array}{l}\text { In Waddington, S.R (Ed) } \\
\text { (2003). Grain legumes } \\
\text { and green manures for } \\
\text { soil fertility in Southern } \\
\text { Africa: Taking Stock of } \\
\text { Progress. Proceedings } \\
\text { of a conference held 8- } \\
11 \text { October } 2002 \text { in } \\
\text { Vumba, Zimbabwe. Soil } \\
\text { Fert Net and CIMMYT, } \\
\text { Harare, Zimbabwe. } 246 \\
\text { p. }\end{array}$ & Zambia & $\begin{array}{l}\text { On-station } \\
\text { trial }\end{array}$ & FALSE & FALSE & FALSE & FALSE & TRUE \\
\hline
\end{tabular}




\begin{tabular}{|c|c|c|c|c|c|c|c|c|c|c|}
\hline $\begin{array}{l}\text { Masinde, A. A. O, } \\
\text { Ojowi, O. M., } \\
\text { Mbugua, D.M., } \\
\text { Odongo, J. A. and } \\
\text { Shisya, M.A. }\end{array}$ & 2000 & $\begin{array}{l}\text { Effect of organic and } \\
\text { inorganic fertilisers and } \\
\text { their combination on } \\
\text { Napier grass dry matter } \\
\text { yields in South West Kenya }\end{array}$ & $\begin{array}{l}\text { Proceedings of the } 2 \text { nd } \\
\text { Scientific Conference of } \\
\text { the Soil Management } \\
\text { and Legume Research } \\
\text { Network Projects, June } \\
\text { 2000, Mombasa, Kenya }\end{array}$ & Kenya & On-farm trial & TRUE & FALSE & FALSE & TRUE & FALSE \\
\hline $\begin{array}{l}\text { Mosimanyana, B., } \\
\text { Kiflewahid, B. }\end{array}$ & 1986 & $\begin{array}{l}\text { Feeding of crop residues to } \\
\text { milking cows in small-scale } \\
\text { farms in Botswana }\end{array}$ & $\begin{array}{l}\text { Proceedings of } \\
\text { workshop on Utilization } \\
\text { of Agricultural By- } \\
\text { Products as Livestock } \\
\text { Feeds in Africa. } \\
\text { Blantyre, Malawi, } \\
\text { September }\end{array}$ & $\begin{array}{l}\text { Botswan } \\
\text { a }\end{array}$ & Feeding trial & FALSE & TRUE & FALSE & FALSE & FALSE \\
\hline $\begin{array}{l}\text { Mpangane, P., Ayisi, } \\
\text { K., Mishiyi, M., } \\
\text { Witbread, A. }\end{array}$ & 2004 & $\begin{array}{l}\text { Grain yield of maize grown } \\
\text { in sole and binary cultures } \\
\text { with cowpea and lablab in } \\
\text { the Limpopo province of } \\
\text { South Africa }\end{array}$ & $\begin{array}{l}\text { In Whitbread, A. and } \\
\text { Bruce C (2004). Tropical } \\
\text { Legumes for } \\
\text { Sustainable Farming } \\
\text { Systems in Southern } \\
\text { Africa and Australia }\end{array}$ & $\begin{array}{l}\text { South } \\
\text { Africa }\end{array}$ & On-farm trial & FALSE & FALSE & FALSE & FALSE & TRUE \\
\hline $\begin{array}{l}\text { Mtengeti, E., Urio, } \\
\text { N., Mlay, G. }\end{array}$ & 2001 & $\begin{array}{l}\text { Intensive fodder gardens } \\
\text { for improving forage } \\
\text { availability for smallholder } \\
\text { dairy production in } \mathrm{Hi} \\
\text { District Tanzania }\end{array}$ & $\begin{array}{l}\text { In Stares, J.E. et al (eds): } \\
\text { The complementarity of } \\
\text { feed resoures for } \\
\text { Animal production in } \\
\text { Africa }\end{array}$ & Tanzania & On-farm trial & TRUE & FALSE & FALSE & FALSE & FALSE \\
\hline $\begin{array}{l}\text { Mubiru, S., Ebong, } \\
\text { C., Rubaire-Akiiki, C., } \\
\text { Kabirizi J., Odur, A., } \\
\text { Nakiganda, A., } \\
\text { Ndyanabo, W., } \\
\text { Bareeba, F., Halberg, } \\
\text { N. }\end{array}$ & 2003 & $\begin{array}{l}\text { Adaptation of feed } \\
\text { resource utilization } \\
\text { techniques to smallholder } \\
\text { dairy farmers in Masaka }\end{array}$ & NARO conference paper & Uganda & Survey & FALSE & TRUE & FALSE & FALSE & FALSE \\
\hline $\begin{array}{l}\text { Mugerwa, S., Sara, } \\
\text { B., Glorios, H., } \\
\text { Nijimbere, A., } \\
\text { Kayiwa, S., Zziwa, E., } \\
\text { Njarui, D. }\end{array}$ & 2011 & $\begin{array}{l}\text { A comparative analysis of } \\
\text { phosphorus fertilizer } \\
\text { regimes on seed } \\
\text { production of Lablab in } \\
\text { East and Central Africa }\end{array}$ & $\begin{array}{l}\text { International Journal of } \\
\text { Agronomy and } \\
\text { Agricultural Research }\end{array}$ & $\begin{array}{l}\text { Uganda, } \\
\text { Sudan, } \\
\text { Burundi }\end{array}$ & $\begin{array}{l}\text { On-station } \\
\text { trial }\end{array}$ & FALSE & FALSE & FALSE & TRUE & FALSE \\
\hline $\begin{array}{l}\text { Muhr, L., Tarawali, } \\
\text { S., Peters, M., } \\
\text { Schultze-Kraft, R. }\end{array}$ & 2001 & $\begin{array}{l}\text { Acceptability of Forage } \\
\text { Legumes for Improved } \\
\text { Fallows - First Experiences } \\
\text { of Agro-Pastoralists in } \\
\text { Subhumid Southwest } \\
\text { Nigeria }\end{array}$ & $\begin{array}{l}\text { Experimental } \\
\text { Agriculture }\end{array}$ & Nigeria & On-farm trial & TRUE & FALSE & FALSE & FALSE & FALSE \\
\hline $\begin{array}{l}\text { Muinga R.W., } \\
\text { Thorpe W., Topps } \\
\text { J.H }\end{array}$ & 1993 & $\begin{array}{l}\text { Lactational performance of } \\
\text { Jersey cows given napier } \\
\text { fodder (Pennisetum } \\
\text { purpureum) with and }\end{array}$ & $\begin{array}{l}\text { Tropical Animal Health } \\
\text { and Production }\end{array}$ & Kenya & Feeding trial & FALSE & TRUE & FALSE & FALSE & FALSE \\
\hline
\end{tabular}


without concentrates in

the semi-humid tropics

Muinga, R., Thorpe,

W., Topps, J.,

Mureithi, J.

Mupangwa, W.

Nemasasi, $\mathrm{H}_{\text {., }}$

Muchadeyi, R.,

Manyawu, G.

Mureithi, J., Thorpe

W.

Murungweni, $C$

Mabuku, O.,

Manyawu, G.
1991 Responses to Pennisetum Purpureum (Napier grass) basal diet harvested at 2 different sites and fed with three levels of Leucaena forage to crossbred dairy cows in the humid tropics. Residual effects of forage legumes on subsequent maize yields and soil fertility in smallholder farming sector of Zimbabwe

The effect of herbaceous legume intercropping and mulching on the productivity of Napier grass (Pennisetum purpureum) and total forage yield in coastal lowland Kenya

Mucuna, Lablab and Paprika Calyx as

substitutes for commercial protein sources used for dairy and pen-fattening diets by smallholder farmers in Zimbabwe
In Stares, J.E. et al (eds).

The complementarity of

feed resoures for

Animal production in

Africa

In Waddington, S.R (Ed)

(2003). Grain legumes

Zimbab

and green manures for

soil fertility in Southern

Africa: Taking Stock of

Progress. Proceedings

of a conference held 8-

11 October 2002 in

Vumba, Zimbabwe. Soil

Fert Net and CIMMYT,

Harare, Zimbabwe. 246

In Ndikumana, J. and

Leeuw P. (eds) (1996).

Kenya

Sustainable Feed

Production and

Utilisation for

Smallholder Livestock

Enterprises in Sub-

Saharan Africa.

Proceedings of the

Second African Feed

Resources Network

(AFRNET) workshop

held in Harare,

Zimbabwe

In: Whitebread E. and

Pengelly B. (2003).

Zimbab

we

Tropical legumes for

sustainable farming

systems in Souther

Africa and Australia
Feeding trial

FALSE

TRUE

FALSE FALSE

FALSE

On-farm trial FALSE FALSE $\quad$ TRUE FALSE

TRUE

TRUE

On-statior

trial



FALSE

FALSE FALSE

FALSE

Feeding trial FALSE TRUE

FALSE FALSE

FALSE 


\begin{tabular}{|c|c|c|c|c|c|c|c|c|c|c|}
\hline $\begin{array}{l}\text { Mutegi, J., Mugendi, } \\
\text { D., Verchot, L., } \\
\text { Kung'u, J. }\end{array}$ & 2008 & $\begin{array}{l}\text { Combining Napier grass } \\
\text { with leguminous shrubs in } \\
\text { contour hedgerows } \\
\text { controls soil erosion } \\
\text { without competing with } \\
\text { crops }\end{array}$ & Agricultural Systems & Kenya & On-farm trial & FALSE & FALSE & TRUE & FALSE & TRUE \\
\hline $\begin{array}{l}\text { Mutimura, M., } \\
\text { Everson, T. }\end{array}$ & 2012 & $\begin{array}{l}\text { On-farm evaluation of } \\
\text { improved Brachiaria } \\
\text { grasses in low rainfall and } \\
\text { aluminium toxicity prone } \\
\text { areas of Rwanda }\end{array}$ & $\begin{array}{l}\text { International Journal of } \\
\text { Biodiversity and } \\
\text { Conservation }\end{array}$ & Rwanda & On-farm trial & TRUE & FALSE & FALSE & FALSE & FALSE \\
\hline $\begin{array}{l}\text { Muyekho, F. and } \\
\text { Mose, L. }\end{array}$ & 2000 & $\begin{array}{l}\text { Economic evaluation of “ } \\
\text { Tumbukiza" as an } \\
\text { alternative method for } \\
\text { increasing Napier grass } \\
\text { (Pennisetum purpureum) } \\
\text { productivity on } \\
\text { smallholder farms in North } \\
\text { Rift valley region of Kenya }\end{array}$ & $\begin{array}{l}\text { KARI: Participatory } \\
\text { technology } \\
\text { development for soil } \\
\text { management by } \\
\text { smallholders in Kenya. } \\
\text { Proceedings of the } 2 \text { nd } \\
\text { Scientific Conference on } \\
\text { the Soil Management } \\
\text { and Legume Research } \\
\text { Network Projects. } \\
\text { Mombasa, Kenya }\end{array}$ & Kenya & On-farm trial & FALSE & FALSE & FALSE & TRUE & FALSE \\
\hline $\begin{array}{l}\text { Muyekho, F., } \\
\text { Cheruiyor, D., } \\
\text { Kapkusum, G. }\end{array}$ & 2000 & $\begin{array}{l}\text { Effects of the " Tumbukiza } \\
\text { " method of planting } \\
\text { Napier grass (Pennisetum } \\
\text { purpureum) on the } \\
\text { quantity and quality of } \\
\text { forage on smallholder } \\
\text { farms in Kenya }\end{array}$ & $\begin{array}{l}\text { KARI: Participatory } \\
\text { technology } \\
\text { development for soil } \\
\text { management by } \\
\text { smallholders in Kenya. } \\
\text { Proceedings of the } 2 \text { nd } \\
\text { Scientific Conference on } \\
\text { the Soil Management } \\
\text { and Legume Research } \\
\text { Network Projects. } \\
\text { Mombasa, Kenya }\end{array}$ & Kenya & On-farm trial & TRUE & FALSE & FALSE & FALSE & FALSE \\
\hline Ngwa, A., Tawah, C. & 2002 & $\begin{array}{l}\text { Effect of Supplementation } \\
\text { with Leguminous Crop } \\
\text { Residues or Concentrates } \\
\text { on the Voluntary Intake } \\
\text { and Performance of Kirdi } \\
\text { Sheep }\end{array}$ & $\begin{array}{l}\text { Tropical Animal Health } \\
\text { and Production }\end{array}$ & $\begin{array}{l}\text { Cameroo } \\
\mathrm{n}\end{array}$ & Feeding trial & FALSE & TRUE & FALSE & FALSE & FALSE \\
\hline $\begin{array}{l}\text { Niang, A., Styger, E., } \\
\text { Gahamanyi, A., } \\
\text { Hoekstra, D., Coe, R. }\end{array}$ & 1998 & $\begin{array}{l}\text { Fodder-quality } \\
\text { improvement through } \\
\text { contour planting of } \\
\text { legume-shrub / grass } \\
\text { mixtures in croplands of } \\
\text { Rwanda highlands }\end{array}$ & Agroforestry Systems & Rwanda & On-farm trial & TRUE & FALSE & FALSE & FALSE & TRUE \\
\hline
\end{tabular}




\begin{tabular}{|c|c|c|c|c|c|c|c|c|c|c|}
\hline $\begin{array}{l}\text { Njarui D., Wandera, } \\
\text { F., Muinga, R. }\end{array}$ & 2000 & $\begin{array}{l}\text { Evaluation of selected } \\
\text { forage legumes as } \\
\text { supplementary feed for } \\
\text { Kenya dual-purpose goat } \\
\text { in semi-arid region of } \\
\text { Eastern Kenya }\end{array}$ & $\begin{array}{l}\text { KARI: Participatory } \\
\text { technology } \\
\text { development for soil } \\
\text { management by } \\
\text { smallholders in Kenya. } \\
\text { Proceedings of the } 2 \text { nd } \\
\text { Scientific Conference on } \\
\text { the Soil Management } \\
\text { and Legume Research } \\
\text { Network Projects. } \\
\text { Mombasa, Kenya }\end{array}$ & Kenya & Feeding trial & FALSE & TRUE & FALSE & FALSE & FALSE \\
\hline $\begin{array}{l}\text { Njarui D., Wandera, } \\
\text { F., Mureithi, J. }\end{array}$ & 2000 & $\begin{array}{l}\text { Potential of jack bean as a } \\
\text { feed supplement for Kenya } \\
\text { dual-purpose goats in the } \\
\text { semi-arid area }\end{array}$ & $\begin{array}{l}\text { KARI: Participatory } \\
\text { technology } \\
\text { development for soil } \\
\text { management by } \\
\text { smallholders in Kenya. } \\
\text { Proceedings of the 2nd } \\
\text { Scientific Conference on } \\
\text { the Soil Management } \\
\text { and Legume Research } \\
\text { Network Projects. } \\
\text { Mombasa, Kenya }\end{array}$ & Kenya & Feeding trial & FALSE & TRUE & FALSE & FALSE & FALSE \\
\hline Njarui, M. & 2007 & $\begin{array}{l}\text { Enhancing livestock feed } \\
\text { supply by integrating } \\
\text { selected forage legumes in } \\
\text { semi-arid region of Eastern } \\
\text { Kenya }\end{array}$ & $\begin{array}{l}\mathrm{PhD} \text { thesis Egerton } \\
\text { University, Kenya }\end{array}$ & Kenya & $\begin{array}{l}\text { On-station } \\
\text { trial }\end{array}$ & TRUE & FALSE & FALSE & TRUE & TRUE \\
\hline $\begin{array}{l}\text { Njoka-Njiru, E., } \\
\text { Njarui, M., } \\
\text { Abulrazak, S., } \\
\text { Mureithi, J. }\end{array}$ & 2006 & $\begin{array}{l}\text { Effect of intercropping } \\
\text { herbaceous legumes with } \\
\text { Napier grass on dry matter } \\
\text { yield and nutritive value of } \\
\text { the feedstuffs in semi-arid } \\
\text { region of Eastern Kenya }\end{array}$ & $\begin{array}{l}\text { Agricultura Tropica et } \\
\text { Subtropica }\end{array}$ & Kenya & $\begin{array}{l}\text { On-station } \\
\text { trial }\end{array}$ & TRUE & FALSE & FALSE & FALSE & FALSE \\
\hline $\begin{array}{l}\text { Njwe, R., Donfack, } \\
\text { N., Djoukam, J., } \\
\text { Endeley, H. }\end{array}$ & 1992 & $\begin{array}{l}\text { Performance of } \\
\text { associations of Brachiaria } \\
\text { ruziziensis with } \\
\text { Desmodium intortium, } \\
\text { Desmodium Uncinatum } \\
\text { and Stylosanthes } \\
\text { guianensis at Dschang, } \\
\text { Cameroon. }\end{array}$ & $\begin{array}{l}\text { In Stares, J.E. et al (eds): } \\
\text { The complementarity of } \\
\text { feed resoures for } \\
\text { Animal production in } \\
\text { Africa }\end{array}$ & $\begin{array}{l}\text { Cameroo } \\
\mathrm{n}\end{array}$ & $\begin{array}{l}\text { On-station } \\
\text { trial }\end{array}$ & TRUE & FALSE & FALSE & FALSE & FALSE \\
\hline $\begin{array}{l}\text { Nyambati, E., } \\
\text { Sollenberger, L., } \\
\text { Kunkle, W. }\end{array}$ & 2003 & $\begin{array}{l}\text { Feed intake and lactation } \\
\text { performance of dairy cows } \\
\text { offered napier grass } \\
\text { supplemented with } \\
\text { legume hay }\end{array}$ & $\begin{array}{l}\text { Livestock Production } \\
\text { Science }\end{array}$ & Kenya & Feeding trial & FALSE & TRUE & FALSE & FALSE & FALSE \\
\hline
\end{tabular}


Nzabi A., Tana, P., Masinde, A., Gesare, M., Ngoti, B., Mwagi, G.

\section{O'Neill, M., Angima, S., Duinker, B.,} Okoba, B.

Ogedegbe, $\mathrm{S}$., Ogunlela, V., Olufajo,

O., Odion, E.

012 Mineral Content Of Lablab (Lablab purpereus L. Application, Cutting Height And Age Of Cutting At Samaru, Nigeria

Ojo, V., Dele, P., Amole, T., Anele, U., Adeoye, S., Hassan, O., Olanite, J., Idowu, 0.

Okeyo R., Masinde A., Ojowi M., Oyure, A.

Nyamonyo and Kamingusa

villages of Southwest

Kenya

Fodder Production from

Hedges in the

entral Kenyan Highland

Fodder Production from

Contour Hedges in the

Effect of Intercropping of

Pannicum maximum var.

Ntchisi and Lablab

purpererus on the Growth,

Herbage Yield and

Chemical Composition of

Pannicum maximum var.

Ntchisi at Different

Harvesting times

2000 Evaluation of grass and

legume production
Sweet) Herbage As

Influened By Phosphorous

KARI: Participatory

technology

development for soil

potential in Kendu Bay,

South West Kenya

KARI: Participatory

technology

development for soil

management by

smallholders in Kenya.

Proceedings of the 2 nd

Scientific Conference on

the Soil Management

and Legume Research

Network Projects.

Mombasa, Kenya

Paterson R., Kiruiro, 1999 Calliandra calothyrsus as a

Tropical Animal Health

supplement for milk

and Production

highlands

Paterson R., Kiruiro, 1999 Calliandra calothyrsus as a

E., Arimi, $\mathrm{H}$.
Calliandra calothyrsus as a

Tropical Animal Health and Production
Kenya

On-farm trial

FALSE

FALSE

TRUE

FALSE

FALSE

On-station FALSE FALSE TRUE FALSE TRUE

trial

On-station FALSE FALSE

trial

On-station TRUE

On-statio
trial

FALSE

FALSE FALSE

FALSE

Kenya

On-farm trial TRUE

FALSE

FALSE FALSE

FALSE

Feeding trial FALSE TRUE

FALSE

Feeding trial FALSE TRUE

FALSE 


\begin{tabular}{|c|c|c|c|c|c|c|c|c|c|c|}
\hline $\begin{array}{l}\text { Rahetlah, V., } \\
\text { Randrianaivoarivony, } \\
\text { J. Andrianarisoa, B. } \\
\text { Razafimpamoa, L., } \\
\text { Ramalanjaoa, v. }\end{array}$ & 2012 & $\begin{array}{l}\text { Yield and quality of } \\
\text { Brachiaria Sp. cv. Mulato- } \\
\text { forage perennial peanut } \\
\text { (Arachis pintoi) mixture in } \\
\text { the Highlands of } \\
\text { Madagascar }\end{array}$ & $\begin{array}{l}\text { Livestock Research for } \\
\text { Rural Development }\end{array}$ & $\begin{array}{l}\text { Madagas } \\
\text { car }\end{array}$ & $\begin{array}{l}\text { On-station } \\
\text { trial }\end{array}$ & TRUE & FALSE & TRUE & FALSE & FALSE \\
\hline $\begin{array}{l}\text { Ruto, C., Muyekho, } \\
\text { F., Rono, S., } \\
\text { Onyango, R., } \\
\text { Bunyatta, D., } \\
\text { Nyambati, E. }\end{array}$ & 2000 & $\begin{array}{l}\text { Participatory evaluation of } \\
\text { the production and } \\
\text { utilisation of improved } \\
\text { forages under different } \\
\text { fertiliser regimes, Keiyo } \\
\text { district }\end{array}$ & $\begin{array}{l}\text { KARI: Participatory } \\
\text { technology } \\
\text { development for soil } \\
\text { management by } \\
\text { smallholders in Kenya. } \\
\text { Proceedings of the } 2 \text { nd } \\
\text { Scientific Conference on } \\
\text { the Soil Management } \\
\text { and Legume Research } \\
\text { Network Projects. } \\
\text { Mombasa, Kenya }\end{array}$ & Kenya & Feeding trial & TRUE & TRUE & FALSE & FALSE & FALSE \\
\hline $\begin{array}{l}\text { Schlecht, E., Mahler, } \\
\text { F., Sangare, M., } \\
\text { Susenbeth, A., } \\
\text { Becker, K. }\end{array}$ & 1993 & $\begin{array}{l}\text { Quantitative and } \\
\text { qualitative estimation of } \\
\text { nutrient intake and faecal } \\
\text { excretion of zebu cattle } \\
\text { grazing natural pasture in } \\
\text { semi-arid Mali }\end{array}$ & $\begin{array}{l}\text { In Powell, J M et al } \\
\text { (1993). Livestock and } \\
\text { sustainable nutrient } \\
\text { cycling in mixed farming } \\
\text { systems of Sub-Sahara } \\
\text { Africa. }\end{array}$ & Mali & Feeding trial & FALSE & TRUE & FALSE & FALSE & FALSE \\
\hline $\begin{array}{l}\text { Singh, B., Ajeigbe, H., } \\
\text { Tarawali, S., } \\
\text { Fernandez-Rivera, S., } \\
\text { Abubakar, M. }\end{array}$ & 2003 & $\begin{array}{l}\text { Improving the production } \\
\text { and utilization of cowpea } \\
\text { as food and fodder }\end{array}$ & Field Crop Research & Nigeria & $\begin{array}{l}\text { On-station } \\
\text { trial }\end{array}$ & TRUE & FALSE & FALSE & FALSE & FALSE \\
\hline $\begin{array}{l}\text { Tedonkeng, P., } \\
\text { Fonteh, F., } \\
\text { Tendonkeng, F., } \\
\text { Boukila, B., Djaga, P., } \\
\text { Fomewang, G. }\end{array}$ & 2006 & $\begin{array}{l}\text { Influence of } \\
\text { supplementary feeding } \\
\text { with multipurpose } \\
\text { leguminous tree leaves on } \\
\text { kid growth and milk } \\
\text { production in the West } \\
\text { African dwarf goat }\end{array}$ & & $\begin{array}{l}\text { Cameroo } \\
\mathrm{n}\end{array}$ & $\begin{array}{l}\text { On-station } \\
\text { trial and on- } \\
\text { farm trial }\end{array}$ & FALSE & TRUE & FALSE & FALSE & FALSE \\
\hline $\begin{array}{l}\text { Tedonkeng, P., } \\
\text { Tendonkeng, F., } \\
\text { Kana, J., Boukila, B., } \\
\text { Nanda, A. }\end{array}$ & 2006 & $\begin{array}{l}\text { Effects of Calliandra } \\
\text { calothyrsus and Leucaena } \\
\text { leucocephala } \\
\text { supplementary feeding on } \\
\text { goat production in } \\
\text { Cameroon }\end{array}$ & $\begin{array}{l}\text { Small Ruminant } \\
\text { Research }\end{array}$ & $\begin{array}{l}\text { Cameroo } \\
\mathrm{n}\end{array}$ & $\begin{array}{l}\text { On-station } \\
\text { trial }\end{array}$ & FALSE & TRUE & FALSE & FALSE & FALSE \\
\hline Turinawe, A. & 2011 & $\begin{array}{l}\text { Socio-Economic Evaluation } \\
\text { of Improved Forage } \\
\text { Technologies in } \\
\text { Smallholder Dairy Cattle } \\
\text { Farming Systems in } \\
\text { Uganda }\end{array}$ & $\begin{array}{l}\text { Journal of Agricultural } \\
\text { Science }\end{array}$ & Uganda & On-farm trial & FALSE & TRUE & FALSE & TRUE & FALSE \\
\hline
\end{tabular}


Wegad, D., Ndumbe, 1987 The effect of different

protein supplements on

weight gain and voluntary

intake of maize stover by

ARNAB (1987)

Utilization of

agricultural by-products

as livestock feed in

Africa. Pp. 99-102 


\section{Chapter 5}

Appendix 1

Greenhouse gas calculations

Total greenhouse gas emissions (in $\mathrm{kg} \mathrm{CO}_{2}$-eq. household and per year) were computed as follows:

GHG emission $=\mathrm{CH}_{\text {enteric }}+\mathrm{CH} 4_{\text {manure }}+\mathrm{N} 2 \mathrm{O}_{\text {man,dir }}+\mathrm{N} 2 \mathrm{O}_{\text {man,ind }}+\mathrm{N} 2 \mathrm{O}_{\text {soil,dir }}+$ $N 2 O_{\text {soil,ind }}(1)$

The methane emissions from enteric fermentation of the entire herd were derived from the sum of the methane emissions from enteric fermentation of each animal species present on the farm (equation 2 ). Tier 2 calculations were used to calculate the emission factor from enteric fermentation for cattle, taking into account the milk production and body weight of the animals. For other livestock (goat, sheep), Tier 1 emission factors were used.

$$
C H 4_{\text {enteric }}=\sum_{g} E F_{g} \times N_{g}
$$

$\mathrm{CH}_{\text {enteric }}$ are the methane emissions from enteric fermentation $\left(\mathrm{kg} \mathrm{CH}_{4} \mathrm{yr}^{-1}\right)$

$E F_{g}$ is the emission factor for the defined livestock species per category $\left(\mathrm{kg} \mathrm{CH}_{4}\right.$ head $\left.^{-1} \mathrm{yr}^{-1}\right)$. The value is based on Tier 2 calculation for cattle, and assuming baseline milk production (340 I year ${ }^{-1}$ for local breed and $680 \mathrm{I}_{\text {year }}^{-1}$ for improved) resulted in $20 \mathrm{~kg} \mathrm{CH}_{4}$ head $^{-1}$ year-1 for local cows and $26 \mathrm{~kg} \mathrm{CH}_{4}$ head $^{-1}$ year $^{-1}$ for improved cows. Tier 1 default emission factors were used for other animals: $5 \mathrm{~kg} \mathrm{CH}_{4}$ head $^{-1}$ year ${ }^{-1}$ for sheep and goats, $1 \mathrm{~kg} \mathrm{CH}_{4}$ head ${ }^{-1} \mathrm{ye}^{\text {ar-1 }}$ for pigs and no emission for poultry.

$N_{g}$ is the number of head of livestock species $g$ on the farm.

The Emission Factor Tier 2 from enteric fermentation is only computed for cattle:

$$
E F_{g}=\frac{G E_{g} \times 365 \times Y m_{g}}{55.65}
$$

$E F_{g}$ is the emission factor of the cattle categories (improved, local, etc...), in $\mathrm{kg} \mathrm{CH}_{4}$.head ${ }^{-1} \cdot \mathrm{yr}^{-1}$.

$G E_{g}$ is the daily gross energy intake of livestock species $g$, in MJ head ${ }^{-1}$.day ${ }^{-1}$. It is calculated from the equation below (equation 4) . 
$\mathrm{Ym}_{\mathrm{g}}$ is the methane conversion factor of livestock species $\mathrm{g}$, i.e. the percentage of gross energy in feed converted to methane.

The factor 55.65 is the energy content of methane in $\mathrm{MJ} . \mathrm{kg} \mathrm{CH}_{4}{ }^{-1}$.

$$
G E_{g}=\left(B W_{g} \times 0.1\right)+\frac{5.5 \times \text { Milk }_{g}}{365}
$$

$B W_{g}$ is the body weight of livestock species $g$, in $\mathrm{kg}$.

Milk $_{g}$ is the average milk production of livestock species $g$, in I. head ${ }^{-1} \cdot \mathrm{yr}^{-1}$.

The methane emissions from manure of the entire herd were derived from the sum of the methane emissions from manure from each animal species present on the farm:

$$
C H 4_{\text {manure }}=\sum_{g} E F_{g} \times N_{g}
$$

$\mathrm{CH}_{\text {manure }}$ is the methane emissions from manure management, in $\mathrm{kg} \mathrm{CH}_{4} \mathrm{yr}^{-1}$

$E F_{g}$ is the emission factor for the defined livestock species $g$, in $\mathrm{kg} \mathrm{CH}_{4}$ head ${ }^{-1} \mathrm{yr}^{-1}$

$N_{g}$ is the number of head of livestock from species $g$

Nitrogen excretion from manure was calculated as follows (Tier 1):

$$
\text { Nex }=N_{\text {rate } g} \times \frac{B W_{g}}{1000} \times 365
$$

$N e x_{g}$ is the annual $\mathrm{N}$ excretion for livestock species $g\left(\mathrm{~kg} \mathrm{~N}\right.$ head $\left.{ }^{-1} \mathrm{yr}^{-1}\right)$

$N_{\text {rate } g}$ is the default $\mathrm{N}$ excretion rate for livestock species $g$, in $\mathrm{kg} \mathrm{N} \mathrm{tanimal}^{-1}$ day $^{-1}$

$B W_{g}$ is the body weight for livestock species $g$, in $\mathrm{kg}$

For calculating direct $\mathrm{N}_{2} \mathrm{O}$ emissions from manure, we assumed that $80 \%$ of the manure is collected across all regions in solid form and was stored for several months before further use. 


$$
N 2 O_{\text {dir }}=\sum_{g}\left(N_{g} \times N e x_{g} \times M S_{g}\right) \times E F 3_{s} \times \frac{44}{28}
$$

$\mathrm{N} 2 \mathrm{O}_{\text {dir }}$ is direct $\mathrm{N}_{2} \mathrm{O}$ emissions from manure management $\left(\mathrm{kg} \mathrm{N}_{2} \mathrm{O} \mathrm{yr}^{-1}\right)$

$N_{g}$ is the number of head of livestock from species $g$

$N e x_{g}$ is the annual average $\mathrm{N}$ excretion rate per head of livestock species $g$ at the farm (in $\mathrm{kg} \mathrm{N}$ head $\left.{ }^{-1} \mathrm{yr}^{-1}\right)$. It is calculated following equation (6).

$M S_{g}$ is the percentage of the total manure excreted collected by the household. It is derived from the time animals spend in the stables throughout the year and by the percentage the household collects to be stored.

$E F 3_{S}$ is the default emission factor for direct $\mathrm{N} 2 \mathrm{O}$ emissions from manure management system $\mathrm{S}$ ( $\mathrm{kg} \mathrm{N}_{2} \mathrm{O}-\mathrm{N} \mathrm{kg} \mathrm{N}^{-1}$ in manure management system).

$44 / 28$ is the conversion of (N2O-N) emissions to N2O emissions.

Indirect $\mathrm{N}_{2} \mathrm{O}$ emissions from manure follow this equation:

$$
N_{2} O_{M M}=N_{\text {volatilization-MMS }} \times E F_{4} \times \frac{44}{28}
$$

$\mathrm{N}_{2} \mathrm{O}_{M M}$ is the indirect $\mathrm{N}_{2} \mathrm{O}$ emissions due to volatilization of $\mathrm{N}$ from manure management on the farm $\left(\mathrm{kg} \mathrm{N}_{2} \mathrm{O} \mathrm{yr}^{-1}\right)$

$N_{\text {volatilization-MMS }}$ is the amount of manure nitrogen that is lost due to volatilization of $\mathrm{NH}_{3}$ and $\mathrm{NO}_{\mathrm{X}}$ (in kg N.yr${ }^{-1}$ ). It is calculated from Eq. 9

$E F_{4}$ is the default emission factor for $\mathrm{N}_{2} \mathrm{O}$ emissions from atmospheric deposition of nitrogen on soils and water surfaces, in $\mathrm{kg} \mathrm{N}_{2} \mathrm{O}-\mathrm{N}\left(\mathrm{kg} \mathrm{NH}_{3}-\mathrm{N}+\mathrm{NO}_{\mathrm{x}}-\mathrm{N} \text { volatilized }\right)^{-1}$ found in the tables of IPCC.

$44 / 28$ is the conversion of (N2O-N) emissions to N2O emissions.

$$
N_{\text {volatilization-MMS }}=\sum_{g}\left[\left(N_{g} \times \text { Nex }_{g} \times M S_{g}\right) \times\left(\frac{\text { Fracgas }_{S}}{100}\right)_{g}\right]
$$

$N_{g}$ is the number of head of livestock from species $g$. 
$N e x_{g}$ is the annual average $\mathrm{N}$ excretion rate per head of livestock species $g$ at the farm (in $\mathrm{kg} \mathrm{N}$. $\left.\operatorname{head}^{-1} \cdot \mathrm{yr}^{-1}\right)$. It is calculated following equation (6).

$M S_{g}$ is the percentage of the total manure excreted collected by the household. It is derived from the time animals spend in the stables throughout the year and by the percentage the household collects to be stored.

Fracgas $_{S}$ is the percent of managed manure nitrogen for livestock level $g$ that volatilizes as $\mathrm{NH}_{3}$ and $\mathrm{NO}_{\mathrm{X}}$ in the manure management system $s$.

Direct $\mathrm{N}_{2} \mathrm{O}-\mathrm{N}$ emissions were calculated from managed soils following the Tier 1 calculations.

$$
\mathrm{N}_{2} \mathrm{O}_{\text {direct }}-\mathrm{N}=\mathrm{N}_{2} \mathrm{O}-\mathrm{N}_{\mathrm{N} \text { inputs }}+\mathrm{N}_{2} \mathrm{O}-\mathrm{N}_{\text {grazed }}
$$

$\mathrm{N}_{2} \mathrm{O}_{\text {direct }}-\mathrm{N}$ is the annual direct $\mathrm{N}_{2} \mathrm{O}-\mathrm{N}$ emissions produced from managed soils, in $\mathrm{kg} \mathrm{N}_{2} \mathrm{O}-$

N.yr-1.

$\mathrm{N}_{2} \mathrm{O}-\mathrm{N}_{\mathrm{N} \text { inputs }}$ is the annual direct $\mathrm{N}_{2} \mathrm{O}-\mathrm{N}$ emissions from $\mathrm{N}$ inputs to managed soils, in $\mathrm{kg} \mathrm{N} \mathrm{N}_{2} \mathrm{O}$ N.yr $r^{-1}$. It is calculated following equation (11).

$\mathrm{N}_{2} \mathrm{O}-\mathrm{N}_{\text {grazed }}$ is the annual direct $\mathrm{N}_{2} \mathrm{O}-\mathrm{N}$ emissions from urine and dung inputs to grazed soils, in $\mathrm{kg} \mathrm{N}_{2} \mathrm{O}-\mathrm{N}$. $\mathrm{yr}^{-1}$. It is calculated following equation (12).

$$
N_{2} O-N_{N \text { inputs }}=\sum_{c}\left(F_{S N}+F_{O N}+F_{C R}\right) \times E F 1_{c}
$$

$F_{S N}$ is the annual amount of synthetic fertilizer $\mathrm{N}$ applied to soils, in $\mathrm{kg} \mathrm{N.yr^{-1 }}$

$F_{O N}$ is the annual amount of animal manure, compost, sewage sludge and other organic $\mathrm{N}$ additions applied to soils, in $\mathrm{kg} \mathrm{N} . \mathrm{yr}^{-1}$. It is calculated from equation (13).

$F_{C R}$ is the annual amount of $\mathrm{N}$ in crop residues (above-ground and below-ground), including $\mathrm{N}$ fixing crops, and from forage/pasture renewal, returned to soils, in $\mathrm{kg} \mathrm{N} \mathrm{yr}^{-1}$. In this study it is assumed that it is 0 because all residues are fed to livestock.

$E F 1_{c}$ is the default emission factor for $\mathrm{N}_{2} \mathrm{O}$ emissions from $\mathrm{N}$ inputs, in $\mathrm{kg} \mathrm{N} \mathrm{N}_{2} \mathrm{O}-\mathrm{N}$.(kg N.input) ${ }^{-1}$ extracted from the IPCC guidelines 
$N_{2} O-N_{\text {grazed }}=\sum_{g} N e x_{g} \times N_{g} \times$ time $_{\text {field }, g} \times\left(1-\right.$ collected $\left._{\text {field }}\right) \times E F 3_{g}$

$N e x_{g}$ is the annual average $\mathrm{N}$ excretion rate per head of livestock species $g$ at the farm (in $\mathrm{kg} \mathrm{N}$. head $\left.^{-1} \cdot \mathrm{yr}^{-1}\right)$. It is calculated following equation (6).

$N_{g}$ is the number of head of livestock species $g$.

time $_{\text {field,g }}$ is percentage of time spent by species $g$ on the field.

collected $_{\text {field }}$ is the percentage of manure collected from the field. In this study, this is assumed to be 0 as it not common practice in Rwanda.

$E F 3_{g}$ is the default emission factor for $\mathrm{N}_{2} \mathrm{O}$ emissions from urine and dung $\mathrm{N}$ deposited on pasture, range and paddock by grazing animals, in $\mathrm{kg} \mathrm{N}_{2} \mathrm{O}-\mathrm{N}$.( $(\mathrm{kg} \mathrm{N} \text { input) })^{-1}$, found in the IPCC emission factors table. The values are different for cattle, poultry and pigs (and Sheep and Other animals

$$
F_{O N}=\sum_{g}\left(N e x_{g} \times N_{g} \times M S_{g}\right) \times \% \text { fert }
$$

$\%$ fert is the percentage of manure collected used on the field.

Indirect $\mathrm{N}_{2} \mathrm{O}-\mathrm{N}$ emissions were calculated from managed soils following the Tier 1 calculations (equation 14)

$$
N_{2} O_{(A T D)}-N=\left[\left(F_{S N} \times \operatorname{Frac}_{G A S F}\right)+\left(\left(F_{O N}+F_{P R P}\right) \times \operatorname{Frac}_{G A S M}\right)\right] \times E F_{4}
$$

$\mathrm{N}_{2} \mathrm{O}_{(A T D)}-\mathrm{N}$ is the annual amount of $\mathrm{N}_{2} \mathrm{O}-\mathrm{N}$ produced from atmospheric deposition of $\mathrm{N}$ volatilized from managed soils (in $\mathrm{kg} \mathrm{N}_{2} \mathrm{O}-\mathrm{N} \mathrm{yr}^{-1}$ ).

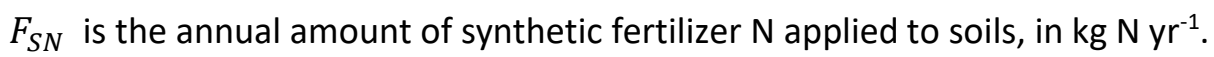

Frac $_{\text {GAS F }}$ is the fraction of synthetic fertilizer N that volatilizes as NH3 and NOx, expressed in $\mathrm{kg}$ $\mathrm{N}$ volatilized (kg of $\mathrm{N}$ applied) $)^{-1}$. It is a default value found in the IPCC guidelines.

$F_{O N}$ is the annual amount of animal manure, applied to soils, in $\mathrm{kg} \mathrm{N} \mathrm{yr}^{-1}$. It is calculated from equation (13). 
$F_{P R P}$ is the annual amount of urine and dung $\mathrm{N}$ deposited by grazing animals on pasture, range and paddock (in kg N.yr ${ }^{-1}$ ). It is similar to $\mathrm{N}_{2} \mathrm{O}-N_{\text {grazed }}$ calculated from equation (12) but without multiplying by EF3.Frac ${ }_{G A S}$ is the fraction of applied organic $\mathrm{N}$ fertilizer materials and of urine and dung $\mathrm{N}$ deposited by grazing animals that volatilize as $\mathrm{NH}_{3}$ and $\mathrm{NO}_{x_{1}}$, expressed in $\mathrm{kg}$ $\mathrm{N}$ volatilized.(kg of $\mathrm{N}$ applied or deposited $)^{-1}$.

$E F_{4}$ is the default emission factor for $\mathrm{N}_{2} \mathrm{O}$ emissions from atmospheric deposition of $\mathrm{N}$ on soils and water surfaces, expressed in $\mathrm{kg} \mathrm{N}-\mathrm{N}_{2} \mathrm{O}\left(\mathrm{kg} \mathrm{NH}_{3}-\mathrm{N}+\mathrm{NO}_{x}-\mathrm{N} \text { volatilized }\right)^{-1}$ extracted from the emission factors table in the IPCC.

\section{Appendix 2}

Figure 1: $F A$ in $\mathrm{kcal}^{\mathrm{MAE}}{ }^{-1}$ day $^{-1}$ in log scale plotted against crop land in ha in log scale.






Appendix 3

Figure 2: GHG in CO2-eq $\mathrm{hh}^{-1}$ year $^{-1}$ plotted against herd size in TLU.



Chapter 6

Appendix 1

Farming systems characterization 
a

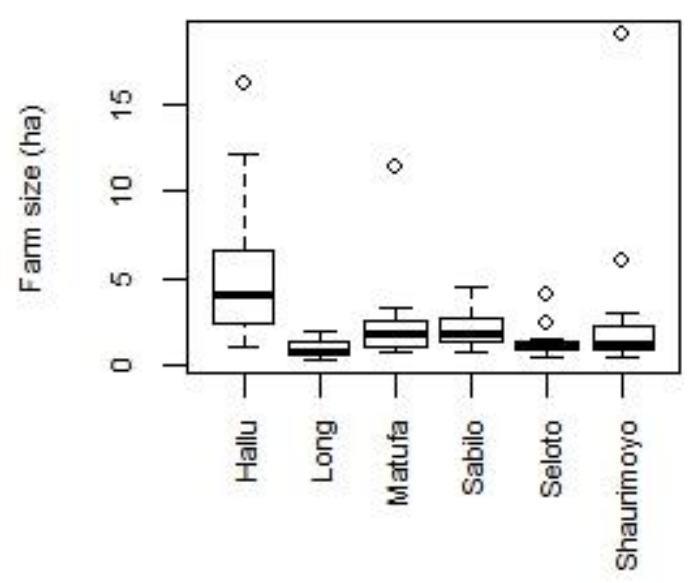

C

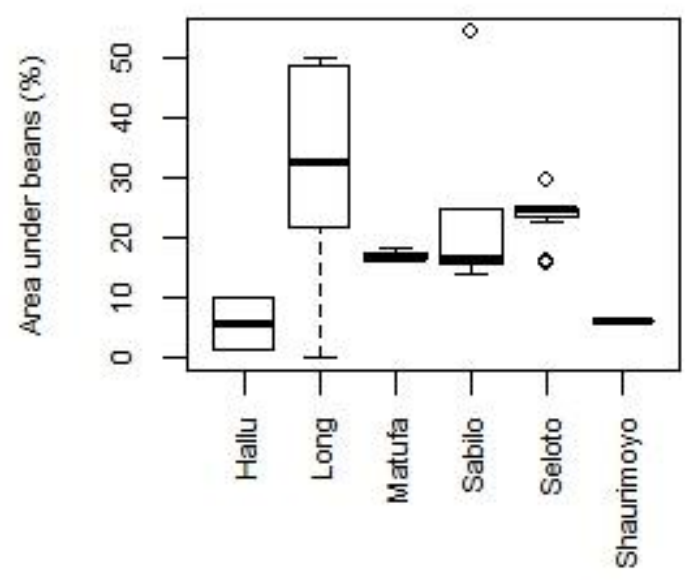

b

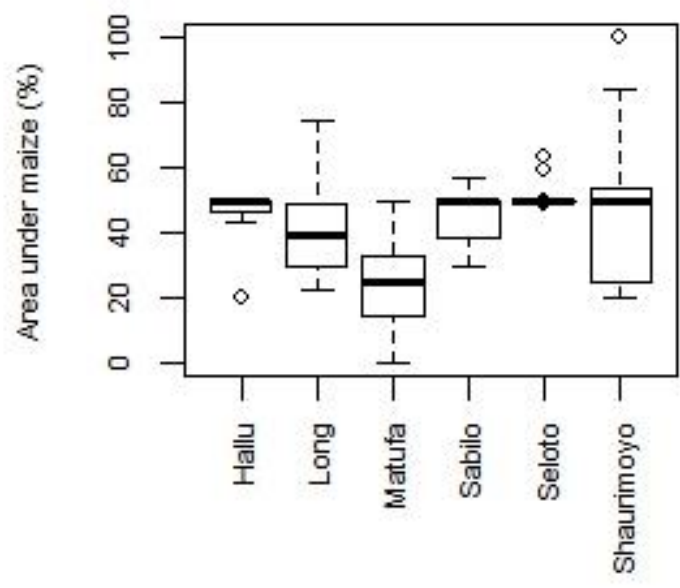

d



Figure A1: Farm size and crop areas by village. a) Total farm size; b) maize area; c) bean area; d) pigeon pea area. Farm sizes ranged from median 0.81 ha in Long to 4.05 ha in Hallu. Roughly half of the farming land was cultivated with maize, with lower areas in Long and Matufa. Bean and pigeon pea areas occupied roughly one third of the farming land, with up to half of the land in Matufa and Seloto. Pigeon pea cultivation was dominant in Hallu and Shaurimoyo, and bean cultivation in Long (Figure A1, Appendix 1). Other crops cultivated included rice in Matufa and Shaurimoyo, sunflower in Hallu and Sabilo, sorghum in Matufa, Sabilo and Shaurimoyo, and wheat and chickpea in Sabilo (results not presented). 


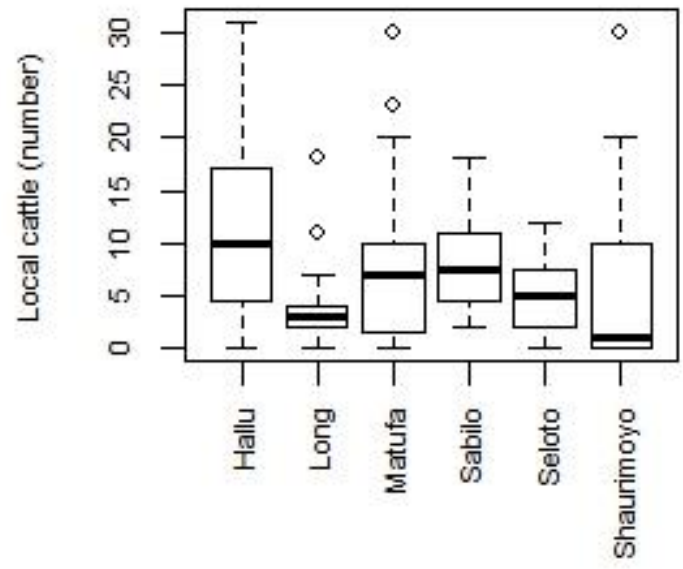

C

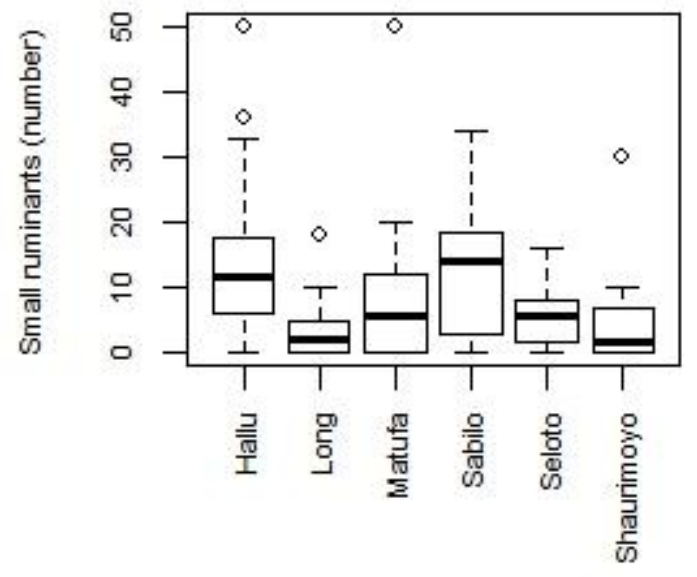

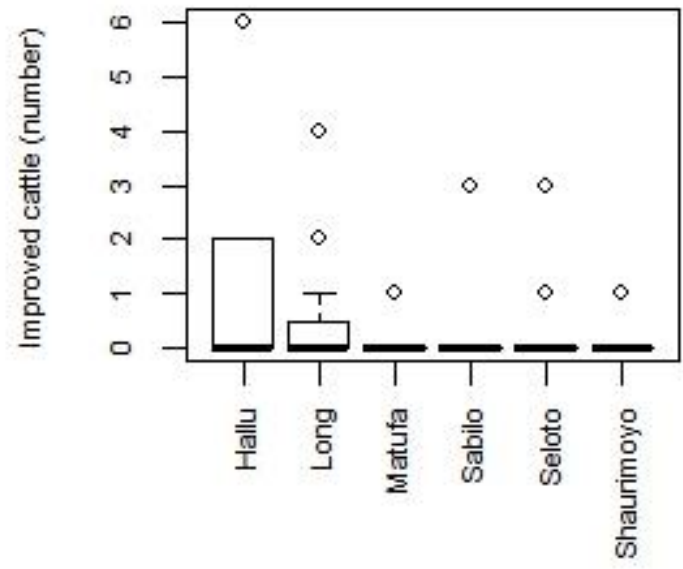

d

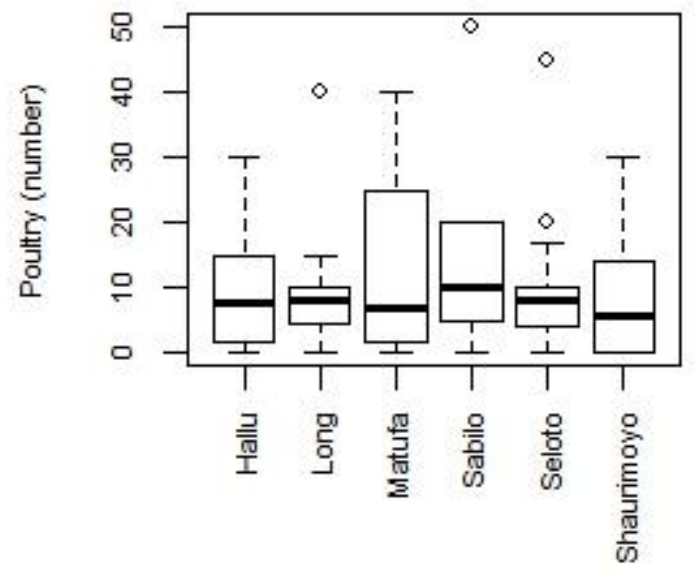

Figure A2: Livestock numbers by villages. a) Local cattle; b) improved cattle; c) small ruminants; d) poultry.

Local cattle holdings per household were generally high, ranging between median one head in Shaurimoyo and three heads in Long to 7.5 in Sabilo and 10 heads in Hallu. Improved cattle was not common, but more found in Hallu and Long than in the other villages. Small ruminants and poultry ranged from 1.5 and 5.5 heads in Shaurimoyo to 14 and 10 heads in Sabilo respectively (Figure A2, Appendix 1). 
a



C



b

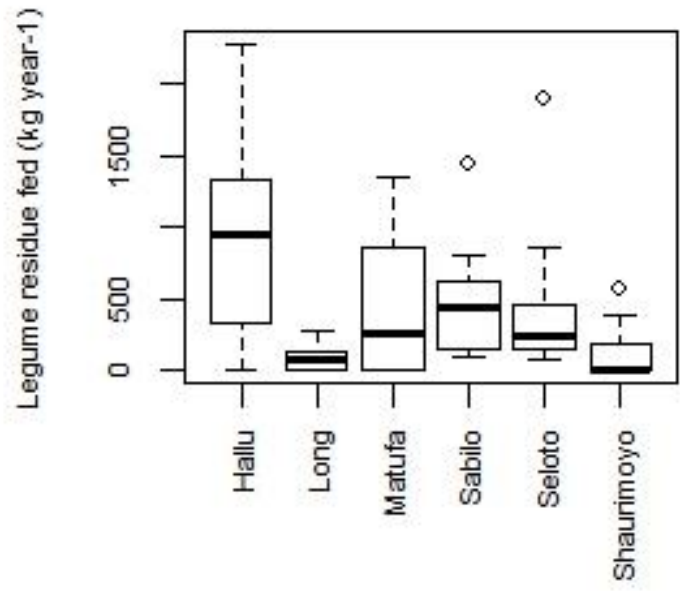

d

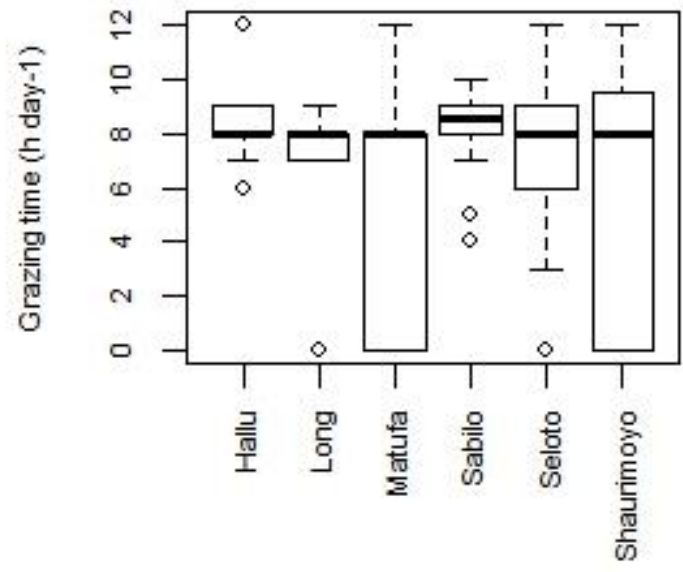

Figure A3: Feed across the study villages. a) Cereal residues fed (excluding farms with $>10,000 \mathrm{~kg}$ ); b) legume residues fed (excluding farms with $>2,500 \mathrm{~kg}$ ); c) purchased feed (excluding farms with >400 kg); d) grazing time.

Grazing was dominant in all villages with median time around 8 hours day ${ }^{-1}$. Higher cereal and legume residues were fed in Hallu, and least in Long and Shaurimoyo. Feeding purchased feed was not common practice, with few farms across villages engaging in it (Figure A3, Appendix 1). 
a

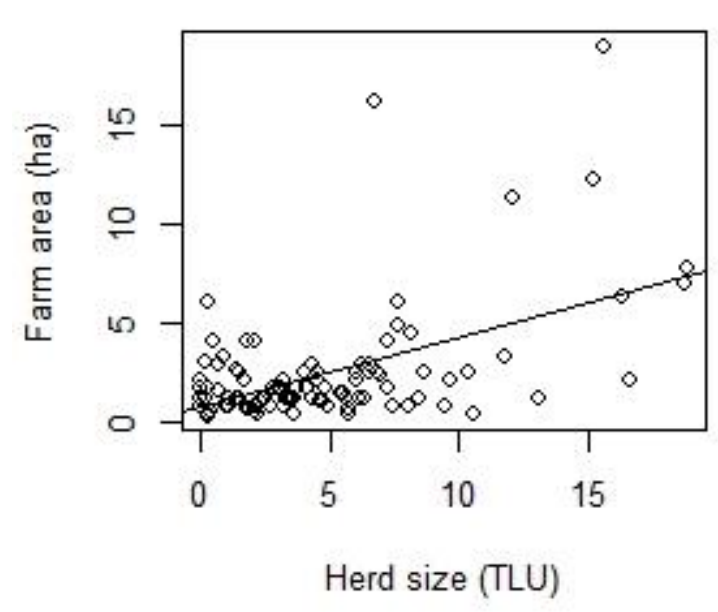

C

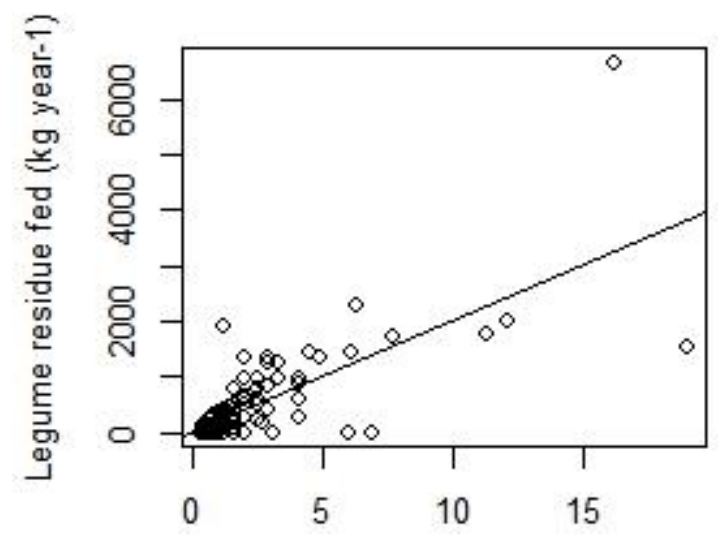

Farm area (ha) b

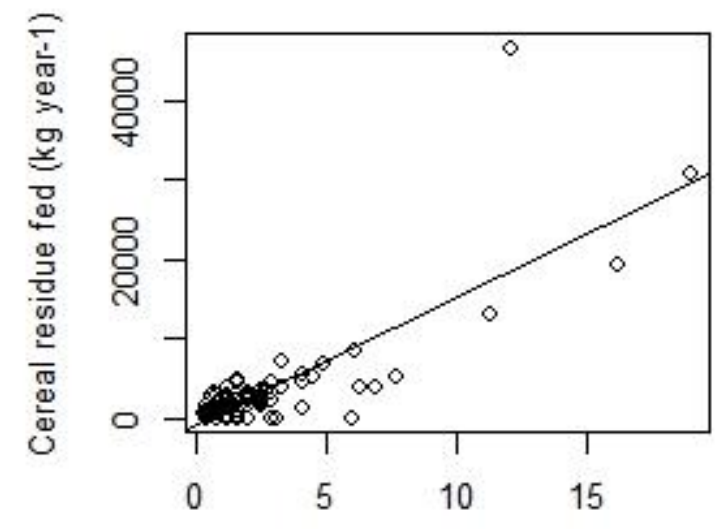

Farm area (ha)

d

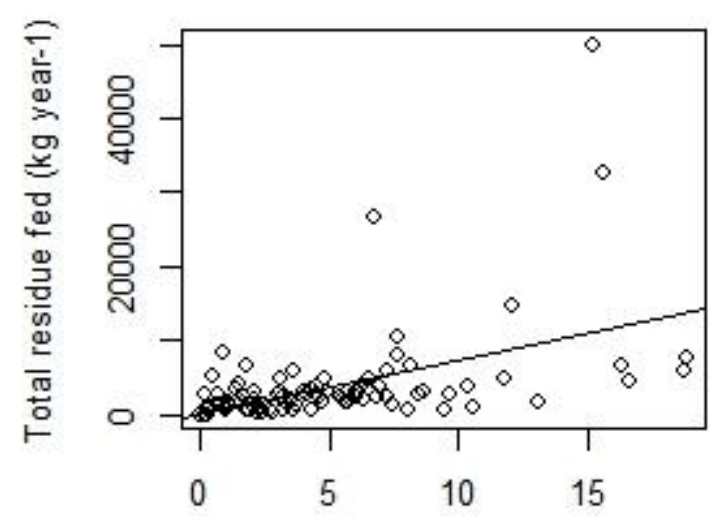

Herd size (TLU)

Figure A4: Correlations between farm area, herd size and residue feeding. a) Farm area vs. TLU R2 0.262, $\mathrm{P}<0.001$; b) Farm area vs. cereal residue feeding $\mathrm{R} 20.65, \mathrm{P}<0.001$; c) Farm area vs. legume residue feeding $\mathrm{R} 2$ $0.53, P<0.001 ;$ d) TLU vs. total residue feeding $R 20.53, P<0.001$.

Farm area and the amount of cereal and legume residue fed were strongly correlated, and farm area and livestock holdings to a lesser degree (Figure A4, Appendix 1). 
Table A1: Soil characteristics and tree $\mathrm{C}$ stocks from different land uses of $\mathbf{1 2}$ farmers across the four study villages and livestock systems. Soil texture refers to sandy clay (SC), sandy clay loam (SCL), clay (C), and clay loam (CL). Villages are separated by horizontal lines.

\begin{tabular}{|c|c|c|c|c|c|c|c|c|c|c|c|}
\hline Village & Type & Land use & $\begin{array}{l}\text { Clay + } \\
\text { silt }\end{array}$ & $\begin{array}{l}\text { Soil } \\
\text { texture }\end{array}$ & Bray P & K & $\mathrm{pH}$ & $\begin{array}{l}\text { Total } \\
\text { soil N }\end{array}$ & $\begin{array}{l}\text { Total } \\
\text { soil C }\end{array}$ & $\begin{array}{l}\text { Total } \\
\text { tree C } \\
\text { stock } \\
\end{array}$ & $\begin{array}{l}\text { Total } \\
\text { tree C } \\
\text { stock }\end{array}$ \\
\hline & & & $\%$ & class & $\mathrm{mg} \mathrm{kg}^{-1}$ & $\mathrm{cmol}^{+\mathrm{kg}^{-1}}$ & in $\mathrm{H}_{2} \mathrm{O}$ & $\mathrm{g} \mathrm{N} \mathrm{kg}^{-1}$ & $\mathrm{~g} \mathrm{C} \mathrm{kg}^{-1}$ & t C farm f $^{-1}$ & $\mathrm{tC} \mathrm{ha-1}$ \\
\hline Hallu & LARGE LIVESTOCK 1 & Cropland & 53 & SC & 1.6 & 0.8 & 7.3 & 1.6 & 20.4 & 22.1 & 2.0 \\
\hline Hallu & LARGE LIVESTOCK 1 & Woodland & 45 & SC & 1.1 & 0.6 & 7.6 & 1.7 & 20.0 & & \\
\hline Hallu & SMALLEST 1 & Cropland & 53 & SC & 4.7 & 0.8 & 7.8 & 1.8 & 23.3 & 3.5 & 2.9 \\
\hline Hallu & LARGE LIVESTOCK 2 & Cropland & 43 & SC & 1.7 & 0.6 & 7.9 & 1.4 & 16.3 & 0.0 & 0.0 \\
\hline Hallu & LARGE LIVESTOCK 2 & Grassland & 41 & $\mathrm{SCL}$ & 0.5 & 0.1 & 9.1 & 0.9 & 14.3 & & \\
\hline Hallu & SMALLEST 2 & Cropland & 65 & $\mathrm{C}$ & 5.9 & 1.1 & 7.2 & 1.8 & 21.2 & 1.8 & 0.4 \\
\hline Long & SMALLEST 3 & Cropland & 54 & SCL & 45.1 & 2.2 & 6.1 & 3.4 & 39.6 & 3.1 & 1.9 \\
\hline Long & SMALLEST 3 & Grassland & 48 & $\mathrm{SCL}$ & 49.8 & 2.1 & 6.4 & 4.1 & 46.0 & & \\
\hline Long & SMALLEST 4 & Cropland & 52 & SC & 24.3 & 0.8 & 5.9 & 2.4 & 23.0 & 2.2 & 1.4 \\
\hline Long & SMALLEST 4 & Grassland & 60 & $\mathrm{CL}$ & 1.7 & 0.1 & 5.2 & 2.7 & 31.3 & & \\
\hline Long & SMALLEST 4 & Woodland & 52 & SC & 7.8 & 0.1 & 4.6 & 2.1 & 21.0 & & \\
\hline Sabilo & DAIRY 1 & Cropland & 73 & $\mathrm{C}$ & 8.6 & 0.6 & 6.1 & 1.5 & 14.7 & 1.1 & 0.3 \\
\hline Sabilo & SHOAT 1 & Cropland & 73 & C & 31.8 & 0.9 & 6.3 & 2.1 & 26.0 & 334.8 & 39.8 \\
\hline Sabilo & SHOAT 1 & Fallow & 74 & $C$ & 23.2 & 0.7 & 6.4 & 1.8 & 17.0 & & \\
\hline Sabilo & SHOAT 1 & Grassland & 68 & $\mathrm{CL}$ & 10.6 & 0.7 & 6.4 & 2.1 & 19.7 & & \\
\hline Sabilo & SMALLEST 5 & Cropland & 70 & $C$ & 33.9 & 2.5 & 6.8 & 2.2 & 21.4 & 6.4 & 2.2 \\
\hline Sabilo & SMALLEST 5 & Grassland & 69 & $\mathrm{C}$ & 2.0 & 0.3 & 7.4 & 1.6 & 16.9 & & \\
\hline Sabilo & DAIRY 2 & Cropland & 70 & $C$ & 26.7 & 0.8 & 7.0 & 2.2 & 22.1 & 17.6 & 2.4 \\
\hline Sabilo & DAIRY 2 & Grassland & 72 & $C$ & 35.6 & 1.2 & 7.0 & 1.9 & 22.3 & & \\
\hline Seloto & SMALLEST 6 & Cropland & 53 & SC & 7.1 & 1.0 & 7.0 & 1.5 & 15.6 & 2.0 & 1.7 \\
\hline Seloto & SHOAT 2 & Cropland & 51 & SC & 10.0 & 0.5 & 6.1 & 1.3 & 13.6 & 1.1 & 1.0 \\
\hline Seloto & SHOAT 2 & Cropland & 55 & C & 11.0 & 0.9 & 6.5 & 1.6 & 15.8 & & \\
\hline
\end{tabular}


In general, soils exhibited a moderate to good level of fertility. Carbon and nitrogen contents were moderate ( $>15 \mathrm{~g} \mathrm{C} \mathrm{kg}^{-1},>1.5 \mathrm{~g} \mathrm{~N} \mathrm{~kg}^{-1}$ ), soil pH was moderate to good ( $\left.>5.5\right)$ and Bray-P was variable but mostly sufficient ( $>10 \mathrm{mg} \mathrm{kg}^{-1}$ ). Differences between villages were apparent, reflecting varying agroecologies. Hallu displayed the lowest soil fertility of all villages in terms of high pH (7.8), and lowest C (19.3 $\left.\mathrm{g} \mathrm{C} \mathrm{kg}^{-1}\right), \mathrm{N}\left(1.5 \mathrm{~g} \mathrm{~N} \mathrm{~kg}^{-1}\right)$, and especially Bray-P $\left(2.6 \mathrm{mg} \mathrm{kg}^{-1}\right)$. Long had the highest average soil fertility with good $\mathrm{pH}(5.6)$, and high $\mathrm{C}\left(32.2 \mathrm{~g} \mathrm{C} \mathrm{kg}^{-1}\right), \mathrm{N}\left(2.9 \mathrm{~g} \mathrm{~N} \mathrm{~kg}^{-1}\right)$, and Bray-P $\left(25.7 \mathrm{mg} \mathrm{kg}^{-1}\right)$. C stocks in trees greatly varied, depending on the age of the trees and their total amount on each farm.

Differences between farming systems or land uses were not apparent (Table A1, Appendix 1).

\section{Appendix 2}

Typology construction

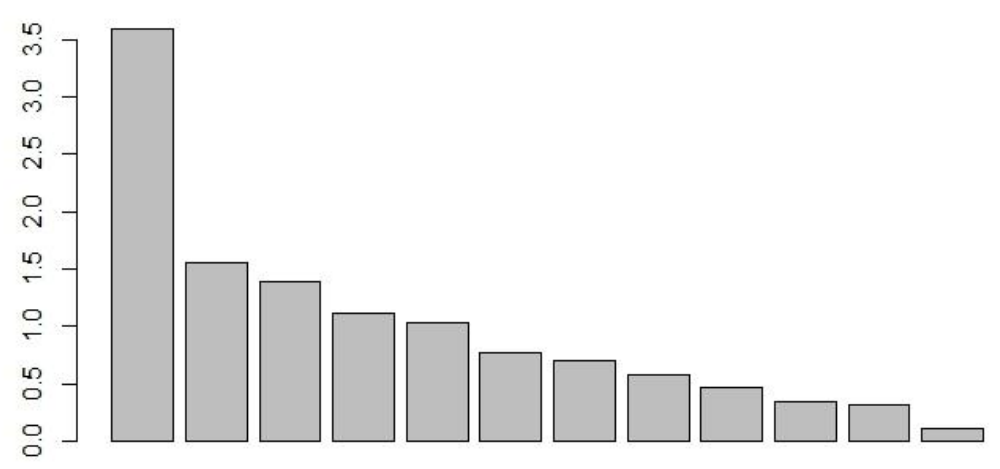

Figure A5: Visual presentation of eigenvalues which are used to limit the number of explanatory variables or principal components. The first five axes have eigenvalues of 3.59, 1.56, 1.39, 1.12 and 1.04. 


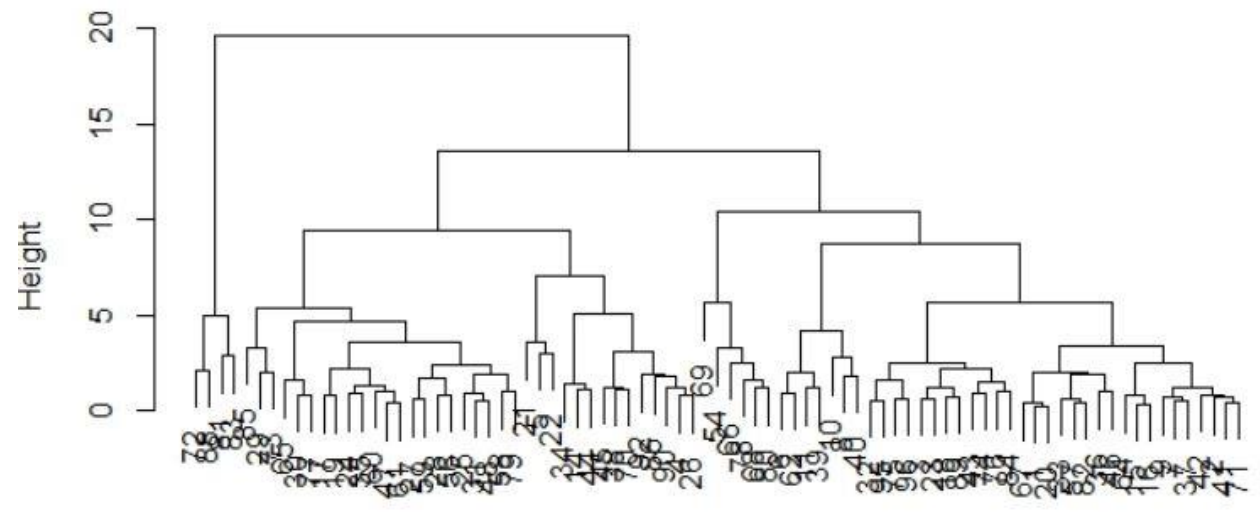

Figure A6: Dendogram, the visual presentation of the hierarchical clustering of individual farms into types as homogenous as possible.
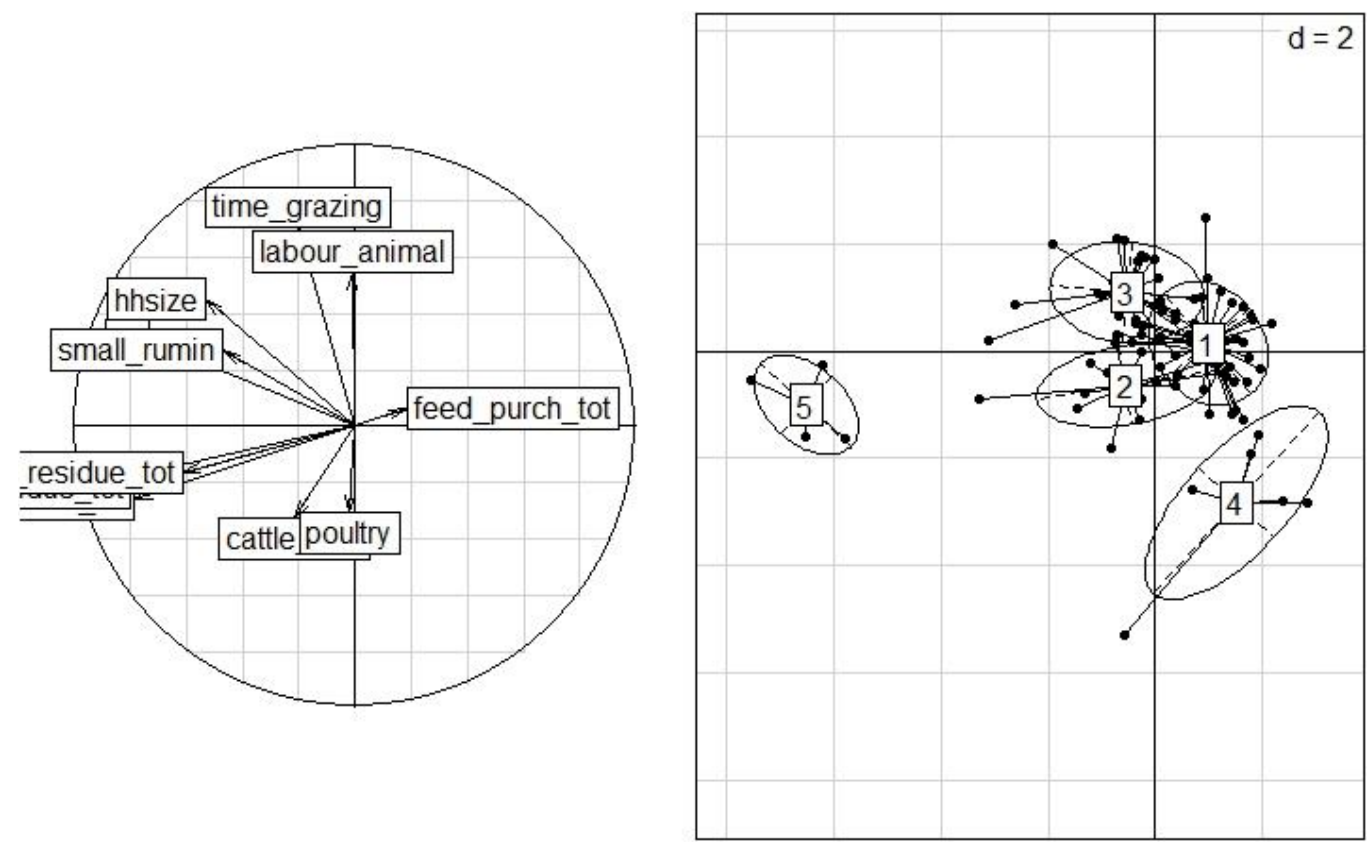

Figure A7: Interpretation of the clusters by mapping them on top of PC1 and PC2.

Cluster number 5: more residue, higher farm area, higher TLU; Cluster number 4: small farm size, low time grazing and labor. 

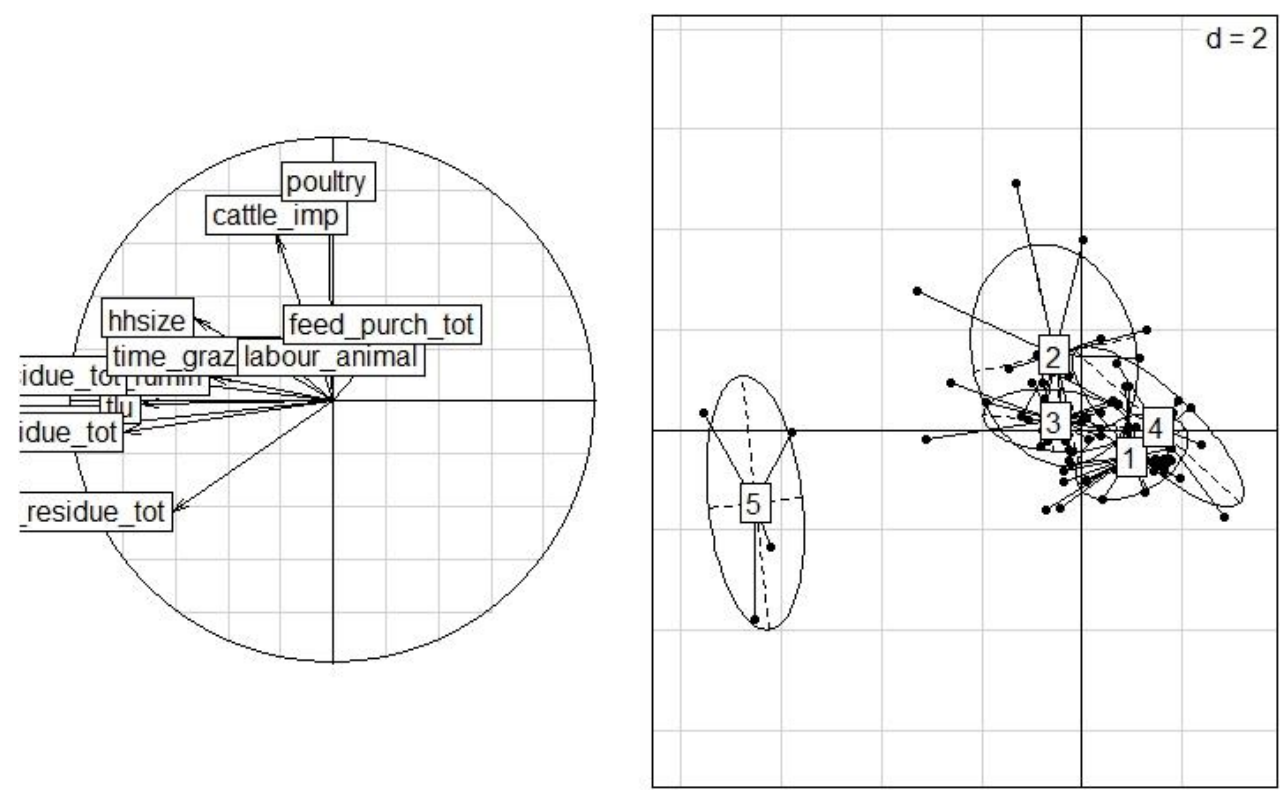

Figure A8: Interpretation of the clusters by mapping them on top of PC1 and PC3.


Figure A9: Interpretation of the clusters by mapping them on top of PC1 and PC

Appendix 3

Model input data 
Table A2: Household and farm sizes, fertilizer and manure application, and family and hired labor hours per various crop activities.

\begin{tabular}{|c|c|c|c|c|c|c|c|c|c|c|c|c|c|}
\hline & $\begin{array}{l}\text { Household } \\
\text { members }\end{array}$ & $\begin{array}{l}\text { Plot } \\
\text { size }\end{array}$ & $\begin{array}{l}\text { Fertilizer } \\
\text { application }\end{array}$ & $\begin{array}{l}\text { Manure } \\
\text { application }\end{array}$ & $\begin{array}{l}\text { Land } \\
\text { prep }\end{array}$ & Planting & Weeding & $\begin{array}{l}\text { Manure } \\
\text { appl }\end{array}$ & Harvesting & $\begin{array}{l}\text { Threshing, } \\
\text { shelling, } \\
\text { drying }\end{array}$ & $\begin{array}{l}\text { Total } \\
\text { labor }\end{array}$ & $\begin{array}{l}\text { Total } \\
\text { regular } \\
\text { labor }\end{array}$ & $\begin{array}{l}\text { Total } \\
\text { hired } \\
\text { labor }\end{array}$ \\
\hline & number & $h a$ & $k g N h a^{-1}$ & $k g D M h a^{-1}$ & \multicolumn{9}{|c|}{ labor hours ha $a^{-1} y r^{1}$} \\
\hline SMALLEST & 7 & 1.60 & & & & & & & & & & & \\
\hline Potato / potato & & 0.30 & 0 & 1800 & 120 & 48 & 160 & 12 & 21 & 0 & 361 & 241 & 120 \\
\hline Maize + bean & & 1.00 & 0 & 1079 & 60 & 32 & 80 & 12 & 21 & 85 & 290 & 230 & 60 \\
\hline Eucalyptus & & 0.10 & 0 & 0 & 6 & 1 & 0 & 0 & 5 & 0 & 12 & 9 & 2 \\
\hline On-farm pasture & & 0.20 & 0 & 147 & 0 & 0 & 0 & 0 & 0 & 0 & 0 & 0 & 0 \\
\hline DAIRY & 7 & 3.65 & & & & & & & & & & & \\
\hline Maize + bean + pigeon pea / bean & & 1.62 & 0 & 3076 & 3 & 36 & 160 & 40 & 64 & 179 & 482 & 399 & 83 \\
\hline On-farm pasture & & 1.50 & 0 & 655 & 0 & 0 & 0 & 0 & 0 & 0 & 0 & 0 & 0 \\
\hline Napier & & 0.53 & 0 & 0 & 5 & 2 & 0 & 0 & 0 & 0 & 7 & 7 & 0 \\
\hline SHOAT & 9 & 8.42 & & & & & & & & & & & \\
\hline Maize + bean + pigeon pea + sunflower & & 3.10 & 0 & 1421 & 1 & 90 & 80 & 40 & 64 & 88 & 363 & 260 & 103 \\
\hline Wheat & & 1.62 & 0 & 100 & 1 & 60 & 120 & 40 & 80 & 120 & 421 & 180 & 241 \\
\hline On-farm pasture & & 3.70 & 0 & 286 & 0 & 0 & 0 & 0 & 0 & 0 & 0 & 0 & 0 \\
\hline LARGE LIVESTOCK & 7 & 11.12 & & & & & & & & & & & \\
\hline Acacia + Senna trees & & 1.00 & 0 & 0 & 0 & 0 & 0 & 0 & 104 & 0 & 104 & 104 & 0 \\
\hline Maize + pigeon pea + sunflower & & 10.12 & 0 & 589 & 1 & 32 & 80 & 10 & 48 & 89 & 260 & 157 & 104 \\
\hline
\end{tabular}


Table A3: Livestock species numbers, and livestock labor required

\begin{tabular}{|c|c|c|c|c|c|c|c|c|c|c|c|}
\hline & $\begin{array}{l}\text { Livestock } \\
\text { heads }\end{array}$ & Grazing & $\begin{array}{l}\text { Fetching } \\
\text { feed }\end{array}$ & Watering & Milking & Cleaning & $\begin{array}{l}\text { Vet } \\
\text { services }\end{array}$ & $\begin{array}{l}\text { Total } \\
\text { labor }\end{array}$ & $\begin{array}{l}\text { Total } \\
\text { labor }\end{array}$ & $\begin{array}{l}\text { Total } \\
\text { regular } \\
\text { labor }\end{array}$ & $\begin{array}{l}\text { Total } \\
\text { hired } \\
\text { labor }\end{array}$ \\
\hline & number & \multicolumn{7}{|c|}{ labor hours yr ${ }^{-1}$} & \multicolumn{3}{|c|}{ labor hours animal ${ }^{-1} \mathrm{yr}^{-1}$} \\
\hline \multicolumn{12}{|l|}{ SMALLEST } \\
\hline Chicken & 3 & 0 & 0 & 0 & 0 & 61 & 2 & 63 & 21 & 21 & 0 \\
\hline Local cows & 2 & 438 & 0 & 34 & 68 & 73 & 2 & 615 & 307 & 307 & 0 \\
\hline Local goat & 4 & 876 & 0 & 68 & 0 & 146 & 1 & 1091 & 273 & 273 & 0 \\
\hline Local young male cattle & 1 & 219 & 0 & 17 & 0 & 37 & 2 & 275 & 275 & 275 & 0 \\
\hline Sheep & 3 & 657 & 0 & 51 & 0 & 110 & 1 & 819 & 273 & 273 & 0 \\
\hline \multicolumn{12}{|l|}{ DAIRY } \\
\hline Improved cows & 3 & 0 & 900 & 150 & 53 & 274 & 4 & 1380 & 460 & 310 & 150 \\
\hline Improved heifer & 1 & 0 & 210 & 50 & 0 & 91 & 1 & 352 & 352 & 247 & 105 \\
\hline Local bulls & 3 & 665 & 0 & 83 & 0 & 183 & 3 & 933 & 311 & 311 & 0 \\
\hline Chicken & 10 & 0 & 0 & 0 & 0 & 60 & 6 & 66 & 7 & 7 & 0 \\
\hline Local cows & 3 & 665 & 0 & 83 & 53 & 183 & 3 & 986 & 329 & 329 & 0 \\
\hline Local goat & 5 & 1108 & 0 & 138 & 0 & 261 & 12 & 1519 & 304 & 304 & 0 \\
\hline Sheep & 2 & 443 & 0 & 55 & 0 & 104 & 5 & 607 & 304 & 304 & 0 \\
\hline \multicolumn{12}{|l|}{ SHOAT } \\
\hline Chicken & 33 & 0 & 0 & 0 & 0 & 180 & 1 & 181 & 5 & 5 & 0 \\
\hline Goats & 20 & 1906 & 0 & 159 & 0 & 270 & 12 & 2347 & 117 & 70 & 48 \\
\hline Local bulls & 3 & 286 & 0 & 24 & 0 & 156 & 4 & 470 & 157 & 109 & 48 \\
\hline Local cows & 3 & 286 & 0 & 24 & 68 & 156 & 6 & 540 & 180 & 132 & 48 \\
\hline Local heifer & 1 & 95 & 0 & 8 & 0 & 52 & 1 & 156 & 156 & 109 & 48 \\
\hline Sheep & 7 & 667 & 0 & 56 & 0 & 95 & 3 & 821 & 117 & 70 & 48 \\
\hline \multicolumn{12}{|l|}{ LARGE LIVESTOCK } \\
\hline Improved cow & 1 & 0 & 1080 & 140 & 53 & 360 & 2 & 1635 & 1635 & 1635 & 0 \\
\hline Local bulls & 4 & 576 & 0 & 51 & 0 & 97 & 4 & 728 & 182 & 38 & 144 \\
\hline Local calves & 5 & 720 & 0 & 64 & 0 & 274 & 5 & 1063 & 213 & 69 & 144 \\
\hline Chicken & 6 & 0 & 0 & 0 & 0 & 61 & 3.6 & 64 & 11 & 11 & 0 \\
\hline Local cows & 11 & 1584 & 0 & 140 & 53 & 268 & 11 & 2055 & 187 & 43 & 144 \\
\hline
\end{tabular}

Table A4: Available on-farm labor livestock system

\begin{tabular}{llllll}
\hline & $\begin{array}{l}\text { Household } \\
\text { member }\end{array}$ & Age & $\begin{array}{l}\text { Available days } \\
\text { for on-farm } \\
\text { labor }\end{array}$ & $\begin{array}{l}\text { Available hours } \\
\text { per day for on- } \\
\text { farm labor }\end{array}$ & $\begin{array}{l}\text { Total available } \\
\text { hours for on- } \\
\text { farm labor }\end{array}$ \\
\hline \multirow{2}{*}{ SMALLEST } & years & days year ${ }^{-1}$ & hours day $^{-1}$ & hours year $^{1}$ \\
& Father & 49 & 261 & 6 & 1566 \\
& Mother & 38 & 261 & 4 & 1044 \\
& Daughter 1 & 21 & 261 & 4 & 1044
\end{tabular}






Table A5: Animal products, productivity and sales per livestock system

\begin{tabular}{lllll}
\hline & Livestock & $\begin{array}{l}\text { Livestock } \\
\text { product }\end{array}$ & $\begin{array}{l}\text { Livestock } \\
\text { productivity }\end{array}$ & Sale \\
\hline \multirow{2}{*}{ SMALLEST } & & kg FW animal $^{-1}$ day $^{-1}$ & $\%$ \\
& \multirow{2}{*}{ Chicken } & Eggs & 0.0 & 100 \\
& Local cows & Whole chicken & 0.0 & 78 \\
& Low milk & 0.4 & 0 \\
& Local goat & Goat milk & 0.0 & 0 \\
& Sheep & Whole goat & 0.5 & 100 \\
& Improved cows & Whole sheep & 0.1 & 100 \\
\hline DAIRY & Cow milk & 3.4 & 67 \\
& Chicken & Eggs & 0.0 & 40
\end{tabular}




\begin{tabular}{lllll}
\hline & & Whole chicken & 0.0 & 66 \\
& \multirow{2}{*}{ Local cows } & Cow milk & 0.7 & 15 \\
& Local goat & Whole cow & 0.7 & 100 \\
& Chicken & Whole goat & 0.1 & 51 \\
\hline SHOAT & Eggs & 0.0 & 50 \\
& Goats & Whole chicken & 0.0 & 80 \\
& Local bulls & Whole goat & 0.1 & 71 \\
& Local cows & Whole bull & 0.2 & 100 \\
& Sheep & Cow milk & 0.6 & 86 \\
LIVESTOCK & Improved cows & Cow milk & 3.4 & 100 \\
& Local bulls & Whole bull & 0.2 & 72 \\
& \multirow{2}{*}{ Chicken } & Eggs & 0.0 & 100 \\
& \multirow{2}{*}{ Local cows } & Whole chicken & 0.0 & 0 \\
& & Cow milk & 0.8 & 27 \\
& & Whole cow & 0.2 & 0 \\
& & & 0.1 & 100 \\
\hline
\end{tabular}

Table A6: Crop products, productivity and sales per livestock system

\begin{tabular}{|c|c|c|c|c|c|c|c|}
\hline Crop & Crop product & $\begin{array}{l}\text { Intercropped } \\
\text { with other } \\
\text { crops }\end{array}$ & Seasons & $\begin{array}{l}\text { Fresh crop } \\
\text { productivity }\end{array}$ & $\begin{array}{l}\text { Dry crop } \\
\text { productivity }\end{array}$ & Sale & $\begin{array}{l}\text { Residue } \\
\text { retained }\end{array}$ \\
\hline & & number & number & $\mathrm{kg} \mathrm{FWha^{-1 }}$ & $\mathrm{kg} D W h a^{-1}$ & $\%$ & $\%$ \\
\hline \multirow{2}{*}{ Maize } & Maize grain & \multirow{2}{*}{1} & \multirow{2}{*}{1} & 700 & 609 & 0 & - \\
\hline & Maize residues & & & 789 & 734 & 0 & 5 \\
\hline \multirow{2}{*}{ Beans } & Bean grain & \multirow{2}{*}{1} & \multirow{2}{*}{1} & 500 & 440 & 0 & - \\
\hline & Bean residues & & & 500 & 465 & 0 & 5 \\
\hline \multirow{2}{*}{ Potato } & Potatoes & \multirow{2}{*}{0} & \multirow{2}{*}{2} & 2000 & 320 & 92 & - \\
\hline & Potatoe residue & & & 1333 & 307 & 0 & 100 \\
\hline On-farm pasture & Grass & 0 & - & 12000 & 3000 & 0 & 0 \\
\hline Napier & Napier grass & - & - & - & - & 0 & 0 \\
\hline Eucalyptus & Timber & 0 & - & 7500 & 6750 & 100 & - \\
\hline \multirow{2}{*}{ Maize } & Maize grain & \multirow{2}{*}{2} & \multirow{2}{*}{1} & 900 & 783 & 0 & - \\
\hline & Maize residues & & & 1050 & 977 & 0 & 0 \\
\hline \multirow{2}{*}{ Beans } & Bean grain & \multirow{2}{*}{2} & \multirow{2}{*}{2} & 800 & 704 & 82 & - \\
\hline & Bean residues & & & 800 & 744 & 0 & 0 \\
\hline \multirow{2}{*}{ Pigeon pea } & Pigeon pea & \multirow{2}{*}{2} & \multirow{2}{*}{1} & 25 & 23 & 100 & - \\
\hline & Pigeon pea residue & & & 59 & 55 & 0 & 0 \\
\hline On-farm pasture & Grass & 0 & - & 10000 & 2500 & 0 & 0 \\
\hline Napier & Napier grass & 0 & - & 26680 & 4749 & 0 & 0 \\
\hline Maize & Maize grain & 3 & 1 & 800 & 696 & 63 & - \\
\hline
\end{tabular}




\begin{tabular}{|c|c|c|c|c|c|c|c|}
\hline \multirow{3}{*}{ Beans } & Maize residues & & & 902 & 839 & 0 & 0 \\
\hline & Bean grain & \multirow{2}{*}{3} & \multirow{2}{*}{1} & 500 & 440 & 90 & - \\
\hline & Bean residues & & & 500 & 465 & 0 & 0 \\
\hline \multirow{2}{*}{ Pigeon pea } & Pigeon pea & \multirow{2}{*}{3} & \multirow{2}{*}{1} & 200 & 180 & 93 & - \\
\hline & Pigeon pea residue & & & 472 & 439 & 0 & 0 \\
\hline \multirow{2}{*}{ Wheat } & Wheat grain & \multirow{2}{*}{1} & \multirow{2}{*}{1} & 1625 & 1414 & 100 & - \\
\hline & Wheat residues & & & 1907 & 1774 & 0 & 0 \\
\hline \multirow{3}{*}{ Sunflower } & Sunflower seeds & \multirow{3}{*}{3} & \multirow{3}{*}{1} & 150 & 105 & 0 & - \\
\hline & Sunflower cake & & & 200 & 190 & 0 & - \\
\hline & Sunflower residues & & & 350 & 333 & 0 & 0 \\
\hline \multirow{2}{*}{$\begin{array}{l}\text { On-farm pasture } \\
\text { Napier }\end{array}$} & Grass & 0 & - & 10000 & 2800 & 0 & 0 \\
\hline & Napier grass & 0 & - & - & - & - & 0 \\
\hline \multirow{2}{*}{ Maize } & Maize grain & \multirow{2}{*}{2} & \multirow{2}{*}{1} & 800 & 696 & 86 & - \\
\hline & Maize residues & & & 902 & 839 & 0 & 60 \\
\hline \multirow{2}{*}{ Pigeon pea } & Pigeon pea & \multirow{2}{*}{2} & \multirow{2}{*}{1} & 250 & 225 & 91 & - \\
\hline & Pigeon pea residue & & & 591 & 550 & 0 & 0 \\
\hline \multirow{2}{*}{ Sunflower } & Sunflower seeds & \multirow{2}{*}{2} & \multirow{2}{*}{1} & 100 & 70 & 81 & - \\
\hline & Sunflower residues & & & 233 & 221 & 0 & 60 \\
\hline Acacia/Senna & Wood & 0 & - & 1111 & 1000 & 0 & 0 \\
\hline Napier & Napier grass & 0 & - & - & - & - & 0 \\
\hline
\end{tabular}

\section{Appendix 4}

Model parameters

Table A7: Animal body weight, saturation, structure and energy requirement parameters. DMI = dry matter intake, $\mathrm{VEM}=$ feed unit milk, $\mathrm{MW}=$ metabolic weight. Metabolic weight $=0.75^{\wedge} \mathrm{BW}$.

\begin{tabular}{|c|c|c|c|c|}
\hline & $\begin{array}{l}\text { Body weight } \\
\text { (BW) }\end{array}$ & $\begin{array}{l}\text { Saturation } \\
\text { factor }\end{array}$ & $\begin{array}{l}\text { Structure } \\
\text { factor }\end{array}$ & $\begin{array}{l}\text { Energy } \\
\text { maintenance }\end{array}$ \\
\hline & $\mathrm{kg}$ & per kg BW & per kg DMI & VEM kg MW-1 \\
\hline Improved cows & 250 & 2.65 & 1 & 38.9 \\
\hline Local cow & 200 & 2.65 & 1 & 38.3 \\
\hline Local bull & 220 & 2.65 & 1 & 38.6 \\
\hline Young cattle & 150 & 2.65 & 1 & 37.7 \\
\hline Improved heifer & 170 & 2.65 & 1 & 38.0 \\
\hline Local heifer & 150 & 2.65 & 1 & 37.7 \\
\hline Calves & 100 & 2.65 & 1 & 37.0 \\
\hline Goats & 60 & 2.65 & 1 & 36.5 \\
\hline Sheep & 55 & 2 & 1 & 36.4 \\
\hline Chicken & 1.2 & 4 & 1 & 35.2 \\
\hline
\end{tabular}


Table A8: Environment and climate parameters. Active organic matter (OM) is the fraction of organic matter that is subject to mineralization; soil depth is where mineralization happens.

\begin{tabular}{|c|c|c|c|c|c|}
\hline & $\begin{array}{l}\text { Active } \\
\text { OM }\end{array}$ & $\begin{array}{l}\text { OM } \\
\text { degradation }\end{array}$ & $\begin{array}{l}\text { Mean } \\
\text { temperature }\end{array}$ & $\begin{array}{l}\text { Soil } \\
\text { depth }\end{array}$ & $\begin{array}{l}\text { Period with } \\
\mathrm{pF}<3.5\end{array}$ \\
\hline & $\%$ & $\%$ year $^{1}$ & ${ }^{\circ} \mathrm{C}$ & $m$ & days \\
\hline SMALLEST & 0.472 & 2.01 & 13 & 0.29 & 275 \\
\hline DAIRY & 0.38 & 2.35 & 17 & 0.3 & 250 \\
\hline SHOAT & 0.366 & 2.3 & 17 & 0.22 & 230 \\
\hline LARGE LIVESTOCK & 0.36 & 2 & 19 & 0.29 & 200 \\
\hline
\end{tabular}

Table A9: Feed parameters

\begin{tabular}{|c|c|c|c|c|}
\hline \multicolumn{5}{|c|}{ Feed saturation value } \\
\hline & & & & LARGE \\
\hline Feed item & SMALLEST & DAIRY & SHOAT & LIVESTOCK \\
\hline Bean residues & 2 & 2 & 2 & - \\
\hline Cow milk & - & - & - & - \\
\hline Goat milk & - & - & - & - \\
\hline Maize grain & - & - & 0.25 & - \\
\hline Maize residues & 2 & 2 & 2 & 2 \\
\hline Maize bran & - & - & 0.8 & - \\
\hline Napier & 1.5 & 1.5 & 1.5 & 1.5 \\
\hline Off-farm pasture & 1.2 & 1.1 & - & 1.2 \\
\hline On-farm pasture & 1.4 & 1.3 & 1.1 & - \\
\hline Pigeon pea pods & - & 1 & 1 & 1 \\
\hline Sunflower cake & 0.5 & 0.5 & 0.5 & 0.5 \\
\hline Sunflower residues & - & - & 2 & 2 \\
\hline Wheat residues & - & - & 2 & - \\
\hline \multicolumn{5}{|l|}{ Feed structure value } \\
\hline Feed item & SMALLEST & DAIRY & SHOAT & $\begin{array}{l}\text { LARGE } \\
\text { LIVESTOCK }\end{array}$ \\
\hline Bean residues & 1 & 1 & 1 & - \\
\hline Cow milk & - & - & - & - \\
\hline Goat milk & - & - & - & - \\
\hline Maize Grain & - & - & 0.15 & - \\
\hline Maize residues & 2 & 2 & 2 & 2 \\
\hline Maize bran & - & - & 0.8 & - \\
\hline Napier & 1.8 & 1.8 & 1.8 & 1.8 \\
\hline Off-farm pasture & 3.5 & 3.5 & - & - \\
\hline On-farm pasture & 3.5 & 3.5 & 3.5 & 3.5 \\
\hline Pigeon pea pods & - & 4 & 4 & 4 \\
\hline
\end{tabular}




\begin{tabular}{|c|c|c|c|c|}
\hline Sunflower cake & 0.5 & 0.5 & 0.5 & 0.5 \\
\hline Sunflower residues & - & - & 1 & 1 \\
\hline Wheat residues & - & - & 4 & - \\
\hline \multicolumn{5}{|c|}{ Energy contents (per kg DM) } \\
\hline Feed item & SMALLEST & DAIRY & SHOAT & $\begin{array}{l}\text { LARGE } \\
\text { LIVESTOCK }\end{array}$ \\
\hline Bean residues & 641 & 641 & 641 & \\
\hline Cow milk & 1000 & 1000 & 1000 & 1000 \\
\hline Goat milk & 1000 & - & - & 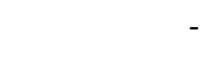 \\
\hline Maize grain & - & - & 1103 & _. \\
\hline Maize residues & 613 & 613 & 613 & 613 \\
\hline Maize bran & - & - & 900 & . \\
\hline Napier & 700 & 700 & 700 & 700 \\
\hline Off-farm pasture & 630 & 630 & - & - \\
\hline On-farm pasture & 680 & 650 & 650 & 650 \\
\hline Pigeon pea pods & - & 703 & 703 & 703 \\
\hline Sunflower cake & 623 & 623 & 623 & 623 \\
\hline Sunflower residues & - & - & 479 & 479 \\
\hline Wheat residues & - & - & 700 &  \\
\hline \multicolumn{5}{|c|}{ Protein contents ( $\left.\mathrm{g} \mathrm{kg}^{-1} \mathrm{DM}\right)$} \\
\hline Feed item & SMALLEST & DAIRY & SHOAT & $\begin{array}{l}\text { LARGE } \\
\text { LIVESTOCK }\end{array}$ \\
\hline Bean residues & 35.7 & 35.7 & 35.7 & - \\
\hline Cow milk & 100 & 100 & 100 & 100 \\
\hline Goat milk & 100 & - & - & - \\
\hline Maize grain & - & - & 102 & - \\
\hline Maize residues & 21.1 & 21.1 & 21.1 & 21.1 \\
\hline Maize bran & - & - & 33 & - \\
\hline Napier & 37.2 & 37.2 & 37.2 & 37.2 \\
\hline Off-farm pasture & 30 & 30 & - & 25 \\
\hline On-farm pasture & 35 & 30 & 25 & - \\
\hline Pigeon pea pods & - & 49.3 & 49.3 & 49.3 \\
\hline Sunflower cake & 66 & 66 & 66 & 66 \\
\hline Sunflower residues & - & - & 8.1 & 8.1 \\
\hline Wheat residues & - & - & 28.8 & - \\
\hline
\end{tabular}

\section{Table A10: Manure parameters}

\begin{tabular}{llll}
\hline & Stable & Yard & Pasture \\
\hline Mineral N loss from excretion (fraction) & 0.05 & 0.15 & 0.15 \\
Mineral N loss from application (fraction) & 0.05 & 0.05 & 0.1
\end{tabular}




\begin{tabular}{|c|c|c|c|}
\hline Portion degraded in aerobic conditions (fraction) & 0.6 & 0.7 & 0.9 \\
\hline Mineral $\mathrm{N}$ loss from aerobic storage (fraction) & 0.3 & 0.3 & 0.35 \\
\hline Degradation rate aerobic conditions & 0.52 & 0.52 & 0.52 \\
\hline Microbial efficiency aerobic $\left(\mathrm{g} \mathrm{g}^{-1}\right)$ & 0.3 & 0.3 & 0.3 \\
\hline Microbial CN ratio aerobic conditions & 8 & 8 & 8 \\
\hline Mineral N loss from anaerobic storage (fraction) & 0.1 & 0.1 & 0.15 \\
\hline Degradation rate anaerobic conditions & 0.1 & 0.1 & 0.1 \\
\hline Microbial efficiency anaerobic $\left(\mathrm{g} \mathrm{g}^{-1}\right)$ & 0.25 & 0.25 & 0.25 \\
\hline Microbial $\mathrm{CN}$ ratio anaerobic conditions & 5 & 5 & 5 \\
\hline Humification coefficient (proportion) & 0.2 & 0.2 & 0.2 \\
\hline Direct $\mathrm{N}_{2} \mathrm{O}$ emissions manure $\left(\mathrm{kg} \mathrm{N}_{2} \mathrm{O} \mathrm{kg}^{-1} \mathrm{~N}\right)$ & 0.01 & 0.01 & 0.01 \\
\hline Indirect $\mathrm{N} 2 \mathrm{O}$ emissions from volatilization $\left(\mathrm{kg} \mathrm{N}_{2} \mathrm{O} \mathrm{kg} \mathrm{NH} \mathrm{NH}^{-1}\right)$ & 0.01 & 0.01 & 0.01 \\
\hline $\mathrm{N}_{2} \mathrm{O}$ emissions from manure application $\left(\mathrm{kg} \mathrm{N}_{2} \mathrm{O} \mathrm{kg} \mathrm{N}{ }^{-1}\right)$ & 0.01 & 0.01 & 0.01 \\
\hline
\end{tabular}

Table A11: Nitrogen and dry matter content as used in crop parameters of the model

\begin{tabular}{lllll}
\hline Nitrogen (g 100 g DM $^{-1}$ ) & SMALLEST & DAIRY & SHOAT & LARGE \\
LIVESTOCK
\end{tabular}




\begin{tabular}{lllll} 
Bean residues & 93 & 93 & 93 & - \\
Eucalyptus & 90 & - & - & - \\
Maize grain & 87 & 87 & 87 & 87 \\
Maize residues & 93 & 93 & 93 & 93 \\
Maize bran & - & - & 89 & - \\
Napier & 17.8 & 17.8 & 17.8 & 17.8 \\
Off-farm pasture & 28 & 28 & - & 28 \\
On-farm pasture & 25 & 25 & 28 & - \\
Pigeon pea grain & - & 90 & 90 & 90 \\
Pigeon pea pods & - & 93 & 93 & 93 \\
Pigeon pea stems & - & 92 & 92 & 92 \\
Potato & 16 & - & - & - \\
Potato residues & 23 & - & - & - \\
Sunflower cake & 95 & 95 & 95 & 95 \\
Sunflower residues & - & - & 95 & 95 \\
Sunflower seed & - & - & 70 & 70 \\
Wheat grain & - & - & 87 & - \\
Wheat residues & - & - & 93 & - \\
\hline
\end{tabular}

\section{Appendix 5}

Model optimization variables and constraints

Table A12: Decision variables with current value and minimum and maximum settings, and current value and minimum and maximum for constraints.

\begin{tabular}{llll} 
SMALLES & & & \\
\hline Decision variables & Minimum & Maximum & Value \\
\hline Off-farm grazing (kg DM year ${ }^{-1}$ ) & 0 & 3850 & 3850 \\
Improved cow milk production $\left(\mathrm{kg} \mathrm{day}^{-1} \mathrm{cow}^{-1}\right)$ & 2 & 6 & 3.37 \\
Local cow milk production $\left(\mathrm{kg} \mathrm{day}^{-1} \mathrm{cow}^{-1}\right)$ & 0.4 & 2 & 0.43 \\
On-farm pasture grass fed (fraction) & 0 & 1 & 1 \\
On-farm pasture grass retained (fraction) & 0 & 1 & 0 \\
Napier grass fed (fraction) & 0 & 1 & 1 \\
Napier grass retained (fraction) & 0 & 1 & 0 \\
Bean residues fed (fraction) & 0 & 1 & 0.95 \\
Bean residues retained (fraction) & 0 & 1 & 0.05 \\
Maize residues fed (fraction) & 0 & 1 & 0.95 \\
Maize residues retained (fraction) & 0 & 1 & 0.05 \\
Sunflower cake fed (kg DM year ${ }^{-1}$ ) & 0 & 500 & 0 \\
Napier field (ha) & 0 & 1 & 0 \\
On-farm pasture (ha) & 0 & 0.5 & 0.2 \\
Maize + bean field (ha) & 0 & 1 & 1
\end{tabular}




\begin{tabular}{|c|c|c|c|}
\hline Potato field (ha) & 0 & 0.3 & 0.3 \\
\hline Local cows (number) & 0 & 2 & 2 \\
\hline Improved cows (number) & 0 & 5 & 0 \\
\hline Local young male cattle (number) & 0 & 1 & 1 \\
\hline Local goat (number) & 0 & 4 & 4 \\
\hline Sheep (number) & 0 & 3 & 3 \\
\hline Constraint variables & Minimum & Maximum & Value \\
\hline Organic matter balance $\left(\mathrm{kg} \mathrm{farm}^{-1}\right)$ & -1 & 1000 & -0.25 \\
\hline Labor balance (hours year ${ }^{-1}$ ) & 0 & 6000 & 3619.8 \\
\hline Farm area (ha) & 0 & 1.6 & 1.6 \\
\hline Feed balance deviation dry matter intake (\%) & -999 & 0 & -0.24 \\
\hline Feed balance deviation energy required (\%) & -5 & 5 & -4.72 \\
\hline Feed balance deviation CP (\%) & -10 & 30 & -8.84 \\
\hline \multicolumn{4}{|l|}{ DAIRY } \\
\hline Decision variables & Minimum & Maximum & Value \\
\hline Off-farm cut/carry grasses fed (kg DM year $\left.{ }^{-1}\right)$ & 0 & 10000 & 10000 \\
\hline Improved cow milk production $\left(\mathrm{kg} \mathrm{day}^{-1} \operatorname{cow}^{-1}\right)$ & 2 & 6 & 3.37 \\
\hline Local cow milk production ( $\mathrm{kg} \mathrm{day}^{-1} \operatorname{cow}^{-1}$ ) & 0.4 & 2 & 0.66 \\
\hline On-farm pasture grass fed (fraction) & 0 & 1 & 1 \\
\hline On-farm pasture grass retained (fraction) & 0 & 1 & 0 \\
\hline Napier grass fed (fraction) & 0 & 1 & 0 \\
\hline Napier grass retained (fraction) & 0 & 1 & 1 \\
\hline Sunflower residues fed (fraction) & 0 & 2000 & 900 \\
\hline Bean residues fed (fraction) & 0 & 1 & 1 \\
\hline Bean residues retained (fraction) & 0 & 1 & 0 \\
\hline Maize residues fed (fraction) & 0 & 1 & 1 \\
\hline Maize residues retained (fraction) & 0 & 1 & 0 \\
\hline Napier field (ha) & 0 & 2 & 0.53 \\
\hline On-farm pasture (ha) & 0 & 2 & 1.5 \\
\hline Maize + bean + pigeon pea field (ha) & 0.5 & 1.62 & 1.62 \\
\hline Local cows (number) & 0 & 3 & 3 \\
\hline Improved cows (number) & 0 & 8 & 3 \\
\hline Local bulls (number) & 0 & 3 & 3 \\
\hline Local goat (number) & 0 & 5 & 5 \\
\hline Constraint variables & Minimum & Maximum & Value \\
\hline Organic matter balance $\left(\mathrm{kg} \mathrm{farm}^{-1}\right)$ & -1 & 1000 & 0.05 \\
\hline Labor balance (hours year ${ }^{-1}$ ) & 0 & 5000 & 584.91 \\
\hline Farm area (ha) & 0.5 & 3.66 & 3.65 \\
\hline Feed balance deviation dry matter intake (\%) & -15 & 0 & -0.35 \\
\hline Feed balance deviation energy required (\%) & -5 & 5 & -4.56 \\
\hline Feed balance deviation $\mathrm{CP}(\%)$ & -10 & 10 & 0 \\
\hline
\end{tabular}

\section{SHOAT}




\begin{tabular}{|c|c|c|c|}
\hline Decision variables & Minimum & Maximum & Value \\
\hline Improved cow milk production ( $\mathrm{kg} \mathrm{day}^{-1} \mathrm{cow}^{-1}$ ) & 2 & 6 & 3.37 \\
\hline Local cow milk production (kg day ${ }^{-1} \operatorname{cow}^{-1}$ ) & 0.4 & 2 & 0.57 \\
\hline On-farm pasture grass fed (fraction) & 0 & 1 & 1 \\
\hline On-farm pasture grass retained (fraction) & 0 & 1 & 0 \\
\hline Napier grass fed (fraction) & 0 & 1 & 1 \\
\hline Napier grass retained (fraction) & 0 & 1 & 0 \\
\hline Bean residues fed (fraction) & 0 & 1 & 1 \\
\hline Bean residues retained (fraction) & 0 & 1 & 0 \\
\hline Maize residues fed (fraction) & 0 & 1 & 1 \\
\hline Maize residues retained (fraction) & 0 & 1 & 0 \\
\hline Sunflower residues fed (fraction) & 0 & 1 & 1 \\
\hline Sunflower residues retained (fraction) & 0 & 1 & 0 \\
\hline Wheat residue fed (fraction) & 0 & 1 & 1 \\
\hline Wheat residue retained (fraction) & 0 & 1 & 0 \\
\hline Napier field (ha) & 0 & 5 & 0 \\
\hline On-farm pasture (ha) & 0 & 5 & 3.7 \\
\hline Maize + bean + pigeon pea + sunflower field (ha) & 0 & 5 & 3.1 \\
\hline Wheat field (ha) & 0 & 5 & 1.62 \\
\hline Local cows (number) & 0 & 6 & 3 \\
\hline Improved cows (number) & 0 & 10 & 0 \\
\hline Local bulls (number) & 2 & 4 & 3 \\
\hline Local goat (number) & 0 & 35 & 20 \\
\hline Sheep (number) & 0 & 10 & 7 \\
\hline Constraint variables & Minimum & Maximum & Value \\
\hline Organic matter balance $\left(\mathrm{kg} \mathrm{farm}^{-1}\right)$ & -1 & 1000 & 0.07 \\
\hline Labor balance (hours year ${ }^{-1}$ ) & 0 & 5000 & 1174.4 \\
\hline Farm area (ha) & 2 & 8.421 & 8.42 \\
\hline Feed balance deviation dry matter intake (\%) & -15 & 0.04 & 0.03 \\
\hline Feed balance deviation energy required (\%) & -7.43 & 5 & -7.42 \\
\hline Feed balance deviation CP (\%) & -10 & 10 & -4.38 \\
\hline \multicolumn{4}{|l|}{ LARGE LIVESTOCK } \\
\hline Decision variables & Minimum & Maximum & Value \\
\hline Off-farm grazing (kg DM year-1) & 0 & 13350 & 13350 \\
\hline Improved cow milk production ( $\mathrm{kg} \mathrm{day}^{-1} \mathrm{cow}^{-1}$ ) & 2 & 6 & 3.37 \\
\hline Local cow milk production $\left(\mathrm{kg} \mathrm{day}^{-1} \mathrm{cow}^{-1}\right)$ & 0.4 & 2 & 0.77 \\
\hline Napier grass fed (fraction) & 0 & 1 & 1 \\
\hline Napier grass retained (fraction) & 0 & 1 & 0 \\
\hline Maize residues fed (fraction) & 0 & 1 & 0.4 \\
\hline Maize residues retained (fraction) & 0 & 1 & 0.6 \\
\hline Sunflower residues fed (fraction) & 0 & 1 & 0.4 \\
\hline Sunflower residues retained (fraction) & 0 & 1 & 0.6 \\
\hline
\end{tabular}




\begin{tabular}{|c|c|c|c|}
\hline Sunflower cake fed (kg DM year ${ }^{-1}$ ) & 0 & 2000 & 0 \\
\hline Purchased maize residues fed $\left(\mathrm{kg} \mathrm{DM}_{\mathrm{year}} \mathrm{r}^{-1}\right)$ & 0 & 1000 & 1000 \\
\hline Napier field (ha) & 0 & 5 & 0 \\
\hline Maize + pigeon pea + sunflower field (ha) & 0 & 10.12 & 10.12 \\
\hline Tree plot (ha) & 0 & 2 & 1 \\
\hline Local cows (number) & 0 & 11 & 11 \\
\hline Improved cows (number) & 0 & 10 & 1 \\
\hline Local bulls (number) & 2 & 4 & 4 \\
\hline Constraint variables & Minimum & Maximum & Value \\
\hline Organic matter balance $\left(\mathrm{kg} \mathrm{farm}^{-1}\right)$ & -1 & 1000 & 0.26 \\
\hline Labor balance (hours year ${ }^{-1}$ ) & 0 & 5000 & 1639.16 \\
\hline Farm area (ha) & 5 & 11.12 & 11.12 \\
\hline Feed balance deviation dry matter intake (\%) & -20 & 0 & -0.01 \\
\hline Feed balance deviation energy required (\%) & -5 & 5 & -0.95 \\
\hline Feed balance deviation CP (\%) & -10.4 & 10 & -10.34 \\
\hline
\end{tabular}




\section{Summary}

Livestock are a resource of significant benefit to society in the form of food, income, nutrients, employment, insurance, traction, and clothing. By 2050, the total demand for meat, milk and eggs is projected to almost double, mostly in the developing world, due to population growth, urbanization, income increase and change in dietary preferences. Dairy development provides substantial potential economic opportunities for smallholder farmers in East Africa, but productivity is constrained by scarcity of quantity and quality feed. Livestock is also associated with negative environmental impacts, including greenhouse gas (GHG) emissions, air pollution, high water consumption, loss of biodiversity and land degradation. Livestock in Sub-Saharan Africa (SSA) has one of the lowest feed use efficiencies and highest GHG emission intensities per unit of product worldwide. Improved livestock feeding and forages have been highlighted as a triple-win strategy towards achieving climate-smart agriculture, increasing food security and climate change adaptation, and decreasing GHG intensities. Improved tropical forages include a wide variety of sown or planted annual and perennial grasses, herbaceous or dual-purpose legumes and shrubs developed for increasing productivity of grazed and cut-and-carry fed livestock. They link crop, livestock and soil components of farming systems, and can deliver other benefits including soil improvements and associated higher food crop yields. Livestock feeding and forages are thus at multiple crossroads: at a point where crucial decisions regarding future pathways are taken, where productivity and environmental impacts meet, and where scientific disciplines including agronomy, soil and animal science intersect. However, knowledge on quantity and quality of feed gaps, and the potential impacts and trade-offs of improved livestock feeding practices on productivity, environment and livelihood dimensions across various crop-livestock systems is limited and fragmented. The main objective of this research was to explore potential impacts and trade-offs associated with the implementation of improved livestock feeding and forage technologies at farm scale, across a diversity of smallholder crop-livestock systems in East Africa. Impacts and trade-offs were explored from different perspectives and scientific disciplines, considering productivity, environmental and livelihood dimensions. Results aim to inform policy makers, project designers, investors, donors and other decision-makers on prioritizing options towards low emission livestock development.

Chapter 2 took stock of published evidence on tropical forage technologies and their multi-dimensional agronomic, livestock, environmental and economic impacts in SSA. We reviewed for the first time 73 studies covering 113 research sites, and calculated average response ratios from 963 pairs of comparisons. Forage technologies were classified in the following four groups: i) germplasm, ii) 
management, iii) cropping system integration, and iv) feeding regime. Major findings include the following: 1) Most studies focused on only one impact dimension, most frequently forage or livestock production; 2) Improved forage germplasm had on average 2.65 higher herbage production than local controls, with the strongest effect in grasses; 3 ) Crude protein of the overall forage doubled when grasses and legumes were intercropped; 4) Feeding regimes that include improved forages increased milk yield by on average $35 \%$, dry matter intake by $25 \%$, and manure production by $24 \%$; and 5 ) When forage technologies were integrated with food crops, soil loss was almost halved, soil organic carbon increased on average by $10 \%$, and grain and stover yields by $60 \%$ and $33 \%$, respectively; 6 ) Variability in the findings from forage agronomy was high.

In Chapter 3, I characterized current feeding systems and quantify feed gaps of East African smallholder farms. The study introduces and provides proof-of concept for a relatively simple approach to quantify feeding systems and feed gaps in data-scarce smallholder systems. Feed gap here is defined as the difference between livestock feed demand for an attainable milk production level (attainable feed demand) and actual feed supply at individual herd level. The approach is illustrated with pilot evidence from crop-livestock production systems across three agro-ecological zones in Tanzania, which broadly represent the diversity found in East Africa. Data was collected during the rainy season of 2016 and included on-farm feed and milk measurements, household surveys and farm observations. A diversity of livestock and feeding systems along an intensification gradient were found, ranging from exclusively zero-grazing of few cross-bred cows on small land sizes to mostly grazing of larger local cattle herds and a mix of both systems. Native vegetation formed the bulk of feed resources everywhere while planted forages were only common in the cut-and-carry site. Grazing systems were more labor intensive per tropical livestock unit than cut-and-carry systems, and most feeding-related labor was provided by men. $61 \%$ of all herds faced an ME feed gap, and $55 \%$ a CP gap between actually supplied feed and calculated requirements at attainable milk production levels. Feed gaps were more prevalent in the grazing than in the cut-and-carry site, although feed losses are likely to be high (up to 30-50\%) in cut-and-carry systems. $24 \%$ of herds did not experience a feed gap, and other yield limiting and reducing factors might explain the low milk production levels. Possible causes for persisting feed gaps include that farmers might prioritize other functions of livestock such as risk management and wealth storage over productivity.

Chapters 4, 5 and 6 analyzed multi-dimensional baseline performance and efficiencies of various croplivestock systems in Tanzania and Rwanda, and explored ex-ante impacts and trade-offs of improved livestock feeding practices, using differing approaches. In Chapter 4, we used the Ruminant model and 
the Trade-offs Analysis model for Multi-Dimensional Impact Assessment (TOA-MD) to assess how improved livestock management options affect the three pillars of Climate Smart Agriculture (CSA): increased productivity, improved food security, and reduced GHG emissions. Our sample was stratified into: 1) households with local cow breeds $(n=28) ; 2)$ households with improved dairy cow breeds $(n=70)$; and 3) households without dairy cows $(n=66)$. Results showed that the predicted adoption rates for improved livestock feeding among households with improved dairy cows (stratum 2) were likely to be higher compared to households with only local cows (stratum 1). Both households with local cows and those with improved cows had increased income and food security. However, overall poverty reduction was only modest for households with local cows. Expected methane emissions intensity declined with adoption of improved livestock feeding strategies both in stratum 1 and stratum 2, and greater impacts were observed when households in stratum 2 received an additional improved cow breed. Providing a cow to households that were not keeping cows showed substantial economic gains.

In Chapter 5, we assessed the potential impact of selected policy programs in Rwanda on food availability and GHG emissions of 884 households across different agro-ecologies and farming systems. The Government of Rwanda has initiated ambitious policies and programs aiming at low emission agricultural development. Crop focused policies include the Crop Intensification Program (CIP) which facilitates access to inorganic fertilizer and improved seeds. In the livestock subsector, zero-grazing and improved livestock feeding are encouraged, and the Girinka program provides poor farm households with a crossbred dairy cow. Household level calculations were used to assess the contribution of current crops, livestock and offfarm activities to food availability (FA) and GHG emissions. Across all sites, $46 \%$ of households were below the $2500 \mathrm{kcal} \mathrm{MAE}^{-1} \mathrm{yr}^{-1}$ line, and livestock and off-farm income were the most important pathways to higher FA. Baseline GHG emissions were low, ranging between 395 - $1506 \mathrm{~kg} \mathrm{CO}_{2} \mathrm{e} \mathrm{hh}^{-1} \mathrm{yr}^{-1}$ per site, and livestock related emissions from enteric fermentation (47.6-48.9\%) and manure $(26.7-31.8 \%)$ were the largest contributors to total GHG emissions across sites and FA classes. GHG emissions increased with FA, with $50 \%$ of the total GHG emitted by $22 \%$ of the households with the highest FA scores. Scenario assessment of three policy options showed strong differences in potential impacts: Girinka only reached one-third of the household population but acted highly pro-poor by decreasing the households below the $2,500 \mathrm{kcal} \mathrm{MAE}^{-1} \mathrm{yr}^{-1}$ line from $46 \%$ to $35 \%$. However, Girinka also increased GHG by $1174 \mathrm{~kg} \mathrm{CO}_{2} \mathrm{e} \mathrm{hh}^{-1} \mathrm{yr}^{-}$

1. Improved livestock feeding was the least equitable strategy, decreasing food insufficient households by only $3 \%$. However, it increased median FA by $755 \mathrm{kcal} \mathrm{MAE}^{-1} \mathrm{yr}^{-1}$ at a small GHG increase $\left(50 \mathrm{~kg} \mathrm{CO}_{2} \mathrm{e} \mathrm{hh}{ }^{-1}\right.$ $\left.\mathrm{yr}^{-1}\right)$. Therefore, it is a promising option to reach the CSA triple win. 
In Chapter 6, we combine a wide variety of data sources and approaches to study productivity, environment and livelihood performance and trade-offs of smallholder livestock production systems in Babati, Northern Tanzania. Using multivariate statistics, a smallholder livestock system typology was constructed from a household survey dataset: SMALLEST represented $45 \%$ of the study sample, DAIRY 17\%, SHOAT 26\%, POULTRY 7\%, and LARGE LIVESTOCK 5\%. Representative farms were selected and their bio-economic performance assessed with the whole farm multi-objective optimization model FarmDESIGN. Only DAIRY cultivated fodder and fed cross-bred cows in zero-grazing units, while the other farm types mainly relied on on-farm and off-farm grazing and crop residues for their local cattle. More than $90 \%$ of on-farm GHG emissions came from livestock, though emissions in Babati (2.9 to $16.2 \mathrm{t}$ $\mathrm{CO}_{2} \mathrm{e}$ ) were higher than in other smallholder systems in East Africa. Emission intensity per kg of milk was lowest for DAIRY $\left(2.1 \mathrm{~kg} \mathrm{CO}_{2} \mathrm{e} \mathrm{kg}^{-1}\right)$, which also showed the lowest trade-offs with other farm performance indicators such as income, and carbon $(\mathrm{C})$ and nitrogen $(\mathrm{N})$ balances. All livestock systems had alternatives available to increase income while decreasing GHG emissions and increasing $\mathrm{N}$ balance, thereby reducing agro-environmental trade-offs. These options included reducing ruminant numbers, replacing local cattle with improved dairy breeds, improve feeding through on-farm Napier grass (Pennisetum purpureum) cultivation to reach higher milk production levels, and reducing crop residue feeding to leave them on the field. However, three main obstacles to adoption of these technologies became apparent: they require a skillful re-organization of the entire production system, resulting in loss of some multi-functionality of livestock, and incur higher production risks. Low baseline farm emissions in Tanzania underline that mitigation cannot be a main objective but rather a co-benefit. If climate change mitigation is synergetic with much needed productivity improvements, and if possible opening avenues to potential financing options e.g. through C credits, climate-smart livestock intensification options should still be a building block of Tanzania's climate policies.

Suggestions and recommendations for future research include the following three broad areas: First, research in this thesis calls for next-level forage agronomy. Agronomy is challenged to develop 'scalable' approaches and results that can be translated into targeting and decision support tools. High-quality, multi-locational, inter-operable, standardized and consistent forage agronomic data has to become available. Systems agronomy approaches and the socio-ecological niche concept can further our understanding of spatial and temporal integration of forages into complex cropping and farming systems to reduce land requirements and deliver multiple benefits. Second, this thesis made a step, but also highlights an urgent need for further multi-disciplinary and systems-level approaches to quantify synergies and trade-offs between different productivity, environmental and livelihood dimensions. Low 
emission livestock for smallholder systems in East Africa is only viable if it does not come with livelihood trade-offs. Validation has been a tricky area in farming systems modeling, and linking ex-ante estimations to on-farm measurements and ex-post impact assessments could improve model predictions. Re-defining the balance between doing justice to the complexity of farming systems, and translating results into simplicity and 'digestibility' requested by decision-makers is another area that deserves further research attention. Third, potential country-level contributions of improved feeding and forages to GHG mitigation and land restoration policy targets is an emerging research demand which can also open potential funding avenues for implementation. This points to policy and institutional implications of this research. Improved livestock feeding practices could play a key role towards low emission livestock development and potentially land restoration at scale. More investment in research and capacity building is needed to quantify and synthesize potential contributions of livestock feeding and forages to mitigation and land restoration commitments by countries without risking trade-offs in smallholder livelihoods. If linked to such policy processes, funding avenues for implementing these practices at scale could be unlocked. Exante impact estimations can assist in policy dialogue and stakeholder engagement to better select and prioritize policies and development programs, despite the complexity of its impacts and trade-offs. 
With the training and education activities listed below the PhD candidate has complied with the requirements set by the C.T. de Wit Graduate School for Production Ecology and Resource Conservation (PE\&RC) which comprises of a minimum total of 32 ECTS ( $=22$ weeks of activities)

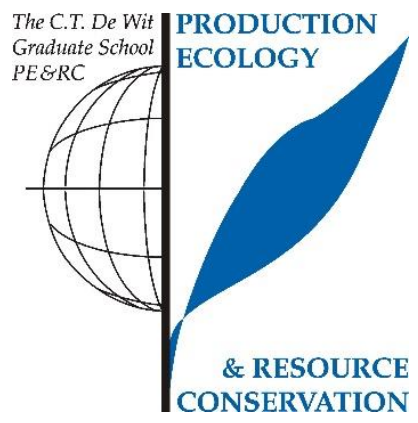

Review of literature (4.5 ECTS)

- $\quad$ Livestock feeding and improved forages in East Africa: opportunities for applying farming systems research and modelling approaches

Writing of project proposal (4.5 ECTS)

- Sustainable intensification of crop-livestock systems through improved forages in East Africa, minimizing trade-offs across scales

Post-graduate courses (6.3 ECTS)

- $\quad$ Statistics: mixed models; PE\&RC, Wageningen (2013)

- $\quad$ Natural resource sampling; PE\&RC, Wageningen (2013)

- $\quad$ Farming systems analysis in the humidtropics; WUR and IITA, Wageningen (2013)

- Meta-analysis; PE\&RC, Wageningen (2014)

- The art of modelling; PE\&RC, Wageningen (2015)

Laboratory training and working visits (4 ECTS)

- $\quad$ Forages, farm and household modelling workshop and work stay; CSIRO, Brisbane, Australia (2013)

- Household modelling workshop and work stay; ILRI, Turrialba, Costa Rica (2014)

Invited review of (unpublished) journal manuscript (6 ECTS)

- PlosOne: evaluation of greenhouse gas emission factors for crop and livestock products in China (2016)

- Experimental Agriculture: participatory evaluation of improved forage legumes for smallholder livestock production (2017)

- Soil Science Society of America Journal: soil organic carbon storage and greenhouse gas emissions in an integrated crop-livestock system (2017)

- $\quad$ Agricultural Systems: the effect of nitrogen fertilization of pastures in Argentina (2017)

- Environment, Development and Sustainability: climate change impacts on soil productivity in developing countries (2017)

- $\quad$ Frontiers in Sustainable Food Systems: climate-smartness index for agricultural systems (2019)

Deficiency, refresh, brush-up courses (2.85 ECTS)

- $\quad$ Basic Statistics; PE\&RC, Wageningen (2013)

- $\quad$ TOA and Ruminant models training; Oregon State University \& CSIRO, Addis Ababa, Ethiopia (2014)

- $\quad$ CSPro and MySQL for data collection and database management; CIAT, Nairobi, Kenya (2015)

- $\quad$ Data analysis with R; CIAT/ILRI, Nairobi, Kenya (2015)

- $\quad$ Last stretch of the PhD; PE\&RC, Wageningen (2017)

Competence strengthening / skills courses (4.2 ECTS)

- $\quad$ Capacity building in development cooperation; GIZ Bad Honnef, Germany (2012)

- $\quad$ Project planning \& monitoring; GIZ Bad Honnef, Germany (2012)

- $\quad$ Professional leadership coaching; AnoukA Training (2014)

- Kiswahili language course; Nairobi Language School (2012-2015)

PE\&RC Annual meetings, seminars and the PE\&RC weekend (1 ECTS) 
Workshop on analysis of trade-offs in agricultural systems; Wageningen (2013)

- $\quad$ Seminar Miguel Altieri; Wageningen (2013)

Discussion groups / local seminars / other scientific meetings (7.5 ECTS)

- $\quad$ CGIAR Research program on Livestock \& Fish, and Environment Flagship annual meetings; Naivasha and Nairobi, Kenya (2014, 2015, 2017, 2018)

- $\quad$ CIAT Annual program review meetings; Cali, Colombia (2014, 2016, 2017)

- $\quad$ Project meetings, writeshops and field visits of various projects; Tanzania and Rwanda (2014-2017)

International symposia, workshops and conferences (8.8 ECTS)

- $\quad$ Tropentag conferences (2013, 2015, 2016, 2017)

- TropAg Conference; Brisbane, Australia (2017)

- International conference on agricultural GHG emissions and food security, connecting research to policy and practice; Berlin, Germany (2018)

- $\quad$ Low emission livestock meeting science and policy; Dakar, Senegal (2019)

Lecturing / Supervision of practicals / tutorials (2.7 ECTS)

- Household modelling course; Lilongwe, Malawi (2016)

- $\quad$ FarmDESIGN course; Phnom Phen, Cambodia (2017)

- $\quad$ Feed gap data collection and analysis training; Kigali, Rwanda (2017)

\section{Supervision of MSc students}

- $\quad$ Systematic literature review and data extraction into Access database on multi-dimensional forage impacts

- Potential multi-dimensional impacts and trade-offs of improved livestock feeding options in Babati, Tanzania

- $\quad$ Participatory forage research and on-farm monitoring in Lushoto and Babati, Tanzania

- Bio-economic evaluation of forage cultivation scenarios in crop-dairy systems in Lushoto District, Tanzania

- The influence of Desmodium and manure on the agronomic performance of fodder plants in Lushoto District, Tanzania

- Ex-ante impact assessment of feed interventions in smallholder dairy production systems in the Southern Highlands of Tanzania 


\section{Acknowledgements}

More than six years it has been. And I won't lie - these six years were actually pretty long. About 20,000 $\mathrm{km}$ of bicycle commuting and 11,000 office hours in the office to be precise. It was in 2011, during my MSc at Wageningen University, that I started to love research: the clarity of setting up a research design, the simplicity of collecting data, the focus of analyzing data, structuring results and writing it up. Seeing my thesis work published in a journal was a great experience. When I registered as an external PhD student at Wageningen University while working full-time at CIAT, people warned me: it will be exhausting, you won't be enjoying it - but I insisted that the moment that happens I will quit...and before you know you have invested so much that the last thing you will do is quitting! Many people have accompanied and helped me on this journey:

Pablo Tittonell, thanks for accepting me as your student. I have learned much from your scientific thinking and strategic insights, and your drive and passion are an inspiration. Jeroen Groot - thanks for always being calm and focused, and giving me continuous and quick feedback. I might have actually quit without you. Mario Herrero, thanks for inspiring me from afar, your work has been the founding stone of my thesis. An Notenbaert and Michael Peters, thanks for allowing me to enroll, travel to Wageningen, take time for writing when I needed it most, and support where you could in securing operational funding for my research. My PhD research plans guided and shaped my profile and career at CIAT more than I expected. Ulrich Lepel from CIM (Center for International Migration) allowed me to embark on this $\mathrm{PhD}$ thesis while CIM co-funded my position for six years - thank you for your trust that I can still deliver on my job objectives.

Numerous colleagues assisted on thesis chapters, for which I thank them: John Mutua and Nicholas (CIAT) Koech helped with mapping and GIS characterization of Chapters 2, 3 and 6; Kees-Jan van Groenigen for extensive advice on data analysis, Celine Birnholz for database checks, Jessica Mukiri for extracting geo-locations, Beatus Nzogela (CIAT) for assistance in pulling together examples from the field, and Di Prestwidge (CSIRO) for advice on Microsoft Access database management and queries, all for Chapter 2; Emily Ouma, Speciose Kantengwa and Eliud Birachi (CIAT) for the CIALCA baseline data collection, Jean Marie Vianney Niyitegeka from The Rwanda Meteorology Agency and Beatrice Uwayezu from The National Institute of Statistics of Rwanda for unpublished secondary data, and Charles Bucagu for sharing the data layers for the agroecological zone map for Chapter 5; Charlotte Klapwijk and Carl Timler (WUR) for the baseline data collection, Mbwana Macheli and George Sayula (SARI), Jessica Koge and Venance Kengwa (CIAT) for intensive household characterization and data entry, Stephanie Alvarez 
(WUR) for advice on statistical typologies, and Ben Lukuyu (ILRI) and Solomon Mwendia (CIAT) for expert advice on forage production of Chapter 6, and Jose Luis Urrea Benitez (CIAT) for improving the design of conceptual graphs of Chapters 2 and 3. Melissa Goldman, thanks so much for brushing up my final thesis draft and your friendship. Bernard Vanlauwe, you have often adviced me throughout the years, and somehow it turned out you were right most of the times. Brigitte Maass, I have always appreciated your encouragement and advice.

My special gratitude goes to all extension officers and farmers who have participated and contributed to this research with time and information - without them, these studies would not have been possible. Extension officers Anna Roman, Edgar Lyakulwa, and Gilbert Mbesere in Babati, Space Komba and Theobald Marcel in Mvomero, and Erick Osmond in Lushoto - thank you. In Lushoto, active participation from the livestock Innovation Platforms in Ubiri and Mbuzii was always certain. In Babati, we relied on collaboration from the AfricaRISING farmers, especially in Hallu, Long, Seloto and Sabilo.

Thanks to all of my CIAT colleagues for your support and for occasionally laughing at me that I am taking so long! Celine, I deeply enjoyed working with you, thank you for being my friend. Rolf, Kelvin, Rao, Sabine, Caroline, I am looking forward to continue working together in one way or another. My fellow FSE students and colleagues made my few stays in Wageningen more enjoyable: Mirja, Carl, Vicky, Pablito, Roos, Yodith, Stephanie. Wampie and Gemma, thanks for all your administrative support and for patiently looking at all of the baby pictures I sent. Mirjam, thanks for listening to a few dozen PhD updates, and for being by advisor and friend. Yodit and Annemiek, thanks so much for accepting to be my paranymphs, but above all for getting to spend time together in Nairobi, Nanyuki, Addis and Wageningen.

Meine lieben Eltern - ihr habt mich immer machen lassen was ich wollte, auch wenn es dann mal länger als 6 Jahre dauert. Wahrscheinlich hättet ihr all die Jahre lieber Zeit mit mir verbracht als mich hinter dem Laptop zu sehen, aber spüren lassen habt ihr es mich nicht. Ich hoffe dass ich eines Tages genauso gut gleichzeitig festhalten und loslassen kann wie ihr!

Meine lieben Freund/innen, mijn lieve vriendinnen, my dear friends: You must have doubted my sanity many times when I kept saying I am almost done - for the last 2.5 years! Thanks for bearing with me, for missing me at (too) many occasions. I will be making up for it. 
Ravic, my unexpected and best synergy ever of Chapter 4. You helped me in key ways to get this done. For example, you told me I can't go running every day and finish my PhD, so I had to prove you wrong. Patrice, by far my best chapter, I cannot wait exchanging computer with sandbox time. 


\section{About the author}

Birthe Katharina Paul was born in Cologne and grew up with three brothers in the German countryside close to the Dutch border. After completing her secondary education in Germany and 6 months volunteering in the Dominican Republic, she enrolled in a BA European Studies in Maastricht, Netherlands. During this time, she

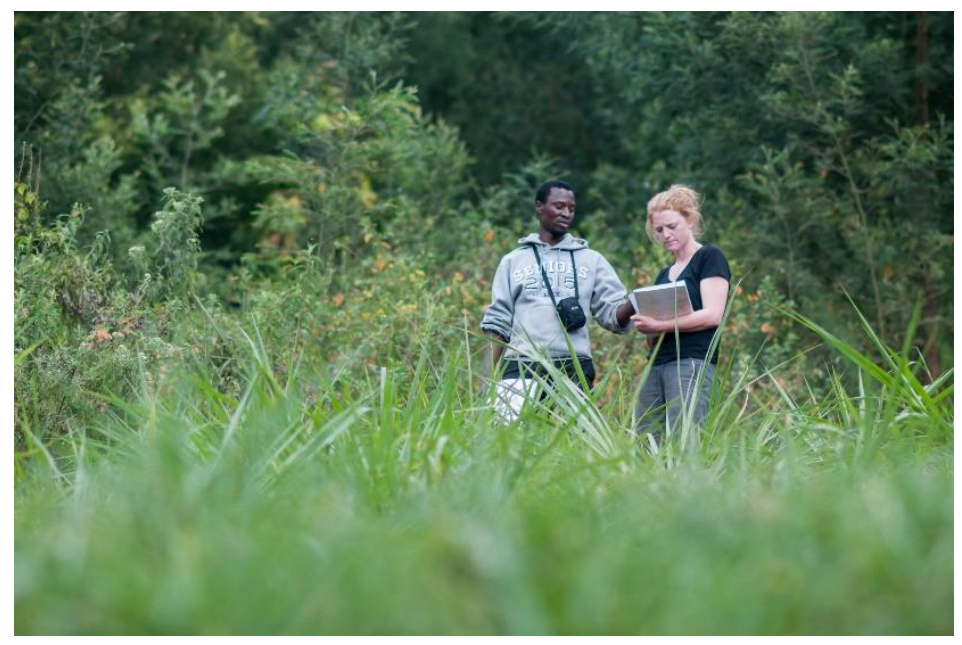
developed her interest in issues around sustainability and agricultural policy. After graduating in 2007, she time in rural Togo designing a train-the-trainer curriculum, and later as research assistant at the Wuppertal Institute for Climate, Environment, and Energy. In 2008, Birthe enrolled in the MSc program of Environmental Sciences at Wageningen University, Netherlands. Majoring in Soil Quality, with minors in Climate Studies and Sustainable Agriculture, she discovered how agriculture lays at the true nexus between human health and nutrition, wellbeing and environmental sustainability. During her studies, she continued working on knowledge management and communications in international development for Euforic in Maastricht, and as a trainer and lead facilitator in Global Learning for InWEnt Capacity Building. From 2009-2012 she worked as part-time research and teaching assistant at the Soil Quality and Cropping Systems groups at Wageningen University. For her MSc research internship, Birthe went to collaborate with the Tropical Soil Biology and Fertility (TSBF) Institute of the International Center for Tropical Agriculture (CIAT) based in Nairobi. Her field work evolved around participatory soil fertility management trials in Eastern DR Congo. After graduation in 2011, she stayed at CIAT through a cofinancing arrangement from the German Center for International Migration (CIM). Birthe moved into the Tropical Forages Program and started working on research for development projects in East, West and Southern Africa, South East Asia and Central America first as Research Associate and from 2014 as Scientist. In 2013, she enrolled as an external PhD at the Farming Systems Ecology group of Wageningen University to start training in farming systems modeling and multi-disciplinary sciences, bringing together her different backgrounds. 


\section{List of publications}

\section{$\underline{\text { Recently submitted manuscripts }}$}

Birnholz, C., Paul, B.K., Sommer, R., Nijbroek, R. Sustainable Land Management Practices in the Central Highlands of Kenya - Modelling Soil Erosion Impacts and Trade-offs. Submitted as book chapter to ASA, CSSA, SSSA book on low input agriculture modeling.

Epper, C., Paul, B.K., Burra, D., Phengsavanh, P., Ritzema, R., Syfongxay, C., Groot, J., Six, J., Frossard, E., Oberson, A., Douxchamps, S. Nutrient flows and intensification options for smallholder farmers of the Lao uplands. Submitted to Agricultural Systems.

Mutua, J.Y., Paul, B.K., Marshall, K., Notenbaert, A. Mapping current and future heat stress in pigs. Submitted to Animal.

Paul, B.K., Groot, J.C.J., Birnholz, C.A., Nzogela, B., Herrero, M., Woyessa, K., Nijbroek, R., A. Notenbaert, Sommer, R., Tittonell, P. Agro-environmental trade-offs across smallholder livestock systems in Babati, Northern Tanzania. Submitted to International Journal for Agricultural Sustainability.

Paul, B.K., Maass, B., Koge, J., Notenbaert, A., Peters, M., Groot, J.G.J., Tittonell, P. Tropical forage technologies can deliver multiple benefits in Sub-Sahara Africa: a quantitative review. Submitted to Agronomy for Sustainable Development.

Paul, B.K., Nzogela, B., Birnholz, C., Notenbaert, A., Herrero, M., Bwire, J., Groot, J., Tittonell, P. Livestock feeding systems and feed gaps in smallholder farms in East Africa. Submitted to Agricultural Systems.

Tessema, B., Sommer, R., Piikki, K., Söderström, M., Namirembe, S., Notenbaert, A., Paul, B., Desta, L., Nyawira, S. Potentials for Soil Carbon Sequestration in Grasslands in East Africa: A Review. Submitted to Grassland Science.

\section{$\underline{\text { Journal articles }}$}

Paul, B.K. Frelat, R., Birnholz, C., Ebong, C., Gahigi, A., Groot, J.C.J., Herrero, M., Kagabo, D., Notenbaert, A., Vanlauwe, B., van Wijk, M., 2018. Agricultural intensification scenarios, household food availability and greenhouse gas emissions in Rwanda: ex-ante impacts and trade-offs. Agricultural Systems 163, 16-26.

Sommer, R., Paul, B.K., Kihara, J., Mukalama, J., 2018. Reducing losses but failing to sequester carbon in soils - the case of Conservation Agriculture and Integrated Soil Fertility Management in the humid tropical agro-ecosystem of Western Kenya. Agriculture, Ecosystem, Environment 254, 8291.

Margenot, A., Pulleman, M.M., Sommer, R., Paul, B.K., Parikh, S.J., Jackson, L.E., Fonte, S.J., 2017. Biochemical proxies indicate differences in soil $C$ cycling induced by long-term tillage and residue management in a tropical agroecosystem. Plant and Soil 420 (1-2), 315-329. 
Margenot, A.J., Paul, B.K., Sommer, R., Pulleman, M.M., Parikh, S.J., Jackson, L.E., Fonte, S.J., 2017. Can conservation agriculture improve phosphorus $(P)$ availability in weathered soils? Effects of tillage and residue management on soil $\mathrm{P}$ status after 9 years in a Kenyan Oxisol. Soil \& Tillage Research 166, 157-166.

Ritzema, R., Frelat, R., Douxchamps, S., Silvestri, S., Rufino, M.C., Herrero, M., Giller, K., Lopez-Ridaura, S., Teufel, N., Paul, B.K., van Wijk, M., 2017. Is production intensification likely to make farm households food-adequate? A simple food availability analysis across smallholder farming systems from East and West Africa. Food Security 9 (1), 115-131.

Shikuku, K.M., Valdivia, R., Paul, B.K., Mwongera, C., Winowiecki, L., Laderach, P., Herrero, M., Silvestri, S., 2017. Prioritizing climate-smart livestock technologies in rural Tanzania: A minimum data approach. Agricultural Systems 151, 204-216.

Simtowe, F., Paul, B.K., Wimba, B.M.M., Bacigale, S.B., Chiuri, W.L., Maass, B.L., 2017. Determinants of participation in cavy marketing: Evidence from the Democratic Republic of Congo. Journal of Agriculture and Rural Development in the Tropics and Subtropics (JARTS) 118 (2), 245-257.

Frelat, R., Lopez-Ridaura, S., Giller, K.E., Herrero, M., Douxchamps, S., Djurfeldt, A.A., Erenstein, O., Henderson, B., Kassie, M., Paul, B.K., Rigolot, C., Ritzema, R.S., Rodriguez, D., Van Asten, P.J.A., van Wijk, M.T., 2016. Drivers of household food availability in sub-Saharan Africa based on big data from small farms. Proceedings of the National Academy of Sciences (PNAS) 113 (2), 458-463

Paul, B.K., Muhimuzi, F.L, Bacigale, S., Wimba, B.M.M., Chiuri, W.L, Amzati, G.S., Maass, B.L., 2016. Towards On-farm Niches for Improved Forages in Sud-Kivu, DR Congo. Journal of Agriculture and Rural Development in the Tropics and Subtropics 117 (2), 243-254.

Paul, B.K., Vanlauwe, B., Six, J., Ayuke, F., Pulleman, M.M., 2016. Response to G.W. Sileshi's Letter to the Editor on AGEE13857 (2015): Exclusion of soil macrofauna did not affect soil quality - statistical artefact or true lack of effect? Agriculture, Ecosystem, Environment 221, 282-284

Rudel, T., Oh-Jung Kwon, Paul, B.K., Boval, M., Rao, I., Burbano, D., McGroddy, M., Lerner, A., White, D., Cuchillo, M., Luna, M., Peters, M., 2016. Do smallholder, mixed crop-livestock livelihoods encourage sustainable agricultural practices?: A meta-analysis. Land 5 (1), 6

Paul, B.K., Vanlauwe, B., Hoogmoed, M., Hurisso, T. T., Ndabamenye, T., Terano, Y., Six, J., Ayuke, F., Pulleman, M. M., 2015. Exclusion of soil macrofauna did not affect soil quality but increased crop yields in a sub-humid tropical maize-based system. Agriculture, Ecosystems and Environment 208, 75-85

Rao, I., Peters, M., Castro, A., Schultze-Kraft, R., White, D., Fisher, M., Miles, J., Lascano, C., Bluemmel, M., Bungenstab, D., Tapasco, J., Hyman, G., Bolliger, A., Paul, B., van der Hoek, R., Maass, B., Tiemann, T., Cuchillo, M., Douxchamps, S., Villanueva, C., Rincon, A., Ayarza, M., Rosenstock, T., Subbarao, G., Arango, J., Cardoso, J., Worthington, M., Chirinda, N., Notenbaert, A., Jenet, A., Schmidt, A., Vivas, N., Lefroy, R., Fahrney, K., Guimaraes, E., Tohme, J., Cook, S., Herrero, M., Chocon, M., Searchinger, T., Rudel, T., 2015. LivestockPlus - The Sustainable Intensification of forage-based agricultural systems to improve livelihoods and ecosystem services in the tropics, 2015. Tropical Grasslands, Volume 3. 
Rudel, T.K., Paul, B.K., White, D., Rao, I.M., van der Hoek, R., Castro, A., Boval, M., Lerner, A., Schneider, L, Peters, M., 2015. LivestockPlus: Forages, sustainable intensification, and food security in the tropics. AMBIO 44 (7), 685-693.

Paul, B.K., Vanlauwe, B., Ayuke, F., Gassner, A., Hoogmoed, M., Hurisso, T. T., Koala, S., Lelei, D., Ndabamenye, T., Six, J., Pulleman, M. M., 2013. Medium-term impact of tillage and residue management on soil aggregate stability, soil carbon and crop productivity. Agriculture, Ecosystems and Environment 164, 14-22.

Peters, M., Herrero, M., Fisher, M., Erb, K., Rao, I., Subbarao, G., Castro, A., Chara, J., Mur, E., van der Hoek, R., Laderach, P., Hyman, G., Paul, B.K., Tapasco, J. et al., 2013. Challenges and opportunities for improving eco-efficiency of tropical forage-based systems to mitigate greenhouse gas emissions. Tropical Grasslands - Forrajes Tropicales 1, 137-149.

Paul, B.K., Lubbers, I.M., van Groenigen, J.W., 2011. Residue incorporation depth as controlling factor of earthworm-induced N2O emissions. Global Change Biology 18 (3), 1141-1151.

\section{Working papers, book chapters and research briefs}

Mukiri, J., Diogo, R.V.C., Gbedjissokpa, S.G.M., Kinyua, M., van der Hoek, R., Sommer, R., Paul, B.K., 2019. Towards a Cropping System Sustainability Tool (CROSST) - pilot results from evaluating green manure cover crops in Benin and Kenya. CIAT Working Paper, International Center for Tropical Agriculture (CIAT), Cali, Colombia.

Ndah, T., Schuler, J., Nkwain, V.N., Nzogela, B., Paul, B.K., 2018. Factors affecting the adoption of forage technologies in smallholder dairy production systems in Lushoto, Tanzania. CIAT Working Paper, International Center for Tropical Agriculture (CIAT), Cali, Colombia 38 p.

Osele, V., Paul, B.K., Mukiri, J., Halder, S., Sagala, T., Juma, A., Notenbaert, A., 2018. Feeding a productive dairy cow in western Kenya: environmental and socio-economic impacts. Working Paper. CIAT Publication No. 472, International Center for Tropical Agriculture (CIAT), Nairobi, Kenya 46 p.

Birnholz, C., Bolliger, A., Tan Khanh, T., Groot, J., Paul, B.K., 2017. Bio-economic evaluation and optimization of livestock intensification options in the Central Highlands of Vietnam. CIAT Working Paper No. 433, International Center for Tropical Agriculture (CIAT), Nairobi, Kenya 31 p.

Birnholz, C., Braslow, J., Koge, J., Notenbaert, A., Sommer, R., Paul, B.K., 2017. Rapid climate smartness assessment of GIZ soil protection and rehabilitation technologies in Benin, Burkina Faso, Ethiopia, Kenya, and India. CIAT Working Paper No. 431, Centro Internacional de Agricultura Tropical (CIAT), Cali, Colombia 84 p.

Birnholz, C., Paul, B., Notenbaert, A., 2016. The CLEANED Excel tool to assess the environmental impacts of livestock production. Livestock and Fish Brief 19, International Livestock Research Institute (ILRI), Nairobi, Kenya.

Mwendia, S., Notenbaert, A., Paul, B., 2016. Forage Seed Systems in Kenya. CIAT Working Paper, Centro International de Agricultura Tropical (CIAT), Nairobi, Kenya 12 p. 
Notenbaert, A., Lannerstad, M., Barron, J., Paul, B.K., Ran, Y., Morris, J., Fraval, S., Mugatha, S., Herrero, M., 2016. A Comprehensive Livestock Environment Assessment for Improved Nutrition, Secured Environment and Sustainable Development. Livestock and Fish Brief 17, International Livestock Research Institute (ILRI), Nairobi, Kenya.

Notenbaert, A., Morris, J., Pfeifer, C., Paul, B.K., Birnholz, C., Fraval, S., Lannerstad, M., Herrero, M., Omore, A., 2016. Using the CLEANED approach to assess environmental impacts in the dairy value chain in Tanga, Tanzania. Livestock and Fish Brief 21, International Livestock Research Institute (ILRI), Nairobi, Kenya.

Umunezero, O., Mwendia, S., Paul, B.K., Maass, B.L., Ebong, C., Kagabo, D., Musana, B., Muhutu, J.C., Mutimura, M., Hirwa, C.A., Shumbusho, F., Nyiransengimana, E., Mukuralinda, A., Notenbaert, A., 2016. Identifying and characterizing areas for potential forage production in Rwanda. CIAT Working Paper No. 417, Centro Internacional de Agricultura Tropical (CIAT), Cali, Colombia 16 p.

Paul, B.K., Birnholz, C., Timler, C., Michalschek, M., Koge, J., Groot, J., Sommer, R., 2015. Assessing and improving organic matter, nutrient dynamics and profitability of smallholder farms in Ethiopia and Kenya: Proof of concept of using the whole farm model FarmDESIGN for trade-off analysis and prioritization of GIZ development interventions. CIAT Working Document No. 408, International Center for Tropical Agriculture (CIAT), Cali, Colombia 20 p.

Paul, B.K., Maass, B.L., Wassena, F., Omore, A.O., Bwana, G., 2015. Dairy development in Tanzania with local innovation platforms: When and how can they be useful? ILRI Research Brief 54, International Livestock Research Institute (ILRI), Nairobi, Kenya.

Ran, Y., Lannerstad, M., Barron, J., Fraval, S., Paul, B., Notenbaert, N., Mugatha, S., Herrero, M., 2015. A Review of Environmental Impact Assessment Frameworks for Livestock Production Systems. SEI Project Report 2015-3, Stockholm, Sweden.

Paul, B.K., Pypers, P., Sanginga, J.M., Bafunyembaka, F., Vanlauwe, B., 2014. ISFM Adaptation Trials: Farmer-to-Farmer Facilitation, Farmer-Led Data Collection, Technology Learning and Uptake. In B. Vanlauwe et al. (Eds.), Challenges and Opportunities for Agricultural Intensification of the Humid Highland Systems of Sub-Saharan Africa. Springer, Geneva.

More than 15 oral or poster contributions were presented at international conferences. 


\section{Picture credits}

Chapter 1: Georgina Smith/CIAT - Farmers of the local livestock Innovation Platform in Mbuzii, Lushoto, Tanzania

Chapter 2: $\quad$ Georgina Smith/CIAT - Brachiaria hybrid cv. Mulato II in Mbuzii, Lushoto, Tanzania

Chapter 3: Georgina Smith/CIAT - Farmer cutting improved forages in Mbuzii, Lushoto, Tanzania

Chapter 4: $\quad$ Georgina Smith/CIAT - Farmer feeding maize residues to cattle in Mbuzii, Lushoto, Tanzania

Chapter 5: $\quad$ Stephanie Malyon/CIAT - Famer with cattle in her shed in Babati, Tanzania Chapter 6: Georgina Smith/CIAT - Milk buckets waiting for transport to collection center in Lushoto, Tanzania

Chapter 7: $\quad$ Stephanie Malyon/CIAT - Farmer milking his cow in a communal feedlot in Rwanda

Chapter 8: $\quad$ Georgina Smith/CIAT - Brachiaria hybrid cv. Mulato II in Lushoto, Tanzania

CIAT photographs are available on FlickR (https://www.flickr.com/photos/ciat/) under the Creative Common license. 


\section{Funding}

The research presented in this thesis was financially supported by various projects, programs and donors. Data collection for Chapter 2 and 6 was financially supported by a United States Agency for International Development (USAID) linkage grant through the CGIAR Research Program on Livestock and Fish. Chapter 3 was funded by the German Federal Ministry for Economic Cooperation and Development (BMZ) under Contract C-151-15. Chapter 4 was co-funded by the International Fund for Agricultural Development (IFAD) grant number 2000000176. Work under Chapter 5 was partly supported by the Norwegian Agency for Development Cooperation (NORAD) through Princeton University, while the household survey data was collected by the CIALCA project, which is funded by the Belgian Directorate General for Development Cooperation (DGDC). Survey data of Chapter 6 was collected under Africa RISING (Africa Research in Sustainable Intensification for the Next Generation), a research program supported by USAID as part of the United States government 'Feed the Future' initiative (http://africarising.net/). I also thank the Center for International Migration (CIM), supported by the German Development Cooperation, for funding my position during the first years of my research. This thesis research was undertaken as part of the CGIAR Research Programs on Livestock, Integrated Systems for the Humid Tropics (Humidtropics), and Climate Change, Agriculture and Food Security (CCAFS). Multiple donors fund these programs through their contributions to the CGIAR Fund.

Cover design by Katya Kuzi, Avocado Studios, Nairobi, Kenya.

Printed by GVO drukkers \& vormgevers B.V. on FSC-certified paper. 
